\title{
Relationships between wildlife/biodiversity and human well-being: a macro-level approach
}

\author{
Dissertation \\ for obtaining the $\mathrm{PhD}$ degree \\ of Natural Sciences \\ submitted to the Faculty of Biological Sciences \\ of the Johann Wolfgang Goethe University \\ in Frankfurt am Main
}

by

Joel Methorst

from Taizhong, Taiwan

Frankfurt am Main

2020

(D30) 

Accepted by the Faculty of Biological Sciences

of the Johann Wolfgang Goethe University

as a dissertation

Dean:

Prof. Dr. Sven Klimpel

Expert Assessors:

Prof. Dr. Katrin Böhning-Gaese

Prof. Dr. Michael Berlemann

Date of disputation: 12.04.2021 

Relationships between wildlife/biodiversity and human well-being: a macro-level approach 

Für meine Familie 



\section{Table of Contents}

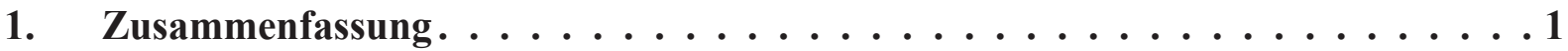

1.1 Forschungsfragen und Zielstellung . . . . . . . . . . . . . . . 1

1.2 Methodischer Ansatz . . . . . . . . . . . . . . . . . . 3

1.3 Zentrale Ergebnisse und Diskussion. . . . . . . . . . . . . . . . 4

1.4 Schlussfolgerungen und Empfehlungen . . . . . . . . . . . . . . . . 5

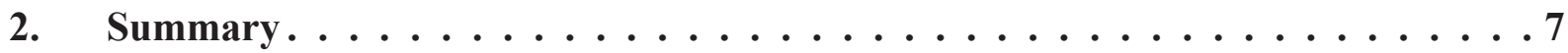

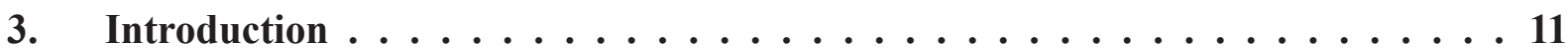

3.1 Nature and human well-being . . . . . . . . . . . . . . . 11

3.2 The IPBES framework. . . . . . . . . . . . . . . . . . . 11

3.2.1 Nature's contributions to people $(\mathrm{NCP}) \ldots \ldots \ldots \ldots 11$

3.2.2 Positive and negative NCP . . . . . . . . . . . . . . . . 13

3.2.3 Nature, biodiversity and wildlife . . . . . . . . . . . . . . 13

3.2 .4 Human well-being . . . . . . . . . . . . . . . . . . . 14

3.3 Non-material NCP . . . . . . . . . . . . . . . . . . . 15

3.3.1 Non-material contributions of biodiversity . . . . . . . . . . 16

3.3.2 Non-material contributions of wildlife . . . . . . . . . . . . . . 16

3.4 Pathways linking biodiversity and wildlife to human well-being . . . . . . . . . 17

4. Thesis structure and research objectives. . . . . . . . . . . . . . . 19

4.1 Review of non-material contribution of wildlife and biodiversity $(\mathrm{CH} 1)$. . . . . 20

4.2 Biodiversity and human well-being relationship on the macro-level . . . . . . . . 21

4.2.1 Biodiversity and human health in Germany $(\mathrm{CH} 2)$. . . . . . . . . . . 22

4.2.2 Biodiversity and life-satisfaction across Europe $(\mathrm{CH} 3) \ldots$. . . . . . . . . 23

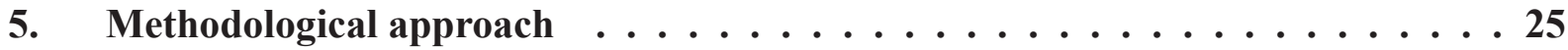

5.1 Macro-level approach . . . . . . . . . . . . . . . . . 25

5.2 Literature review methodology $(\mathrm{CH} 1) \ldots \ldots . \ldots . \ldots 26$

5.2 .1 Systematic literature search . . . . . . . . . . . . 26

5.2 .2 Wildlife definition . . . . . . . . . . . . . . . . 27

5.2.3 Human well-being \& positive and negative WCP . . . . . . . . . . . 27

5.2.4 Channels linking WCP to human well-being. . . . . . . . . . . . 28

5.2 .5 Data collection process . . . . . . . . . . . . . . . . . 29

5.3 Empirical analysis on macro-level $(\mathrm{CH} 2 \& 3) \ldots . . \ldots . \ldots$

5.3.1 Human well-being indicators \& socio-economic data . . . . . . . . . . 30 
5.3.2 Macro-level biodiversity indicators . . . . . . . . . . . . . 32

5.3 .3 Merging different data sets . . . . . . . . . . . . . . . 34

5.3 .4 Statistical analysis . . . . . . . . . . . . . . . . . 34

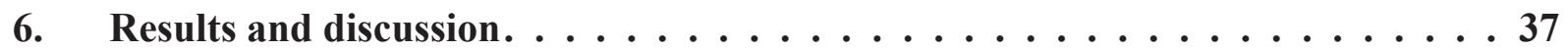

6.1 Literature search results $(\mathrm{CH} 1) \ldots \ldots \ldots \ldots$

6.1.1 Temporal and geographical patterns of WCP . . . . . . . . . . . . 37

6.1 .2 Patterns related to human well-being indicators . . . . . . . . . . . . 38

6.1 .3 Taxon dependency of WCP . . . . . . . . . . . . . . . . . . 39

6.1.4 Channels of wildlife experiences . . . . . . . . . . . . . . . . 39

6.1.5 Terminology and indicators for wildlife and wildlife diversity . . . . . . . . 41

6.2 Macro-level relationship between biodiversity and human well-being . . . . . . . 42

6.2.1 Species diversity and human health in Germany $(\mathrm{CH} 2)$. . . . . . . . . . . 42

6.2.2 Species diversity and life-satisfaction across Europe $(\mathrm{CH} 3) \ldots . . . . . .44$

6.2 .3 Possible mechanisms and mediators . . . . . . . . . . . . . . . . 46

6.2 .4 Study limitations . . . . . . . . . . . . . . . . . . . . . . 48

7. Conclusion and synthesis . . . . . . . . . . . . . . . 51

7.1 Wildlife and non-material NCP . . . . . . . . . . . . . . . 51

7.2 Biodiversity and human well-being on the macro-level . . . . . . . . . . 52

7.3 Recommendations and policy implications . . . . . . . . . . . . 53

7.3.1 Research recommendations. . . . . . . . . . . . . . . 53

7.3.2 Conservation and human well-being . . . . . . . . . . . . . . . . 54

7.3.3 Macro-level indicators for non-material NCP . . . . . . . . . . . . . 55

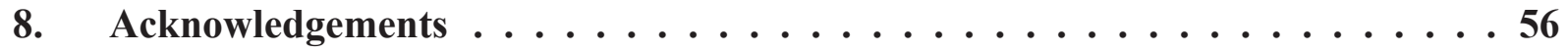

9. List of abbreviations. . . . . . . . . . . . . . . . 57

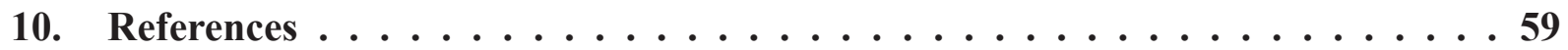

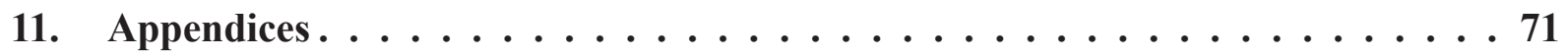

01. Appendix I. . . . . . . . . . . . . . . . . 73

02. Appendix II . . . . . . . . . . . . . . . . . . . . . . . . 999

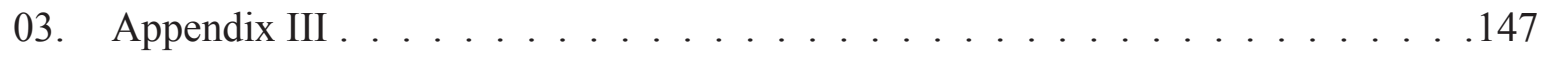




\section{Zusammenfassung}

Es ist bekannt, dass die Natur und ihre Bestandteile das menschliche Wohlbefinden auf positive und negative Weise beeinflusst. Die Natur kann für den Menschen nützlich sein, indem sie beispielsweise Nahrung, Erholung oder Inspiration bietet. Naturkatastrophen oder übertragene Krankheiten sind andererseits Beispiele für den schädlichen oder nachteiligen Beitrag der Natur zum menschlichen Wohlbefinden. Solche positiven wie auch negativen Auswirkungen wurden von der Intergovernmental Science-Policy Platform for Biodiversity and Ecosystem Services (IPBES, Deutsch: Weltbiodiversitätsrat) als Nature's Contributions to People (NCP) bezeichnet und können in drei verschiedene Kategorien von NCP eingeteilt werden: regulierende, materielle und nicht-materielle NCP.

Regulierende NCP sind wichtige strukturelle und unterstützende Funktionen der Natur, die Umweltprozesse steuern oder beeinflussen (z.B. Luftreinigung, Nährstoffkreislauf). Materielle NCP sind Substanzen oder Rohstoffe aus der Natur, die die physische Existenz von Menschen direkt unterstützen und materielle Güter (z.B. Nahrung, Holz) bereitstellen. Dahingegen decken nicht-materielle NCP die immateriellen Dimensionen des menschlichen Wohlergehens ab und betreffen u.a. physische und psychische Gesundheit, Lernerfahrungen, Inspiration, Spiritualität oder die Identität des Menschen. Nicht-materielle NCP können u.a. durch verschiedene Aktivitäten und Aufenthalte in der Natur (z.B. Besuch im Park, Wald oder Naturschutzgebiet) ausgelöst werden.

Während die regulierenden und die materiellen NCP umfassend untersucht wurden, ist die Forschung zu nicht-materiellen NCP im Vergleich dazu weniger verbreitet, insbesondere im Hinblick auf die nicht-materiellen NCP von Biodiversität und Wildtieren. Ziel dieser Dissertation ist es daher, die nicht-materiellen Auswirkungen von Biodiversität und Wildtieren auf das menschliche Wohlergehen besser zu beleuchten. Diese Dissertation präsentiert die Ergebnisse von drei Studien in drei einzelnen Kapiteln (K 1, 2 \& 3, Englisch: CH 1, 2, \& 3).

\subsection{Forschungsfragen und Zielstellung}

Im ersten Kapitel (K1) erstelle ich eine systematische Literaturübersicht (Englisch: „review“) über die nicht-materiellen Auswirkungen bzw. NCP der Wildtiere. Eine umfassende Zusammenfassung der aktuellen wissenschaftlichen Erkenntnisse ist entscheidend um besser zu verstehen, wie Wildtiere das menschliche Wohlbefinden beeinflussen und relevant, weil Interaktionen zwischen Menschen und Wildtieren oft zum täglichen Leben vieler Menschen 
gehören (z.B. Vögel füttern). Nicht-materielle NCP von Wildtieren (im weiteren Verlauf abgekürzt durch WCP) können sowohl positive als auch negative Auswirkungen auf das menschliche Wohlbefinden haben. Insgesamt gibt es jedoch nur wenige Übersichtsarbeiten, die sowohl die positiven als auch die negativen Auswirkungen von WCP in Kombination untersuchen. Hinzu kommt, dass die geringe Anzahl solcher Studien meist nur wenige Aspekte des menschlichen Wohlbefindens abdecken oder sich nur auf eine bestimmte Gruppe von Wildtierarten (z.B. Raubtiere oder Aasfresser) konzentrieren. Darüber hinaus sind die mechanistischen Pfade, die beschreiben wie Wildtiere das menschliche Wohlbefinden beeinflussen, noch wenig verstanden. Das Ziel dieses Literaturüberblicks ist es somit, eine ganzheitliche Übersicht zum aktuellen Forschungsstand der WCP zu schaffen, Wissenslücken aufzudecken und die mechanistischen Pfade zu entschlüsseln. Obwohl der Schwerpunkt auf den Wildtieren liegt, umfasst die Literaturübersicht dennoch auch Studien zu Biodiversität. Folglich bildet der Inhalt des ersten Kapitels auch die Wissensgrundlage für alle weiteren Kapitel (K2 \& 3) dieser Dissertation.

Die Kapitel 2 und 3 (K2 \& 3) bestehen aus zwei empirischen Fallstudien, in denen ich die nicht-materiellen Beiträge von Biodiversität zum menschlichen Wohlergehen untersuche. Dabei verwende ich einem Makroebenen-Ansatz, sprich, ich beleuchte den Zusammenhang zwischen Biodiversität und dem menschlichen Wohlbefinden auf einer höheren räumlichen bzw. höher-skaligen Ebene. Bisher haben nur wenige veröffentlichte Studien diesen Zusammenhang erforscht (siehe die Ergebnisse von K1) und Analysen, welche insbesondere die größeren räumlichen Zusammenhänge untersuchen, sind selten. So ist zum Beispiel wenig bekannt, ob Biodiversität auf nationaler und kontinentaler Ebene positiv mit dem menschlichen Wohlbefinden assoziiert. Jedoch sind empirische Studien auf der Makroebene, die sich mit solchen Fragestellungen auseinandersetzen, wichtig um Erkenntnisse für die Politikberatung und den Naturschutz zu gewinnen. Die beiden Fallstudien konzentrieren sich daher jeweils auf Deutschland und Europa als Modellregion um einen größeren räumlichen Maßstab der empirischen Analysen zu ermöglichen. Um empirische Analysen auf der Makroebene zu ermöglichen, kombiniere ich ökonomische und ökologische Methoden und führe sozio-ökonomische Daten mit makro-ökologischen Datensätzen zusammen. Außerdem verwende ich in jeder Studie verschiedene Indikatoren für Biodiversität (Artenvielfalt, z.B. Anzahl verschiedener Vogelarten) und konzentriere mich jeweils auf eine der folgenden Dimensionen des menschlichen Wohlbefindens: die menschliche Gesundheit (gemessen als geistige und körperliche Gesundheit) und das subjektive Wohlbefinden (gemessen als Lebenszufriedenheit). Die generierten Ergebnisse ermöglichen ein besseres Verständnis darüber, ob die biologische Vielfalt in 
Deutschland und Europa zum menschlichen Wohlbefinden beiträgt. Dieses neue Wissen kann auch wertvolle Informationen für politische Entscheidungsträger liefern.

\subsection{Methodischer Ansatz}

Um die Literaturübersicht des ersten Kapitels (K1) zu erstellen führe ich eine systematische Literaturrecherche durch. Relevante wissenschaftliche Artikel werden dazu gezielt mit spezifischen Suchbegriffen im „Web of Science“ gesucht und nach klar definierten Kriterien für die Recherche ausgewählt. Die Literaturrecherche konzentriert sich speziell auf die positiven und negativen WCP von vier verschiedenen taxonomischen Gruppen: Vögel, Säugetiere, Reptilien und Amphibien. Außerdem werden die Einflüsse von WCP auf insgesamt 12 verschiedene Dimensionen des menschlichen Wohlbefindens erkundet, darunter physische und mentale Gesundheit, Spiritualität, Identität, Inspiration oder Emotionen. Zusätzlich werden bei der Bewertung von WCP, verschiedene mechanistische Pfade mit einbezogen, die beschreiben, wie Menschen Wildtiere erleben und begegnen können. Diese Pfade heißen: Interaktion (Englisch: Interaction), Geteilter Lebensraum (Englisch: Living Within), Sinneswahrnehmungen (Englisch Perceiving) und Wissen (Englisch Knowing). Der Pfad Interaktion beschreibt die direkten multisensorischen Erlebnisse zwischen Menschen und Wildtieren (z.B. Tiere füttern oder streicheln), während sich der Pfad Sinneswahrnehmungen eher auf Begegnungen bezieht, die auf rein visuellen oder auditiven Sinneseindrücken beruhen. Geteilter Lebensraum bezieht sich auf die alltägliche, unbewusste Erfahrung oder Wahrnehmung von Wildtieren und Wissen beschreibt das Denken über Wildtiere oder die Erinnerung an Erfahrungen mit Wildtieren.

Im zweiten Kapitel (K2) analysiere ich den Zusammenhang zwischen Artenreichtum, einem Maß für Biodiversität, und der menschlichen Gesundheit in Deutschland. Konkret verwende ich dafür sowohl Messwerte für die Artenanzahl als auch für die Populationsgrößen zweier Artengruppen: Pflanzen und Vögel. Die Messwerte werden mit der Hilfe von räumlichen Daten über die Ausbreitung von Pflanzen und Vögeln in Deutschland ermittelt. Die menschliche Gesundheit wird getrennt als physische und psychische Gesundheit untersucht. Als Indikatoren verwende ich jeweils die Messwerte der Mental Health Component Scale (MCS) und der Physical Health Component Scale (PCS), die mit dem Short Form Health Survey (SF-12) erstellt wurden. MCS und PCS sind beides wichtige Indikatoren für die gesundheitsbezogene Lebensqualität (Englisch: Health Related Quality of Life). In meinen Analysen berücksichtige ich darüber hinaus auch sozioökonomische und makroökonomische Faktoren. Sowohl die Gesundheitsdaten als auch die ökonomischen Daten wurden dem Sozioökonomischen Panel 
Deutschland entnommen (SOEP).

Im dritten Kapitel (K3) untersuche ich, ob Artenvielfalt sich positiv auf die Lebenszufriedenheit von Menschen in Europa auswirkt. Diese Studie ist die erste kontinentale Studie, die die Auswirkungen der Artenvielfalt auf die Lebenszufriedenheit untersucht. Wie in der Deutschlandstudie (K2) verwende ich Messwerte für Artenvielfalt, die mit räumlichen Daten über die Ausbreitung verschiedener taxonomischer Gruppen in Europa generiert werden. Die Anzahl von Arten in Europa wird separat für Vögel, Säugetiere und Waldbäume ermittelt. Daten über die Lebenszufriedenheit der Menschen in Europa sowie ökonomische Daten werden der European Quality of Life Survey (EQLS) entnommen. In den Analysen für Europa berücksichtige ich auch die möglichen Auswirkungen anderer Naturmerkmale und sozioökonomischer Faktoren.

\subsection{Zentrale Ergebnisse und Diskussion}

Insgesamt werden 277 publizierte Studien und deren Ergebnisse im ersten Kapitel (K1) zusammengefasst. Die entstandene Literaturübersicht zeigt, dass die Mehrheit aller Studien über negative WCP berichten. In den letzten zehn Jahren hat jedoch die Zahl der Veröffentlichungen über positive WCP zugenommen, vor allem im globalen Norden. Diese Veränderung des Forschungsschwerpunkts begann um die Jahrtausendwende und könnte mit den in dieser Zeit neu aufkommenden Ideen und Perspektiven über die Natur zusammenhängen (z.B. Ökosystemdienstleistungen). Die Ergebnisse deuten möglicherweise auch auf unterschiedliche Forschungsinteressen und einer Publikationsverzerrung in den verschiedenen Weltregionen hin. Des Weiteren stellt die Literaturübersicht einen Mangel an umfassenden, systematischen Studien über WCP fest. Zum Beispiel gibt es taxon-spezifische Unterschiede bei den untersuchten WCP, wobei überwiegend positive WCP für Vögel und überwiegend negative WCP für Säugetiere oder Reptilien veröffentlicht werden. Außerdem ist die körperliche Gesundheit die am meisten untersuchte Dimension des menschlichen Wohlbefindens, während viele andere Dimensionen, wie subjektives Wohlbefinden, soziales Wohlbefinden, Lernen oder Identität nur selten untersucht werden. Von den vier mechanistischen Pfaden der Mensch-Wildtier-Erlebnisse sind Interaktion und Wissen am häufigsten untersucht.

Die Ergebnisse der ersten Fallstudie auf Makroebene (K2) zeigen eine signifikante positive Beziehung zwischen dem Artenreichtum von Pflanzen- und Vogelarten und der psychischen Gesundheit in Deutschland bei gleichzeitiger Berücksichtigung einer Vielzahl sozioökonomischer und demographischer Faktoren sowie anderer Naturmerkmale. Im dritten Kapitel (K3) 
wird eine positive Beziehung zwischen Artenvielfalt von Vögeln und Lebenszufriedenheit in Europa festgestellt. Die Artenvielfalt von Säugetieren und Waldbäumen hat auf europäischer Ebene keine signifikanten Auswirkungen auf die Lebenszufriedenheit von Menschen. Auch hier werden in der Analyse sozioökonomische und makroökonomische Faktoren mitberücksichtigt.

Beide Befunde stehen im Einklang mit früheren Untersuchungen auf lokaler und nationaler Ebene. Mögliche Gründe für die positive Beziehung zwischen Artenreichtum und Wohlbefinden, und vor allem offene Fragen bezüglich der beteiligten Mechanismen, werden zurzeit in der Literatur diskutiert. In meiner Dissertation argumentiere ich, dass aufgrund der großen räumlichen Skala der beiden Fallstudien zwei Möglichkeiten existieren, die erklären könnten, wie Artenreichtum (gemessen als Anzahl von Vogel- und Pflanzenarten) die psychische Gesundheit und Lebenszufriedenheit positiv beeinflussen: ein Effekt der Artenvielfalt selbst über multisensorische Erfahrungen (siehe K1, Interaktion oder Sinneswahrnehmungen) oder ein Effekt von Landschaftsmerkmalen, die sowohl die Artenvielfalt als auch das Wohlbefinden der Menschen begünstigen.

\subsection{Schlussfolgerungen und Empfehlungen}

Insgesamt kann ich in meiner Dissertation zeigen, dass Wildtiere und Biodiversität das menschliche Wohlergehen stark beeinflussen und wesentliche nicht-materielle NCP liefern. Diese Ergebnisse liefern sowohl einen wichtigen Beitrag für die Forschung, als auch wichtige Erkenntnisse für lokale und nationale politische Entscheidungsträger und den internationalen Naturschutz.

In meinem Literaturüberblick kann ich einen Überblick über die verschiedenen positiven und negativen nicht-materiellen NCP von Wildtieren geben. Die identifizierten zeitlichen und räumlichen Unterschiede in den Forschungstrends können auf normative Einflüsse hindeuten, die den relativen Anteil der gemeldeten positiven oder negativen WCP in der Literatur steuern. Diese normativen Einflüsse sind noch nicht gut untersucht. Aber es gibt Hinweise, dass einige größere internationale politisch-gesellschaftliche Prozesse die Forschungsziele durch ein größeres öffentliches Bewusstsein sowie durch politische und finanzielle Anreize beeinflusst haben könnten. Überraschenderweise stellt die Literaturübersicht einen Mangel an umfassenden, systematischen Studien über WCP fest. Zukünftige Studien sollten daher sowohl die positiven als auch die negativen Auswirkungen von Wildtieren auf das menschliche Wohlergehen bewerten, um ein ausgewogeneres und umfassenderes Verständnis von WCP zu erhalten. Das 
neu generierte Wissen würde dazu beitragen, die Beziehungen zwischen Menschen und Wildtieren besser zu verstehen und unser Verständnis darüber zu vertiefen, wie Wildtiere das menschliche Wohlbefinden beeinflussen.

In meinen beiden empirischen Fallstudien (K2 \& 3) kann ich zeigen, dass die Artenvielfalt, ein Indikator für Biodiversität, positiv mit dem menschlichen Wohlbefinden auf der Makroebene zusammenhängt. Beide Fallstudien weisen auf die Möglichkeit hin, dass positive nicht-materielle Einflüsse der Biodiversität auf den Menschen nicht nur auf lokaler Ebene bestehen, sondern auch auf nationaler und kontinentaler Ebene. Darüber hinaus ist gerade das Ergebnis des zweiten Kapitels (K2) ein erster Hinweis darauf, dass Biodiversität ein gesundheitsförderndes Merkmal in Naturräumen ist und somit zur Lebensqualität des Menschen beitragen kann. Zukünftige Forschung sollte jedoch vermehrt die Mechanismen bzw. mechanistischen Pfade untersuchen, mit der die biologische Vielfalt und das menschliche Wohlbefinden auf größeren räumlichen Skalen verbunden sind. Die abgeleiteten Erkenntnisse aus den empirischen Fallstudien sollten außerdem politische Entscheidungsträger dazu motivieren, den Erhalt der biologischen Vielfalt als auch artenreicher Naturgebiete als Maßnahme zur Förderung des allgemeinen menschlichen Wohlergehens anzuerkennen. Solche Erhaltungsbemühungen könnten zu starken Synergieeffekten führen, indem zum Beispiel Kosten für das öffentliche Gesundheitswesen gemindert werden. Konkrete Maßnahmen zu Förderung von Gesundheit und Biodiversität könnten die Förderung und der Schutz der Artenvielfalt in städtischen Grünflächen sein. Um die wichtigen Naturschutzmaßnahmen zu präzisieren, könnten auch spezielle Indikatoren auf der Basis von Verbreitungsdaten (z.B. von Vögeln und Pflanzen) erstellt und verwendet werden. 


\section{Summary}

Nature and its constituents are known to affect human well-being in positive and negative ways. Nature can be beneficial for humans by providing, for instance, food, recreation or inspiration. Natural disasters or transmitted diseases are, on the other hand, examples of nature's detrimental or harmful contributions to human well-being. Such positive as well as negative effects have been termed Nature's Contributions to People (NCP) by the Intergovernmental Science-Policy Platform for Biodiversity and Ecosystem Services (IPBES) and can be categorized into three different types of contributions: regulating, material and non-material NCP. While regulating and material NCP have been studied extensively, research on the non-material $\mathrm{NCP}$ is less common in comparison, especially regarding non-material NCP of biodiversity and wildlife. This dissertation therefore aims at shedding light on the non-material links between biodiversity, wildlife and human well-being. The thesis presents the results of three individual research studies in three separate chapters $(\mathrm{CH} 1,2 \& 3)$.

In the first chapter $(\mathrm{CH} 1)$ I conduct a systematic literature review on the non-material contributions of wildlife. Several previous reviews have published overviews on the non-material contributions of wildlife. However, only a few of these reviews examine both the positive and negative effects of wildlife in combination. These reviews usually cover few aspects of human well-being (e.g. recreation, health, psychological well-being) or just focus on a specific group of wildlife species (e.g. carnivores, scavengers). In addition, the pathways determining how wildlife affects human well-being are yet little understood. The aim of this review is therefore to create a holistic overview of the current knowledge on non-material contributions of wildlife (WCP), by summarising research on positive and negative effects and disentangling potential channels of human-wildlife experiences.

My results show that most studies in scientific literature report negative WCP. However, over the last decade the number of publications on positive WCP has increased, mainly in the Global North. This change in research focus, at the turn of the century, may be related to the newly emerging ideas and perspectives on nature during that time (e.g. Ecosystem Services and NCP). The results may also indicate different research interests across global regions and a focus on positive WCP (especially in the Global North). Surprisingly, the review identifies a lack of joint systematic assessments of positive and negative WCP across taxa, human well-being dimensions and ways (channels) of wildlife experiences. Studies show taxon-specific differences, with predominantly positive WCP reported for birds and predominantly negative WCP 
published for mammals and reptiles. Physical health was the most examined human well-being dimension, while many others, such as subjective well-being, social well-being, learning, identity or sense of place were rarely studied in comparison. The two channels of wildlife experiences that have been mainly studied or reported are Interaction and Knowing. While Interaction describes multisensory experiences in which people physically interact with wildlife. Knowing describes the metaphysical connection between humans and wildlife that arises through thinking or remembering experiences from wildlife encounters (including knowledge about wildlife).

To date, only few published studies examine the relationship between biodiversity and human well-being across larger spatial scales. For instance, little is known about how biodiversity is related to human well-being on the national or continental level. The second and third chapter $(\mathrm{CH} 2 \& 3)$ are thus comprised of two empirical case studies which examine the relationship between biodiversity and human well-being across Germany and Europe, respectively. As indicator for biodiversity, I use different species diversity measures including species richness and abundance. In the second chapter (CH2) I analyse the association between species richness and human health across Germany. The results demonstrate a significant positive relationship between plant and bird species richness and mental health while controlling for a multitude of socio-economic and demographic factors as well as other nature characteristics. In the third chapter $(\mathrm{CH} 3)$ I conduct the first study on the relationship between species diversity and subjective well-being on the continental level. The results show that bird species richness (unlike mammal, megafauna and tree richness) is positively associated with life-satisfaction, a measure for subjective well-being across Europe. These results are robust while accounting for socio-economic and macro-economic factors. The results of both empirical studies are in correspondence with previous research, conducted on the local and national level.

Overall, my dissertation shows that wildlife and biodiversity greatly affect human well-being and provide substantial non-material NCP. My literature review highlights the increasing number of publications on positive and negative effects of wildlife on human well-being (WCP), but also the lack of studies examining both effect outcomes. Future studies should jointly evaluate positive and negative effects of wildlife and biodiversity on human well-being to obtain a more balanced and comprehensive understanding of non-material effects. My empirical analyses produce some of the first indications of a positive association between biodiversity and human health and well-being on the national and continental level. This dissertation, however, also emphasizes that further research should investigate the mechanisms linking biodiversity 
and human well-being on larger spatial scales.

Based on the results of this dissertation, policy makers should consider conserving wildlife and biodiversity as a joint strategy to promote overall human well-being. This is especially important since global biodiversity is declining. If this decline is not halted, severe consequences for the future provision of NCP may be the result. In addition, my dissertation offers suggestions for local landscape and urban planners. To foster health and well-being, urban parks could be designed to create more opportunities for people to interact with nature, biodiversity, and wildlife daily. Such efforts could also result in strong synergies, for instance, a decrease in public health service costs. 


\section{Introduction}

\subsection{Nature and human well-being}

Nature has influenced people`s quality of life in many ways for centuries. Humans depend on natural food resources or materials and also benefit from non-material contributions of nature, such as opportunities for recreation or inspiration (MA, 2005; Washington, 2013). Since a few decades the role of nature for human well-being has been debated in international politics. A starting point, among others (e.g. Convention on Biological Diversity 1992), was the Millennium Ecosystem Assessment (MA, 2005) which was the first major international assessment of the status of the world's ecosystems. Hundreds of scientists were engaged in an intensive effort to summarize and share their knowledge with policy makers and the public, with the aim to highlight the importance of nature for human well-being. They also promoted the concept of Ecosystem Services (ES) to explain and condense the multiple benefits humans obtain from nature (MA, 2005). These ES can be grouped into 3 categories (Haines-Young and Potschin, 2018): Provisioning ES (e.g. food, water, timber), Regulating ES (e.g. climate, nutrients, air quality) and Cultural ES (e.g. spirituality, inspiration). In addition, the fundamental role of biodiversity (genetic diversity, species diversity etc.) for ecosystem functions and ES and thus human well-being was also emphasized (MA, 2005; Naeem et al., 2016). Overall, the MA probably played a major role in advancing the notion that human well-being and nature are irreversibly linked and interdependent.

\subsection{The IPBES framework}

To further promote and strengthen the science-policy interface for ES, biodiversity conservation, human well-being, and sustainable development, the 'Intergovernmental Science-Policy Platform for Biodiversity and Ecosystem Services' (IPBES) was established in 2012 (resolution of member states in Panama City 2012). The IPBES introduced a new framework (Fig. 1) that describes how nature and biodiversity contribute to human well-being (Díaz et al., 2015). This framework is elaborated in detail in the following sub-sections.

\subsubsection{Nature's contributions to people (NCP)}

To describe the link between nature and human well-being, the IPBES introduced the concept of 'Nature Contributions to People' (Díaz et al., 2018, 2015). This newly formulated frame- 


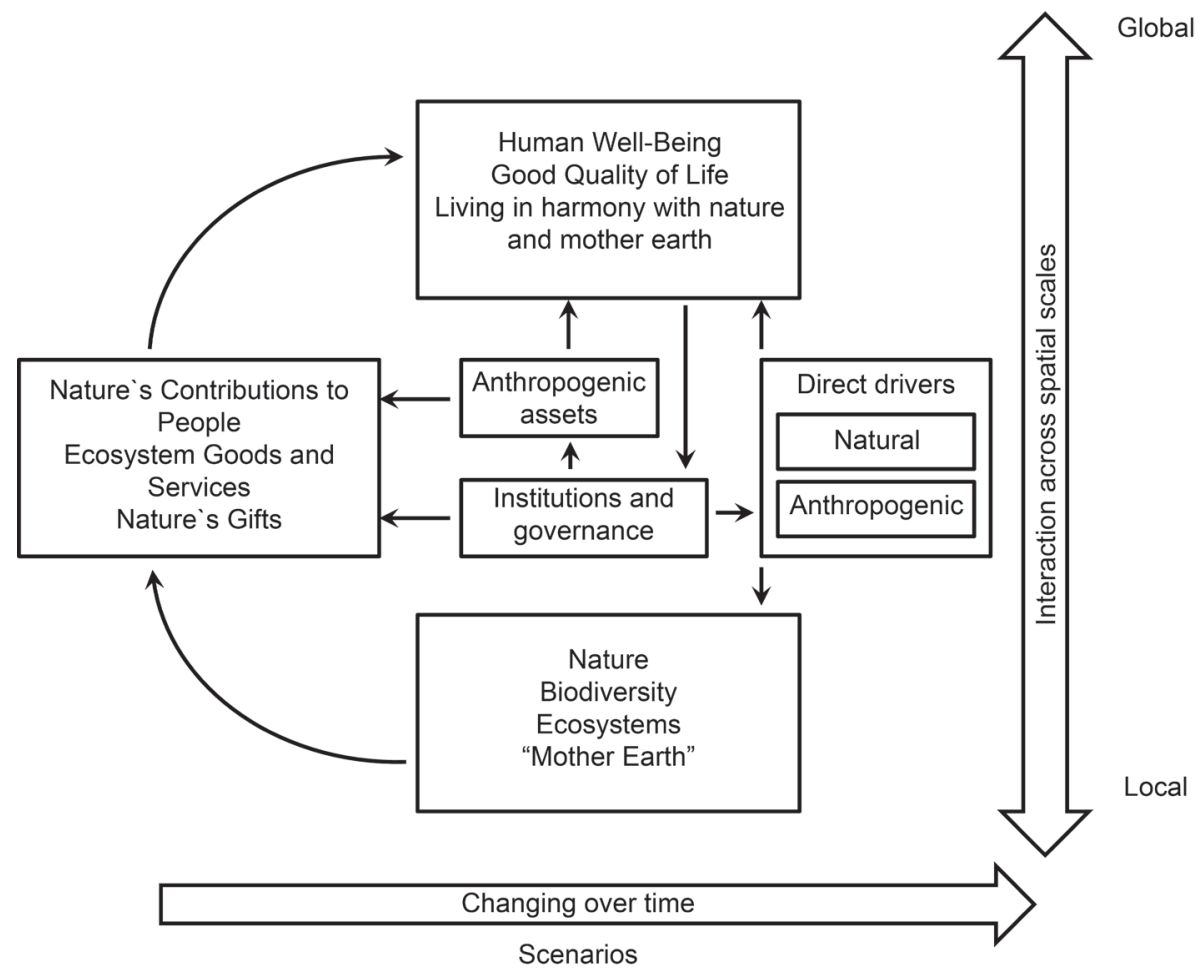

Fig. 1: IPBES conceptual framework adapted from Díaz et al. (2015).

work is based on the previously introduced ES framework (e.g. Daily, 1997; Haines-Young and Potschin, 2018), but initiated some alterations and advancements. For example, the original ES framework predominately focuses on western, scientific concepts of ES (Christie et al., 2019), and is seen as too narrow to capture a broad range of worldviews, knowledge systems and stakeholders (Kadykalo et al., 2019). In response, the IPBES framework and its concept of 'Nature Contributions to People' explicitly acknowledges the wider conceptualizations of preferences and values associated with indigenous and local knowledge (Díaz et al., 2018; Pascual et al., 2017).

Nature's Contributions to People (NCP) are defined as all contributions that capture both beneficial and harmful effects of nature on human well-being (Pascual et al., 2017) (Fig. 1). Similar to the ES framework, the NCP are grouped in three different categories (Díaz et al., 2018):

1. Regulating NCP are functional, structural or supporting aspects of nature and ecosystems that modify and regulate environmental conditions experienced by people and the production of materials used by people.

2. Material NCP are substances or other material elements from nature that directly sustain people's physical existence and provide material assets (food, energy, or materials for 
ornamental purposes).

3. Non-material NCP describe how nature affects the intangible aspects of people's lives that influence their well-being. Overlaps between the NCP categories are possible, e.g. the provision of food is connected to both material and non-material NCP because it also promotes good human health.

\subsubsection{Positive and negative NCP}

The IPBES highlights the possibility that NCP can have both positive and negative impacts on human well-being (Díaz et al., 2018; Pascual et al., 2017). Positive NCP are usually attributed to benefits such as the provision of food, inspiration or recreation (Haines-Young and Potschin, 2018; MA, 2005). Negative NCP, on the other hand, comprise detrimental contributions such as greenhouse gases from agroecosystems, invasive pests, infectious diseases or nuisance algae which can negatively affect human health, promote climate change, cause negative feelings and emotions or cause economic damage (e.g. Lyytimäki et al., 2008; von Döhren and Haase, 2015).

This emphasis on the fact that nature does not only provide benefits is not new (Kadykalo et al., 2019). Previously, the existence of negative effects of nature has been emphasized and discussed within the ES literature (Dunn, 2010; Shackleton et al., 2016; Zhang et al., 2007). The so-called negative ES have been termed 'ecosystem disservices' and are defined as '[...] ecosystem generated functions, processes and attributes that result in perceived or actual negative impacts on human wellbeing' (Shackleton et al., 2016). Despite their acknowledgement in the literature, the consideration of ecosystem disservices or negative NCP in the scientific literature has been low over the past decades (Shackleton et al., 2016; von Döhren and Haase, 2015). However, recently more attention has been payed towards such detrimental impacts of nature (Kadykalo et al., 2019).

\subsubsection{Nature, biodiversity and wildlife}

According to the IPBES framework, nature refers to all living organisms and their interactions among themselves and with their environment (Díaz et al., 2015). The term does not only cover species, biodiversity, or ecosystems, but also ecosystem functions and services. As this new framework tries to include a pluralistic view regarding the values of nature and different worldviews (Christie et al., 2019; Díaz et al., 2018) the IPBES framework uses also includes 
non-scientific terminology such as 'mother earth' to describe nature (Fig. 1). However, in this thesis I favour the more scientific understanding of nature and thus solely focus on the ecological definitions of biodiversity and wildlife (Fig. 2).

The IPBES framework explicitly highlights biodiversity as an important characteristic of nature. The Convention on Biological Diversity (CBD) defines biodiversity as 'the variability among living organisms from all sources including, inter alia, terrestrial, marine and other aquatic ecosystems and the ecological complexes of which they are part; this includes diversity within species, between species and of ecosystems' (United Nations CBD, 1992). In accordance, biodiversity has many different forms and facets (e.g. genetic variation, species diversity or functional diversity) within the IPBES framework (Díaz et al., 2015), which each contribute to human well-being (e.g. Díaz et al., 2006; MA, 2005; Sandifer et al., 2015).

Besides emphasizing the role of biodiversity and the diversity of all organisms, the IPBES framework also distinguishes important subgroups of species (IPBES, 2014). Wild animals, for instance, encompass non-domestic animals or species living in the wild (e.g. Fryxell et al., 2014) and are highly relevant for human well-being. This fact is supported by a large body of literature which has investigated the role of wildlife for human well-being and specifically focuses on human-wildlife relationships (e.g. Goodrich, 2010; Mayberry et al., 2017; Redpath et al., 2015). In addition, the diversity of wild animal species is an important aspect of global biodiversity and contributes to ecosystem functions and services. Even though wild animals, also termed wildlife, are not explicitly mentioned in the IPBES conceptual figure (Fig. 1), the importance of wildlife for humans has been stressed during the sixth session (IPBES-6) of the IPBES Plenary where the delegates approved the undertaking of a global thematic assessment on the sustainable use of wild species (IPBES/6/INF/8).

\subsubsection{Human well-being}

The concept of human well-being is at the centre of the IPBES framework (Fig. 1) and comprises multiple dimensions and domains, each covering an aspect of human livelihood or a specific human need. Altogether, the IPBES framework defines several human well-being domains, covering access to basic materials (e.g. food, water, energy), personal security and freedom, health, good social relationships as well as freedom of choice and action (Díaz et al., 2015). Similarly, the Millennium Ecosystem Assessment (MA) also defines well-being dimensions that encompass both material and intangible components of human well-being (e.g. MA, 2005). 
This dissertation focuses on the non-material NCP of biodiversity and wildlife to human well-being (Fig. 2). Some previous studies have solely focused on the intangible or non-material connections between nature and human well-being and are therefore particularly useful for my research by delivering concepts and definitions for human well-being dimensions. One such study on which this dissertation relies on classifies 10 dimensions of human well-being: subjective well-being, physical and psychological health, security, connection to nature, inspiration, spirituality, sense of place, identity and learning (Russell et al., 2013).

\subsection{Non-material NCP}

Besides regulating and material NCP, the IPBES framework also introduces the concept of non-material NCP (see section 3.2.1). Non-material NCP mostly have an impact on intangible aspects of human lives and, therefore, usually affect well-being dimensions such as human physical and psychological health, education and acquisition of knowledge, inspiration, recreation (e.g. leisure, tourism), religion and spiritually, social-cohesion experiences or a person`s sense of place and belonging (Díaz et al., 2018). Correspondingly, non-material NCP directly relate to cultural ES as defined in the ES framework (e.g. Haines-Young and Potschin, 2018; Milcu et al., 2013).

Non-material NCP can have positive as well as negative effects on human well-being (e.g. Martin-Lopez et al., 2019). Among the various well-being dimensions, the positive effects of nature on human health and subjective well-being are probably best studied. Many epidemiological studies for instance, show that people report better subjective health and well-being when they live close to vegetated areas (e.g. Bertram and Rehdanz, 2015; Krekel et al., 2016; Maas et al., 2006; Triguero-Mas et al., 2015). Studies also show that better access to public green spaces (e.g. parks, forests) and water bodies (e.g. lakes) improves mental health and reduces common mental health disorders (de Vries et al., 2016; Gascon et al., 2015). Especially the frequency of green space visits or physical activity within nature promote human mental and physical health (Cox et al., 2017b; Hartig et al., 2014; Shanahan et al., 2016; Sugiyama et al., 2008). Non-material NCP can also positively influence many more well-being dimensions, such as people's sense of place, identity or connection to nature (Russell et al., 2013; Schebella et al., 2017). Beside positive and other beneficial contributions, non-material NCP can also affect humans in negative ways. For instance, to some people nature is considered as ugly or unpleasant and as causing health problems, due to allergies or transmitted diseases (Lyytimäki et al., 2008; von Döhren and Haase, 2015). 


\subsubsection{Non-material contributions of biodiversity}

While biodiversity fulfils an important role for regulating and material NCP (e.g. ecosystem functioning and medical products), different forms of biodiversity can also provide non-material NCP (Mace et al., 2012; Naeem et al., 2016). So far, only little is known about the non-material contribution (or cultural ES) of biodiversity as published research is rather scarce. Over the past decade however, there has been an increase in publications on topics related to biodiversity and human mental health and psychological well-being.

Several studies have summarized scientific evidence for positive associations between biodiversity and human health (Aerts et al., 2018; Lovell et al., 2014; Marselle et al., 2019; Sandifer et al., 2015). These reviews cover studies that show how biodiversity in urban parks or neighbourhoods is related to better psychological well-being (Dallimer et al., 2012; Fuller et al., 2007) and associated with better mental health (Cox et al., 2017c). In addition, biodiversity can provide health-promoting services to people and these benefits include, for instance, the provisioning of food and natural products for medicine (Bernstein, 2014) or the regulation of diseases (Hough, 2014). However, besides the published positive influence of biodiversity, there have also been cases of reported negative effects. For example, perceived bird biodiversity (an individual's subjective assessment of the species richness in an environment) increased negative affect (negative emotions) after people participated in outdoor group-walks (Marselle et al., 2015).

\subsubsection{Non-material contributions of wildlife}

Even though it is not explicitly mentioned in the IPBES framework, wildlife's influence on human well-being can be categorized according to the three proposed NCP categories (Díaz et al., 2015; IPBES, 2014). Many studies have focused on material and regulating NCP of wildlife. For instance, food and other resources provided by wildlife can be counted as positive material contributions (e.g. Alves, 2012).The economic consequences of human-wildlife conflicts can in turn be considered as negative material NCP of wildlife (e.g. Expósito-Granados et al., 2019; Soulsbury and White, 2015). Regulatory contributions are, among others, the ecological role of birds and insects as seed dispersers and pollinators (Klein et al., 2007; Sekercioglu, 2006), ants as 'ecosystem engineers' (e.g. Del Toro et al., 2012; Folgarait, 1998) or the certain benefits provided by carnivores and scavengers (O’Bryan et al., 2018). 
Non-material NCP of wildlife have also been investigated. For example, wildlife experiences can foster positive emotions (Curtin, 2009; Farber and Hall, 2007) and social relationships (e.g. Bell et al., 2017) or contribute to tourist satisfaction and recreation (Arbieu et al., 2017; Mcintosh and Wright, 2017). Unfortunately, wildlife experiences can also lead to negative outcomes for humans. Especially in regard to direct interactions or encounters with dangerous animals (e.g. large carnivores or poisonous snakes), there are large numbers of published cases in which humans are harmed (e.g. Debata et al., 2016; Moore Jr. et al., 2013; Penteriani et al., 2016). Such negative wildlife experiences can have long lasting psychological consequences for humans and cause depression and other mental disorders (Barua et al., 2013; Mayberry et al., 2017). The mere knowledge that potentially harmful animals (e.g. wolves or bears) live nearby can also foster fear and feelings of insecurity (e.g. Bisi et al., 2007; Dhakal and Thapa, 2019; Frank et al., 2015).

\subsection{Pathways linking biodiversity and wildlife to human well-being}

Pathways linking biodiversity and wildlife to human well-being via non-material NCP are not yet very well understood. While several conceptual frameworks exist that describe the mechanisms or channels of how nature can influence human well-being, especially human health (e.g. Markevych et al., 2017; Russell et al., 2013), concepts that exclusively focus on biodiversity or wildlife are scarce. Only recently, for instance, researchers have started to explore the mechanisms involved in how biodiversity influences human health, especially mental health (e.g. Aerts et al., 2018; Marselle, 2019).

The framework published by Russell et al. (2013) proposes 4 distinct channels that portray how people experience nature and how these experiences are linked to non-material aspects of human well-being: Interaction, Perceiving, Living Within and Knowing. Interaction comprises human direct multisensory interactions with nature while Perceiving rather refers to a remote interaction often associated with visual or auditory processing. Living Within describes people's every-day, pervasive, subconscious experiences with nature and Knowing is defined as thinking about nature, ecosystems and other nature components (e.g. wildlife, trees and plants).

This dissertation adopts the framework by Russell et al. (2013) in several chapters and, especially in the literature review ( $\mathrm{CH} 1$, section 5.2.4). While this framework was originally designed to characterize non-material links between humans and nature, it is also particularly suited to disentangle the different types of biodiversity and wildlife experiences which lead to 
non-material NCP that influence human well-being. By integrating biodiversity and wildlife, my dissertation extends the scope of this framework and creates new insights into how they influence human well-being via non-material channels.

The mostly positive effect of biodiversity and wildlife on human psychological health has been extensively studied in environmental psychology. In environmental psychology the effect of biodiversity on mental health, for instance, is attributed to attention restoration and stress recovery (Marselle, 2019). These two potential mechanisms (mediators) are based on two established psychological theories: Attention Restoration Theory (ART) and Stress Reduction Theory (SRT). The ART emphasises that an environment can influence a person's ability to concentrate or direct attention (Kaplan, 1995) while the SRT considers the physiological impact of viewing environments which then facilitates the reduction of psychological stress and negative affect and enhances positive affect (Ulrich, 1991). Several studies have empirically explored which mechanisms are involved in how biodiversity effects people, however, the majority of these studies focus on attention restoration (Marselle et al., 2019). In this dissertation, the role of ART and SRT are not extensively explored. Instead, both concepts are called upon to understand the potential relationship between biodiversity, human well-being and the psychological mechanisms involved. Furthermore, it is not the aim of this dissertation to provide a new integrated framework in which all above mentioned concepts (e.g. ART, SRT and Russel et al. 2013) are combined. Nonetheless, by discussing all established concepts, my studies provide valuable insights in how these ideas from different scientific disciplines might be connected. 


\section{Thesis structure and research objectives}

This dissertation is my original work in which I investigate the relationship between biodiversity, wildlife, and human well-being. It consists of three individual studies (Fig. 2, Chapters 1-3) centred around the question how biodiversity and wildlife influence human well-being on the macro-level, with a focus on non-material NCP. Each one of the three individual studies is presented as a manuscript, and of each one I am the lead author (see Appendix I-III). The manuscripts have been published in or submitted to international peer-reviewed scientific journals. The first and third chapters ( $\mathrm{CH} 1 \& \mathrm{CH} 3$, Appendix I \& III) were published in Environmental Research Letters (Methorst et al., 2020a) and Ecological Economics (Methorst et al., 2020b, early online print), respectively. The second chapter (CH2, Appendix II) is currently under review at Landscape and Urban Planning.

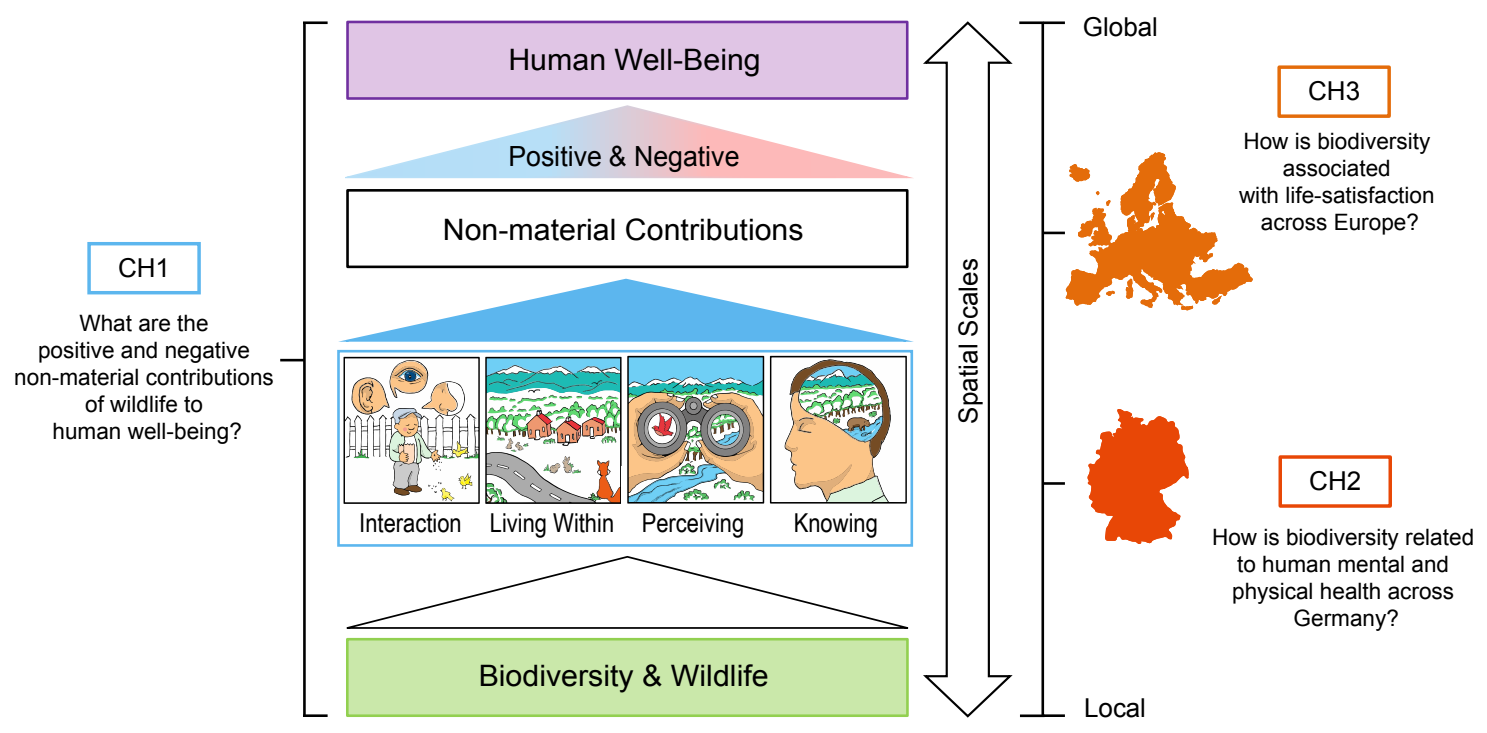

Fig. 2: Conceptual figure and main research questions. The aim of this dissertation is to study the non-material contributions of biodiversity and wildlife on human well-being (see explanation on non-material NCP, section 3.2). The dissertation is comprised of three chapters (CH). In the first chapter I conduct a comprehensive literature review on the positive and negative non-material contributions of wildlife (CH1). Here I also define and investigate the different channels through which humans might experience biodiversity and wildlife: Interaction, Living Within, Perceiving and Knowing. In the second and third chapters, I conduct case studies $(\mathrm{CH} 2 \& 3)$ to investigate the relationship between biodiversity and human well-being. In each chapter, I look at different human well-being dimensions: human health (measured as mental and physical health) and subjective well-being (measured as life-satisfaction) respectively. Each case study is conducted in a different model region and on a different spatial level: Germany (CH2) and Europe (CH3). The illustrations portraying the four channels are in part inspired by Russell et al. (2013, Fig. 1).

In the first chapter (CH1) I conduct a comprehensive literature review, addressing non-material contributions of wildlife on human well-being (Fig. 2). A comprehensive summary of the current scientific knowledge is crucial to better understand how wildlife influences human 
well-being, as human-wildlife interactions are part of people's daily lives (especially during outdoor activities and nature visits) (e.g. Bell et al., 2017; Cox and Gaston, 2016; Schebella et al., 2017). In addition, the review was designed to establish a knowledge foundation for the second and third chapters $(\mathrm{CH} 2 \& 3)$. Therefore, the literature assessment did not only focus on wildlife research, but also includes studies on biodiversity (see section 5.2.2). As a result, this review might help deepen our understanding of the complex non-material links between biodiversity and human well-being.

In the second and third chapters $(\mathrm{CH} 2 \& 3)$ I conduct two empirical case studies on biodiversity's non-material contribution to human well-being, by applying a macro-level approach. I chose to concentrate on the effects of biodiversity since studies on this topic are yet scarce, especially for research across larger spatial scales. The two case studies therefore focus on two model regions, which enable analyses across larger spatial scales: Germany $(\mathrm{CH} 2)$ and Europe (CH3). In each study I use different indicators for biodiversity and focus on two distinct dimensions of human well-being: human health (measured as mental and physical health) and subjective well-being (measured as life-satisfaction). For this purpose, I merge economic and ecological methods and combine socio-economic data with macro-ecological data sets. The results of the two case studies provide crucial knowledge for policy makers and to better understand how biodiversity contributes to human well-being on larger spatial scales.

\subsection{Review of non-material contribution of wildlife and biodiversity (CH1)}

In the first part of my dissertation, I summarize knowledge on the non-material NCP between wildlife and human well-being (CH1, Appendix I). Several studies provide overviews regarding the material and regulating NCP of wildlife (Alves, 2012; Harrison et al., 2014; Inskip and Zimmermann, 2009; Marchini and Crawshaw, 2015; Sandifer et al., 2015). However, only a few literature reviews on non-material NCP of wildlife have been published. In this study, I therefore conduct a systematic review on non-material NCP of wildlife (including biodiversity), termed thereafter 'Non-material Contribution of Wildlife to People' (WCP) (Fig. 2). For this reason, the research question has been phrased as follows:

What are the positive and negative non-material contributions of wildlife

to human well-being?

Past research either emphasizes on positive non-material NCP of wildlife (WCP) (e.g. Shackleton et al., 2016; Vaz et al., 2017) or on negative effects of WCP (e.g. Barua et al., 2013; 
Inskip and Zimmermann, 2009; Marchini and Crawshaw, 2015). Most importantly, few reviews examine both the positive and negative effects of WCP in combination, and those that do so, usually cover few aspects of human well-being, for example, recreation, health, psychological well-being, religion (e.g. Alves, 2012; Barua et al., 2013; Harrison et al., 2014; Lovell et al., 2014; Marselle et al., 2019), or focus on a specific group of wildlife species, for instance, carnivores or scavengers (Expósito-Granados et al., 2019; Lozano et al., 2019; Moleón et al., 2014).

This study reviews the positive and negative outcomes of WCP for different taxa (birds, mammals, reptiles, and amphibians) and multiple dimensions of well-being, while incorporating different channels by which people experience wildlife (Fig. 2). In regard to the human well-being dimensions, the review builds on previous efforts and broadens the set of dimensions used by Russell et al. (2013) (section 3.2.4) by including aspects such as emotions and social well-being, to further improve my literature synthesis (see Appendix I). The four channels comprise Interaction, Living Within, Perceiving and Knowing (Russell et al., 2013) and are adapted to describe how people experience wildlife (section 5.2.4). Overall, the review looks at (a) the spatial and temporal patterns of positive and negative WCP, (b) the distribution of positive and negative WCP per wildlife taxa in the literature, (c) differences in the distribution of positive and negative WCP per human well-being dimension, (d) the channels that shape human-wildlife experience, and (e) the differences in methodology and use of wildlife and biodiversity measures.

\subsection{Biodiversity and human well-being relationship on the macro-level}

In the second part of my dissertation, I conduct empirical analyses to study the relationship between biodiversity and human well-being. Previous studies mostly investigate this relationship on the local level, i.e. in urban parks and neighbourhoods (Cox et al., 2017c; Dallimer et al., 2012; Luck et al., 2011). Only one study exists in which the influence of biodiversity on human health is examined on the national level (Great Britain) and in which a positive correlation between bird species richness and good health prevalence is found (Wheeler et al., 2015).

Since studies on higher spatial levels are scarce, I conduct two empirical case studies $(\mathrm{CH} 2$ \& 3) on the macro-level. Such epidemiological studies on a larger spatial scale are important to identify relevant associations between biodiversity and human well-being and provide evidence-based information for local and national policy design. Each case study is conducted in a specific model region, representing the national and continental level, respectively: Germany 
$(\mathrm{CH} 2)$ and Europe $(\mathrm{CH} 3)$. I chose these two regions because of two reasons. First, spatially explicit data on biodiversity and people's socio-economic and well-being information are available and easily accessible for both regions and have few quality issues. Second, much empirical research has been conducted in European countries (see CH1, Appendix I) which provides knowledge that may support the findings from my dissertation. The two empirical studies in my dissertation examine the effects of different biodiversity indicators measured for multiple taxa. Each case study only focuses on one specific dimension of human well-being, either human health or subjective well-being.

\subsubsection{Biodiversity and human health in Germany (CH2)}

In the second chapter ( $\mathrm{CH} 2$, Appendix II) I examine the relationship between biodiversity and human health. Several studies have summarized scientific evidence for positive associations between biodiversity and human health (Aerts et al., 2018; Lovell et al., 2014; Marselle et al., 2019; Sandifer et al., 2015). For instance, local level studies show that urban park visitors exhibit better psychological well-being in urban parks with high bird and plant species richness (Dallimer et al., 2012; Fuller et al., 2007) and that afternoon bird abundances positively influenced human mental health in an urban neighbourhood (Cox et al., 2017c). In this study, however, I aim to go beyond previous efforts to study the relationship between biodiversity and human health. While previous studies are mostly conducted on a local scale (but see Wheeler et al. 2015), I apply a macro-level approach and analyse the influence of biodiversity on human health on the national level, specifically, across Germany. Hence, the research question has been phrased as follows:

How is biodiversity related to human mental and physical health across Germany?

To answer this research question, I use different species diversity measures as indicators for biodiversity, these were available for the entire area of Germany. In specific, I use species richness and species abundance measures of two species groups: plants and birds. Only few studies previously investigate the effect of species abundance on human health (e.g. Cox et al., 2017c). Since it is also my aim to understand biodiversity`s effect on different facets of human health, I use two different measures representing the physical and psychological aspects of human health. I therefore use the mental health component scale (MCS) and physical health component scale (PCS), which are important indicators for 'Health Related Quality of Life' (HRQoL) (e.g. Busija et al., 2011; Coons et al., 2000). So far, no previous study has explored 
the relationship between biodiversity and HRQoL (MCS and PCS) on a national scale. I aim to test the following hypotheses:

1. Based on previous evidence, I expect that plant and bird species richness have a positive influence on MCS across Germany (H1).

2. Resting on a previous study that shows that bird afternoon abundance influences mental health (Cox et al. 2017c), I also expect that bird abundance may positively influence MCS across Germany (H2).

3. Founded on the fact that some studies show a positive influence of species richness (e.g. birds and plants) on general and composite human health measures (Carrus et al. 2015, Wheeler et al. 2015), I assume that the examined bird and plant richness variables are positively correlated with physical health (H3).

\subsubsection{Biodiversity and life-satisfaction across Europe (CH3)}

In my second empirical analyses I study the relationship between biodiversity and human well-being, by using life-satisfaction as indicator for subjective well-being (CH3, Appendix III). Several studies use life-satisfaction or happiness to explore the relationship between nature and human well-being (Krekel et al., 2016; MacKerron and Mourato, 2013; White et al., 2017). These studies are conducted on an number of spatial levels, i.e. in urban areas (Bertram and Rehdanz, 2015; Krekel et al., 2016; White et al., 2017), on the national scale (e.g. White et al., 2013) or even on the continental scale (e.g. Kopmann and Rehdanz, 2013). Most studies, however, make use of a limited set of measures to examine the different effects of nature on human well-being, for instance, studies mainly focus on water bodies, vegetated areas or urban parks - also termed blue space or green space (de Bell et al., 2017; Völker and Kistemann, 2013, 2011). There is yet no study available that investigates the influence of biodiversity on life-satisfaction, especially on the continental scale. The aim of my study is, therefore, to examine the relationship between biodiversity and life-satisfaction across Europe. Accordingly, the research question has been phrased as follows:

How is biodiversity associated with life-satisfaction across Europe?

To address this question, I again use species diversity measures (see $\mathrm{CH} 2$ ) as indicator for biodiversity. This study is also the first continental study that explores the effect of species diversity on life-satisfaction. In addition, this dissertation wants to better understand how the 
taxon group influences the potential effect of species diversity (measured as species richness) on life-satisfaction. I therefore measure species richness for multiple species groups, such as birds, mammals and trees. Overall, my third study aims at addressing one main hypothesis that is formulated as follows:

4. I expect that species richness is positively associated with life-satisfaction of people living in Europe (H4). Furthermore, I expect that especially bird species richness will have a positive influence, as several previous studies find positive effects of bird species richness on human well-being (Luck et al. 2011, Dallimer et al. 2012). 


\section{Methodological approach}

\subsection{Macro-level approach}

The term 'macro' comes from the Greek word $\mu \alpha \kappa \rho o$ s meaning long (or large) (McGill, 2019). In my dissertation I analyse the relationship between biodiversity, wildlife and human well-being on a macro-level by linking methods and data from economics with ecological data across larger spatial scales. This approach is originally adopted from macroecology, a subdiscipline of ecology, which aims to uncover general mechanisms operating at different levels of spatial scale (e.g. across regions, countries and global) and ecological organization (McGill, 2019).

Similar to macroecology, the macro-level approach applied in this dissertation provides several advantages. The approach does not only allow comparisons between larger regions or countries, but also enables the combination and utilization of methods and data from different disciplines. Therefore, the macro-level approach will be able to reveal large scale patterns which are not evident at the local scale, thus creating new viewpoints on specific relationships and processes.

Disadvantages to this approach are that methodological problems can arise or that understanding the mechanisms can present a considerable challenge. Experiences from macroecology show that macro-level studies face practical limitations, such as difficulties to conduct and organize large-scale experiments or high financial costs (McGill, 2019). Furthermore, researchers argue that the analysis of large-scale ecological patterns and processes is difficult (Blackburn, 2004) and that understanding the mechanism is more challenging, because some mechanisms may act differently at local levels (e.g. ecological communities) compared to the macro-level (Beck et al., 2012).

To address the first problem and avoid methodological complication in my dissertation, I use existing secondary, socio-economic data sets as well as published and open-source macro-ecological data sets. This has been done in large-scale studies that investigate the effect of land-cover or climate on human well-being (Kopmann and Rehdanz, 2013; Rehdanz and Maddison, 2005; Wheeler et al., 2015). The second issue regarding the difficulty to understand macro-level processes can be solved by establishing a solid theoretical basis, by summarizing all existing literature and studies before conducting macro-level studies. For this purpose, experimental and local-level studies on biodiversity, wildlife and human well-being, which may 
infer the causal mechanisms, have been reviewed and summarized in the first chapter $(\mathrm{CH} 1$, section 5.2). The results support the formulation of adequate hypotheses for the subsequent empirical, macro-level analyses in the second and third chapter $(\mathrm{CH} 2 \& 3)$. In addition, the knowledge generated in the first chapter $(\mathrm{CH} 1)$ is also able to help avoid false interpretation of results and assists in separating known mechanisms or processes from artefact of a particular methodology (Blackburn, 2004).

\subsection{Literature review methodology (CH1)}

In the first chapter (CH1) I conduct a systematic review on the positive and negative non-material NCP of wildlife and biodiversity, also termed Non-material Contribution of Wildlife (WCP). As mentioned above (section 4.1), the purpose of this review is to establish the knowledge foundation for the second and third chapter $(\mathrm{CH} 2 \& 3)$ and to collect scientific evidence of a relationship between wildlife and human well-being by accessing information from experimental and local level studies.

\subsubsection{Systematic literature search}

I conduct a systematic literature search, using Web of Science to find relevant scientific articles. The literature search follows the PRISMA guidelines (Moher et al., 2009). I use specific search strings by combining ('AND') search terms covering wildlife, the human well-being indicators of interest and four channels of wildlife experiences (Appendix I - Manuscript: Table 1). Relevant articles are identified by looking at titles and abstracts for specific criteria: (1) the article has been published in a peer-reviewed journals before 2020 (reviews in peer-reviewed journals are allowed, book chapters and other forms of publication are excluded); (2) articles have been published in relevant scientific disciplines; and (3) titles and abstracts had to contain information on whether or not wildlife (e.g. individual animals, species richness) and human well-being play a major role in the study. During this first initial literature search I collect a set of 513 research articles for a detailed full text assessment.

During the full text assessment, I conduct a more thorough evaluation of each research article based on predefined criteria and organized according to a fixed procedure. I only consider articles when the following conditions are met: (a) studies examine human adults, (b) studies examine wildlife species and human well-being dimensions according to the definition (as explained in the next section 5.2.2), (c) studies clearly report or observe an effect of wildlife on a human well-being dimension (see section 5.2.3 and 5.2.5). After the full text assessment, 
I adopt a snowball-approach and additionally search for literature referenced in the reviewed papers in order to identify relevant studies that might have been missed during my previous systematic search and screening process (e.g. Hansen and Pauleit, 2014). The identified articles are then added to the full text assessment. At the end, I obtain 277 articles that are included in the review.

\subsubsection{Wildlife definition}

In this study I define wildlife as wild, non-domestic living vertebrate species in their (semi-) natural environment (Fryxell et al., 2014). I specifically concentrate on species belonging to the following taxon groups: mammals (terrestrial and aquatic), birds, reptiles and amphibians. I exclude animals in captivity and domesticated animals (e.g. zoo, farm animals and pets), because they have been extensively reviewed elsewhere (e.g. Herzog, 2011; Wells, 2009) and are not covered by my definition of wildlife. I also exclude invertebrates, because I assume that vertebrate species are more likely to provide non-material contributions to humans.

To gather information about the use of biodiversity indicators and the specific influence of wildlife diversity on human well-being, I also include studies that use different measures for the diversity of wild animals. Wildlife diversity measures comprise ecological species diversity measures (e.g. species richness, total abundance) or perceived species richness (people`s subjective assessment of species richness) of wild animals.

\subsubsection{Human well-being \& positive and negative WCP}

Here, I focus on multiple constituents of human well-being and their indicators which represent aspects of well-being that are affected by non-material NCP (Díaz et al., 2018). I choose to focus on 10 dimensions of human well-being (see Appendix I - Manuscript: Table 2) used in previous studies including subjective well-being, physical and psychological health, spirituality, inspiration or sense of place (Russell et al., 2013). I further include social well-being (social relationships) and emotions as dimensions because the Millennium Ecosystem Assessment recognizes social relationships as an important component of human well-being (MA, 2005) and to provide a more complete perspective on human emotional responses and dispositions in the context of human-wildlife relationships (e.g. Jacobs and Vaske, 2019; Jacobs, 2012).

All 12 human well-being dimensions cover positive and negative effects of wildlife on human well-being. I identify these positive or negative wildlife contributions to people (WCP) 
based on a predefined strategy (see Appendix I). According to these predefined criteria, positive WCP outcomes include better mental health, positive emotions or memories, and better social relationships (e.g. Cox et al., 2017c; Curtin, 2009; Lee and Davey, 2015). Negative WCP include detrimental experiences with wildlife in which humans for instance, come to harm (e.g. Debata et al., 2016; Gunther et al., 2004; Penteriani et al., 2016) or suffer from negative emotions after encountering wildlife species (Barua et al., 2013). For more details regarding the definition of positive and negative WCP, see Methorst et al. (2020a) (Appendix I - Manuscript: Methods).

\subsubsection{Channels linking WCP to human well-being}

In my review I am interested in understanding the different ways how people experience wildlife (Fig. 2) and how these experiences influence human lives. I therefore adopt the framework from Russell et al. (2013) that describes four different ways (or channels) how people experience nature and ecosystems: Interaction, Living Within, Perceiving and Knowing (see also Introduction, section 3.4). Even though these channels are meant to explain human-nature experiences, they are also well-suited for understanding WCP because they are also able to describe the non-material links between humans and wildlife.

I redefined the channels as follows:

- Interaction describes multisensory experiences where people physically interact with wildlife. Examples are catching fish, hunting or feeding wild animals.

- Living Within defines the everyday, conscious or subconscious, voluntary and involuntary contact with wildlife in areas where a person lives. This entails living in a forested area, close to the coast and near urban parks and sharing these habitats with wild animals.

- Perceiving is the remote sensory interaction with wildlife, often associated with a single sensory ability such as the visual processing of information (e.g. watching birds or watching a nature documentary). However, it could also include a person's ability to hear, feel and smell things that are associated with wildlife (e.g. listening to bird sounds).

- Knowing describes the cognitive/metaphysical connection between humans and wildlife that arises through thinking, contemplating or remembering experiences from wildlife encounters. Knowing also describes people's knowledge about wildlife, as well as expressed statements or opinions that reflect people's emotions towards wildlife (e.g. if someone had no prior experience with wildlife but still feels positive attachment, inse- 
curity or fear). I also assume that wildlife-induced inspiration and spirituality are based on and influenced by Knowing.

As a note, most reviewed studies explore multiple channels at the same time as, for instance, Living Within and Interaction or Living Within and Knowing are often connected.

\subsubsection{Data collection process}

For every article reviewed I record information on title, authors, publishing year and study origin (e.g. country and continent) as well as for wildlife taxon (mammals, birds, reptiles or amphibians) and the wildlife measure used (e.g. single species, species groups or species diversity measure). For further interpretation, I coded studies according to whether they find either positive or negative WCP or both, which dimension of human well-being they study and which channel (type of wildlife experiences) is involved in linking wildlife to human well-being.

When a study reports a clear connection or relationship (positive or negative) between wildlife and a human well-being dimension, this is counted as one effect. These effects can either be based on reported significant statistical relationships, based on quantitative records such as descriptive statistics (e.g. number of attacks and injuries) or it can be based on specific statements, observations and qualitative assessments derived from interviews, surveys, field work or literature analysis (e.g. reported personal statement about faith beliefs). It is possible that multiple effects are recorded for one single study, as some studies examine several human well-being dimensions and wildlife taxa with different channels (types of experiences) involved.

After data collecting and arranging, I calculate descriptive statistics for the number of studies examining positive and negative WCP (or both) and count the number of identified effects (positive and negative) on each human well-being dimension and channel. For more information see Methorst et al. (2020a) (Appendix I - Manuscript: Methods). 


\subsection{Empirical analysis on macro-level $(\mathrm{CH} 2 \& 3)$}

In the chapters 2 and $3(\mathrm{CH} 2 \& 3)$ I conduct empirical analyses on the macro-level for two model regions: Germany and Europe. In the following section I describe how I collected, processed and analysed the data to answer my research questions (Fig. 2).

\subsubsection{Human well-being indicators $\&$ socio-economic data}

Human well-being is a multidimensional concept which describes the state of an individuals' life situation (McGillivray, 2007). Consequently, different indicators are used to describe and investigate human well-being. Many of these indicators are, for instance, measured on the individual level and can be assessed using two approaches: the objective and subjective approach (e.g. Dale, 1980; Western and Tomaszewski, 2016). Objective measurement of human well-being requires that impartial outsiders assess explicit criteria such as life expectancy, income, living conditions or medication (Veenhoven, 2007). In contrast, subjective measurements are primarily concerned with the respondents' own internal judgement on aspects of his/her personal life (Diener, 1984) and therefore comprise self-reports based on implicit criteria for assessing work, family, health or leisure (Veenhoven, 2007). Such subjective measures of well-being are indispensable for assessing policy success and for selecting policy goals (Veenhoven, 2007).

In my two empirical case studies I examine two different dimensions of human well-being. In Germany (CH2) I study human health and in Europe (CH3) I look at human subjective well-being (see section 4.2). Each dimension is described by indicators that rely on subjective measurements and the use of survey questions comprised of multi-item or single-item scale. Subjective measurements of human health indicators are often measured via questionnaires using multiple items (questions). The World Health Organization Quality of Life scale (WHOQOL) for instance, focuses on 100 variables representing different life domains (McGillivray, 2007). Other health questionnaires have fewer items and are, like the Short Form Health Survey (SF-12), used to assess different dimensions of Health Related Quality of Life (HRQoL), covering aspects of mental and physical health (e.g. Busija et al., 2011; Coons et al., 2000). Subjective well-being can also be measured with multi-item (e.g. Diener et al., 1985) or single-item scales (Dolan et al., 2008). Life-satisfaction, i.e. how a person evaluates or appraises his or her life as a whole, is considered an important aspect of subjective well-being (Diener, 1984) and can be measure with single-item scales (one question). Especially in the social-science and economic literature such single item scales are often applied and survey respondents are then 
asked, for example, 'All things considered, how satisfied are you with your life as a whole these days?' (Kahneman and Krueger, 2006).

\subsubsection{Human health indicators for Germany}

To study the influence of species diversity on human health in Germany (CH2) I use data from the Socio-Economic Panel Germany (SOEP). The SOEP is a representative panel of private households in Germany that conducted its first survey conducted in 1984 (Goebel et al., 2019). The SOEP provides socio-economic, demographic and health information on the individual and household level, including geographical locations of each household on different spatial levels, such as counties (German: Landkreise) or municipalities. In my analyses I utilize SOEP data from the year 2008 (SOEP-Data Version 33.1), that covers a sample of more than 13,000 individuals, located in 401 counties. In addition, I also include data only available from the 2009 SOEP survey on walking distance to parks (green space availability) and the 'Big Five'-personality variables (see also Appendix II - Manuscript: Methods).

The 2008 SOEP survey includes a short-form health questionnaire (SF-12 version 2) with questions addressing people's health (Ware et al., 1994). The 12 questions comprise several positively- and negatively worded items and address eight domains of mental and physical health-related topics: general health; vitality; mental health; emotional roles; social functioning; physical functioning; role physical, and bodily pain. Each answer to the 12 questions is used to calculate the Mental Health (MCS) and Physical Health (PCS) Component Scale scores, these are provided with the SOEP data. MCS and PCS are well-established and common indicators for human Health Related Quality of Life (Oiamo et al., 2015; Ware and Sherbourne, 1992). Originally, MCS and PCS are used to evaluate the effectiveness of health care interventions for specific health outcomes (Coons et al., 2000). Other studies, however, have used MCS and PCS to examine the health-benefits of green space use (Petersen et al., 2018) or neighbourhood environment and greenness (Sugiyama et al., 2008; Theodoropoulou et al., 2017). So far there has been no study that investigates the influence of species diversity on MCS and PCS on the national level.

\subsubsection{Life-satisfaction indicator for Europe}

For the study on subjective well-being across Europe (CH3), I use life-satisfaction scores obtained from the European Quality of Life Survey (EQLS) as indicator for subjective well-being. The EQLS provides socio-economic data from several thousand individuals in 34 Europe- 
an countries and 330 NUTS regions. NUTS regions (French: Nomenclature des unités territoriales statistiques, NUTS) are designated areas in Europe based on a classification system from the European Union. In the EQLS, information on life-satisfaction has been obtained by asking people the following question: "All things considered, how satisfied would you say you are with your life these days?". Each respondent can choose to assess their life-satisfaction based on a scale with values between 1 and 10, where 1 means very dissatisfied and 10 means very satisfied.

Life-satisfaction is increasingly used as a subjective well-being indicator, and thus for human well-being. As an indicator, life-satisfaction has also undergone a critical evaluation by comparing it to various other objective measures of well-being. For instance, strong correlations have been found between life-satisfaction and physiological and medical measures such as smiling frequency, ratings of happiness by friends or self-reported health (Kahneman and Krueger, 2006). Life-satisfaction measures have already been frequently adopted in national and international surveys (Diener, 2006; OECD, 2013) because the information it provides is recognized by public policy makers as relevant for decision making (Schimmack, 2006).

\subsubsection{Macro-level biodiversity indicators}

Biodiversity itself covers many aspects of diversity and thus, multiple measures exist to describe the many facets of genetic, species or ecosystem diversity. Researchers commonly investigate non-material NCP of biodiversity by using species diversity measures as proxy indicators for biodiversity (e.g. Marselle et al., 2019). Such measures include species richness (e.g. number of species) or species abundance (e.g. population size) that are mostly based on species distribution data or ecological field samplings (e.g. Magurran, 1988). Some authors, do not use objective measures of species diversity, but subjective measures, such as perceived species richness. This is often done by asking study participants survey questions about how they perceives/assess the number of species in a certain area (Marselle et al., 2015; Southon et al., 2018).

In my two case studies ( $\mathrm{CH} 2 \& 3$ ) I compile macro-ecological data sets on biodiversity for Germany and Europe. As an indicator of biodiversity, I mainly use the two species diversity measures: species richness and abundance. Both species diversity measures are calculated for different species groups (e.g. birds, mammals, plants). I only select species groups for which positive effects on humans have been demonstrated in previous studies (e.g. Curtin, 2009; Dal- 
limer et al., 2012; Folmer et al., 2019; Southon et al., 2018) and for which species distribution data are available.

\subsubsection{Species diversity measures for Germany}

To study the effects of species diversity on human health across Germany (CH2) I collect macroecological data on species richness (number of different species) and abundance for two taxonomic groups: plant and bird species. These two species groups are the only taxa for which currently nationwide data is available. Bird species richness and abundance estimates have been created based on data provided by the 'Atlas of German Breeding Birds' (Gedeon et al., 2014). Plant data is obtained from the German atlas for flowering plants and ferns 'Verbreitungsatlas der Farn- und Blütenpflanzen Deutschlands' (Deutschland Netzwerk Phytodiversität and Bundesamt für Naturschutz, 2013). Both data-sets for birds and plants are provided on a 10x10km spatial grid.

\subsubsection{Species diversity measures for Europe}

For Europe (CH3) I collect species distribution data and calculate species richness for four species groups: birds, mammals, megafauna and trees. All species richness variables are generated on a 50x50 km grid (European Universal Transversal Mercator, UTM) originally used for the European Breeding Bird Atlas (EBBA).

Bird species richness estimates are based on bird data obtained from the first European Bird Census Council's (EBCC) European Breeding Bird Atlas (EBBA) (Hagemeijer and Blair, 1997). I estimate four different species richness variables for mammals and megafauna based on mammal species distribution data for Europe. All mammal data was obtained from global IUCN range maps retrieved from the IUCN Red List data portal (www.iucnredlist.org, accessed 16 December 2016). For the two mammal variables, I consider (1) all mammal species, and (2) all mammal species excluding bats, as bats are mainly active at night and might therefore be less noticeable to humans. For megafauna, I define two variable based on body size measures (Jones et al., 2009), (1) mammals with a body mass larger than $44 \mathrm{~kg}$, and (2) mammals with a body mass larger than $0.5 \mathrm{~kg}$. Mammals with a mass $>44 \mathrm{~kg}$ have been defined as megafauna (Barnosky, 2008; Doughty et al., 2016) and are often described as charismatic, especially in wildlife or ecotourism (Lindsey et al., 2007; Skibins et al., 2013). Tree species richness is calculated using distribution data published by Mauri et al. (2017). This EU-Forest dataset includes occurrence records for over 200 tree species across Europe. 


\subsubsection{Merging different data sets}

To analyse the effect of species diversity on human well-being on the macro level it is necessary to combine the macroecological data on the regional level (NUTS region and German county) with the human-wellbeing and socioeconomic data on the individual level. This is possible by using spatial information on where people live to extract species diversity levels in these specific locations from macroecological data sets. For Germany, the SOEP provides information on the county people live in for 13,328 individuals (after removing missing values from the data-set). For Europe, the EQLS provides data on the NUTS regions where 26,749 participants live in (see Appendix II and III).

To allow the merging of the data in each empirical study, the species diversity variables are aggregated to the county level (for Germany) and the NUTS level (for Europe) respectively. To do this, the 10x10 km grids are superimposed over each German county and the 50x50 km grid is laid over each European NUTS region to estimate area weighted means. The two resulting data sets contain human well-being indicators and socio-economic data on the individual level and information on species diversity on the German county level and European NUTS level, respectively.

\subsubsection{Statistical analysis}

In both case studies I conduct multivariate statistical analyses to explore the macro-level relationship between biodiversity and human well-being and to test the previously formulated hypotheses (section 4.2.1 and 4.2.2).

In the second chapter (CH2) I use linear regression models (ordinary least squares, OLS) to study the relationship between species diversity and human health. I test OLS models with MCS and PCS (see section 5.3.1.1) as dependant variables, respectively. To answer hypotheses 1-3, I include different measures of species diversity as predictor variables: plant species richness, bird species richness or bird abundance.

Similar to the second chapter, I use OLS models to study the relationship between species diversity and life-satisfaction across Europe (CH3). To answer the hypothesis formulated in section 4.2.2, each OLS model has life-satisfaction as the dependant variable and different species richness variables as independent variables. Since there is an ongoing debate about whether or not to assume ordinality or cardinality of life-satisfaction scores (Ferrer-i-Carbonell and Frijters, 2004; Kristoffersen, 2017; Kromrey and Rendina-Gobioff, 2003; Ng, 1997), I also 
conduct ordered logit models to compare the results with the OLS results. Results show that the outcomes of both statistical methods are consistent (Methorst et al., 2020b, Appendix III).

Each statistical model within the two empirical case studies $(\mathrm{CH} 2 \&$ 3) contains a set of socio-economic and demographic characteristics as well as macro-economic factors to account for other important confounding factors. Examples for socio-economic variables on the individual level (e.g. survey participant) are household income, age, gender, education level, health, household structure, employment status, volunteering behaviour and access to parks and recreation areas. Models in the second chapter also account for specific health related factors such as number of doctor or hospital visits in a year. Macro-economic variables on the regional level (e.g. NUTS region or county level) are, among other, unemployment rate, GDP per capita or population density. In addition, I include other nature and climate characteristics in the statistical models of both chapters (e.g. landscape heterogeneity, topographic heterogeneity, green space cover, blue space cover, protected area cover or temperature) that are generated on the NUTS region or county level. For more methodological details see Appendix II and III.

All models have been tested in regard to multicollinearity issues by calculating the generalized variance inflation factor (Fox and Monette, 1992). Furthermore, explanatory variables have been omitted from the models when they had a pairwise correlation coefficient higher than 0.6 with another independent variable (Dormann et al., 2013). To account for heteroscedasticity in the models, I use heteroscedasticity-robust standard errors. Standard errors in the models for Germany (CH2) are clustered on the county level and in models for Europe (CH3) on the NUTS regional level. All data preparation and analyses have been conducted with R Studio Version 1.0.143 (RStudio Team, 2016). 


\section{Results and discussion}

\subsection{Literature search results (CH1)}

In my literature review I include a final set of 277 studies. These studies were published between 1940 and 2019 and conducted in 74 different countries (excluding studies of entire continents and reviews). Most of these studies originated from the Global North (i.e. from Europe, North America, Australia and New Zealand) (Appendix I - Manuscript: Fig. 2 C). I also found a substantial number of studies that were conducted in Asian and African countries. The number of studies reporting negative WCP is higher than the number of studies reporting positive WCP (Appendix I - Manuscript: Fig. 2 A). Reptiles comprise the taxonomic group that was most often studied in the reviewed literature, followed by mammals and birds. Compared to the other wildlife taxon groups, amphibians were rarely studied (Appendix I - Manuscript: Fig. 2 B).

\subsubsection{Temporal and geographical patterns of $\mathrm{WCP}$}

Over the past decades there has been an increase in number of studies addressing issues of wildlife and human well-being. From the year 2000, the number of publications has increased steeply, including higher numbers of published positive WCP (Appendix I - Manuscript: Fig. 2 A). This change in research focus at the turn of the century may be related to the newly emerging ideas and perspectives on nature during that time. Since the early years of the new century these ideas have been propagated in several key publications with lasting impact on societal and political awareness. For instance, the Millennium Ecosystem Assessment (MA) published in 2005 (MA, 2005) emphasizes the importance of nature and biodiversity for human well-being and makes this knowledge available to a wider public. Around the same time, researchers start focusing, among other, on the benefits humans can obtain from nature and the complex relationship between people and the environment (Balvanera et al., 2017; Mace, 2014). Subsequently, research on the relationship between nature and human society (e.g. Carpenter et al., 2012) and on topics such as ES (McDonough et al., 2017) are fostered by new established funding programs, indicating that science policies and funding might have had a tacit effect on the choice of research topics (Vihervaara et al., 2010). The recent introduction of the concept of Nature`s Contributions to People (NCP) (Díaz et al., 2018) may have further accelerated the increase in research on positive WCP. Like the ES framework, the NCP framework strongly incorporates the idea that humans benefit from nature, including wildlife species and biodiversity. The rediscovery of the human-nature relationship after the turn of the century might have es- 
pecially affected WCP research in developed countries of the western world, the Global North.

The review results show that negative WCP dominate the global literature and that positive WCP are proportionally more often published in the Global North than in the Global South. These results may indicate different research interests across global regions and a focus on positive WCP, maybe even a reporting bias, especially in the Global North. The higher number of negative WCP in the Global South might also be caused by the fact that people there, especially in rural areas, still live-in direct vicinity of dangerous and harmful mammals or reptiles (e.g. poisonous snakes, large carnivores). In the Global North, on the other hand, people usually are more removed from contact with wildlife in their daily lives (Cox et al., 2017a; Soga and Gaston, 2016).

\subsubsection{Patterns related to human well-being indicators}

In the review all 12 different human well-being dimensions are assessed in relation to WCP. Most articles examine only one single human well-being dimension, but some also analyse multiple aspects of well-being in a single study. Among the different well-being dimensions, physical health is most often studied within the reviewed literature, followed by emotions, spirituality, inspiration, security and psychological well-being. Those human well-being dimensions that appear less frequently in the literature are subjective well-being, social well-being, sense of place, connection to wildlife, learning and personal identity (Appendix I - Manuscript: Fig. $3 \mathrm{~A}, \mathrm{~B})$.

These results indicate that some human well-being dimensions have been better studied than others. For instance, many of the reviewed studies examine physical health and report negative WCP. This high representation of physical health in the literature may be attributed to the large number of publications from the medical sciences, where a greater attention is given to wildlife issues (e.g. injuries and human fatalities) compared to other scientific disciplines (e.g. psychology, social sciences). Other well-being dimensions such as sense of place, identity, subjective well-being and social well-being are less frequently studied. This may be related to the fact that these aspects of well-being have only recently emerged as research topics in the context of wildlife and human well-being (Chan et al., 2018; Hausmann et al., 2016). For instance, before the year 2000 no reviewed article deals with these human well-being indicators. In addition, much research and knowledge about the culturally influenced WCP, i.e. learning, inspiration and spirituality, is not often published in English peer-reviewed journals and thus lost to the 
broader scientific community (e.g. Alves, 2012; Arroyo-Quiroz et al., 2017).

\subsubsection{Taxon dependency of WCP}

There are strong differences in regard to the number of reported positive or negative WCP per taxon group. Often, the number of studies reporting negative WCP outnumbered positive ones, except for studies on birds. Among the studies on birds, $64.1 \%$ reported positive WCP. In comparison, studies on mammals $(24.5 \%)$, amphibians $(14.3 \%)$ and reptiles $(8.8 \%)$ report much fewer positive WCP (Appendix I - Manuscript: Fig. 2: B).

Birds are known to have beneficial effects on humans, which might be the cause of the greater proportion of reported positive WCP for this taxon group. First, birds are usually not harmful to humans (but see below). Second, birds can also be visually and acoustically attractive because of their physical appearance (e.g. colourfulness, behaviour) and the sounds they produce(Belaire et al., 2015; Hedblom et al., 2017). These bird characteristics or the fact that they are generally better perceived by people compared to mammals or reptiles (Cox et al., 2017c) may also be the reason why many positive WCP of birds are reported in studies on psychological well-being or mental health (e.g. Cox et al., 2017c; Dallimer et al., 2012; Fuller et al., 2007). Even though proportionally less often, positive WCP are also reported for mammals, reptiles and amphibians, in some cases related to religion, folklore or traditional beliefs and positive superstitions (e.g. Alves, 2012).

Many studies report negative WCP, especially for reptiles and mammals. This is not surprising, as these taxonomic groups usually include harmful carnivores, otherwise dangerous large mammals (e.g. elephants) or poisonous animals such as snakes. Consequently, most of the negative WCP identified for these species groups are either injuries (e.g. Behdarvand and Kaboli, 2015; Gunther et al., 2004) or bites and poisoning (e.g. Pugh et al., 1979; Sarkhel et al., 2017). Interestingly, a few studies also report attacks on humans by birds (Lees et al., 2013; Warne and Jones, 2003) or show examples of birds and amphibians that are targeted by superstitions and negative folklore (Ceríaco, 2011; Hull and Fergus, 2017).

\subsubsection{Channels of wildlife experiences}

All four channels of human-wildlife experiences (Interaction, Living Within, Perceiving and Knowing) can be found in the reviewed literature. The number of reported WCP per channel, however, vary greatly (Appendix I - Manuscript: Fig. 3). The number of studies investigating 
the channel Interaction is the highest and alone comprises $53.2 \%$ of the total number of studies (Appendix I - Manuscript). The second most often studied channel is Knowing, followed by Living Within and Perceiving.

The results show that people interact with wildlife in multiple ways during their daily lives, outdoor activities or as tourists. Such interactions can have both positive and negative outcomes, with negative effects being in the majority. Positive effects caused by Interaction are found when people experience positive emotions when feeding birds (Cox and Gaston, 2016; Galbraith et al., 2014). Interactions with wildlife also foster social relationships, for instance when human-macaque interactions nurture family and social ties of park visitors (Lee and Davey, 2015) and people's connection to wildlife (Cox and Gaston, 2016). Negative effects of Interaction are mainly related to the human well-being dimensions of physical health (e.g. attacks and injuries). Other negative effects of wildlife interactions are negative emotions such as fear (Arroyo-Quiroz et al., 2017; Ogra, 2008) or bad mental health after conflicts or injuries (Jadhav and Barua, 2012).

Many investigations have been conducted on human populations that live near or within the natural habitat of certain wildlife species and their results relate to the channel Living Within. The review finds that Living Within, i.e. living in areas with wildlife, has both positive and negative effects on different human well-being dimensions (Appendix I - Manuscript: Fig. 3). For example, living in areas with high bird abundance and species richness can increase personal well-being and connection to nature in urban neighbourhoods (Luck et al., 2011). On the other hand, living in areas with large carnivore species or other dangerous animals can often produce undesirable negative emotions and feelings of unsafety (e.g. Mayberry et al., 2017; Mormile and Hill, 2016).

The effect of Perceiving wildlife on human well-being is identified most frequently through visual perception of wildlife during outdoor activities (e.g. urban parks) or while watching wildlife (e.g. safari, whale watching). Perceiving wildlife triggers both positive and negative effects on various human well-being dimensions (Appendix I - Manuscript). Psychological well-being, feeling connected with wildlife, emotions and learning are the dimensions of human well-being that are most often influenced by Perceiving wildlife. For example, just listening to bird sounds can improve people's stress restoration (Medvedev et al., 2015; Ratcliffe et al., 2016, 2013) and watching wildlife can foster positive emotions such as joy, awe or surprise (Curtin, 2009; Farber and Hall, 2007; Pearce et al., 2017). Negative effects of Perceiving wildlife are usually 
related to negative emotions like fear or anxiety (Farber and Hall, 2007; Mcintosh and Wright, 2017).

Knowing mostly occurs when people reflect on past wildlife experiences, gained during time spent outdoors (e.g. vacation, garden) or when they own or acquire specific knowledge and opinions about wildlife species. For Knowing the literature also show evidence for both positive and negative effects. Typically, Knowing affects spirituality, human emotions and inspiration (Appendix I - Manuscript: Fig. 3). For instance, beliefs and superstitions can address wildlife as carriers of bad luck and negative omens but also as signs of good fortune (Ceríaco, 2012; Ohemeng et al., 2017; Wyndham and Park, 2018). Positive emotions such as joy, interest or surprise are also fostered via Knowing (e.g. Jacobs et al., 2014; Mcintosh and Wright, 2017) as well as negative emotions such as feelings of fear and disgust (Davey et al., 1998; Johansson and Karlsson, 2011; Tucker and Bond, 1997). Studies that show Knowing also influences human inspiration as can be seen in wildlife inspired legends, folklore and tales, where different species play the main characters or occur as important symbols (e.g. Berndt, 1940; Clarke, 2016).

\subsubsection{Terminology and indicators for wildlife and wildlife diversity}

The literature review contains a variety of different measures for wildlife and wildlife diversity. A large majority of studies use qualitative measures for wildlife or definitions that either loosely described species groups $(n=172)$ or single species $(n=95)$. Examples for species groups are carnivores or birds in general, while single species often refer to commonly known animals such as wolf, bear, tiger or elephant. As studies on wildlife diversity are also included in my literature review (section 5.2.2), I also identify articles which investigate how the diversity of wild animal species affects human well-being. Most of these studies use quantitative ecological indicators (e.g. based on field sampling) for species diversity such as species richness $(n=7)$ or abundance $(n=3)$, but a few also measure perceived species richness $(n=4)$, a measure based on the subjective assessment of the number of species in a given area by people. In general, however, the use of ecological diversity measures is less frequent, compared to the more qualitative measures of wildlife.

Why quantitative/ecological wildlife diversity indicators are rarely used to study WCP is not clear. One possible explanation could be that the observed custom in social sciences is to prefer questionnaires over experiments that in turn produce qualitative wildlife measures. Another 
explanation for the low use of quantitative wildlife diversity indicators within the reviewed literature might be that there is lack of cooperation between scientific disciplines or interdisciplinary research that combines ecological data and methods with methods from social sciences. To engage in interdisciplinary research and combine ecological data on biodiversity with human well-being indicators from the social, psychological and economic disciplines should therefore be a major focal point for researchers in the future (but see $\mathrm{CH} 2 \& 3$ ).

\subsection{Macro-level relationship between biodiversity and human well-being}

Here, I present and discuss the results of the two empirical case studies on the macro-level for both Germany $(\mathrm{CH} 2)$ and Europe $(\mathrm{CH} 3)$.

\subsubsection{Species diversity and human health in Germany (CH2)}

In my macro-level analyses for Germany, I find that bird and plant species richness are positively associated with human mental health. In line with my first hypothesis (H1, see section 4.2.1), my study results demonstrate a strong and significant positive relationship between plant species richness and mental health (measured as MCS), with p-values $<0.001$ (Appendix II Manuscript: Tables 1 \& 2). Similarly, I found a significant positive relationship between bird species richness and mental health. The significance of bird species richness, however, was less strong than plant species richness (Appendix II - Manuscript: Table $1 \&$ 2). All results are derived from statistical models that account for multiple socio-economic, demographic variables, as well as nature and climate characteristics.

These results are the first evidence of a national-scale relationship between species richness and mental health and for species richness as a health-promoting (salutogenic) nature characteristic. This macro-level relationship is comparable to the only other national-scale study that finds a positive relationship between bird species richness and reported general health in Great Britain (Wheeler et al., 2015). These results also correspond to previous findings from local level studies on species richness and human mental health. Studies, for instance, show that plant species richness in public parks can reduce stress (Lindemann-Matthies and Matthies, 2018) and that plant and bird species richness both positively affect psychological well-being (Dallimer et al., 2012; Fuller et al., 2007). Similar positive effects of species richness are found in an online experiment where participants watching videos with high tree and bird species 
richness show better mental health (e.g. positive affect, vitality) compared to people watching videos with low levels of species richness (Wolf et al., 2017).

Besides plant and bird species richness, I also analyse the influence of bird abundance (population size) on mental health and physical health (Appendix II). Based upon the results I am not able to identify a significant relationship between bird abundance and mental health (measured as MCS) and, consequently, reject my second hypothesis (H2). A first possible explanation for this outcome could be that the county level and local level abundance estimates differ in their sampling and estimation procedure. A previous (local) study finds that afternoon - but not morning - bird abundances can be positively associated with better mental health, suggesting that it is the time and likelihood a person experiences birds, rather than the objectively measured abundance of birds, that influences mental health (Cox et al., 2017c). The bird abundance data in this study, however, is obtained from the German atlas where bird monitoring likely took place in the early morning. The resulting bird abundance estimates are probably not correlated to afternoon bird activities. In addition, the atlas data have been sampled across multiple years and thus cannot be compared to the local afternoon bird abundance estimates used in the study by Cox et al. (2017c). Another factor to be considered is that the observed relationship might be driven by the spatial variation of bird populations across Germany. The bird abundance variable may be influenced by certain bird species (e.g. pigeons, sparrows, blackbirds) with high population numbers in urbanized areas (see also Appendix II - Manuscript: Fig. 2). Some of these species are not necessarily popular among the general public (Bjerke and Østdahl, 2004; Harris et al., 2016) and may not provide any positive contribution to people's emotions and mental state (e.g. Ratcliffe et al., 2013).

Contrary to my expectations, I do not find any relationship between my species diversity measures and physical health (measured as PCS) even though some studies show positive effects of species richness and microbial diversity on physical and general health (Aerts et al., 2018; Sandifer et al., 2015; Wheeler et al., 2015). I therefore also have to reject my third hypothesis (H3). A possible reason for such lack of evidence may be that, compared to mental health, physical health (measured as PCS) is not directly influenced by species diversity. Instead the relationship could be more indirect, i.e. mediated through other relevant factors (Hartig et al., 2014; Markevych et al., 2017). In this particular study context, I argue that a potential relationship between species diversity and physical health may only occur when mediators such as physical activity in green space or in natural landscapes are accounted for. This argument is based on previously published evidence that outdoor physical activity as well as the frequency 
and duration of green space use mediates the relationship between nature and human health (Cox et al., 2017b; Mowen et al., 2007; Shanahan et al., 2016; Sugiyama et al., 2008). This assumption, however, remains speculative and needs to be tested in future research.

Here, it should also be mentioned that many other confounding factors are significantly associated with MCS or PCS. Especially, the socio-economic and demographic variables (e.g. income, age, employment) explain a large proportion of the variance in mental and physical health (Appendix II). These results are in line with previous findings and their implications have been extensively discussed in scientific literature (e.g. Hopman et al., 2009; Modini et al., 2016; Sturm and Gresenz, 2002; Virtanen et al., 2005). Models that include county level nature and climate characteristics do not show any robust effects for these variables. However, good access to parks is a factor that has a strong relationship with good mental (MCS) and physical health (PCS) (Appendix II - Manuscript: Tables $1 \& 2)$. This outcome matches with previous studies that show that better mental and physical health is associated with shorter walking distance between the place of residence and parks or the availability of green space (e.g. Mowen et al., 2007; World Health Organization, 2016). The results are discussed further in Appendix II.

\subsubsection{Species diversity and life-satisfaction across Europe (CH3)}

In my macro-level case study for Europe, I find that bird species richness is positively related to life-satisfaction (Appendix III - Manuscript: Fig. 1). This relationship is robust across all OLS model outcomes with p-values below the $5 \%$ threshold (Appendix III - Supplementary Material). These results are also consistent with model outcomes of the ordered logit specification. This finding therefore confirms my fourth hypotheses (see section 4.2.2) and is in correspondence with previous research, conducted on the local and national level. Besides the previously mentioned local studies on bird species richness and mental well-being (Dallimer et al., 2012; Fuller et al., 2007), a study also shows that bird species richness positively influences personal well-being and neighbourhood well-being in an urban neighbourhood (Luck et al., 2011). In addition, a national level study finds that subjective health is positively related to bird species richness (Wheeler et al., 2015) and mental health (see CH2).

Contrary to my expectations (see section 4.2.2), I do not find any association between mammal-, megafauna- or tree species richness and life-satisfaction (Appendix III - Manuscript: Fig. 1). In regard to mammals and megafauna, the missing relationship could be explained by the rather low likelihood of people perceiving or interacting with these species, compared to birds 
(see CH1, Methorst et al., 2020a). Especially urban residents might not regularly encounter mammals (especially large megafauna) because many species are either evasive and tend to avoid places with high human population density or mainly occur in rural or less populated areas (Basille et al., 2013; Theuerkauf et al., 2003). Many mammal species are also nocturnal (Gaynor et al., 2018) and therefore less noticeable to humans, while small mammals and bats are often difficult to detect even though they are present. Birds, on the other hand, are often very active and detectable in human vicinities (e.g. bird feeding) and can therefore be perceived by people due to the sounds they produce, despite the possibility that they might not always be visible in the vegetation. In addition, my literature review $(\mathrm{CH} 1)$ shows that encounters with mammals or other experiences can result in negative outcomes for human well-being (see section 6.1.3). Considering these results, the effects of mammals and megafauna could indeed be neutral or even negative for some mammalian species.

Turning attention to tree species richness, study results could be explained by the high possibility that people might be more affected by the amount of vegetation or plant aesthetics (Hoyle et al., 2017; Luck et al., 2011; Southon et al., 2017). In addition, overall plant species richness or even local street tree abundance in urban neighbourhoods might be more important than macro-level (regional) patterns of tree species richness (Dallimer et al., 2014; Lindemann-Matthies and Matthies, 2018; Taylor et al., 2015) (see also CH2, Appendix II). Unfortunately, data for measures of total plant diversity or plant aesthetics were not available at the large spatial scale of my study.

All statistical models in this study account for multiple confounding factors. Similar to the results of the second chapter $(\mathrm{CH} 2)$, the socio-economic and demographic variables are often significantly related to life-satisfaction. Again, income and good access to recreational areas (e.g. parks and sport facilities) show a strong positive effect that corresponds to previous findings (e.g. Dolan et al., 2008; Mowen et al., 2007; World Health Organization, 2016). All other nature and climate characteristics on NUTS level included in the models were not significantly related to life-satisfaction. These results are discussed further in Methorst et al. (2020b) (Appendix III - Manuscript \& Supplementary Material). 


\subsubsection{Possible mechanisms and mediators}

The two empirical studies $(\mathrm{CH} 2 \& 3)$ show that species diversity is positively related to two subjective measures of human well-being on the macro-level. There is clear evidence for positive associations between the richness of plant and bird species and human mental health and between bird species richness and life-satisfaction. This positive relationship between species diversity and well-being is still not well understood, but recent research discusses possible mechanisms involved (e.g. Aerts et al., 2018; Marselle, 2019). In this dissertation I argue that at the large spatial scale of these studies two possible, non-exclusive pathways exist that may explain how species diversity could influence mental health and life-satisfaction; an effect of species diversity itself via multisensory experiences and an effect of beneficial landscape properties that promotes both species diversity and people's well-being.

\subsubsection{Effect of species diversity via multisensory experiences}

The first pathway refers to the positive contributions obtained after people directly experience plant and bird species as well as their diversity (e.g. species richness) on the local level. Such experiences are often characterized by two channels of wildlife experiences: Interaction and Perceiving (see CH1, Methorst et al., 2020a).

In regard to plant diversity, local level studies report that higher plant diversity in urban and peri-urban areas could positively contribute to people's perceived restoration (Carrus et $a l ., 2015)$ and that natural looking plantations with high perceived plant diversity trigger better attention restoration (Hoyle et al., 2019). Higher plant species richness can even improve stress recovery, measured as reduced blood pressure (Lindemann-Matthies and Matthies, 2018). Such effects on restoration might be attributed to the fact that people enjoy natural areas or urban green spaces with higher species diversity of plants, as these areas appear more naturalistic or more aesthetic (Gunnarsson et al., 2017; Muratet et al., 2015). Similarly, meadows are also considered as more aesthetic when they have a higher numbers of plant species (Lindemann-Matthies et al., 2010; Southon et al., 2017).

For birds, many studies report that Interaction and Perceiving could cause positive outcomes for human mental health and well-being (CH1, Appendix I). For example, bird watching and feeding in gardens or in nature can foster positive emotions, feeling of relaxation and increase people's happiness (Cox and Gaston, 2016, 2015; MacKerron and Mourato, 2013). Such activities involving birds might be popular among people because they find the physical appear- 
ance of birds attractive or have an interest in the ecology of birds (Belaire et al., 2015). Bird songs might also play a special role as studies show that people tend to favour songbird over non-songbirds (Cox and Gaston, 2015) and appreciate listening to birds, considering bird songs as relaxing (Hedblom et al., 2017, 2014). Interestingly, experiments show that just listening to bird songs can be beneficial to people as it could reduce psychological stress (Alvarsson et al., 2010) and has a high restorative potential (Medvedev et al., 2015; Ratcliffe et al., 2016). This fact is further supported by interviews and surveys amongst the general public and elderly people (Dzhambov and Dimitrova, 2014; Ratcliffe et al., 2013).

Two psychological theories might explain why the experience of bird and plant diversity (e.g. Interaction and Perceiving) has positive effects on people's well-being, especially on mental health: Attention Restoration Theory (ART) and Stress Reduction Theory (SRT). The ART emphasises that an environment can influence a person's ability to concentrate or direct attention. However, the ability to direct attention can fatigue and for its restoration a person requires four types of experiences: fascination, being away, coherence and compatibility (Kaplan, 1995). Species diversity of plants and birds may restore direct attention because it provides fascinating stimuli in an environments and afford the experience of being away (Marselle, 2019). On the other hand, the SRT (Ulrich, 1991) considers the physiological impact of viewing environments which then facilitates the reduction of psychological stress and negative affect and enhances positive affect. Species diversity of plants and birds may represent a certain level of complexity in nature that, if viewed by people, may trigger immediate emotional reaction and behavioural responses to explore the environment (Marselle, 2019). Both theories have been proposed to function as mediators between species diversity and human mental health and well-being (e.g. Marselle, 2019).

Positive emotions might be another potential mediator between species diversity and mental health (Irvine et al., 2019) and may offer an alternative explanation for the observed relationship (section 6.2.1 \& 6.2.2). As illustrated in chapter 1 (CH1), studies show that interacting with birds or perceiving bird could foster positive emotions. Of course, birds can also trigger negative emotions in humans (e.g. Davey, 1994), but these feeling are often directed at single species like gulls or Egyptian geese (e.g. Little and Sutton, 2013; Rock, 2005). So far, however, there is no consensus in regard to the mediating role of emotions and future research will be necessary to depict the role of emotions within the relationship between species diversity and human health. 


\subsubsection{Species diversity as proxy indicator}

The second pathway refers to the possibility that high species diversity may serve as an indicator for regional and local landscape properties that are beneficial to human well-being. This argument is influenced by the fact that the two empirical studies presented here are both conducted on the macro-level (national and continental level). Thus, it is difficult to estimate whether or not people directly experience higher plant and bird species richness (or plants and birds in general), for instance via bird feeding or outdoor activities. Therefore, a likely explanation for the results in the second and third chapter could be that species diversity measures on the macro-level (plant and bird species richness) are proxy indicators for certain landscape properties or nature characteristics that foster high species richness as well as human health and subjective well-being, i.e. mental health and life-satisfaction. This argument includes the possibility that the channel Living Within (e.g. living in diverse nature or near wildlife) may explain more of the observed macro-level relationship between biodiversity and well-being than Interaction or Perceiving (see also section 5.2.4).

Multiple studies support this argument that regional level species richness is a proxy for beneficial and health promoting landscape characteristics. They, for instance, present evidence that plant species richness increases in areas with lower pollution and higher environmental quality (Duprè et al., 2010; Zvereva et al., 2008) or that high bird species richness is related to greater availability of natural space in urban areas (Loss et al., 2009), including high vegetation cover and water bodies (Beninde et al., 2015). Usually, such areas with high plant or bird species richness are also characterized by elements with high restorative potential (Oteros-rozas et al., 2018; Velarde et al., 2007) such as local landscape diversity (Weber et al., 2004), diverse forests (Gil-Tena et al., 2007), vegetation and water (Cox et al., 2017c; Luck et al., 2011; Völker and Kistemann, 2011). Correspondingly, especially bird species richness is included in composite measures of landscape diversity, as in the Swiss Biodiversity Monitoring program (Weber et al., 2004), and used as an environmental quality indicator in health studies (Wheeler et al., 2015). The possibility of plant and bird species richness being proxy indicators for beneficial landscape properties may also explain the lack of significant results for other nature variables included in the data analyses (see section 6.2.1 and 6.2.2., Appendix II and III).

\subsubsection{Study limitations}

One caveat to be mentioned in regard to the macro-level studies $(\mathrm{CH} 2 \& 3)$ is that they have limited power to infer causal links between species diversity and human well-being. As already 
mentioned above (section 6.2.3.2), it is unknown in which way people encounter plants and bird species richness and thus my assumption that people experience species diversity within their county or NUTS region is rather hypothetical. In addition, it is also likely that people with higher socio-economic status or income, and consequently higher well-being, prefer to live in areas with high biodiversity or close to nature. This possibility could bias the observed relationships in the empirical analyses.

One possible strategy to report a causal relationship in empirical studies is to account for selection effects, commonly by including relevant demographic and socioeconomic traits in the data analysis (de Vries et al., 2016). I do this by accounting for many socio-economic, demographic and even macro-economic factors in both case studies (see Appendix II and III). These methods are, however, often not sufficient enough to deal with selection effects. Alternative strategies are to carry out longitudinal studies (White et al., 2013) and experimental techniques which include mediators and moderators (e.g. Marselle et al., 2016). Unfortunately, in this dissertation I am not able to analyse time series data or conduct experiments, as currently only cross-sectional (one point or period in time) data are available for species diversity in Germany and Europe and experiments are not feasible on the spatial level of my studies. Furthermore, possible mediators such as ART, SRT and outdoor physical activity (Hartig et al., 2014; Markevych et al., 2017; Marselle, 2019) are difficult to include in the empirical analyses because information is not available in the two survey data sets (SOEP and EQLS). Another important factor to account for is the duration and frequency of species diversity experiences. Unfortunately, here as well, the data sets do not include a question addressing the survey respondent's frequency and duration of outdoor activities in species-rich environments.

Overall, this dissertation produces strong 'correlative' evidence for a positive influence of biodiversity (and wildlife) on human well-being. Especially the second and third chapters show how species diversity of plants and birds is positively related to well-being measures on different spatial scales. This conclusion is further supported by the evidence found in the literature review (CH1). However, determining a causal link between species diversity and human well-being remains a major challenge. Future research should therefore test this relationship and the two proposed pathways (section 6.2.3) between species diversity and different measures for human well-being with longitudinal data sets and experiments. 


\section{Conclusion and synthesis}

This dissertation examines how biodiversity and wildlife affect human well-being. The first chapter $(\mathrm{CH} 1)$ conducts a literature review on the non-material contributions of wildlife on human well-being. This review provides a comprehensive overview of the current research literature and established a helpful knowledge foundation for two empirical case studies on the macro-level. In these case studies the influence of biodiversity (using species diversity measures such as species richness) on human well-being is examined across Germany (CH2) and Europe (CH3), respectively. The results show that there is a positive relationship between biodiversity and two human well-being dimensions (human health and subjective well-being) on the macro-level. Consequently, my dissertation highlights that biodiversity and wildlife can both contribute to non-material NCP and that the positive contributions can provide substantial benefits to human well-being.

\subsection{Wildlife and non-material NCP}

The literature review $(\mathrm{CH} 1)$ provides an overview of the different positive and negative non-material NCP of wildlife (including biodiversity of wildlife) (WCP). While negative reports of WCP are more common, the synthesis of the literature shows that the proportion of published positive studies has grown over the past years, especially in the Global North. These temporal and spatial patterns may hint towards normative influences that influence the relative proportion of reported positive or negative WCP. These normative influences are not yet well understood, but there might be some indications that at least some larger international processes such as the Millennium Ecosystem Assessment or the IPBES may have influenced research objectives through greater public awareness as well as policy and funding incentives. Future research should therefore examine these potential biases by conducting policy assessments or surveys among researchers to understand driving forces and motivations behind their research questions.

Surprisingly, the review identifies a lack of joint systematic assessments of positive and negative WCP (except e.g. Harrison et al. 2014) and therefore finds differences in the types of WCP studied per wildlife taxa. For instance, most positive WCP are reported for birds and most negative for mammals and reptiles. In addition, a strong variation in how different human well-being dimensions examined in the literature is found. Physical health is the most dominant aspect of human well-being studied while other well-being dimensions (e.g. learning, identity) 
are less common. Future studies should therefore explore multi-taxon approaches and examine both positive and negative WCP and should also consider the multi-dimensionality of human well-being. Such systematic assessments are critical for evaluating the costs and benefits of wildlife, for these have become increasingly important to managing wildlife in close proximity to humans and human-wildlife conflicts (Lozano et al., 2019).

The review observes increase in studies on psychological health together with increases in studies which report positive WCP. In this context, future wildlife studies should contribute to the expanding field of biodiversity and mental health studies (e.g. Marselle et al., 2019). My study also finds many positive and negative effects of wildlife on human emotions in correspondence with previous assessments that have increasingly studied this topic over the past years (Jacobs, 2012). However, efforts still need to be made to better understand people's emotional responses towards wildlife and how these emotions shape human-wildlife coexistence and relationships (Gaston et al., 2018).

My review increases the understanding of how wildlife contributes to human well-being by incorporating four different channels of wildlife experience (section 5.2.4). For instance, we now know that studies most often report WCP where channels such as Interaction and Knowing are involved. It is also clear that some aspects of human well-being are more likely to be caused by certain types of experience. For example, human physical health is often affected by Interaction, Living Within often relates to security while inspiration or learning are mainly triggered via Knowing. This new knowledge will contribute to understanding human-wildlife relationships and will deepen our understanding of how wildlife influences human well-being.

\subsection{Biodiversity and human well-being on the macro-level}

The two empirical case studies $(\mathrm{CH} 2 \& 3)$ could show that biodiversity is related to human well-being (human health and subjective well-being) on the macro-level. Species diversity measures as indicators for biodiversity could demonstrate that plant and bird species richness are both positively related to human mental health across Germany $(\mathrm{CH} 2)$. Based on these results species diversity might be defined as a salutogenic (health promoting) characteristic of natural areas that could foster good Health Related Quality of Life for people. The third chapter $(\mathrm{CH} 3)$ shows evidence that bird species richness is positively related to life-satisfaction across

Europe. Both case studies point towards the possibility that a positive relationship between biodiversity and human well-being is also evident on a national and continental scale and not 
only on the local level (Fuller et al., 2007; Lindemann-Matthies and Matthies, 2018; Luck et $a l ., 2011)$. The results also suggest that positive effects of biodiversity can be taxon-dependent (see also CH1) since mammal and tree diversity are not significantly related to life-satisfaction across Europe. Overall, these conclusions are highly relevant for future research on wildlife and biodiversity and political decision makers.

\subsection{Recommendations and policy implications}

The global assessment of the Intergovernmental Platform on Biodiversity and Ecosystem Services (IPBES) highlights the fact that nature and biodiversity are essential for human existence and well-being. However, it also warns of biodiversity loss that will further increase in severity due to increasing land use change and climate change (Díaz et al., 2019; IPBES, 2019). To safe-guard NCP, wildlife and biodiversity scientists and policy makers may implement the following recommendations (section 7.3.1) to (1) improve scientific output that informs policy makers, (2) to improve global policy for biodiversity and wildlife conservation and (3) to improve macro-level indicators to monitor biodiversity conservation and the provision of NCP.

\subsubsection{Research recommendations}

In respect of the non-material NCP of biodiversity and wildlife, my dissertation emphasizes the need for holistic approaches and interdisciplinary collaborations. Besides the necessity for more multi-taxon approaches, considering both positive and negative non-material NCP, future research still needs to broaden the range of human well-being dimensions considered and should also include less studied aspects of well-being, such as social well-being, sense of place, learning or identity (see section 6.1.2, Appendix I). Furthermore, methods and indicators from ecology and social sciences should be combined and explored within new research collaborations. Especially the use of quantitative biodiversity indicators (e.g. species richness) should be fostered (section 6.1.5). Such interdisciplinary approaches are critical for evaluating the importance of biodiversity for human well-being.

For empirical examinations of the relationship between biodiversity and human well-being it is important to improve the methodological approaches to infer causal relationships and understand possible mechanisms. To test causality, future research should try and implement longitudinal or experimental studies. However, an important prerequisite for longitudinal studies is the availability of time series data for biodiversity. It will therefore also be necessary to invest in long-term ecological monitoring programs and open access data, either implemented 
by universities or government institutions or with the help of citizen science (Chandler et al., 2017; Tulloch et al., 2013). Experiments are crucial to investigate the mechanisms involved in how biodiversity affects human well-being. First, the mediating role of ART and SRT, as well as the potential importance of emotions will have to be investigated to depict the specific mechanisms that link biodiversity with mental health and well-being. Second, it needs to be tested how the frequency and duration of wildlife and biodiversity experiences moderate the effect on human well-being.

\subsubsection{Conservation and human well-being}

To foster human well-being and good quality of life, investment into biodiversity conservation and restoration need to become crucial strategies (Cook et al., 2019; Romanelli et al., 2014). However, conservation efforts should not only focus on specific focal and so-called charismatic species, established protected areas or hotspots with high biodiversity, especially as these strategies have been criticized before (e.g. Lindenmayer et al., 2002; Small, 2011). Instead, conservation needs to also incorporate ES and NCP to identify synergies and improve conservation goals (Brooks et al., 2006; Cimon-Morin et al., 2013).

Synergies could be related to the fact that securing biodiversity (e.g. species diversity and richness) can also lead to the preservation of health-promoting (salutogenic) nature characteristics $(\mathrm{CH} 2)$. Furthermore, investments into biodiversity conservation may produce good cost-benefit ratios for society as they can be seen as additional means to avoid high costs to public health services, especially considering that countries of the Global North are facing increasing problems of rising mental ill health and associated high costs to society (e.g. OECD / European Union, 2018). As an example, for a possible measure to foster good public health local and national decision makers could protect biodiversity in urban green space and promote an increase in human-wildlife experiences.

Overall, incorporating ES and NCP into conservation plans could prove to be a powerful incentive for nature and biodiversity conservation and not only because of economic benefits (Cimon-Morin et al., 2013; Goldman et al., 2008). However, it is still unclear how best to integrate ES and NCP into systematic conservation planning. For this purpose, good spatial indicators on the macro-level are necessary to not only monitor species loss and conservation success but to also assess ES and NCP (e.g. Feld et al., 2009; Geijzendorffer and Roche, 2013). 


\subsubsection{Macro-level indicators for non-material NCP}

In my macro-level case studies ( $\mathrm{CH} 2 \& 3)$, I argue that the observed pattern between species diversity and human well-being (human mental health and life-satisfaction) may be caused by species diversity being a proxy indicator for regional environmental and landscape quality. Consequently, species diversity (e.g. measured species richness) should be used as macro-level indicator to monitor non-material NCP of biodiversity as well as areas of high importance for human well-being (e.g. areas with salutogenic nature characteristics).

To monitor ES, some studies present different indicators on the national (Rabe et al., 2016) and European level (Paracchini et al., 2014). None of these proposed indicators, however, consider species diversity as an indicator for non-material NCP or salutogenic (health promoting) contributions of biodiversity and nature. Species diversity measures (e.g. species richness) are usually used to monitor ecosystem functions or habitat quality and are rarely used for reasons beyond the monitoring of ecosystem processes and evaluation of species conservation success. For example, the MAES report by the EU Joint Research Council presents a European map for habitat quality to monitor breeding habitats for birds that is based on common bird species distribution data (Maes et al., 2015; Vallecillo et al., 2016).

Using available species distribution data, it may be possible to establish species diversity measures as indicators for non-material NCP and health promoting nature characteristic. This proposition may be highly interesting, as simple macro-level measures of green or blue space cover or other nature characteristics might not be adequate proxies, especially for identifying effects on human mental health and life-satisfaction (Appendix II \& III). Combined with other measures for environmental quality (e.g. air quality) such a species diversity indicator could not only be used to improve the monitoring of non-material NCP but also of other NCP and ES (e.g. regulating and material). Finally, this new indicator could be used as a tool by decision makers to find priority areas for nature and biodiversity conservation and may help produce synergies between biodiversity protection and preservation of NCP. 


\section{Acknowledgements}

I would like to thank all those who have supported me in doing this PhD-research. Without their help it would have been impossible to successfully complete it.

To Prof. Dr. K. Böhning-Gaese and Prof. Dr. K. Rehdanz I would like to express my gratitude for inviting me to work on this research project. I have greatly benefited from their valuable guidance, advice and support in facing and dealing with the many challenges involved in doing scientific research.

My profound appreciation also goes to Prof. Dr. A. Bonn, Prof. Dr. B. Hansjürgens and Prof. Dr. T. Müller for their many fruitful comments that have helped me write the research papers.

I am particularly grateful to Dr. U. Arbieu, Dr. M. Marselle and for having been my co-authors. Many thanks to them for their valuable suggestions and contributions!

Prof. Dr. M. Berlemann I would like to thank for acting as a second expert-reviewer (German: Zweitgutachter) for my dissertation.

I am greatly thankful to the Senckenberg Gesellschaft für Naturforschung for granting me a $\mathrm{PhD}$-scholarship that enabled me to do this $\mathrm{PhD}$ research-project. I also sincerely appreciate the financial support received from yDiv, the iDiv Flexpool Fund and the iDiv Open Science Fund.

Many thanks also go out to J. Müller, Dr. N. Sachmerda-Schulz and all the yDiv PhD students for their support and friendship. Working with you has been a wonderful experience!

Special thanks also to all the colleagues from the Senckenberg Biodiversity and Climate Research Centre (SBiK-F) for their guidance, advice and support.

Last but not least, I want to thank the Dachverband Deutscher Avifaunisten (DDA) for providing me with useful information and data sets. 


\section{List of abbreviations}

$\begin{array}{ll}\text { ART } & \text { Attention Restoration Theory } \\ \text { CBD } & \text { Convention on Biological Diversity } \\ \text { CH } & \text { Chapter } \\ \text { ES } & \text { Ecosystem Services } \\ \text { EQLS } & \text { European Quality of Life Survey } \\ \text { HRQOL } & \text { Health Related Quality of Life } \\ \text { IPBES } & \text { Intergovernmental Panel on Biodiversity and Ecosystem Services } \\ \text { MA } & \text { Millennium Ecosystem Assessment } \\ \text { NCP } & \text { Nature's Contributions to People } \\ \text { SOEP } & \text { Socio-economic Panel Germany } \\ \text { SRT } & \text { Stress Reduction Theory } \\ \text { WCP } & \text { Wildlife's non-material Contributions to People } \\ \text { WHOQOL } & \text { World Health Organization Quality of Life Scale }\end{array}$




\section{References}

Aerts, R., Honnay, O., Van Nieuwenhuyse, A., 2018. Biodiversity and human health: mechanisms and evidence of the positive health effects of diversity in nature and green spaces. Br. Med. Bull. 127, 5-22.

Alvarsson, J.J., Wiens, S., Nilsson, M.E., 2010. Stress recovery during exposure to nature sound and environmental noise. Int. J. Environ. Res. Public Health 7, 1036-1046.

Alves, R., 2012. Relationships between fauna and people and the role of ethnozoology in animal conservation. Ethnobiol. Conserv. 1, 1-69.

Arbieu, U., Grünewald, C., Schleuning, M., Böhning-Gaese, K., 2017. The importance of vegetation density for tourists' wildlife viewing experience and satisfaction in African savannah ecosystems. PLoS One 12, e0185793.

Arroyo-Quiroz, A.I., García-Barrios, R., Argueta-Villamar, A., Smith, R.J., Salcido, P.R.G., 2017. Local perspectives on conflicts with wildlife and their management in the Sierra Gorda Biosphere Reserve, Mexico. J. Ethnobiol. 37, 719-742.

Balvanera, P., Caldero, R., Castro, A.J., Geijzendorffer, I.R., Jacobs, S., Martı, B., Arbieu, U., Speranza, C.I., Locatelli, B., Lynes, L., Spierenburg, M.J., Gillson, L., 2017. Interconnected place-based social-ecological research can inform global sustainability. Curr. Opin. Environ. Sustain. 29, 1-7.

Barnosky, A.D., 2008. Megafauna biomass tradeoff as a driver of Quaternary and future extinctions. Proc. Natl. Acad. Sci. 105, 11543-11548.

Barua, M., Bhagwat, S.A., Jadhav, S., 2013. The hidden dimensions of human-wildlife conflict: health impacts, opportunity and transaction costs. Biol. Conserv. 157, 309-316.

Beck, J., Ballesteros-Mejia, L., Buchmann, C.M., Dengler, J., Fritz, S.A., Gruber, B., Hof, C., Jansen, F., Knapp, S., Kreft, H., Schneider, A.K., Winter, M., Dormann, C.F., 2012. What's on the horizon for macroecology? Ecography. 35, 673-683.

Behdarvand, N., Kaboli, M., 2015. Characteristics of gray wolf attacks on humans in an altered landscape in the West of Iran. Hum. Dimens. Wildl. 20, 112-122.

Belaire, J.A., Westphal, L.M., Whelan, C.J., Minor, E.S., 2015. Urban residents' perceptions of birds in the neighborhood: biodiversity, cultural ecosystem services, and disservices. Condor 117, 192-202.

Bell, S.L., Westley, M., Lovell, R., Wheeler, B.W., Bell, S.L., Westley, M., Lovell, R., Wheeler, B.W., 2017. Everyday green space and experienced well-being: the significance of wildlife encounters. Landsc. Res. 6397, $1-12$.

Beninde, J., Veith, M., Hochkirch, A., 2015. Biodiversity in cities needs space: a meta-analysis of factors determining intra-urban biodiversity variation. Ecol. Lett. 18, 581-592.

Berndt, R.M., 1940. A curlew and owl legend from the Narunga Tribe, South Australia. Oceania 10, 456-462.

Bernstein, A.S., 2014. Biological Diversity and Public Health. Annu. Rev. Public Health 35, 153-167.

Bertram, C., Rehdanz, K., 2015. The role of urban green space for human well-being. Ecol. Econ. 120, 139-152.

Bisi, J., Kurki, S., Svensberg, M., Liukkonen, T., 2007. Human dimensions of wolf (Canis lupus) conflicts in Finland. Eur. J. Wildl. Res. 53, 304-314.

Bjerke, T., Østdahl, T., 2004. Animal-related attitudes and activities in an urban population. Anthrozoos 17, 109-129.

Blackburn, T.M., 2004. Method in macroecology. Basic Appl. Ecol. 5, 401-412.

Brooks, T.M., Mittermeier, R.A., Da Fonseca, G.A.B., Gerlach, J., Hoffmann, M., Lamoreux, J.F., Mittermeier, C.G., Pilgrim, J.D., Rodrigues, A.S.L., 2006. Global biodiversity conservation priorities. Science. 313, 58-61.

Busija, L., Pausenberger, E., Haines, T.P., Haymes, S., Buchbinder, R., Osborne, R.H., 2011. Adult measures of general health and health-related quality of life. Arthritis Care Res. 63, S383-S412.

Carpenter, S.R., Folke, C., Norström, A., Olsson, O., Schultz, L., Agarwal, B., Balvanera, P., Campbell, B., Castilla, J.C., Cramer, W., DeFries, R., Eyzaguirre, P., Hughes, T.P., Polasky, S., Sanusi, Z., Scholes, R., Spierenburg, M., 2012. Program on ecosystem change and society: an international research strategy for integrated 
social-ecological systems. Curr. Opin. Environ. Sustain. 4, 134-138.

Carrus, G., Scopelliti, M., Lafortezza, R., Colangelo, G., Ferrini, F., Salbitano, F., Agrimi, M., Portoghesi, L., Semenzato, P., Sanesi, G., 2015. Go greener, feel better? The positive effects of biodiversity on the well-being of individuals visiting urban and peri-urban green areas. Landsc. Urban Plan. 134, 221-228.

Ceríaco, L.M.P., 2012. Human attitudes towards herpetofauna: the influence of folklore and negative values on the conservation of amphibians and reptiles in Portugal. J. Ethnobiol. Ethnomed. 8, 8.

Ceríaco, L.M.P., 2011. Folklore and traditional ecological knowledge of geckos in Southern Portugal: implications for conservation and science. J. Ethnobiol. Ethnomed. 7, 26.

Chan, K.M.A., Gould, R.K., Pascual, U., 2018. Editorial overview: relational values: what are they, and what's the fuss about? Curr. Opin. Environ. Sustain. 35, A1-A7.

Chandler, M., See, L., Copas, K., Bonde, A.M.Z., López, B.C., Danielsen, F., Legind, J.K., Masinde, S., Miller-Rushing, A.J., Newman, G., Rosemartin, A., Turak, E., 2017. Contribution of citizen science towards international biodiversity monitoring. Biol. Conserv. 213, 280-294.

Christie, M., Martín-López, B., Church, A., Siwicka, E., Szymonczyk, P., Mena Sauterel, J., 2019. Understanding the diversity of values of "Nature's contributions to people": insights from the IPBES Assessment of Europe and Central Asia. Sustain. Sci. 14, 1267-1282.

Cimon-Morin, J.Ô., Darveau, M., Poulin, M., 2013. Fostering synergies between ecosystem services and biodiversity in conservation planning: A review. Biol. Conserv. 166, 144-154.

Clarke, P.A., 2016. Birds as totemic beings and creators in the Lower Murray, South Australia. J. Ethnobiol. 36, 277-293.

Cook, P.A., Howarth, M., Wheater, C.P., 2019. Biodiversity and health in the face of climate change: implications for public health, in: Marselle, M.R., Stadler, J., Korn, H., Irvine, K.N., Bonn, A. (Eds.), Biodiversity and Health in the Face of Climate Change. Springer International Publishing, Cham, pp. 251-281.

Coons, S.J., Rao, S., Keininger, D.L., Hays, R.D., 2000. A comparative review of generic quality-of-life instruments. Pharmacoeconomics 17, 13-35.

Cox, D.T.C., Gaston, K.J., 2016. Urban bird feeding: connecting people with nature. PLoS One 11, 1-13.

Cox, D.T.C., Gaston, K.J., 2015. Likeability of garden birds: importance of species knowledge \& richness in connecting people to nature. PLoS One 10, 1-14.

Cox, D.T.C., Hudson, H.L., Shanahan, D.F., Fuller, R.A., Gaston, K.J., 2017a. The rarity of direct experiences of nature in an urban population. Landsc. Urban Plan. 160, 79-84.

Cox, D.T.C., Shanahan, D.F., Hudson, H.L., Fuller, R.A., Anderson, K., Hancock, S., Gaston, K.J., 2017b. Doses of nearby nature simultaneously associated with multiple health benefits. Int. J. Environ. Res. Public Health 14, E172.

Cox, D.T.C., Shanahan, D.F., Hudson, H.L., Plummer, K.E., Siriwardena, G.M., Fuller, R.A., Anderson, K., Hancock, S., Gaston, K.J., 2017c. Doses of neighborhood nature: the benefits for mental health of living with nature. Bioscience 67, 147-155.

Curtin, S., 2009. Wildlife tourism: the intangible, psychological benefits of human-wildlife encounters. Curr. Issues Tour. 12, 451-474.

Daily, G.C., 1997. Introduction: what are ecosystem services?, in: Daily, G.C. (Ed.), Nature's Services: Societal Dependence On Natural Ecosystems. Island Press, Washington, D.C., pp. 1-10.

Dale, B., 1980. Subjective and Objective Social Indicators in Studies of Regional Social Well-Being. Reg. Stud. $14,503-515$.

Dallimer, M., Davies, Z.G., Irvine, K.N., Maltby, L., Warren, P.H., Gaston, K.J., Armsworth, P.R., 2014. What personal and environmental factors determine frequency of urban greenspace use? Int. J. Environ. Res. Public Health 11, 7977-7992.

Dallimer, M., Irvine, K.N., Skinner, A.M.J., Davies, Z.G., Rouquette, J.R., Maltby, L.L., Warren, P.H., Armsworth, P.R., Gaston, K.J., 2012. Biodiversity and the feel-good factor: understanding associations between self-reported human well-being and species richness. Bioscience 62, 47-55. 
Davey, G.C., McDonald, A.S., Hirisave, U., Prabhu, G.G., Iwawaki, S., Jim, C.I., Merckelbach, H., de Jong, P.J., Leung, P.W., Reimann, B.C., 1998. A cross-cultural study of animal fears. Behav. Res. Ther. 36, 735-50.

Davey, G.C.L., 1994. Self-reported fears to common indigenous animals in an adult UK population: The role of disgust sensitivity. Br. J. Psychol. 85, 541-554.

de Bell, S., Graham, H., Jarvis, S., White, P., 2017. The importance of nature in mediating social and psychological benefits associated with visits to freshwater blue space. Landsc. Urban Plan. 167, 118-127.

de Vries, S., ten Have, M., van Dorsselaer, S., van Wezep, M., Hermans, T., de Graaf, R., 2016. Local availability of green and blue space and prevalence of common mental disorders in the Netherlands. Br. J. Psychiatry Open 2, 366-372.

Debata, S., Swain, K.K., Sahu, H.K., Shekhar, H., 2016. Human-sloth bear conflict in a human-dominated landscape of northern Odisha, India. Ursus 27, 90-98.

Del Toro, I., Ribbons, R.R., Pelini, S.L., 2012. The little things that run the world revisited: a review of ant-mediated ecosystem services and disservices (Hymenoptera: Formicidae). Myrmecological News 17, 133-146.

Deutschland Netzwerk Phytodiversität, D., Bundesamt für Naturschutz, B., 2013. Verbreitungsatlas der Farnund Blütenpflanzen Deutschlands. Landwirtschaftsverlag, Münster.

Dhakal, B., Thapa, B., 2019. Residents' perceptions of human-elephant conflict: case study in Bahundangi, Nepal. Environ. Dev. Sustain. 21, 461-481.

Díaz, S., Demissew, S., Carabias, J., Joly, C., Lonsdale, M., Ash, N., Larigauderie, A., Adhikari, J.R., Arico, S., Báldi, A., Bartuska, A., Baste, I.A., Bilgin, A., Brondizio, E., Chan, K.M.A., Figueroa, V.E., Duraiappah, A., Fischer, M., Hill, R., Koetz, T., Leadley, P., Lyver, P., Mace, G.M., Martin-Lopez, B., Okumura, M., Pacheco, D., Pascual, U., Pérez, E.S., Reyers, B., Roth, E., Saito, O., Scholes, R.J., Sharma, N., Tallis, H., Thaman, R., Watson, R., Yahara, T., Hamid, Z.A., Akosim, C., Al-Hafedh, Y., Allahverdiyev, R., Amankwah, E., Asah, T.S., Asfaw, Z., Bartus, G., Brooks, A.L., Caillaux, J., Dalle, G., Darnaedi, D., Driver, A., Erpul, G., Escobar-Eyzaguirre, P., Failler, P., Fouda, A.M.M., Fu, B., Gundimeda, H., Hashimoto, S., Homer, F., Lavorel, S., Lichtenstein, G., Mala, W.A., Mandivenyi, W., Matczak, P., Mbizvo, C., Mehrdadi, M., Metzger, J.P., Mikissa, J.B., Moller, H., Mooney, H.A., Mumby, P., Nagendra, H., Nesshover, C., Oteng-Yeboah, A.A., Pataki, G., Roué, M., Rubis, J., Schultz, M., Smith, P., Sumaila, R., Takeuchi, K., Thomas, S., Verma, M., Yeo-Chang, Y., Zlatanova, D., 2015. The IPBES conceptual framework - connecting nature and people. Curr. Opin. Environ. Sustain. 14, 1-16.

Díaz, S., Fargione, J., Chapin, F.S., Tilman, D., 2006. Biodiversity loss threatens human well-being. PLoS Biol. 4, 1300-1305.

Díaz, S., Pascual, U., Stenseke, M., Martín-lópez, B., Watson, R.T., Molnár, Z., Hill, R., Chan, K.M.A., Baste, I.A., Brauman, K.A., Polasky, S., Church, A., Lonsdale, M., Larigauderie, A., Leadley, P.W., Alexander, P.E., Oudenhoven, V., Plaat, F. Van Der, Schröter, M., Lavorel, S., Aumeeruddy-thomas, Y., Bukvareva, E., Davies, K., Demissew, S., Erpul, G., Failler, P., Guerra, C.A., Hewitt, C.L., Keune, H., Lindley, S., Shirayama, Y., 2018. Assessing nature's contributions to people. Science. 359, 270-272.

Díaz, S., Settele, J., Brondizio, E.S., Ngo, H.T., Agard, J., Arneth, A., Balvanera, P., Brauman, K.A., Butchart, S.H.M., Chan, K.M.A., Garibaldi, L.A., Ichii, K., Liu, J., Subramanian, S.M., Midgley, G.F., Miloslavich, P., Molnár, Z., Obura, D.O., Pfaff, A., Polasky, S., Purvis, A., Razzaque, J., Reyers, B., Chowdhury, R.R., Shin, Y.-J., Visseren-Hamakers, I., Willis, K., Zayas, C.N., 2019. Pervasive human-driven decline of life on Earth points to the need for transformative change. Science. 366, eaax3100.

Diener, E., 2006. Guidelines for national indicators of subjective well-being and ill-being. J. Happiness Stud. 7, 397-404.

Diener, E., 1984. Subjective well-being. Psychol. Bull. 95, 542-575.

Diener, E., Emmons, R.A., Larsen, R.J., Griffin, S., 1985. The satisfaction with life scale. J. Pers. Assess. 49, $71-75$.

Dolan, P., Peasgood, T., White, M., 2008. Do we really know what makes us happy? A review of the economic literature on the factors associated with subjective well-being. J. Econ. Psychol. 29, 94-122. 
Dormann, C.F., Elith, J., Bacher, S., Buchmann, C., Carl, G., Carré, G., Marquéz, J.R.G., Gruber, B., Lafourcade, B., Leitão, P.J., Münkemüller, T., Mcclean, C., Osborne, P.E., Reineking, B., Schröder, B., Skidmore, A.K., Zurell, D., Lautenbach, S., 2013. Collinearity: a review of methods to deal with it and a simulation study evaluating their performance. Ecography 36, 027-046.

Doughty, C.E., Wolf, A., Morueta-Holme, N., Jørgensen, P.M., Sandel, B., Violle, C., Boyle, B., Kraft, N.J.B., Peet, R.K., Enquist, B.J., Svenning, J.C., Blake, S., Galetti, M., 2016. Megafauna extinction, tree species range reduction, and carbon storage in Amazonian forests. Ecography 39, 194-203.

Dunn, R.R., 2010. Global Mapping of Ecosystem Disservices: The Unspoken Reality that Nature Sometimes Kills us. Biotropica 42, 555-557.

Duprè, C., Stevens, C.J., Ranke, T., Bleeker, A., Peppler-Lisbach, C., Gowing, D.J.G., Dise, N.B., Dorland, E., Bobbink, R., Diekmann, M., 2010. Changes in species richness and composition in European acidic grasslands over the past 70 years: The contribution of cumulative atmospheric nitrogen deposition. Glob. Chang. Biol. 16, 344-357.

Dzhambov, A.M., Dimitrova, D.D., 2014. Elderly visitors of an urban park, health anxiety and individual awareness of nature experiences. Urban For. Urban Green. 13, 806-813.

Expósito-Granados, M., Castro, A.J., Lozano, J., Aznar-Sanchez, J.A., Carter, N.H., Requena-Mullor, J.M., Malo, A.F., Olszańska, A., Morales-Reyes, Z., Moleón, M., Sánchez-Zapata, J.A., Cortés-Avizanda, A., Fischer, J., Martín-López, B., 2019. Human-carnivore relations: conflicts, tolerance and coexistence in the American West. Environ. Res. Lett. 14, 123005.

Farber, M.E., Hall, T.E., 2007. Emotion and environment: visitors' extraordinary experiences along the Dalton highway in Alaska. J. Leis. Res. 39, 248-270.

Feld, C.K., Da Silva, P.M., Sousa, J.P., De Bello, F., Bugter, R., Grandin, U., Hering, D., Lavorel, S., Mountford, O., Pardo, I., Pärtel, M., Römbke, J., Sandin, L., Bruce Jones, K., Harrison, P., 2009. Indicators of biodiversity and ecosystem services: a synthesis across ecosystems and spatial scales. Oikos 118, 1862-1871.

Ferrer-i-Carbonell, A., Frijters, P., 2004. How important is methodology for the estimates of the determinants of happiness? Econ. J. 114, 641-659.

Folgarait, P.J., 1998. Ant biodiversity and its relationship to ecosystem functioning: a review. Biodivers. Conserv. 7, 1221-1244.

Folmer, A., Haartsen, T., Huigen, P.P.P., 2019. How ordinary wildlife makes local green places special. Landsc. Res. 44, 393-403.

Fox, J., Monette, G., 1992. Generalized collinearity diagnostics. J. Am. Stat. Assoc. 87, 178-183.

Frank, J., Johansson, M., Flykt, A., 2015. Public attitude towards the implementation of management actions aimed at reducing human fear of brown bears and wolves. Wildlife Biol. 21, 122-130.

Fryxell, J.M., Graeme, C., Sinclair, A.R.E., 2014. Wildlife ecology, conservation and management, Third Edit. ed. John Wiley \& Sons, Incorporated, Chichester, UK.

Fuller, R.A., Irvine, K.N., Devine-Wright, P., Warren, P.H., Gaston, K.J., 2007. Psychological benefits of greenspace increase with biodiversity. Biol. Lett. 3, 390-394.

Galbraith, J.A., Beggs, J.R., Jones, D.N., McNaughton, E.J., Krull, C.R., Stanley, M.C., 2014. Risks and drivers of wild bird feeding in urban areas of New Zealand. Biol. Conserv. 180, 64-74.

Gascon, M., Mas, M.T., Martínez, D., Dadvand, P., Forns, J., Plasència, A., Nieuwenhuijsen, M.J., 2015. Mental health benefits of long-term exposure to residential green and blue spaces: a systematic review. Int. J. Environ. Res. Public Health 12, 4354-4379.

Gaston, K.J., Soga, M., Duffy, J.P., Garrett, J.K., Gaston, S., Cox, D.T.C., 2018. Personalised ecology. Trends Ecol. Evol. 33, 916-925.

Gaynor, K.M., Hojnowski, C.E., Carter, N.H., Brashares, J.S., 2018. The influence of human disturbance on wildlife nocturnality. Science. 360, 1232-1235.

Gedeon, K., Grüneberg, C., Mitschke, A., Sudfeldt, C., Eickhorst, W., Fischer, S., Flade, M., Frick, S., Geiersberger, I., Koop, B., Kramer, M., Krüger, T., Roth, N., Ryslav, T., Stübin, S., Sudmann, S.R., Steffens, R., 
Vökler, F., Witt, K., 2014. Atlas Deutscher Brutvogelarten - Atlas of German Breeding Birds, 1st ed. Stiftung Vogelmonitoring Deutschland \& Dachverband Deutscher Avifaunisten (DDA), Münster.

Geijzendorffer, I.R., Roche, P.K., 2013. Can biodiversity monitoring schemes provide indicators for ecosystem services? Ecol. Indic. 33, 148-157.

Gil-Tena, A., Saura, S., Brotons, L., 2007. Effects of forest composition and structure on bird species richness in a Mediterranean context: implications for forest ecosystem management. For. Ecol. Manage. 242, 470-476.

Goebel, J., Grabka, M.M., Liebig, S., Kroh, M., David, R., Carsten, S., Schupp, J., 2019. The German Socio-Economic Panel (SOEP). J. Econ. Stat. 239, 345-360.

Goldman, R.L., Tallis, H., Kareiva, P., Daily, G.C., 2008. Field evidence that ecosystem service projects support biodiversity and diversify options. Proc. Natl. Acad. Sci. U. S. A. 105, 9445-9448.

Goodrich, J.M., 2010. Human-tiger conflict: A review and call for comprehensive plans. Integr. Zool. 5, 300-312.

Gunnarsson, B., Knez, I., Hedblom, M., Sang, O., 2017. Effects of biodiversity and environment-related attitude on perception of urban green space. Urban Ecosyst. 20, 37-49.

Gunther, K.A., Haroldson, M.A., Frey, K., Cain, S.L., Copeland, J., Schwartz, C.C., 2004. Grizzly bear - human conflicts in the Greater Yellowstone ecosystem, $1992-2000$. Ursus 15, 10-22.

Hagemeijer, W.J.M., Blair, M.J., 1997. The EBCC Atlas of European Breeding Birds - their Distribution and Abundance. T. \& A.D. Poyser, London.

Haines-Young, R., Potschin, M., 2018. Common International Classification of Ecosystem Services (CICES) V5.1 and Guidance on the Application of the Revised Structure. Nottingham.

Hansen, R., Pauleit, S., 2014. From multifunctionality to multiple ecosystem services? A conceptual framework for multifunctionality in green infrastructure planning for urban Areas. Ambio 43, 516-529.

Harris, E., de Crom, E.P., Wilson, A., 2016. Pigeons and people: mortal enemies or lifelong companions? A case study on staff perceptions of the pigeons on the University of South Africa, Muckleneuk campus. J. Public Aff. 16, 331-340.

Harrison, P.A., Berry, P.M., Simpson, G., Haslett, J.R., Blicharska, M., Bucur, M., Dunford, R., Egoh, B., Garcia-Llorente, M., Geamănă, N., Geertsema, W., Lommelen, E., Meiresonne, L., Turkelboom, F., 2014. Linkages between biodiversity attributes and ecosystem services: a systematic review. Ecosyst. Serv. 9, 191-203.

Hartig, T., Mitchell, R., de Vries, S., Frumkin, H., 2014. Nature and health. Annu. Rev. Public Health 35, 207-228.

Hausmann, A., Slotow, R., Burns, J.K., Di Minin, E., 2016. The ecosystem service of sense of place: benefits for human well-being and biodiversity conservation. Environ. Conserv. 43, 117-127.

Hedblom, M., Heyman, E., Antonsson, H., Gunnarsson, B., 2014. Bird song diversity influences young people's appreciation of urban landscapes. Urban For. Urban Green. 13, 469-474.

Hedblom, M., Knez, I., Ode Sang, Å., Gunnarsson, B., 2017. Evaluation of natural sounds in urban greenery: potential impact for urban nature preservation. R. Soc. Open Sci. 4, 170037.

Herzog, H., 2011. The impact of pets on human health and psychological well-being: fact, fiction, or hypothesis? Curr. Dir. Psychol. Sci. 20, 236-239.

Hopman, W.M., Harrison, M.B., Coo, H., Friedberg, E., Buchanan, M., VanDenkerkhof, E.G., 2009. Associations between chronic disease, age and physical and mental health status. Chronic Dis. Can. 29, 108-116.

Hough, R.L., 2014. Biodiversity and human health: Evidence for causality? Biodivers. Conserv. 23, 267-288.

Hoyle, H., Hitchmough, J., Jorgensen, A., 2017. All about the 'wow factor'? The relationships between aesthetics, restorative effect and perceived biodiversity in designed urban planting. Landsc. Urban Plan. 164, $109-123$.

Hoyle, H., Jorgensen, A., Hitchmough, J.D., 2019. What determines how we see nature? Perceptions of naturalness in designed urban green spaces. People Nat. 167-180.

Hull, K., Fergus, R., 2017. Birds as seers: an ethno-ornithological approach to omens and prognostication among the Ch'Orti' Maya of Guatemala. J. Ethnobiol. 37, 604-620.

Inskip, C., Zimmermann, A., 2009. Human-felid conflict: a review of patterns and priorities worldwide. Oryx 43, 
$18-34$.

IPBES, 2019. The global assessment report on biodiversity and ecosystem services - summary for policy makers. IPBES secretariat, Bonn.

IPBES, 2014. Annex: Conceptual framework for the Intergovernmental Science-Policy Platform on Biodiversity and Ecosystem Services. Intergovernmental Science-Policy Platform on Biodiversity and Ecosystem Services.

Irvine, K.N., Hoesly, D., Bell-Williams, R., Warber, S.L., 2019. Biodiversity and spiritual well-being, in: Marselle, M.R., Stadler, J., Korn, H., Irvine, K.N., Bonn, A. (Eds.), Biodiversity and Health in the Face of Climate Change. Springer International Publishing, Cham, pp. 213-247.

Jacobs, M., Vaske, J.J., 2019. Understanding emotions as opportunities for and barriers to coexistence with wildlife, in: Frank, B., Glikman, J.A., Marchini, S. (Eds.), Human-Wildlife Interactions. Cambridge University Press, pp. 65-84.

Jacobs, M.H., 2012. Human emotions toward wildlife. Hum. Dimens. Wildl. 17, 1-3.

Jacobs, M.H., Vaske, J.J., Dubois, S., Fehres, P., 2014. More than fear: role of emotions in acceptability of lethal control of wolves. Eur. J. Wildl. Res. 60, 589-598.

Jadhav, S., Barua, M., 2012. The elephant vanishes: impact of human - elephant conflict on people's wellbeing. Health Place 18, 1356-1365.

Johansson, M., Karlsson, J., 2011. An subjective experience of fear and the cognitive interpretation of large carnivores. Hum. Dimens. Wildl. 16, 15-29.

Jones, K.E., Bielby, J., Cardillo, M., Fritz, S.A., O’Dell, J., Orme, C.D.L., Safi, K., Sechrest, W., Boakes, E.H., Carbone, C., Connolly, C., Cutts, M.J., Foster, J.K., Grenyer, R., Habib, M., Plaster, C.A., Price, S.A., Rigby, E.A., Rist, J., Teacher, A., Bininda-Emonds, O.R.P., Gittleman, J.L., Mace, G.M., Purvis, A., 2009. PanTHERIA: a species-level database of life history, ecology, and geography of extant and recently extinct mammals. Ecology 90, 2648-2648.

Kadykalo, A.N., López-Rodriguez, M.D., Ainscough, J., Droste, N., Ryu, H., Ávila-Flores, G., Le Clec'h, S., Muñoz, M.C., Nilsson, L., Rana, S., Sarkar, P., Sevecke, K.J., Harmáčková, Z. V., 2019. Disentangling 'ecosystem services' and 'nature's contributions to people.' Ecosyst. People 15, 269-287.

Kahneman, D., Krueger, A.B., 2006. Developments in the measurement of subjective well being. J. Econ. Perspect. 20, 3-24.

Kaplan, S., 1995. The resporative benefits of nature: toward and integrative framework. J. Environ. Psychol. 15, 169-182.

Klein, A.M., Vaissière, B.E., Cane, J.H., Steffan-Dewenter, I., Cunningham, S.A., Kremen, C., Tscharntke, T., 2007. Importance of pollinators in changing landscapes for world crops. Proc. R. Soc. B Biol. Sci. 274, 303-313.

Kopmann, A., Rehdanz, K., 2013. A human well-being approach for assessing the value of natural land areas. Ecol. Econ. 93, 20-33.

Krekel, C., Kolbe, J., Wüstemann, H., 2016. The greener, the happier? The effect of urban land use on residential well-being. Ecol. Econ. 121, 117-127.

Kristoffersen, I., 2017. The metrics of subjective wellbeing data: an empirical evaluation of the ordinal and cardinal comparability of life satisfaction scores. Soc. Indic. Res. 130, 845-865.

Kromrey, J.D., Rendina-Gobioff, G., 2003. An empirical comparison of regression analysis strategies with discrete ordinal variables. Mult. Linear Regres. Viewpoints 29, 30-43.

Lee, W.N., Davey, G., 2015. Chinese visitors' experiences of nature and wild macaques: inspiration and personal growth for living in Hong Kong. Hum. Dimens. Wildl. 20, 206-219.

Lees, D., Sherman, G. d. H., Maguire, G.S., Dann, P., Cardilini, A.P.A., Weston, M.A., 2013. Swooping in the suburbs; parental defence of an abundant aggressive urban bird against humans. Animals 3, 754-766.

Lindemann-Matthies, P., Junge, X., Matthies, D., 2010. The influence of plant diversity on people's perception and aesthetic appreciation of grassland vegetation. Biol. Conserv. 143, 195-202. 
Lindemann-Matthies, P., Matthies, D., 2018. The influence of plant species richness on stress recovery of humans. Web Ecol. 18, 121-128.

Lindenmayer, D.B., Manning, A.D., Smith, P.L., Possingham, H.P., Fischer, J., Oliver, I., McCarthy, M.A., 2002. The focal-species approach and landscape restoration: a critique. Conserv. Biol. 16, 338-345.

Lindsey, P.A., Alexander, R., Mills, M.G.L., Romañach, S., Woodroffe, R., 2007. Wildlife viewing preferences of visitors to protected areas in South Africa: implications for the role of ecotourism in conservation. J. Ecotourism 6, 19-33.

Little, R.M., Sutton, J.L., 2013. Perceptions towards Egyptian Geese at the Steenberg Golf Estate, Cape Town, South Africa. Ostrich 84, 85-87.

Loss, S.R., Ruiz, M.O., Brawn, J.D., 2009. Relationships between avian diversity, neighborhood age, income, and environmental characteristics of an urban landscape. Biol. Conserv. 142, 2578-2585.

Lovell, R., Wheeler, B.W., Higgins, S.L., Irvine, K.N., Depledge, M.H., 2014. A systematic review of the health and well-being benefits of biodiverse environments. J. Toxicol. Environ. Heal. - Part B Crit. Rev. 17, 1-20.

Lozano, J., Olszańska, A., Morales-Reyes, Z., Castro, A.A., Malo, A.F., Moleón, M., Sánchez-Zapata, J.A., Cortés-Avizanda, A., von Wehrden, H., Dorresteijn, I., Kansky, R., Fischer, J., Martín-López, B., 2019. Human-carnivore relations: a systematic review. Biol. Conserv. 237, 480-492.

Luck, G.W., Davidson, P., Boxall, D., Smallbone, L., 2011. Relations between urban bird and plant communities and human well-being and connection to nature. Conserv. Biol. 25, 816-826.

Lyytimäki, J., Petersen, L.K., Normander, B., Bezák, P., 2008. Nature as a nuisance? Ecosystem services and disservices to urban lifestyle. Environ. Sci. 5, 161-172.

MA, Millennium Ecosystem Assessment, 2005. Ecosystems and human well-being: synthesis. Island Press, Washington, DC.

Maas, J., Verheij, R.A., Groenewegen, P.P., De Vries, S., Spreeuwenberg, P., 2006. Green space, urbanity, and health: how strong is the relation? J. Epidemiol. Community Health 60, 587-592.

Mace, G.M., 2014. Whose conservation? Science. 345, 1558-1560.

Mace, G.M., Norris, K., Fitter, A.H., 2012. Biodiversity and ecosystem services: a multilayered relationship. Trends Ecol. Evol. 27, 19-25.

MacKerron, G., Mourato, S., 2013. Happiness is greater in natural environments. Glob. Environ. Chang. 23, 992-1000.

Maes, J., Fabrega, N., Zulian, G., Barbosa, A., Ivits, E., Polce, C., Vandecasteele, I., Marí, I., Guerra, C., Castillo, C.P., Vallecillo, S., Baranzelli, C., Barranco, R., Batista, F., Trombetti, M., Lavalle, C., 2015. Mapping and assessment of ecosystems and their services trends in ecosystems and ecosystem - JRC report number JRC94889.

Magurran, A.E., 1988. Ecological Diversity and Its Measurement. Springer Netherlands, Dordrecht.

Marchini, S., Crawshaw, P.G., 2015. Human-wildlife conflicts in Brazil: a fast-growing issue. Hum. Dimens. Wildl. 20, 323-328.

Markevych, I., Schoierer, J., Hartig, T., Chudnovsky, A., Hystad, P., Dzhambov, A.M., Vries, S. De, Triguero-mas, M., Brauer, M., Nieuwenhuijsen, M.J., Lupp, G., Richardson, E.A., Astell-burt, T., Dimitrova, D., Feng, X., Sadeh, M., Standl, M., Heinrich, J., Fuertes, E., 2017. Exploring pathways linking greenspace to health: theoretical and methodological guidance. Environ. Res. 158, 301-317.

Marselle, M.R., 2019. Theoretical foundations of biodiversity and mental well-being relationships, in: Marselle, M.R., Stadler, J., Korn, H., Irvine, K.N., Bonn, A. (Eds.), Biodiversity and Health in the Face of Climate Change. Springer International Publishing, Cham, pp. 133-158.

Marselle, M.R., Irvine, K.N., Lorenzo-Arribas, A., Warber, S.L., 2016. Does perceived restorativeness mediate the effects of perceived biodiversity and perceived naturalness on emotional well-being following group walks in nature? J. Environ. Psychol. 46, 217-232.

Marselle, M.R., Irvine, K.N., Lorenzo-Arribas, A., Warber, S.L., 2015. Moving beyond green: exploring the relationship of environment type and indicators of perceived environmental quality on emotional well-being 
following group walks. Int. J. Environ. Res. Public Health 12, 106-130.

Marselle, Melissa R., Martens, D., Dallimer, M., Irvine, K.N., 2019. Review of the mental health and well-being benefits of biodiversity, in: Marselle, M.R., Stadler, J., Korn, H., Irvine, K., Bonn, A. (Eds.), Biodiversity and Health in the Face of Climate Change. Springer International Publishing, Cham, pp. 175-211.

Martin-Lopez, B., Leister, I., Cruz, P.L., Palomo, I., Gr, A., Harrison, P.A., Lavorel, S., Locatelli, B., Luque, S., Walz, A., 2019. Nature's contributions to people in mountains: a review. PLoS One 1-24.

Mauri, A., Strona, G., San-Miguel-Ayanz, J., 2017. EU-Forest, a high-resolution tree occurrence dataset for Europe. Sci. Data 4, 160123.

Mayberry, A.L., Hovorka, A.J., Evans, K.E., 2017. Well-being impacts of human-elephant conflict in Khumaga, Botswana: exploring visible and hidden dimensions. Conserv. Soc. 15, 280-291.

McDonough, K., Hutchinson, S., Moore, T., Hutchinson, J.M.S., 2017. Analysis of publication trends in ecosystem services research. Ecosyst. Serv. 25, 82-88.

McGill, B.J., 2019. The what, how and why of doing macroecology. Glob. Ecol. Biogeogr. 28, 6-17.

McGillivray, M., 2007. Human well-being: issues, concepts and measures, in: McGillivray, M. (Ed.), Human Well-Being: Concept and Measurement. Palgrave Macmillan UK, London, pp. 1-22.

Mcintosh, D., Wright, P.A., 2017. Emotional processing as an important part of the wildlife viewing experience. J. Outdoor Recreat. Tour. 18, 1-9.

Medvedev, O., Shepherd, D., Hautus, M.J., 2015. The restorative potential of soundscapes: a physiological investigation. Appl. Acoust. 96, 20-26.

Methorst, J., Arbieu, U., Bonn, A., Böhning-Gaese, K., Müller, T., 2020a. Non-material contributions of wildlife to human well-being: A systematic review. Environ. Res. Lett. 15, 093005.

Methorst, J., Rehdanz, K., Mueller, T., Hansjürgens, B., Bonn, A., Böhning-Gaese, K., 2020b. The importance of species diversity for human well-being in Europe. Ecol. Econ. printed online.

Milcu, A.I., Hanspach, J., Abson, D., Fischer, J., 2013. Cultural ecosystem services: a literature review and prospects for future research. Ecol. Soc. 18, 44.

Modini, M., Joyce, S., Mykletun, A., Christensen, H., Bryant, R.A., Mitchell, P.B., Harvey, S.B., 2016. The mental health benefits of employment: Results of a systematic meta-review. Australas. Psychiatry 24, 331-336.

Moher, D., Liberati, A., Tetzlaff, J., Altman, D.G., Altman, D., Antes, G., Atkins, D., Barbour, V., Barrowman, N., Berlin, J.A., Clark, J., Clarke, M., Cook, D., D’Amico, R., Deeks, J.J., Devereaux, P.J., Dickersin, K., Egger, M., Ernst, E., Gøtzsche, P.C., Grimshaw, J., Guyatt, G., Higgins, J., Ioannidis, J.P.A., Kleijnen, J., Lang, T., Magrini, N., McNamee, D., Moja, L., Mulrow, C., Napoli, M., Oxman, A., Pham, B., Rennie, D., Sampson, M., Schulz, K.F., Shekelle, P.G., Tovey, D., Tugwell, P., 2009. Preferred reporting items for systematic reviews and meta-analyses: The PRISMA statement. PLoS Med. 6, e1000097.

Moleón, M., Sánchez-Zapata, J.A., Margalida, A., Carrete, M., Owen-Smith, N., Donázar, J.A., 2014. Humans and scavengers: the evolution of interactions and ecosystem services. Bioscience 64, 394-403.

Moore Jr., R.M., Zehmer, R.B., Moutlthrop, J.I., Parker, R.L., 2013. Surveillance of animal-bite cases in the United States, 1971-1972. Arch. Environ. Health 32, 267-270.

Mormile, J.E., Hill, C.M., 2016. Living with urbanbaboons: exploring attitudes and their implications for local baboon conservation and management in Knysna, South Africa. Hum. Dimens. Wildl. 22, 99-109.

Mowen, A., Orsega-Smith, E., Payne, L., Ainsworth, B., Godbey, G., 2007. The Role of Park Proximity and Social Support in Shaping Park Visitation, Physical Activity, and Perceived Health among Older Adults. J. Phys. Act. Heal. 4, 167-179.

Muratet, A., Pellegrini, P., Dufour, A.B., Arrif, T., Chiron, F., 2015. Perception and knowledge of plant diversity among urban park users. Landsc. Urban Plan. 137, 95-106.

Naeem, S., Chazdon, R., Duffy, J.E., Prager, C., Worm, B., 2016. Biodiversity and human well-being: An essential link for sustainable development. Proc. R. Soc. B Biol. Sci. 283.

Ng, Y., 1997. A case for happiness, cardinalism, and interpersonal comparability. Econ. J. 107, 1848-1858.

O’Bryan, C.J., Braczkowski, A.R., Beyer, H.L., Carter, N.H., Watson, J.E.M., McDonald-Madden, E., 2018. The 
contribution of predators and scavengers to human well-being. Nat. Ecol. Evol. 2, 229-236.

OECD, 2013. OECD guidelines on measuring subjective well-being. OECD Publishing.

OECD / European Union, 2018. Health at a Glance: Europe 2018, Health at a glance: Europe. OECD Publishing, Paris.

Ogra, M. V, 2008. Human-wildlife conflict and gender in protected area borderlands: A case study of costs, perceptions, and vulnerabilities from Uttarakhand (Uttaranchal), India. Geoforum 39, 1408-1422.

Ohemeng, F., Lawson, E.T., Ayivor, J., Leach, M., Waldman, L., Ntiamoa-Baidu, Y., 2017. Socio-cultural Determinants of Human-Bat Interactions in Rural Ghana. Anthrozoos 30, 181-194.

Oiamo, T.H., Luginaah, I.N., Baxter, J., 2015. Cumulative effects of noise and odour annoyances on environmental and health related quality of life. Soc. Sci. Med. 146, 191-203.

Oteros-rozas, E., Martín-lópez, B., Fagerholm, N., Bieling, C., Plieninger, T., 2018. Using social media photos to explore the relation between cultural ecosystem services and landscape features across five European sites. Ecol. Indic. 94, 74-86.

Paracchini, M.L., Zulian, G., Kopperoinen, L., Maes, J., Schägner, J.P., Termansen, M., Zandersen, M., Perez-Soba, M., Scholefield, P.A., Bidoglio, G., 2014. Mapping cultural ecosystem services: a framework to assess the potential for outdoor recreation across the EU. Ecol. Indic. 45, 371-385.

Pascual, U., Balvanera, P., Díaz, S., Pataki, G., Roth, E., Stenseke, M., Watson, R.T., Başak Dessane, E., Islar, M., Kelemen, E., Maris, V., Quaas, M., Subramanian, S.M., Wittmer, H., Adlan, A., Ahn, S.E., Al-Hafedh, Y.S., Amankwah, E., Asah, S.T., Berry, P., Bilgin, A., Breslow, S.J., Bullock, C., Cáceres, D., Daly-Hassen, H., Figueroa, E., Golden, C.D., Gómez-Baggethun, E., González-Jiménez, D., Houdet, J., Keune, H., Kumar, R., Ma, K., May, P.H., Mead, A., O’Farrell, P., Pandit, R., Pengue, W., Pichis-Madruga, R., Popa, F., Preston, S., Pacheco-Balanza, D., Saarikoski, H., Strassburg, B.B., van den Belt, M., Verma, M., Wickson, F., Yagi, N., 2017. Valuing nature's contributions to people: the IPBES approach. Curr. Opin. Environ. Sustain. 26-27, $7-16$.

Pearce, J., Strickland-Munro, J., Moore, S.A., 2017. What fosters awe-inspiring experiences in nature-based tourism destinations? J. Sustain. Tour. 25, 362-378.

Penteriani, V., Delgado, M., Pinchera, F., Naves, J., Fernández-gil, A., Kojola, I., Härkönen, S., Norberg, H., Frank, J., Fedriani, J.M., Sahlén, V., Støen, O., Swenson, J.E., 2016. Human behaviour can trigger large carnivore attacks in developed countries. Sci. Rep. 6, 1-8.

Petersen, E., Schoen, G., Liedtke, G., Zech, A., 2018. Relevance of urban green space for physical activity and health-related quality of life in older adults. Qual. Ageing Older Adults 19, 158-166.

Pugh, R.N.H., Bourdillon, C.C.M., Theakston, R.D.G., Reid, H.A., 1979. Bites of the carpet viper in the Niger Valley. Lancet 314, 625-627.

Rabe, S.E., Koellner, T., Marzelli, S., Schumacher, P., Grêt-Regamey, A., 2016. National ecosystem services mapping at multiple scales - The German exemplar. Ecol. Indic. 70, 357-372.

Ratcliffe, E., Gatersleben, B., Sowden, P.T., 2016. Associations with bird sounds: how do they relate to perceived restorative potential? J. Environ. Psychol. 47, 136-144.

Ratcliffe, E., Gatersleben, B., Sowden, P.T., 2013. Bird sounds and their contributions to perceived attention restoration and stress recovery. J. Environ. Psychol. 36, 221-228.

Redpath, S.M., Bhatia, S., Young, J., 2015. Tilting at wildlife: reconsidering human-wildlife conflict. Oryx 49, $222-225$.

Rehdanz, K., Maddison, D., 2005. Climate and happiness. Ecol. Econ. 52, 111-125.

Rock, P., 2005. Urban gulls: problems and solutions. Br. Birds 98, 338-355.

Romanelli, C., Corvalan, C., Cooper, H.D., Manga, L., Maiero, M., Campbell-Lendrum, D., 2014. From Manaus to Maputo: Toward a public health and biodiversity framework. Ecohealth 11, 292-299.

RStudio Team, 2016. RStudio: Integrated Development for R.

Russell, R., Guerry, A.D., Balvanera, P., Gould, R.K., Basurto, X., Chan, K.M.A., Klain, S., Levine, J., Tam, J., 2013. Humans and nature: how knowing and experiencing nature affect well-being. Annu. Rev. Environ. 
Resour. 38, 473-502.

Sandifer, P.A., Sutton-Grier, A.E., Ward, B.P., 2015. Exploring connections among nature, biodiversity, ecosystem services, and human health and well-being: opportunities to enhance health and biodiversity conservation. Ecosyst. Serv. 12, 1-15.

Sarkhel, S., Ghosh, R., Mana, K., Gantait, K., 2017. A hospital based epidemiological study of snakebite in Paschim Medinipur. Toxicol. Reports 4, 415-419.

Schebella, M.F., Weber, D., Lindsey, K., Daniels, C.B., 2017. For the love of nature: exploring the importance of species diversity and micro-variables associated with favorite outdoor places. Front. Psychol. 8, 2094.

Schimmack, U., 2006. Internal and external determinants of subjective well-being: Review and policy implications, in: Ng, Y.-K., Ho, L.S. (Eds.), Happiness and Public Policy: Theory, Case Studies and Implications. Palgrave Macmillan UK, pp. 67-88.

Sekercioglu, C.H., 2006. Increasing awareness of avian ecological function. Trends Ecol. Evol. 21, 464-471.

Shackleton, C.M., Ruwanza, S., Sinasson Sanni, G.K., Bennett, S., De Lacy, P., Modipa, R., Mtati, N., Sachikonye, M., Thondhlana, G., 2016. Unpacking pandora's box: understanding and categorising ecosystem disservices for environmental management and human wellbeing. Ecosystems 19, 587-600.

Shanahan, D.F., Bush, R., Gaston, K.J., Lin, B.B., Dean, J., Barber, E., Fuller, R.A., 2016. Health benefits from nature experiences depend on dose. Sci. Rep. 6, 1-10.

Skibins, J.C., Powell, R.B., Hallo, J.C., 2013. Charisma and conservation: charismatic megafauna's influence on safari and zoo tourists' pro-conservation behaviors. Biodivers. Conserv. 22, 959-982.

Small, E., 2011. The new Noah's Ark: beautiful and useful species only. Part 1. Biodiversity conservation issues and priorities. Biodiversity 12, 232-247.

Soga, M., Gaston, K.J., 2016. Extinction of experience: the loss of human-nature interactions. Front. Ecol. Environ. $14,94-101$.

Soulsbury, C.D., White, P.C.L., 2015. Human-wildlife interactions in urban areas: a review of conflicts, benefits and opportunities. Wildl. Res. 42, 541-553.

Southon, G.E., Jorgensen, A., Dunnett, N., Hoyle, H., Evans, K.L., 2018. Perceived species-richness in urban green spaces: Cues, accuracy and well-being impacts. Landsc. Urban Plan. 172, 1-10.

Southon, G.E., Jorgensen, A., Dunnett, N., Hoyle, H., Evans, K.L., 2017. Biodiverse perennial meadows have aesthetic value and increase residents' perceptions of site quality in urban green-space. Landsc. Urban Plan. $158,105-118$

Sturm, R., Gresenz, C.R., 2002. Relations of income inequality and family income to chronic medical conditions and mental health disorders: National survey in USA. Br. Med. J. 324, 20-23.

Sugiyama, T., Leslie, E., Giles-Corti, B., Owen, N., 2008. Associations of neighbourhood greenness with physical and mental health: do walking, social coherence and local social interaction explain the relationships? J. Epidemiol. Community Heal. 62, e9.

Taylor, M.S., Wheeler, B.W., White, M.P., Economou, T., Osborne, N.J., 2015. Research note: urban street tree density and antidepressant prescription rates-A cross-sectional study in London, UK. Landsc. Urban Plan. 136, 174-179.

Theodoropoulou, E., Stavrou, N.A.M., Karteroliotis, K., 2017. Neighborhood environment, physical activity, and quality of life in adults: Intermediary effects of personal and psychosocial factors. J. Sport Heal. Sci. 6, 96-102.

Triguero-Mas, M., Dadvand, P., Cirach, M., Martínez, D., Medina, A., Mompart, A., Basagaña, X., Gražulevičienè, R., Nieuwenhuijsen, M.J., 2015. Natural outdoor environments and mental and physical health: relationships and mechanisms. Environ. Int. 77, 35-41.

Tucker, M., Bond, N.W., 1997. The roles of gender, sex role, and disgust in fear of animals. Pers. Individ. Dif. 22, 135-138.

Tulloch, A.I.T., Possingham, H.P., Joseph, L.N., Szabo, J., Martin, T.G., 2013. Realising the full potential of citizen science monitoring programs. Biol. Conserv. 165, 128-138. 
Ulrich, R.S., 1991. Stress recovery during exposure to natural environments. J. Environ. Psychol. 11, 201-230.

United Nations CBD, 1992. Convention on biological diversity. United Nations.

Vallecillo, S., Maes, J., Polce, C., Lavalle, C., 2016. A habitat quality indicator for common birds in Europe based on species distribution models. Ecol. Indic. 69, 488-499.

Vaz, A.S., Kueffer, C., Kull, C.A., Richardson, D.M., Vicente, J.R., Kühn, I., Schröter, M., Hauck, J., Bonn, A., Honrado, J.P., 2017. Integrating ecosystem services and disservices: insights from plant invasions. Ecosyst. Serv. 23, 94-107.

Veenhoven, R., 2007. Subjective measures of well-being., in: McGillivray, M. (Ed.), Human Well-Being: Concept and Measurement. Palgrave Macmillan UK, London, pp. 214-239.

Velarde, M.D., Fry, G., Tveit, M., 2007. Health effects of viewing landscapes - landscape types in environmental psychology. Urban For. Urban Green. 6, 199-212.

Vihervaara, P., Rönkä, M., Walls, M., 2010. Trends in ecosystem service research: early steps and current drivers. Ambio 39, 314-324.

Virtanen, M., Kivimäki, M., Joensuu, M., Virtanen, P., Elovainio, M., Vahtera, J., 2005. Temporary employment and health: A review. Int. J. Epidemiol. 34, 610-622.

Völker, S., Kistemann, T., 2013. Reprint of: “I’m always entirely happy when I'm here!” Urban blue enhancing human health and well-being in Cologne and Düsseldorf, Germany. Soc. Sci. Med. 91, 141-152.

Völker, S., Kistemann, T., 2011. The impact of blue space on human health and well-being - salutogenetic health effects of inland surface waters: a review. Int. J. Hyg. Environ. Health 214, 449-460.

von Döhren, P., Haase, D., 2015. Ecosystem disservices research: A review of the state of the art with a focus on cities. Ecol. Indic. 52, 490-497.

Ware, J.E., Kosinski, M., Keller, S.D., 1994. SF-36 physical and mental health summary scales: a user's manual. Health Assessment Lab, New England Medical Center, Boston, MA.

Ware, J.E., Sherbourne, C.D., 1992. The MOS 36-item short-form health survey (SF-36): I. conceptual framework and item selection. Med. Care 30, 473-483.

Warne, R.M., Jones, D.N., 2003. Evidence of target specificity in attacks by Australian magpies on humans. Wildl. Res. 30, 265-267.

Washington, H., 2013. Human Dependence on Nature. Routledge, London.

Weber, D., Hintermann, U., Zangger, A., 2004. Scale and trends in species richness: considerations for monitoring biological diversity for political purposes. Glob. Ecol. Biogeogr. 13, 97-104.

Wells, D.L., 2009. The effects of animals on human health and well-being. J. Soc. Issues 65, 523-543.

Western, M., Tomaszewski, W., 2016. Subjective wellbeing, objective wellbeing and inequality in Australia. PLoS One 11, 1-20.

Wheeler, B.W., Lovell, R., Higgins, S.L., White, M.P., Alcock, I., Osborne, N.J., Husk, K., Sabel, C.E., Depledge, M.H., 2015. Beyond greenspace: an ecological study of population general health and indicators of natural environment type and quality. Int. J. Health Geogr. 14, 1-17.

White, M.P., Alcock, I., Wheeler, B.W., Depledge, M.H., 2013. Coastal proximity, health and well-being: Results from a longitudinal panel survey. Heal. Place 23, 97-103.

White, M.P., Pahl, S., Wheeler, B.W., Depledge, M.H., Fleming, L.E., 2017. Natural environments and subjective wellbeing: different types of exposure are associated with different aspects of wellbeing. Health Place 45, $77-84$.

Wolf, L.J., Zu Ermgassen, S., Balmford, A., White, M., Weinstein, N., 2017. Is variety the spice of life? An experimental investigation into the effects of species richness on self-reported mental well-being. PLoS One $12,1-17$.

World Health Organization, 2016. Urban green spaces and health. WHO Regional Office for Europe, Copenhagen.

Wyndham, F.S., Park, K.E., 2018. "Listen carefully to the voices of the birds": a comparative review of birds as signs. J. Ethnobiol. 38, 533. 


\section{References}

Zhang, W., Ricketts, T.H., Kremen, C., Carney, K., Swinton, S.M., 2007. Ecosystem services and dis-services to agriculture. Ecol. Econ. 64, 253-260.

Zvereva, E.L., Toivonen, E., Kozlov, M. V., 2008. Changes in species richness of vascular plants under the impact of air pollution: A global perspective. Glob. Ecol. Biogeogr. 17, 305-319. 


\section{Appendices}

\section{List of Content}

01. Appendix I

01.1 Manuscript

01.2 Supplementary Material

01.3 Author contributions

02. Appendix II

02.1 Manuscript

02.2 Supplementary Material

02.3 Author contributions

03. Appendix III

03.1 Manuscript

03.2 Supplementary Material

03.3 Author contributions 


\section{Appendix I}

\subsection{Manuscript}

Title:

'Positive and Negative Contributions of Wildlife to Human Well-Being'

Status: published in Environmental Research Letters

Citation:

Joel Methorst, Ugo Arbieu, Aletta Bonn, Katrin Böhning-Gaese and Thomas Müller (2020): Non-material contributions of wildlife to human well-being: a systematic review. Environmental Research Letters, Volume 15, 093005. https://oi.org/10.1088/1748-9326/ ab9927 


\title{
Environmental Research Letters
}

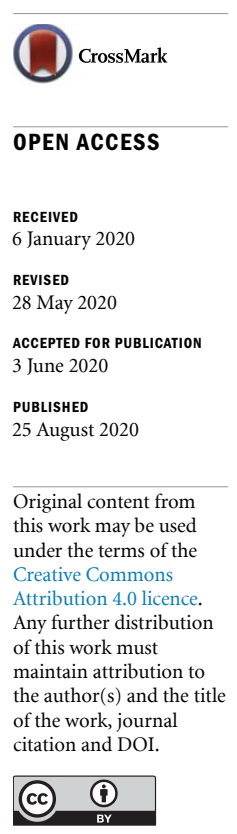

Topical Review

\section{Non-material contributions of wildlife to human well-being: a systematic review}

\author{
Joel Methorst ${ }^{1,2,3,7}$ (D), Ugo Arbieu ${ }^{2,6}$ (D) , Aletta Bonn ${ }^{1,4,5}\left(\mathbb{D}\right.$, Katrin Böhning-Gaese ${ }^{1,2,3}$ (D) \\ and Thomas Müller ${ }^{2,3}$ (D) \\ ${ }^{1}$ German Centre for Integrative Biodiversity Research (iDiv), Halle-Jena-Leipzig, Deutscher Platz 5e, 04103 Leipzig, Germany \\ 2 Senckenberg Biodiversity and Climate Research Centre (SBiK-F), Georg-Voigt-Straße 14, 60325 Frankfurt am Main, Germany \\ ${ }^{3}$ Department of Biological Sciences, Goethe University Frankfurt am Main, Max-von-Laue-Str. 13, 60438 Frankfurt am Main, Germany \\ ${ }^{4}$ Helmholtz Center for Environmental Research - UFZ, Department of Ecosystem Services, Permoserstraße 15, 04318, Leipzig, Germany \\ 5 Institute of Biodiversity, Friedrich Schiller University Jena, Dornburger Straße 159, 07743 Jena, Germany \\ ${ }^{6}$ Smithsonian Conservation Biology Institute, National Zoological Park, 1500 Remount Road, Front Royal, VA 22630, United States of \\ America \\ 7 Author to whom any correspondence should be addressed. \\ E-mail: joel.methorst@senckenberg.de \\ Keywords: nature's contributions to people, ecosystem services, ecosystem disservices, human-wildlife coexistence, human-wildlife \\ conflicts \\ Supplementary material for this article is available online
}

\begin{abstract}
Wildlife has important effects on human well-being, ranging from beneficial contributions to life threatening interactions. Here, we systematically reviewed publications of both positive and negative non-material contributions of wildlife to people (WCP) for different taxonomic groups (birds, mammals, reptiles and amphibians) and dimensions of human well-being such as health, social well-being, identity and spirituality. Overall, the majority of studies reported negative WCP, such as feelings of insecurity or injuries. However, over the last decade the number of publications on positive WCP such as good mental health, positive emotions or learning increased, mainly in the Global North. These spatial and temporal patterns may hint towards normative influences that drive the relative proportion of reported WCP. However, these normative influences are not yet well understood and future research should examine potential biases by conducting policy assessments or surveys among researchers to understand drivers and motivations behind their research questions. We found almost no joint assessments of positive and negative WCP for any wildlife species. Studies also showed taxon-specific differences in WCP outcomes, with predominantly positive WCP reported for birds and predominantly negative WCP published for mammals or reptiles. Physical health was the most dominant aspect of well-being studied and affected by WCP while other well-being dimensions such as social well-being, learning or identity were less frequently covered in the literature. Future studies should jointly evaluate positive and negative effects of wildlife on human well-being and implement multi-taxon approaches to obtain a more balanced and comprehensive understanding of WCP. These assessments of WCP will provide actionable science outcomes that will shape human-wildlife coexistence and promote human health and well-being.
\end{abstract}

\section{Introduction}

Wildlife is important for human well-being (Díaz et al 2006, Mace et al 2012) and plays a major role in many people's lives (Mackerron and Mourato 2013, Cox and Gaston 2016, Chang et al 2017). Wildlife's influence on human well-being can be described through 'Nature's Contributions to People (NCP)', which are categorized as non-material, material and regulating NCP (Díaz et al 2018). All three types of NCP affect multiple aspects of human well-being such as access to food, water, shelter, health, education, social relationships, security or freedom of choice (Díaz et al 2015, 2018). Several studies have 
summarized the material and regulating NCP of wildlife to human well-being (Inskip and Zimmermann 2009, Alves 2012, Harrison et al 2014, Sandifer et al 2015, Marchini and Crawshaw 2015). This review focuses on non-material NCP of wildlife, with a focus on vertebrate species in terrestrial and aquatic environments (i.e. mammals, birds, reptiles and amphibians).

Non-material NCP cover the non-material dimensions of people's quality of life and affect, among others, subjective physical or psychological experiences, learning and inspiration or people's identities (Díaz et al 2018). They directly relate to cultural ecosystem services as defined in the ecosystem service framework (e.g. Milcu et al 2013, Haines-Young and Potschin 2018). In this study, we therefore refer to both cultural ecosystem services and non-material NCP of wildlife and also include studies published under the umbrella of cultural ecosystem services or outside of both frameworks. In the following, we use the term 'Wildlife's Contributions to People (WCP)' throughout the remainder of the manuscript. Examples for WCP are experiences of wildlife which can, among other things, improve health, foster spiritual and inspirational experiences or support social relationships (Ramstad et al 2007, Dallimer et al 2012, Bryce et al 2016, Penteriani et al 2016, Forrester et al 2018).

While both the ecosystem service literature and the NCP framework have acknowledged the existence of positive and negative impacts of nature on human well-being (Pascual et al 2017, Díaz et al 2018), past research within these frameworks has mostly emphasized on positive effects (Shackleton et al 2016, Vaz et al 2017). For wildlife, however, many studies do not refer to the NCP or ecosystem service frameworks and reports of negative effects are actually frequent. As an example, studies on human-wildlife coexistence usually report negative outcomes where people come to harm economically, physically or mentally (e.g. Inskip and Zimmermann 2009, Barua et al 2013, Marchini and Crawshaw 2015). Studies that report positive effects of wildlife show that, for instance, experiencing wildlife can improve psychological and mental health, and has a recreational value (Farber and Hall 2007, Dallimer et al 2012, Arbieu et al 2017, Cox et al 2017b). Most importantly, with regard to non-material NCP, only few reviews have examined both, the positive and negative WCP in combination, and those that exist usually cover only few aspects of WCP (Harrison et al 2014, Pascual-Rico et al 2020) or just focus on a specific group of wildlife species such as scavengers or carnivores (Moleón et al 2014, Expósito-Granados et al 2019, Lozano et al 2019).

Several conceptual frameworks exist that describe the mechanisms or channels of how nature and ecosystems can influence human well-being (e.g. Russell et al 2013, Markevych et al 2017). These concepts can also be used to disentangle the different types of wildlife experiences which lead to the positive and negative WCP that influence human wellbeing. Here we adopted the framework of (Russell et al 2013), which is particularly suited to characterize non-material linkages between humans and nature, and adapted the four proposed channels Interaction, Living Within, Perceiving and Knowing to describe how people experience wildlife (box 1).

Box 1. Channels describing the non-material linkages between humans and wildlife (Wildlife's Contributions to People, WCP) that contribute to human well-being. We adopted the framework from (Russel et al 2013) and adjusted the definitions in order to describe how people specifically experience wildlife: Interaction describes multisensory experiences where people physically interact with wildlife. Examples are catching fish, hunting or feeding wild animals. Living Within defines the everyday, conscious or subconscious, voluntary and involuntary contact with wildlife in areas in which a person lives. This entails living in a forested area, close to the seashore and near urban parks and sharing these same habitats with wild animals. Perceiving is the remote sensory interaction with wildlife, often associated with a single sensory ability such as the visual processing of information (e.g. watching birds or watching a nature documentary). However, it could also include a person's ability to hear, feel and smell things that are associated with wildlife (e.g. listening to bird sounds). Knowing describes the cognitive/metaphysical connection between humans and wildlife that arises through thinking, contemplating or remembering experiences from wildlife encounters.

Overall, this review synthesizes how the positive and negative WCP emerge through the different channels by which people experience wildlife and how they have been studied in the scientific literature (figure 1). Specifically, we were interested in (a) the spatio-temporal pattern of different types of reported human-wildlife experiences and WCP, (b) the distribution of positive and negative WCP reported for vertebrate species in terrestrial and aquatic environments (i.e. mammals, birds, reptiles and amphibians), (c) differences in the number of studied WCP effects with regards to human well-being dimensions and (d) highlighting the dominant channels that shape human-wildlife experiences and their effect on human well-being as well as how well studied they are in the scientific literature.

For this purpose, we examined different wildlife taxa and multiple human well-being dimensions. Recent WCP overviews focused on particular aspects 

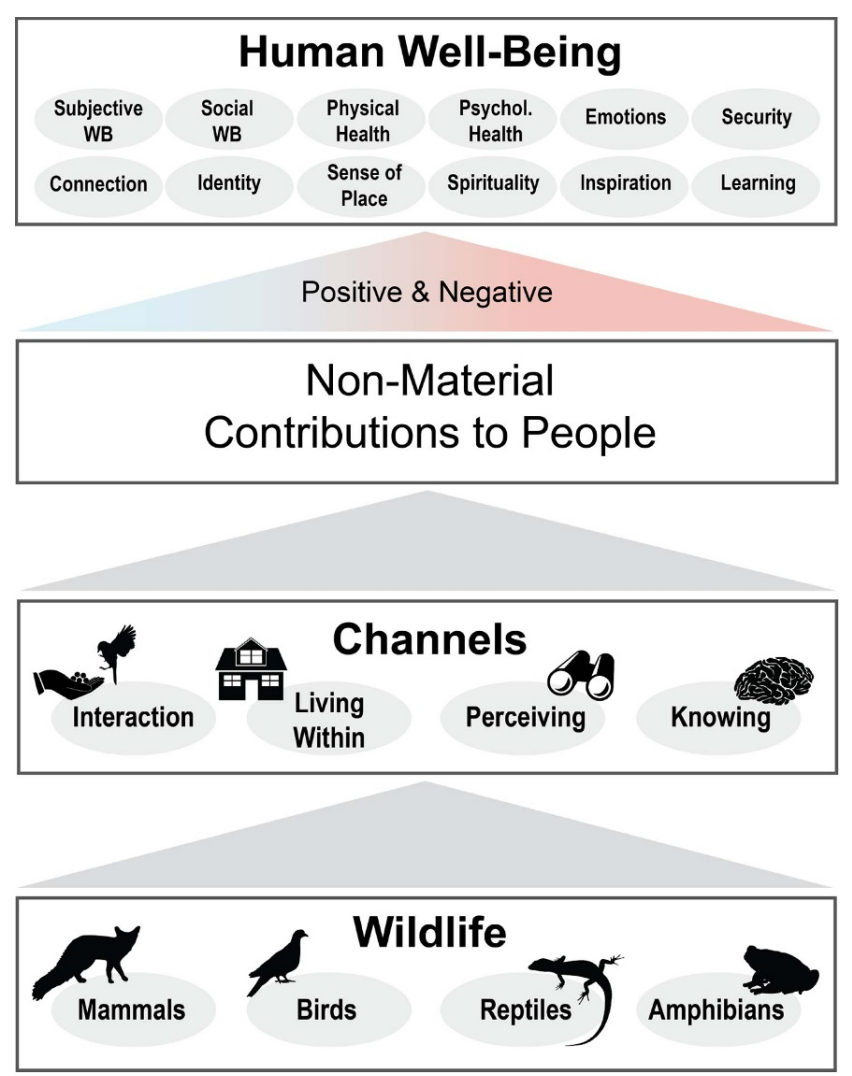

Figure 1. Wildlife's contributions to people (WCP). Conceptual graph linking wildlife to non-material NCP and different human well-being dimensions via the four channels: Interaction, Living Within, Perceiving and Knowing.

of human well-being such as recreation, health, psychological well-being or religion (e.g. Alves 2012, Barua et al 2013, Harrison et al 2014, Lovell et al 2014, Marselle et al 2019). Here, we built on these efforts and broadened the set of human well-being dimensions (e.g. Russell et al 2013) including aspects such as emotions, learning experience and social well-being to develop our synthesis (see table 2). In addition, we assigned studies to world regions depending on which local areas, regions or countries were studied.

\section{Review methods}

We conducted a systematic literature search using Web of Science (21.11.17-25.03.2020) and following the PRISMA guidelines (Moher et al 2009). To select relevant scientific articles, we used specific search strings by combining search terms covering wildlife, the human well-being dimensions of interest and different types of wildlife experiences (table 1). Each search string consisted of a wildlife search term and either a keyword for a human wellbeing dimension or a channel combined by using 'AND'. For instance, we used search queries such as 'mammals AND inspiration', 'reptiles AND human health' or 'birds AND mental health' (for a full list of search strings see supplementary material I, table A1 (available online at stacks.iop.org/ERL/15/093005/ mmedia)).

Our initial search query produced a total of more than 20000 search hits of research articles. We then screened through the search hits looking at titles and abstracts in detail. This screening process was based on the following criteria: (1) articles were published in a peer-reviewed journal before 2020 (reviews in peerreviewed journals were allowed, book chapters and other forms of publication were excluded); (2) articles were published in relevant scientific disciplines such as ecology, wildlife management, environmental psychology, medicine or ethnobiology; and (3) articles contained information on whether or not wildlife (e.g. individual animals, species richness) and human well-being played a major role in the study. During the screening process we only selected relevant articles for the review and, after additionally removing duplicate studies, obtained a list of 513 research articles for a detailed full text assessment (supplementary material I, figure A1).

During the full text assessment, we selected articles that met the following conditions: (a) studies examined human adults, (b) studies examined wildlife species and human well-being dimensions according to our definition (see next section), (c) 
Table 1. Search terms used for the literature review in web of science. The asterisk symbol $\left({ }^{*}\right)$ enables wildcards in the Web of Science searches and represents a character, group of characters, or no character.

\begin{tabular}{|c|c|}
\hline Wildlife & Search term \\
\hline Wildlife & 'wildlife' \\
\hline Birds & 'birds', 'bird*' \\
\hline Mammals & 'mammals', 'mammal', 'carnivore' \\
\hline Reptiles & 'reptiles', 'reptile*', 'alligator', 'snake' \\
\hline Amphibians & 'amphibians', 'amphibian*' \\
\hline \multicolumn{2}{|l|}{ Human well-being } \\
\hline Subjective well-being & 'subjective well-being,' 'well-being', 'life-satisfaction', 'happiness' \\
\hline Social well-being & 'social relationships' \\
\hline Physical health & 'human health', 'human injury', 'human physiological health', 'attack', 'bite injury', \\
\hline Psychological health & 'mental health', 'psychological well-being', 'phobia' \\
\hline Emotions & 'human emotions' \\
\hline Security & 'security' \\
\hline Connection to wildlife & 'connection to nature' \\
\hline Personal identity & 'identity’ \\
\hline Sense of place & 'sense of place' \\
\hline Spirituality & 'spirituality' \\
\hline Inspiration & 'inspiration', 'folklore', 'tales', 'cultur* significance' \\
\hline Learning & 'human learning experience' \\
\hline \multicolumn{2}{|l|}{ Channels } \\
\hline Interaction & 'human interaction', 'hunting', 'feeding', 'conflict', 'diving' \\
\hline Living Within & 'human coexistence' \\
\hline Perceiving & 'sound', 'bird watching' \\
\hline Knowing & 'knowing AND education', 'thinking', 'memory AND thinking' \\
\hline
\end{tabular}

Table 2. Categorization of human well-being dimensions and human emotions used in this study (e.g. Russell et al 2013).

\begin{tabular}{|c|c|}
\hline Human well-being dimension & Description \\
\hline Subjective well-being & $\begin{array}{l}\text { life satisfaction, composite measures of well-being } \\
\text { (specific indicators used in psychology or other dis- } \\
\text { ciplines), multiple aspects of well-being (e.g. personal } \\
\text { growth) }\end{array}$ \\
\hline Social well-being & $\begin{array}{l}\text { relationship with family and friends, contact with other } \\
\text { people }\end{array}$ \\
\hline Physical health & subjective health, injuries and deaths \\
\hline Psychological well-being & $\begin{array}{l}\text { mental and psychological well-being indicators, e.g. } \\
\text { stress, depression, phobia }\end{array}$ \\
\hline Emotions & $\begin{array}{l}6 \text { basic emotions: interest (e.g. awe), joy, sadness, dis- } \\
\text { gust, anger and fear }\end{array}$ \\
\hline Security & $\begin{array}{l}\text { social and personal insecurity, fear of safety, worry, } \\
\text { concern, sense of freedom, less control, perception of } \\
\text { risk }\end{array}$ \\
\hline Connection to wildlife & $\begin{array}{l}\text { connection to nature fostered by wildlife experience, } \\
\text { or actual measures of connection to wildlife or animals } \\
\text { (e.g. scale of connectedness to nature) }\end{array}$ \\
\hline Identity & $\begin{array}{l}\text { kinship between human and animals or wildlife, sense } \\
\text { of self, indentity measures }\end{array}$ \\
\hline Sense of place & $\begin{array}{l}\text { special value of certain places, people's attachment or } \\
\text { identification with places, dependence on places, place } \\
\text { identity }\end{array}$ \\
\hline Spirituality & $\begin{array}{l}\text { spiritual meaning of animals, beliefs (signs of bad luck } \\
\text { etc), magic and taboos }\end{array}$ \\
\hline Inspiration & $\begin{array}{l}\text { literature (stories and folklore), language (metaphors, } \\
\text { proverbs etc), music and art }\end{array}$ \\
\hline Learning & Learning experiences, opportunity for education \\
\hline
\end{tabular}

studies clearly reported or observed an 'effect' of wildlife on a human well-being dimension (see section below on human well-being and on data collection, further details are provided in supplementary material I, table A2). These effects could either be based on reported significant statistical relationships, based on quantitative records such as descriptive statistics (e.g. number of attacks and injuries) 
or it could be based on specific statements, observations and qualitative assessments derived from interviews, surveys, field work or literature analysis (e.g. reported personal statement about faith beliefs). Finally, we did not include research with a focus on medical practices or surgical techniques and also excluded vector-borne diseases, because we consider the effects of such diseases on human health to be caused by pathogens and microbes (e.g. bacteria or viruses) and not the vectors (e.g. wildlife and other animals). However, we did include medical studies if they specifically referred to incidents between wildlife and humans, for example epidemiological studies. We also considered articles where the effect of wildlife on human well-being had been examined through questionnaires, the use of media, such as pictures and movies, or where wildlife sounds were displayed through audio files. Reviews were also considered when they summarized non-peer reviewed literature (e.g. poems, books, ethnological studies).

In order to identify relevant studies that where potentially missed by our systematic search and screening process, we also adopted a snowballapproach and additionally looked for literature referenced in the reviewed papers (e.g. Hansen and Pauleit 2014). These articles were added to the full text assessment right away. In the end, the full text assessment yielded 277 articles that were included in this review.

\subsection{Definition of wildlife}

In this study we refer to wildlife as wild, non-domestic living animal species in their terrestrial and aquatic environment that belong to the following vertebrate species group: mammals (including terrestrial, aquatic and marine), birds, reptiles and amphibians (Fryxell et al 2014). We excluded animals in captivity (e.g. zoo and farm animals) and pets, because they have been extensively reviewed elsewhere (Wells 2009, Herzog 2011) and are not covered by our definition of wildlife. As there has been an increase in studies showing how species richness or abundance of birds positively effect human mental health and well-being (Dallimer et al 2012, Cox et al 2017b), we included studies that used a variety of measures for wildlife. We considered articles that used biodiversity indicators (e.g. species richness, diversity, total abundance), perceived species richness, single species and animals, several species or broadly defined species groups (e.g. carnivores, songbirds).

\subsection{Human well-being dimensions}

We focused on multiple aspects of human well-being and their dimensions which can be affected by WCP. We chose to focus on 10 constituents of human well-being (e.g. subjective well-being, physical and psychological health or connection to nature) used in a previous study (Russell et al 2013). We further included social well-being (social relationships), because the Millennium Ecosystem Assessment (MA 2005) recognizes social relationships as an important component of human well-being.

There is increasing recognition that emotions may influence or determine other human well-being dimensions such as subjective well-being or physical health (e.g. Diener and Suh 1997, Kemeny and Shestyuk 2008). Emotions are also acknowledged as potential drivers of human well-being constituents in Russel et al's framework (2013) and the Millennium Ecosystem Assessment (MA 2005) (e.g. fear is affecting 'sense of control' and emotional states can affect 'health' in each framework, respectively), but have not been considered as a separate dimension of human well-being. However, we believe that emotions should be considered as a separate aspect of human wellbeing in this review, since the human well-being dimensions described in (Russell et al 2013) and the Millennium Ecosystem Assessment (MA 2005) might rather describe the results of cognitive processes (e.g. thinking, contemplation) than the affective reactions (e.g. instinctive emotional reaction before a cognitive process) and emotional dispositions towards life events and circumstances (e.g. Gläser-Zikuda 2012).

We therefore included human emotions as a separate dimension of human well-being to provide a more complete perspective on human emotional responses and dispositions in the context of humanwildlife relationships (e.g. Jacobs 2012, Jacobs and Vaske 2019). Specifically, we look at the 6 basic emotions described by Izard (2007) because this set of emotions captures the variety of emotional dispositions and states toward wildlife: interest (e.g. awe), joy, sadness, disgust, anger and fear. As emotions have been increasingly studied over the past years (Jacobs and Vaske 2019), we consider the addition of emotions as an opportunity to reflect the current trend in human-wildlife research.

These final 12 well-being dimensions all cover positive and negative effects of wildlife on human well-being. We identified these positive and negative WCP according to a predefined identification strategy (see supplementary material I, table A2). According to these criteria, positive WCP outcomes include better mental health, positive emotions (e.g. joy, happiness, positive affect) or better social relationships (e.g. Curtin 2009, Lee and Davey 2015, Cox et al 2017b). Negative effects include detrimental experiences with wildlife where humans, for instance, come to harm (e.g. Gunther et al 2004, Debata et al 2016, Penteriani et al 2016) or cases where people suffer from feelings of insecurity because of wildlife living in the same area (Jadhav and Barua 2012, Mayberry et al 2017). Learning, connection to wildlife or inspiration triggered by wildlife experiences were generally defined as positive WCP.

Here, it should also be noted that positive and negative WCP might also influence those 
dimensions of human well-being that relate to material contributions of wildlife (Díaz et al 2018). For instance, hunting wildlife may provide food for people, but also recreational benefits.

\subsection{Channels}

Because most studies describe multiple ways how WCP are experienced, we chose the framework of (Russell et al 2013) to categorize people's experience with wildlife according to four different channels: Interaction, Living Within, Perceiving and Knowing (box 1). These channels are well-suited for understanding WCP because they are able to describe the non-material links between humans and wildlife (figure 1). We note that in our review, Knowing does not only describe how people think about and remember their own personal wildlife experiences, but also their knowledge about wildlife, as well as expressed statements or opinions that reflect people's emotions towards wildlife (e.g. if someone had no prior experience with wildlife but still feels positive attachment, insecurity or fear). We also assumed that wildlifeinduced inspiration or spirituality is based on and influenced by Knowing. In addition, it should be mentioned that single studies could also cover multiple channels as, for instance, Living Within and Interaction or Living Within and Knowing were often connected.

\subsection{Data collection process}

For each selected article we recorded information on title, authors, publishing year and study origin (e.g. country and continent). If a study covered multiple continents, we categorized them as 'multiple continents' and global studies were categorized as 'global'. Each studied wildlife taxa (mammals, birds, reptiles or amphibians) was also recorded as well as the wildlife measure (e.g. single species, species groups or species richness indicator, supplementary material I, table A3). In addition, we coded studies according to whether or not they examined either positive or negative WCP or both (see supplementary material I, table A2), which human well-being dimension they studied and what channel (type of wildlife experiences) was involved in linking wildlife to human wellbeing.

When a study reported a clear connection or relationship between wildlife and a human well-being dimension this was counted as one 'effect'. Some studies examined several human well-being dimensions in relation to different wildlife taxa. Similarly, several channels could be involved in how wildlife affected the same human well-being dimension. A single study in the review could thus report several effects per wildlife taxon for different human wellbeing dimensions and for different channels. As mentioned earlier, reported 'effects' could be based on both quantitative and qualitative methodology, i.e. they were not only based on statistically significant relationships.

All data processing was conducted in R ( $\mathrm{R}$ Development Core Team 2020). We calculated descriptive statistic for the number of studies examining positive and negative WCP (or both) and also counted the identified effects on human well-being. We estimated the total number of positive or negative effects for each human well-being dimension per wildlife taxon and per channel. We additionally created network plots to visualize the links (e.g. number of effects) between wildlife and human well-being via the four channels of wildlife experience (Interaction, Living Within, Perceiving and Knowing). To produce the network plots (figure 3) we created a data sheet with the sum of all effects (positive and negative) for each possible combination between wildlife taxon, human well-being dimension and channel. The final figure was created with the $\mathrm{R}$ package 'bipartite' and the function 'plotweb' (Dormann et al 2020).

\section{Results and discussion}

The 277 studies included in our review were published between 1940 and 2019 (figure 2(a)). The number of studies reporting only negative WCP $(n=203)$ affecting human well-being was 3.8 times higher than the number of studies reporting positive WCP $(\mathrm{n}=53$; figure 2(a)). 21 studies reported both types of outcomes. Likewise, the total number of positive effects per human well-being dimension identified within studies $(33.3 \%, \mathrm{n}=120$ out of 360 ) was also smaller than the number of negative effects $(66.6 \%$, $\mathrm{n}=240$ ). Mammals comprised the taxonomic group where WCP were most often studied in the reviewed literature $(n=127)$, followed by reptiles $(n=119)$ and birds $(n=68)$. Compared to the other wildlife groups, amphibians were rarely studied $(n=7)$ (figure 2(b)).

\subsection{Taxon-dependency of positive and negative WCP}

We found differences among taxonomic groups with regard to the frequency of identified positive and negative WCP and their effects on the different human well-being dimensions. In all groups except birds (i.e. mammals, reptiles and amphibians) the number of studies reporting negative WCP outnumbered positive ones (figure 2(b)). Among the studies on birds, $64.1 \%(n=50$ out of 78 ) reported positive WCP. In comparison, positive WCP were reported in much fewer studies for mammals $(24.5 \%, n=34$ out of $139)$, amphibians ( $14.3 \%, \mathrm{n}=1$ out of 7$)$ and reptiles $(8.8 \%, \mathrm{n}=11$ out of 125$)$ (figure 2(b)).

The positive WCP of birds are most likely due to the fact that birds are usually not harmful to humans. Birds can also be visually and acoustically attractive to humans because of their physical appearance (e.g. colourfulness, behaviour) and their songs (Belaire 


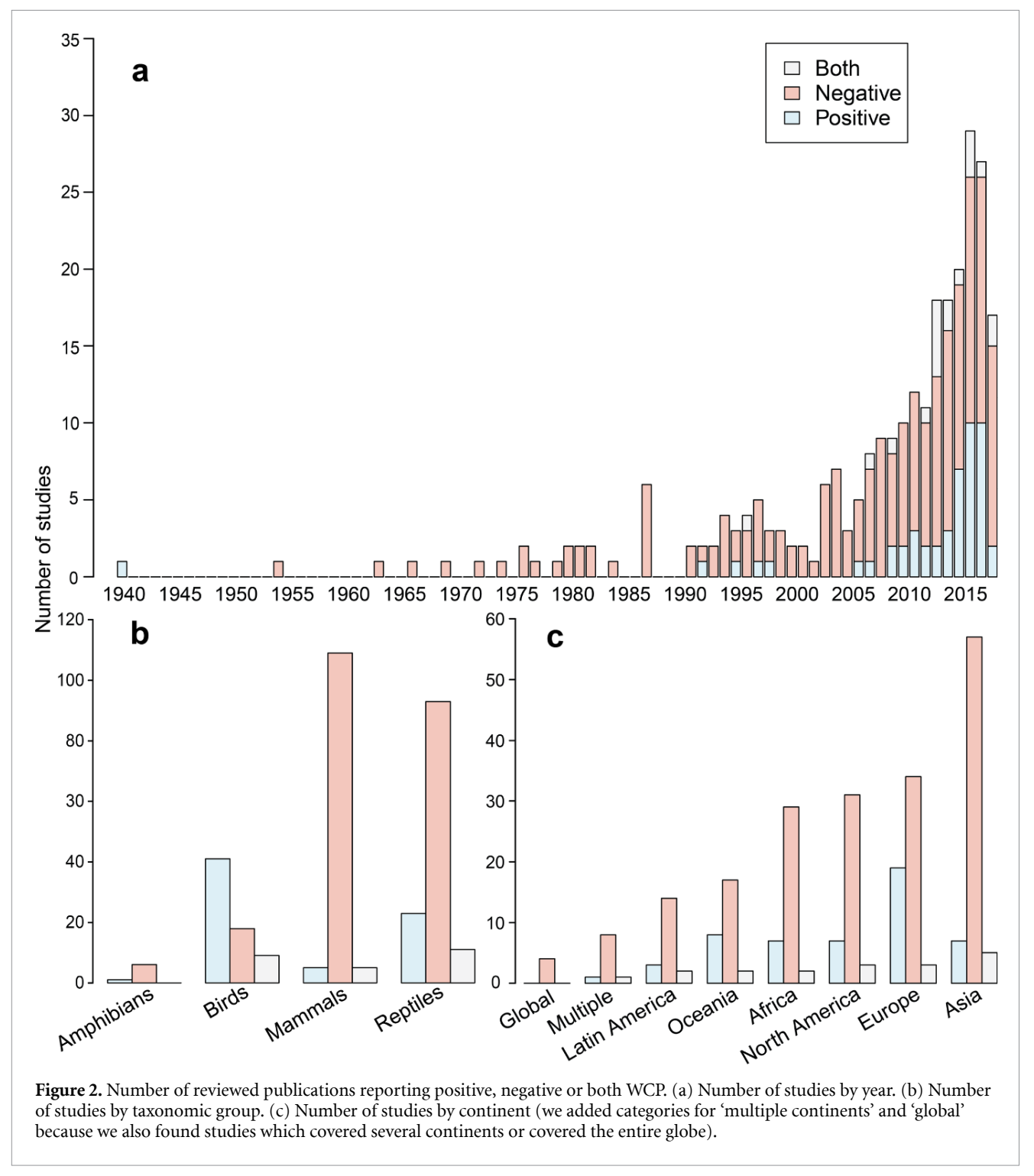

et al 2015, Hedblom et al 2017). Since they are mostly active during daytime and thus easier to observe compared to mammals, birds are more likely to positively affect human lives and their well-being (Cox et al 2017b). In fact, many positive WCP of birds are reported in psychological studies (see supplementary material I, figure A3) (e.g. Fuller et al 2007, Dallimer et al 2012). Birds and other taxon groups also appear in cultural and ethnographic publications where they are described as sources of inspiration for myths and legends or play an important role in religious beliefs (e.g. Berndt 1940, Altaf et al 2017). For example, in Aboriginal myths from the Lower Murray (Australia) birds have prominent roles as clan ancestors and are credited with powers to transform land and to establish customs and laws (Clarke 2016).
In other cases, amphibians and reptiles were involved with inspirational or spiritual aspects of human well-being, because they were part of folklore, traditional beliefs or positive superstitions (e.g. Alves 2012). For instance, the Nage people in Indonesia believe that the call of the tiny house-lizard guarantees success for decisions made or confirms the truth of an expressed statement (Forth 2013). Well-being benefits obtained from other taxonomic groups (e.g. mammals and reptiles) were also most often reported in reference to inspiration, spirituality or connection to wildlife. In some cases, for instance, when tourists watched specific wildlife species, mammals (e.g. whales, wolf) also triggered positive emotions such as surprise and joy (e.g. Farber and Hall 2007, Curtin 2009). 
We found, in regard to the overall number of studies reporting negative WCP, that the majority of studies examined reptiles $(45.1 \%, \mathrm{n}=114)$ and mammals $(41.5 \%, \mathrm{n}=105)$. These numbers are not surprising, considering that many potentially harmful carnivores or other large mammals (e.g. elephants) that pose problems for human-wildlife coexistence as well as poisonous species are found within these two taxonomic groups. Consequently, most of the negative effects on human well-being dimensions identified for these species groups were either injuries (e.g. Gunther et al 2004, Behdarvand and Kaboli 2015) or bites and poisoning (e.g. Pugh et al 1979, Sarkhel et al 2017). A few studies reported attacks on humans by birds (Warne and Jones 2003, Lees et al 2013) and we also found studies where birds and amphibians were the main target of superstitions and negative folklore (Ceríaco 2011, Hull and Fergus 2017).

\subsection{Geographical patterns of WCP}

We identified studies from 74 different countries (excluding studies of entire continents and reviews) with research on WCP. Most of the studies (excluding reviews, global studies and studies on multiple continents, $\mathrm{n}=27$ ) originated from the Global North $(49.6 \%, n=124$ out of 250$)$, i.e. from Europe, North America, and Oceania (Australia and New Zealand) (figure 2(c)). However, we also found a substantial number of studies conducted in Asian (27.6\%, $\mathrm{n}=69)$ and African countries $(15.2 \%, \mathrm{n}=38)$.

Our results may indicate different research interests across global regions and a focus on positive effects, maybe even a reporting bias, in the Global North. For instance, the proportion of studies publishing positive WCP in comparison to negative WCP was relatively high in Europe with $37.3 \%$ ( $\mathrm{n}=22$ out of 59), in Oceania (Australia and New Zealand) with $36.7 \%(\mathrm{n}=11$ out of 30$)$, while less so in North America with $22.2 \%(\mathrm{n}=10$ out of 45$)$. In comparison, there were fewer studies on positive WCP in regions of the Global South, including Asia $(16.2 \%, \mathrm{n}=12$ out of 74), Latin America (23.8\%, $\mathrm{n}=5$ out of 21 ) and Africa $(22.0 \%, \mathrm{n}=9$ out of 40$)$. This geographic pattern corresponds to findings from another literature review that identified similar publication biases in ES research and linked them to the influence of large funding agencies such as the European Commission or US government organizations (Mcdonough et al 2017). Overall, negative WCP dominated the global literature which was particularly the case in the Global South.

One explanation for the larger number of studies reporting negative WCP in the Global South could be that in some of these regions, especially in rural areas, people still live in direct vicinity of mammals and reptiles that can cause real danger (e.g. poisonous snakes, large carnivores), while in the Global North people usually are more removed from direct contact with wildlife in their daily lives (Cox et al 2017a). The reporting bias of more positive WCP reported in the Global North might be related to the recent increase in awareness of positive contributions of nature (MA 2005, Díaz et al 2018). This increased research interest may be linked to an observed disconnection of people to nature in the Global North (Soga and Gaston 2016, Cox et al 2017a). Future research should examine how the prevalence of harmful wildlife and the disconnection of people to nature shape both negative and positive WCP.

\subsection{Temporal patterns of WCP}

Over the past decades, we saw an increase in the number of studies addressing issues of wildlife and human well-being. Interestingly, before the 21 st century almost all studies were concerned with negative WCP. One notable exception was an ethnographic paper on bird legends from the Narunga Tribe in South Australia published in 1940 (Berndt 1940) (figure 2 (a)). Before the year $2000,86.5 \%$ of the studies published negative WCP, $9.6 \%$ positive WCP and $1.9 \%$ both outcomes $(n=52)$. From 2000 , the number of publications increased steeply, including higher numbers of published positive WCP (figure 2(a)). The percentage of studies (published between 2001 and 2019) reporting positive WCP increased to $21.3 \%$ $(\mathrm{n}=48$ out of 225$)$ and $8.9 \%$ reported both positive and negative WCP.

This shift in the focus of wildlife-human wellbeing studies may be related to a general change in the perspective on nature at the turn of the century (e.g. Mace 2014). Several publications addressed the importance of nature for human well-being and had a strong impact on both policy and society. For instance, the Millennium Ecosystem Assessment published in 2005 (MA 2005) did not only emphasize the importance of nature and biodiversity for human well-being but also re-established the formerly introduced concept of ecosystem services (Ehrlich and Mooney 1983, Daily 1997) and made this knowledge available to a wider public. Around the same time, researchers started focusing more on the benefits humans can obtain from nature and the multilayered relationship between people and the environment (Mace 2014, Balvanera et al 2017), leading also to the establishment of the Intergovernmental Science-Policy Platform on Biodiversity and Ecosystem Services (IPBES) in 2012. Funding programs were started that supported research on the relationship between ecosystems and human society (e.g. Carpenter et al 2012) and fostered increasing research emphasis on topics such as ecosystem services (Mcdonough et al 2017), indicating that science policies and funding might have had a tacit effect on ecosystem services research (Vihervaara $e t$ al 2010). Besides the ecosystem services framework, the more recently introduced Nature's Contributions to People (NCP) concept (Díaz et al 2018) also strongly incorporated the idea that humans benefit 
from nature and that nature and people are intensely interlinked. Through these concepts, the role of species, and thus also wildlife, has been brought to the forefront as is also evident in the increase of research on biodiversity's and wildlife's effects on human well-being (figure 2(a)).

\subsection{Patterns related to human well-being dimensions}

We were able to identify all human well-being categories in relation to WCP (figures 3(a), (b)). Researchers often examined only a single human well-being dimension, while some also analysed multiple aspects of well-being in a single study. Overall, we found that some human well-being dimensions were more frequently studied than others. Physical health was the well-being dimensions that was most often studied within the reviewed literature (45.4\%, $\mathrm{n}=154$ out of 277 studies), followed by emotions $(11.5 \%, \mathrm{n}=39)$, spirituality $(11.2 \%, \mathrm{n}=38)$, inspiration $(10.0 \%, \mathrm{n}=34)$, security $(6.5 \%, \mathrm{n}=22)$ and psychological well-being $(5.9 \%, \mathrm{n}=20)$. Those human well-being dimensions which appeared less frequently in the literature were subjective well-being, social well-being, sense of place, connection to wildlife, learning and personal identity (all $<3 \%$, figures 3(a), (b)).

Most of the studies examining physical health reported negative effects $(98.1 \%, \mathrm{n}=152$ out of 155$)$ such as injuries caused by wildlife. Only three studies $(1.9 \%)$ reported positive physical health outcomes after experiencing wildlife (figure 3(a)). One study found a positive relationship between bird species richness, a proxy indicator for environmental quality, and good human health (Wheeler et al 2015), the second examined the longevity of people in areas where Cuckoos co-occur (Møller et al 2017) and the third mentioned the health benefits of hunting (Delisle et al 2018). Similarly, negative effects of wildlife on security $(96.2 \%, n=25$ out of 26$)$, emotions $(63.3 \%, \mathrm{n}=31$ out of 49$)$ or spirituality $(55.0 \%$, $\mathrm{n}=28$ out of 51) prevailed, for example feelings of insecurity, fear or negative beliefs (e.g. superstitions, dark omens). The number of positive and negative effects of wildlife affecting psychological well-being were mostly equal in number $(50.0 \%, \mathrm{n}=11$ out of $22)$; study results for inspiration, learning and connection to wildlife were all considered positive WCP.

Our results indicate that well-being dimensions such as sense of place, learning, personal identity, subjective well-being and social well-being were less often studied compared to others (e.g. human physical health or emotions). One possible reason for the low publication numbers might be that these topics have only recently emerged as research topics in the context of wildlife and human well-being (Hausmann et al 2016, Chan et al 2018). In fact, none of the articles addressing these human well-being dimensions were published before the year 2000. Even the dimensions for connection or psychological well-being were only found after the year 2000 (e.g. Sandifer et al 2015). The use of vague terminology might additionally explain why certain well-being dimensions were underrepresented. For instance, there are multiple uses and definitions for the term 'identity', covering personal identity, cultural identity or place identity (O’Brien 2006, Tengberg et al 2012, Rall et al 2017). Finally, researchers with interest in these topics may have mainly studied nature in the broader sense (e.g. vegetation cover or urban green spaces) rather than wildlife, for instance, because ecological and spatial data are more readily available.

The high proportion of physical health-related studies and results may be explained by the large number of research from the medical sciences, where attention may have focused on wildlife issues more than in other scientific disciplines (e.g. psychology), and by the generally higher publication numbers in the medical field compared to other disciplines. We also noticed that much research and knowledge about the culturally influenced WCP, i.e. inspirational and spiritual value, were often not published in peerreviewed journals or in other languages than English and, as a consequence, are often lost to the broader scientific community (e.g. Alves 2012, Arroyo-Quiroz et al 2017). In addition, we want to emphasize that non-material WCP that are not directly health-related are almost always subject to the cultural background of people and that this cultural dependency of the role of wildlife for human societies is currently not well understood and deserves more attention in future research.

\subsection{Channels}

We found examples for all four types of wildlife experiences (Interaction, Living Within, Perceiving and Knowing), albeit at varying frequencies. For instance, $53.2 \%$ of the studies ( $n=167$ out of 277$)$ investigated the channel Interaction, but only $8.9 \%$ of the reviewed studies investigated the channel Perceiving $(\mathrm{n}=28$ out of 277).

We found that people interact with wildlife in multiple ways during their daily lives, outdoor activities or as tourists. Only a few studies reported positive WCP of human-wildlife interactions on different human well-being dimensions and consequently, identified effects were low $(11.4 \%, \mathrm{n}=21$ out of 184$)$ (figure 3). For instance, people experienced positive emotions when feeding birds (Galbraith et al 2014, Cox and Gaston 2016) or obtained new knowledge and insights about wildlife through learning experiences (e.g. Haywood et al 2016, Hanisch et al 2019). Interactions with wildlife also fostered social relationships, for instance when human-macaque interactions nurtured family and social ties of park visitors (Lee and Davey 2015), and people's connection to wildlife (Cox and Gaston 2016). However, studies 


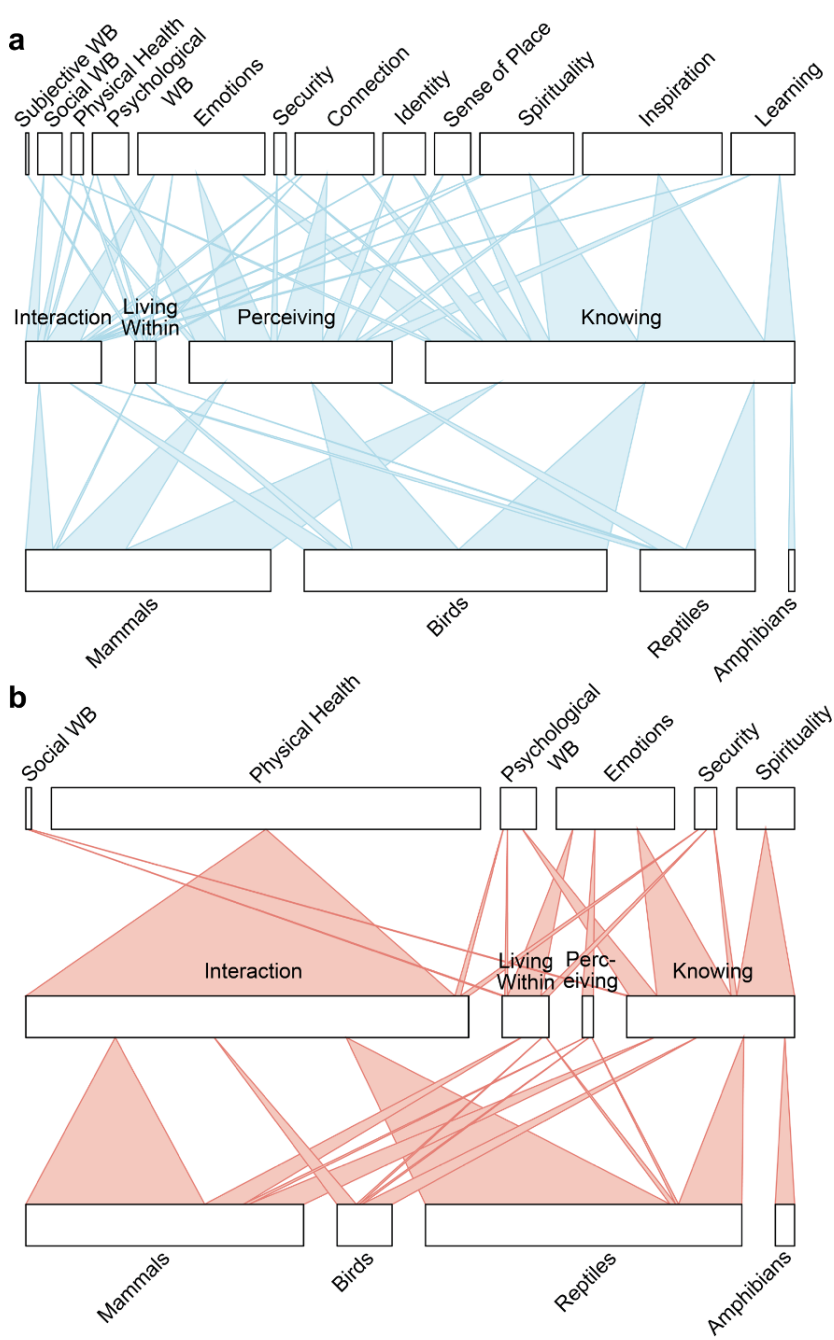

Figure 3. Identified positive (a) and negative (b) effects of non-material contributions provided by wildlife (WCP) affecting different human well-being dimensions. The effects on human well-being are linked to each wildlife taxon through the four channels of human-wildlife experiences: Interaction, Living Within, Perceiving and Knowing (see box 1 and table 2 for categorization; $\mathrm{WB}=$ well-being)

on Interaction mainly reported negative effects (figure 3) on human well-being $(88.6 \%, \mathrm{n}=163)$, with the majority of these effects being related to physical health $(93.3 \%)$. Other negative effects of wildlife interactions were emotions such as fear and anger (Arroyo-Quiroz et al 2017), concern for safety (Ogra 2008) or bad mental health after conflicts or injuries (Jadhav and Barua 2012), outcomes indirectly linked to physical health (supplementary material I, table A2).

Living Within describes how people, either consciously or subconsciously, experience wildlife during their daily lives. Many investigations were conducted on human populations that lived near or within the natural habitat of certain wildlife species $(n=34)$. Thus, the likelihood of the studied populations being aware of or encountering wildlife during daily life was high. We found that living in areas with wildlife had both positive $(17.1 \%, \mathrm{n}=7$ out of 41$)$ and negative $(82.9 \%, \mathrm{n}=34)$ effects on different human well-being dimensions (figure 3 ). For instance, living in areas with high bird abundance and species richness was found to increase mental health, personal and neighbourhood well-being as well as connection to nature (Luck et al 2011, Cox et al 2017b). On the other hand, living in areas with large carnivores or other dangerous animals could often produce insecurity and negative emotions (e.g. Mormile and Hill 2016, Mayberry et al 2017). In fact, the majority of reported negative effects triggered via Living Within were associated with feelings of insecurity due to unsafe conditions, exposure to danger or risk (Security, 58.8\%, $\mathrm{n}=20$ ) or fear (Emotions, $32.4 \%, \mathrm{n}=11$ ) 
In several studies $(\mathrm{n}=28)$ the importance of Perceiving wildlife for human well-being was investigated (figure 3), and most frequently through visual perception during outdoor activities (e.g. urban parks) or while watching wildlife (e.g. safari, whale watching). Several laboratory studies using audio recordings to test the importance of other sensory perceptions also showed that listening to nature sounds mixed with bird songs reduced stress or facilitated recovery after psychological stress (Alvarsson et al 2010, Medvedev et al 2015). In addition, bird songs were attributed with restorative and stress reducing effects (Ratcliffe et al 2013), made people feel calm while being outdoors (Hedblom et al 2017) and reduced health anxiety among elderly people (Dzhambov and Dimitrova 2014). We found 41 positive $(87.2 \%)$ and 6 negative $(12.8 \%)$ effects on various human well-being dimensions caused by Perceiving wildlife. Among all the positive effects, four human well-being dimensions were prominently associated with Perceiving wildlife, i.e. psychological well-being $(24.4 \%, \mathrm{n}=10)$, connection to wildlife $(22.0 \%, \mathrm{n}=9)$, human emotions $(19.5 \%$, $\mathrm{n}=8)$, and learning $(12.2 \%, \mathrm{n}=5)$. Negative effects of Perceiving wildlife were usually found for emotions $(83.3 \%, \mathrm{n}=5)$.

The channel Knowing was the second most often studied channel among the reviewed articles $(27.1 \%$, $\mathrm{n}=87$ out of 277). Knowing often occurred when people reflected on past wildlife experiences gained during time spent outdoors (e.g. vacation, gardening, hunting) or when they owned or acquired specific knowledge and opinions about wildlife species. This means that in many cases the human well-being dimension learning was affected by Knowing. Education also played an important role, as was shown in some studies which tested if education programs and information meetings influenced how people felt towards wildlife (Johansson et al 2017).

Again, we found reports of both positive (57.2\%, $\mathrm{n}=83$ out of 145$)$ and negative $(42.8 \%, \mathrm{n}=62)$ effects of wildlife on human well-being elicited through Knowing (figure 3). Contrary to Interaction (associated with mostly negative effects) and similar to Perceiving, the number of reported positive effects were higher than the associated negative effects on human well-being. Typically, Knowing affected spirituality, human emotions and inspiration (figure 3). In these cases, wildlife's influence on spirituality was both positive $(44.9 \%, \mathrm{n}=22$ out of 49 ) and negative $(55.1 \%, \mathrm{n}=27)$. For instance, beliefs and superstitions can address wildlife as carriers of bad luck and negative omens but also signs of good fortune (Ceríaco 2012, Ohemeng et al 2017, Wyndham and Park 2018). Similarly, positive emotions such as joy, interest or surprise $(26.7 \%, \mathrm{n}=8$ out of 30$)$ were fostered via Knowing, i.e. through remembering or reflecting on past wildlife experiences (e.g. Jacobs et al 2014, Mcintosh and Wright 2017). Knowing additionally affected emotions in negative ways (73.3\%, $\mathrm{n}=22$ ) by provoking feelings of fear and disgust (Tucker and Bond 1997, Davey et al 1998, Johansson and Karlsson 2011). All identified cases where Knowing wildlife influenced human inspiration $(\mathrm{n}=34)$ reported positive effects. These studies reported that wildlife inspired people to create legends, folklore and tales, where different species play the main characters or occur as important symbols (e.g. Berndt 1940, Clarke 2016).

\section{Conclusion}

Our synthesis shows that WCP have received a strong increase in attention over the past decades. While overall, globally, negative reports of WCP are more common, the proportion of positive studies was greater in the Global North compared to the Global South, and positive effects were increasingly reported in recent decades. These temporal and spatial patterns and the lack of systematic assessments of positive and negative WCP may indicate possible normative influences that drive research and the relative proportion of reported positive or negative WCP. These normative influences are not well understood yet, but there might be an indication that at least some larger international processes such as the Millennium Ecosystem Assessment in 2005 (MA 2005), the Intergovernmental Science-Policy Platform on Biodiversity and Ecosystem Services in 2012 (IPBES), and even the UN Sustainable Development Goals in 2015 (SDGs) may have influenced research objectives through greater public awareness as well as policy and funding incentives. Future research could better examine these potential biases by conducting policy assessments or surveys among researchers to understand drivers and motivations behind their research questions.

Most positive WCP were reported for birds while studies on mammals and reptiles mostly reported negative WCP. Surprisingly, we found almost no systematic, joint assessments of positive and negative contributions for any wildlife species (but see Harrison et al 2014 or Pascual-Rico et al 2020). Future studies should therefore explore multi-taxon approaches considering both positive and negative WCP and should consider the culture- and contextdependencies of human experiences with wildlife. Such systematic assessments of both positive and negative WCP will be critical for evaluating the costs and benefits of wildlife, which has become increasingly important to managing wildlife in close proximity to humans and wildlife conflicts (Lozano et al 2019).

Physical health was the most dominant aspect of human well-being that was negatively affected by WCP and there were almost no medical studies that focus on the potential positive effects of WCP on health. Studies examining positive effects of WCP on psychological health are still relatively rare, but publication numbers are increasing. In this 
context, future wildlife studies should contribute to the expanding field of biodiversity and mental health studies (e.g. Marselle et al 2019) or even the hidden mental health impacts of human-wildlife conflicts (Barua et al 2013). Mental health problems in the Global North are increasing (e.g. OECD/European Union 2018) and promoting wildlife experiences, for instance by resource provisioning to increase wildlife populations (Cox and Gaston 2018) as well as increasing opportunities for wildlife contact, e.g. through nature education or creating wildlife viewing opportunities, might lead to more positive WCP which could in turn increase people's well-being and provide a nature-based solution to public health.

We identified many positive and negative effects of wildlife on human emotions in the reviewed literature. In general, the human emotional responses to wildlife have been increasingly studied over the past years (Jacobs 2012), but efforts still need to be made to better understand positive and negative emotions towards wildlife and how these emotions influence how people coexist with wildlife or experience wildlife (Gaston et al 2018).

Building on recent efforts, future research on wildlife now needs to broaden the range of human well-being dimensions considered and should also include aspects of well-being, such as subjective and social well-being, sense of place, learning or identity, that to date are rarely studied. This will help to deepen our understanding of how wildlife influences human well-being.

\section{Acknowledgments}

The authors kindly acknowledge the support by the German Centre for Integrative Biodiversity Research (iDiv) Halle-Jena-Leipzig, funded by the German Science Foundation (FZT 118). The authors also acknowledge support from the iDiv Open Science Publication Fund.

\section{Author contributions}

J M, K B-G and T M designed the study. J M carried out the literature review and analysis. J $\mathrm{M}$ wrote the initial draft of the manuscript. All authors contributed substantially to the writing of the manuscript.

\section{Data availability statement}

The data that support the findings of this study are available from the corresponding author upon request.

\section{ORCID iDs}

Joel Methorst (1) https://orcid.org/0000-0001-83635332
Ugo Arbieu (1) https://orcid.org/0000-0002-06558756

Aletta Bonn () https://orcid.org/0000-0002-83454600

Katrin Böhning-Gaese (1) https://orcid.org/00000003-0477-5586

Thomas Müller (1) https://orcid.org/0000-0001-

9305-7716

\section{References}

Altaf M, Javid A, Umair M, Iqbal K J, Rasheed Z and Abbasi A M 2017 Ethnomedicinal and cultural practices of mammals and birds in the vicinity of river Chenab, Punjab-Pakistan J. Ethnobiol. Ethnomed. 1341

Alvarsson J J, Wiens S and Nilsson M E 2010 Stress recovery during exposure to nature sound and environmental noise Int. J. Environ. Res. Public Health 7 1036-46

Alves R 2012 Relationships between fauna and people and the role of ethnozoology in animal conservation Ethnobiol. Conserv. $11-69$

Arbieu U, Grünewald C, Schleuning M and Böhning-Gaese K 2017 The importance of vegetation density for tourists' wildlife viewing experience and satisfaction in African savannah ecosystems PLoS One 12 e 0185793

Arroyo-Quiroz A I, García-Barrios R, Argueta-Villamar A, Smith R J and Salcido P R G 2017 Local perspectives on conflicts with wildlife and their management in the Sierra Gorda Biosphere Reserve, Mexico J. Ethnobiol. 37 719-42

Balvanera P et al 2017 Interconnected place-based social-ecological research can inform global sustainability Curr. Opin. Environ. Sustain. 29 1-7

Barua M, Bhagwat S A and Jadhav S 2013 The hidden dimensions of human-wildlife conflict: health impacts, opportunity and transaction costs Biol. Conserv. 157 309-16

Behdarvand N and Kaboli M 2015 Characteristics of gray wolf attacks on humans in an altered landscape in the West of Iran Hum. Dimens. Wildl. 20 112-22

Belaire J A, Westphal L M, Whelan C J and Minor E S 2015 Urban residents' perceptions of birds in the neighborhood: biodiversity, cultural ecosystem services, and disservices Condor 117 192-202

Berndt R M 1940 A curlew and owl legend from the Narunga Tribe, South Australia Oceania 10 456-62

Bryce R, Irvine K N, Church A, Fish R, Ranger S and Kenter J O 2016 Subjective well-being indicators for large-scale assessment of cultural ecosystem services Ecosyst. Serv. 21 258-69

Carpenter S R et al 2012 Program on ecosystem change and society: an international research strategy for integrated social-ecological systems Curr. Opin. Environ. Sustain. 4 134-8

Ceríaco L M P 2011 Folklore and traditional ecological knowledge of geckos in Southern Portugal: implications for conservation and science J. Ethnobiol. Ethnomed. 726

Ceríaco L M P 2012 Human attitudes towards herpetofauna: the influence of folklore and negative values on the conservation of amphibians and reptiles in Portugal J. Ethnobiol. Ethnomed. 88

Chan K M A, Gould R K and Pascual U 2018 Editorial overview: relational values: what are they, and what's the fuss about? Curr. Opin. Environ. Sustain. 35 Al-7

Chang C H, Barnes M L, Frye M, Zhang M, Quan R, Reisman L M G, Levin S A and Wilcove D S 2017 The pleasure of pursuit: recreational hunters in rural Southwest China exhibit low exit rates in response to declining catch Ecol. Soc. 2243

Clarke P A 2016 Birds as totemic beings and creators in the Lower Murray, South Australia J. Ethnobiol. 36 277-93

Cox D T C and Gaston K J 2016 Urban bird feeding: connecting people with nature PLoS One 11 1-13 
Cox D T C and Gaston K J 2018 Human-nature interactions and the consequences and drivers of provisioning wildlife Philos. Trans. R. Soc. B: Biol. Sci. 37320170092

Cox D T C, Hudson H L, Shanahan D F, Fuller R A and Gaston K J 2017a The rarity of direct experiences of nature in an urban population Landsc. Urban Plan. $16079-84$

Cox D T C, Shanahan D F, Hudson H L, Plummer K E, Siriwardena G M, Fuller R A, Anderson K, Hancock S and Gaston K J 2017b Doses of neighborhood nature: the benefits for mental health of living with nature Bioscience 67 $147-55$

Curtin S 2009 Wildlife tourism: the intangible, psychological benefits of human-wildlife encounters Curr. Issues Tour. 12 $451-74$

Daily G C 1997 Introduction: what are ecosystem services? Nature's Services: Societal Dependence On Natural Ecosystems, ed G C Daily (Washington, DC: Island Press) pp $1-10$

Dallimer M, Irvine K N, Skinner A M J, Davies Z G, Rouquette J R, Maltby L L, Warren P H, Armsworth P R and Gaston K 2012 Biodiversity and the feel-good factor: understanding associations between self-reported human well-being and species richness Bioscience 62 47-55

Davey G C, Mcdonald A S, Hirisave U, Prabhu G G, Iwawaki S, Jim C I, Merckelbach H, de Jong P J, Leung P W and Reimann B C 1998 A cross-cultural study of animal fears Behav. Res. Ther. $36735-50$

Debata S, Swain K K, Sahu H K and Shekhar H 2016 Human-sloth bear conflict in a human-dominated landscape of northern Odisha, India Ursus 27 90-98

Delisle A, Kiatkoski Kim M, Stoeckl N, Watkin Lui F and Marsh H 2018 The socio-cultural benefits and costs of the traditional hunting of dugongs Dugong dugon and green turtles Chelonia mydas in Torres Strait, Australia Oryx 52 250-61

Díaz B S et al 2018 Assessing nature's contributions to people Science 359 270-2

Díaz S et al 2015 The IPBES conceptual framework-connecting nature and people Curr. Opin. Environ. Sustain. 14 1-16

Díaz S, Fargione J, Chapin F S and Tilman D 2006 Biodiversity loss threatens human well-being PLoS Biol. 4 1300-5

Diener E and Suh E 1997 Measuring quality of life: economic, social, and subjective indicators Soc. Indic. Res. 40 189-216

Dormann C F, Fruend J and Gruber B 2020 Package 'bipartite' Version 2.15 (available at: https://github.com/biometry/bipartiteDescription)

Dzhambov A M and Dimitrova D D 2014 Elderly visitors of an urban park, health anxiety and individual awareness of nature experiences Urban For. Urban Green. 13 806-13

Ehrlich P R and Mooney H A 1983 Extinction, substitution, ecosystem services Bioscience 33 248-54

Expósito-Granados M et al 2019 Human-carnivore relations: conflicts, tolerance and coexistence in the American West Environ. Res. Lett. 14123005

Farber M E and Hall T E 2007 Emotion and environment: visitors' extraordinary experiences along the Dalton highway in Alaska J. Leis. Res. 39 248-70

Forrester J A, Weiser T G and Forrester J D 2018 An update on fatalities due to venomous and nonvenomous animals in the United States (2008-2015) Wilderness Environ. Med. 29 36-44

Forth G 2013 Symbolic lizards: forms of special purpose classification of animals among the Nage of Eastern Indonesia Anthrozoos 26 357-72

Fryxell J M, Graeme C and Sinclair A R E 2014 Wildlife Ecology, Conservation and Management, ed J M Fryxell, C Graeme and A R E Sinclair (Chichester: Wiley)

Fuller R A, Irvine K N, Devine-Wright P, Warren P H and Gaston K J 2007 Psychological benefits of greenspace increase with biodiversity Biol. Lett. 3 390-4

Galbraith J A, Beggs J R, Jones D N, Mcnaughton E J, Krull C R and Stanley M C 2014 Risks and drivers of wild bird feeding in urban areas of New Zealand Biol. Conserv. 180 64-74
Gaston K J, Soga M, Duffy J P, Garrett J K, Gaston S and Cox D T C 2018 Personalised ecology Trends Ecol. Evol. 33 916-25

Gläser-Zikuda M 2012 Affective and emotional dispositions of/for learning Encyclopedia of the Sciences of Learning, ed N M Seel (Boston, MA: Springer) pp 165-9

Gunther K A, Haroldson M A, Frey K, Cain S L, Copeland J and Schwartz C C 2004 Grizzly bear-human conflicts in the Greater Yellowstone ecosystem, 1992-2000 Ursus 15 10-22

Haines-Young R and Potschin M 2018 Common International Classification of Ecosystem Services (CICES) V5.1 And Guidance on the Application of the Revised Structure (available at: www.cices.eu)

Hanisch E, Johnston R and Longnecker N 2019 Cameras for conservation: wildlife photography and emotional engagement with biodiversity and nature Hum. Dimens. Wildl. 24 267-84

Hansen R and Pauleit S 2014 From multifunctionality to multiple ecosystem services? A conceptual framework for multifunctionality in green infrastructure planning for urban areas Ambio 43 516-29

Harrison P A et al 2014 Linkages between biodiversity attributes and ecosystem services: a systematic review Ecosyst. Serv. 9 191-203

Hausmann A, Slotow R, Burns J K and Di Minin E 2016 The ecosystem service of sense of place: benefits for human well-being and biodiversity conservation Environ. Conserv. 43 117-27

Haywood B K, Parrish J K and Dolliver J 2016 Place-based and data-rich citizen science as a precursor for conservation action Conserv. Biol. 30 476-86

Hedblom M, Knez I, Ode Sang A and Gunnarsson B 2017 Evaluation of natural sounds in urban greenery: potential impact for urban nature preservation R. Soc. Open Sci. 4 170037

Herzog H 2011 The impact of pets on human health and psychological well-being: fact, fiction, or hypothesis? Curr. Dir. Psychol. Sci. $20236-9$

Hull K and Fergus R 2017 Birds as seers: an ethno-ornithological approach to omens and prognostication among the Ch'Orti' Maya of Guatemala J. Ethnobiol. 37 604-20

Inskip C and Zimmermann A 2009 Human-felid conflict: a review of patterns and priorities worldwide Oryx 43 18-34

Izard C E 2007 Basic emotions, natural kinds, emotion schemas, and a new paradigm Perspect. Psychol. Sci. $2260-80$

Jacobs M and Vaske J J 2019 Understanding emotions as opportunities for and barriers to coexistence with wildlife Human-Wildlife Interactions, ed B Frank, J A Glikman and S Marchini (Cambridge: Cambridge University Press) pp 65-84

Jacobs M H 2012 Human emotions toward wildlife Hum. Dimens. Wildl. 17 1-3

Jacobs M H, Vaske J J, Dubois S and Fehres P 2014 More than fear: role of emotions in acceptability of lethal control of wolves Eur. J. Wildl. Res. 60 589-98

Jadhav S and Barua M 2012 The elephant vanishes: impact of human-elephant conflict on people's wellbeing Health Place 18 1356-65

Johansson M, Frank J, Støen O G and Flykt A 2017 An evaluation of information meetings as a tool for addressing fear of large carnivores Soc. Nat. Resour. 30 281-98

Johansson M and Karlsson J 2011 An subjective experience of fear and the cognitive interpretation of large carnivores Hum. Dimens. Wildl. 16 15-29

Kemeny M E and Shestyuk A 2008 Emotions, the neuroendocrine and immune systems, and health Handbook of Emotions, ed M Lewis, H M Haviland-Jones and L FeldMan Barrett (New York: The Guilford Press) pp 661-75

Lee W N and Davey G 2015 Chinese visitors' experiences of nature and wild macaques: inspiration and personal growth for living in Hong Kong Hum. Dimens. Wildl. 20 206-19

Lees D, Sherman G D H, Maguire G S, Dann P, Cardilini A P A and Weston M A 2013 Swooping in the suburbs; parental 
defence of an abundant aggressive urban bird against humans Animals 3 754-66

Lovell R, Wheeler B W, Higgins S L, Irvine K N and Depledge M $\mathrm{H} 2014$ A systematic review of the health and well-being benefits of biodiverse environments J. Toxicol. Environ. Health B: Crit. Rev. 17 1-20

Lozano J et al 2019 Human-carnivore relations: a systematic review Biol. Conserv. 237 480-92

Luck G W, Davidson P, Boxall D and Smallbone L 2011 Relations between urban bird and plant communities and human well-being and connection to nature Conserv. Biol. 25 816-26

MA-Millennium Ecosystem Assessment 2005 Ecosystems and Human Well-being: Synthesis (Washington, DC: Island Press)

Mace G M 2014 Whose conservation? Science 345 1558-60

Mace G M, Norris K and Fitter A H 2012 Biodiversity and ecosystem services: a multilayered relationship Trends Ecol. Evol. 27 19-25

Mackerron G and Mourato S 2013 Happiness is greater in natural environments Glob. Environ. Change 23 992-1000

Marchini S and Crawshaw P G 2015 Human-wildlife conflicts in Brazil: a fast-growing issue Hum. Dimens. Wildl. $20323-8$

Markevych I et al 2017 Exploring pathways linking greenspace to health: theoretical and methodological guidance Environ. Res. 158 301-17

Marselle M R, Martens D, Dallimer M and Irvine K N 2019 Review of the mental health and wellbeing benefits of biodiversity Biodiversity and Health in the Face of Climate Change, ed M R Marselle, J Stadler, H Korn, K Irvine and A Bonn (Berlin: Springer) pp 75-211

Mayberry A L, Hovorka A J and Evans K E 2017 Well-being impacts of human-elephant conflict in Khumaga, Botswana: exploring visible and hidden dimensions Conserv. Soc. 15 280-91

Mcdonough K, Hutchinson S, Moore T and Hutchinson J M S 2017 Analysis of publication trends in ecosystem services research Ecosyst. Serv. 25 82-88

Mcintosh D and Wright P A 2017 Emotional processing as an important part of the wildlife viewing experience J. Outdoor Recreat. Tour. 18 1-9

Medvedev O, Shepherd D and Hautus M J 2015 The restorative potential of soundscapes: a physiological investigation Appl. Acoust. 96 20-26

Milcu A I, Hanspach J, Abson D and Fischer J 2013 Cultural ecosystem services: a literature review and prospects for future research Ecol. Soc, 1844

Moher D et al 2009 Preferred reporting items for systematic reviews and meta-analyses: the PRISMA statement PLoS Med. 6 e 1000097

Moleón M, Sánchez-Zapata J A, Margalida A, Carrete M, Owen-Smith N and Donázar J A 2014 Humans and scavengers: the evolution of interactions and ecosystem services Bioscience 64 394-403

Møller A P, Morelli F and Tryjanowski P 2017 Cuckoo folklore and human well-being: cuckoo calls predict how long farmers live Ecol. Indic. 72 766-8

Mormile J E and Hill C M 2016 Living with urbanbaboons: exploring attitudes and their implications for local baboon conservation and management in Knysna, South Africa Hum. Dimens. Wildl. 22 99-109

O'Brien E A 2006 A question of value: what do trees and forests mean to people in Vermont? Landsc. Res. 31 257-75

OECD/European Union 2018 Health at a Glance: Europe 2018 (Paris: OECD Publishing)

Ogra M V 2008 Human-wildlife conflict and gender in protected area borderlands: A case study of costs, perceptions, an vulnerabilities from Uttarakhand (Uttaranchal), India Geoforum 39 1408-22

Ohemeng F, Lawson E T, Ayivor J, Leach M, Waldman L and Ntiamoa-Baidu Y 2017 Socio-cultural determinants of human-bat interactions in Rural Ghana Anthrozoos 30 181-94

Pascual U et al 2017 Valuing nature's contributions to people: the IPBES approach Curr. Opin. Environ. Sustain. 26-27 7-16

Pascual-Rico R, Martín-López B, Sánchez-Zapata J A and Morales-Reyes Z 2020 Scientific priorities and shepherds' perceptions of ungulate's contributions to people in rewilding landscapes Sci. Total Environ. 705135876

Penteriani V et al 2016 Human behaviour can trigger large carnivore attacks in developed countries Sci. Rep. 6 1-8

Pugh R N H, Bourdillon C C M, Theakston R D G and Reid H A 1979 Bites of the carpet viper in the Niger Valley Lancet 314 625-7

R Development Core Team R 2020 R: A language and environment for statistical computing (available at: www.r-project.org/)

Rall E, Bieling C, Zytynska S and Haase D 2017 Exploring city-wide patterns of cultural ecosystem service perceptions and use Ecol. Indic. 77 80-95

Ramstad K M, Nelson N J, Paine G, Beech D, Paul A, Paul P, Allendorf F W and Daugherty C H 2007 Species and cultural conservation in New Zealand: maori traditional ecological knowledge of Tuatara Conserv. Biol. 21 455-64

Ratcliffe E, Gatersleben B and Sowden P T 2013 Bird sounds and their contributions to perceived attention restoration and stress recovery J. Environ. Psychol. 36 221-8

Russell R, Guerry A D, Balvanera P, Gould R K, Basurto X, Chan K M A, Klain S, Levine J and Tam J 2013 Humans and nature: how knowing and experiencing nature affect well-being Annu. Rev. Environ. Resour. 38 473-502

Sandifer P A, Sutton-Grier A E and Ward B P 2015 Exploring connections among nature, biodiversity, ecosystem services, and human health and well-being: opportunities to enhance health and biodiversity conservation Ecosyst. Serv. 12 1-15

Sarkhel S, Ghosh R, Mana K and Gantait K 2017 A hospital based epidemiological study of snakebite in Paschim Medinipur Toxicol. Rep. 4 415-9

Shackleton C M, Ruwanza S, Sinasson Sanni G K, Bennett S, De Lacy P, Modipa R, Mtati N, Sachikonye M and Thondhlan G 2016 Unpacking pandora's box: understanding and categorising ecosystem disservices for environmental management and human wellbeing Ecosystems 19 587-600

Soga M and Gaston K J 2016 Extinction of experience: the loss of human-nature interactions Front. Ecol. Environ. 14 94-101

Tengberg A, Fredholm S, Eliasson I, Knez I, Saltzman K and Wetterberg O 2012 Cultural ecosystem services provided by landscapes: assessment of heritage values and identity Ecosyst. Serv. 2 14-26

Tucker M and Bond N W 1997 The roles of gender, sex role, and disgust in fear of animals Pers. Individ. Differ. 22 135-8

Vaz A S, Kueffer C, Kull C A, Richardson D M, Vicente J R, Kühn I, Schröter M, Hauck J, Bonn A and Honrado J P 2017 Integrating ecosystem services and disservices: insights from plant invasions Ecosyst. Serv. 23 94-107

Vihervaara P, Rönkä M and Walls M 2010 Trends in ecosystem service research: early steps and current drivers Ambio 39 $314-24$

Warne R M and Jones D N 2003 Evidence of target specificity in attacks by Australian magpies on humans Wildl. Res. 30 265-7

Wells D L 2009 The effects of animals on human health and well-being J. Soc. Issues 65 523-43

Wheeler B W, Lovell R, Higgins S L, White M P, Alcock I, Osborne N J, Husk K, Sabel C E and Depledge M H 2015 Beyond greenspace: an ecological study of population general health and indicators of natural environment type and quality Int. J. Health Geogr. 14 1-17

Wyndham F S and Park K E 2018 'Listen carefully to the voices of the birds': a comparative review of birds as signs J. Ethnobiol. 38533 


\subsection{Supplementary Material}

Supplementary Material

'Non-material contributions of wildlife to human well-being: a systematic review'

Authors:

Joel Methorst, Ugo Arbieu, Aletta Bonn, Katrin Böhning-Gaese, Thomas Müller 


\subsubsection{Search strings}

Table A.I-1: List of search strings used in Web of Science.

wildlife AND life-satisfaction, wildlife AND mental health, wildlife AND psychological well-being, wildlife AND emotion*, wildlife AND subjective well-being, wildlife AND happiness, wildlife AND human health, wildlife feeding AND well-being, wildlife AND sound AND well-being, wildlife AND human conflict, wildlife AND sense of place, wildlife AND human identity, wildlife AND human physiological health, wildlife AND connection to nature, wildlife AND hunting AND well-being, wildlife AND hunting AND pleasure, wildlife AND bird watching AND pleasure, wildlife AND bird watching AND well-being, wildlife AND spirituality, wildlife AND inspiration, wildlife AND cultur* significance, wildlife AND folklore, wildlife AND tales, wildlife AND thinking, wildlife AND knowing, wildlife AND social relationships, wildlife AND security, wildlife AND disgust, wildlife AND human fear, wildlife AND human attack injury, wildlife AND human injury, wildlife AND diving AND well- being, wildlife AND diving AND happiness, wildlife AND learning experience, wildlife AND human coexistence

bird* AND life-satisfaction, bird* AND human health, bird* AND well-being, bird* AND mental health, bird* AND psychological well-being, bird* AND subjective well-being, bird* AND happiness, bird* AND cultur* significance, bird* AND human interaction AND feeding, bird feeding AND well-being, bird* AND sound AND well-being, bird* AND human emotion*, bird* AND folklore, bird* AND knowing AND education, bird* AND memory AND thinking, bird watching AND well-being, bird* AND spirituality, bird* AND connection to nature, bird* AND disgust, bird* AND human fear, bird* AND human attack injury, bird* AND human injury, bird* AND sadness, bird* AND learning experience, birds AND human coexistence

mammal* AND life-satisfaction, mammal* AND human health, mammal* AND well-being, mammal* AND mental health, mammal* AND psychological well-being, mammal* AND subjective well-being, mammal* AND happiness, mammal* AND cultur* significance, mammal* AND human interaction AND feeding, mammal feeding AND well-being, mammal* AND sound AND well-being, mammal* AND human emotion*, mammal* AND folklore, mammal* AND sense of place, mammal* AND identity, mammal* AND memory AND thinking, mammal* AND knowing AND education, mammal* AND spirituality, mammal* AND connection to nature, mammal* AND disgust, mammal* AND human fear, mammal* AND human injury, mammal* AND human attack injury, mammal* AND sadness, carnivore AND phobia, mammal AND bite injury, mammal* AND learning experience, mammal* AND human coexistence

reptile* AND life-satisfaction, reptile* AND human health, reptile* AND well-being, reptile* AND mental health, reptile* AND psychological well-being, reptile* AND subjective well-being, reptile* AND happiness, reptile* AND cultur* significance, reptile* AND human interaction AND feeding, reptile feeding AND well-being, reptile human interaction well-being, reptile sound AND well-being, reptile* AND sound AND well-being, reptile* AND human emotion*, reptile* AND folklore, reptile* AND sense of place, reptile* AND identity, reptile* AND memory AND thinking, reptile* AND knowing And education, reptile* AND spirituality, reptile* AND connection to nature, reptile* AND disgust, reptile* AND human fear, reptile* AND human attack injury, reptile* AND human attack injury, snake AND bite injury, alligator AND injury, snake AND phobia, reptile* AND sadness, reptile* AND learning experience, reptile* AND human coexistence

amphibian* AND life-satisfaction, amphibian* AND human health, amphibian* AND well-being, amphibian* AND mental health, amphibian* AND psychological well-being, amphibian* AND subjective well-being, amphibian* AND happiness, amphibian* AND cultur* significance, amphibian* AND human interaction AND feeding, amphibian feeding AND well-being, amphibian AND human interaction AND well-being, amphibian sound AND well-being, amphibian* AND sound AND well- being, amphibian* AND human emotion*, amphibian* AND folklore, amphibian* AND sense of place, amphibian* AND identity, amphibian* AND memory AND thinking, amphibian* AND knowing AND education, amphibian* AND spirituality, amphibian* AND connection to nature, amphibian* AND disgust, amphibian* AND human fear, amphibian* AND human attack injury, amphibian* AND human injury, amphibian* AND sadness, amphibian* AND learning experience, amphibian* AND human coexistence 


\subsubsection{Flow diagram}

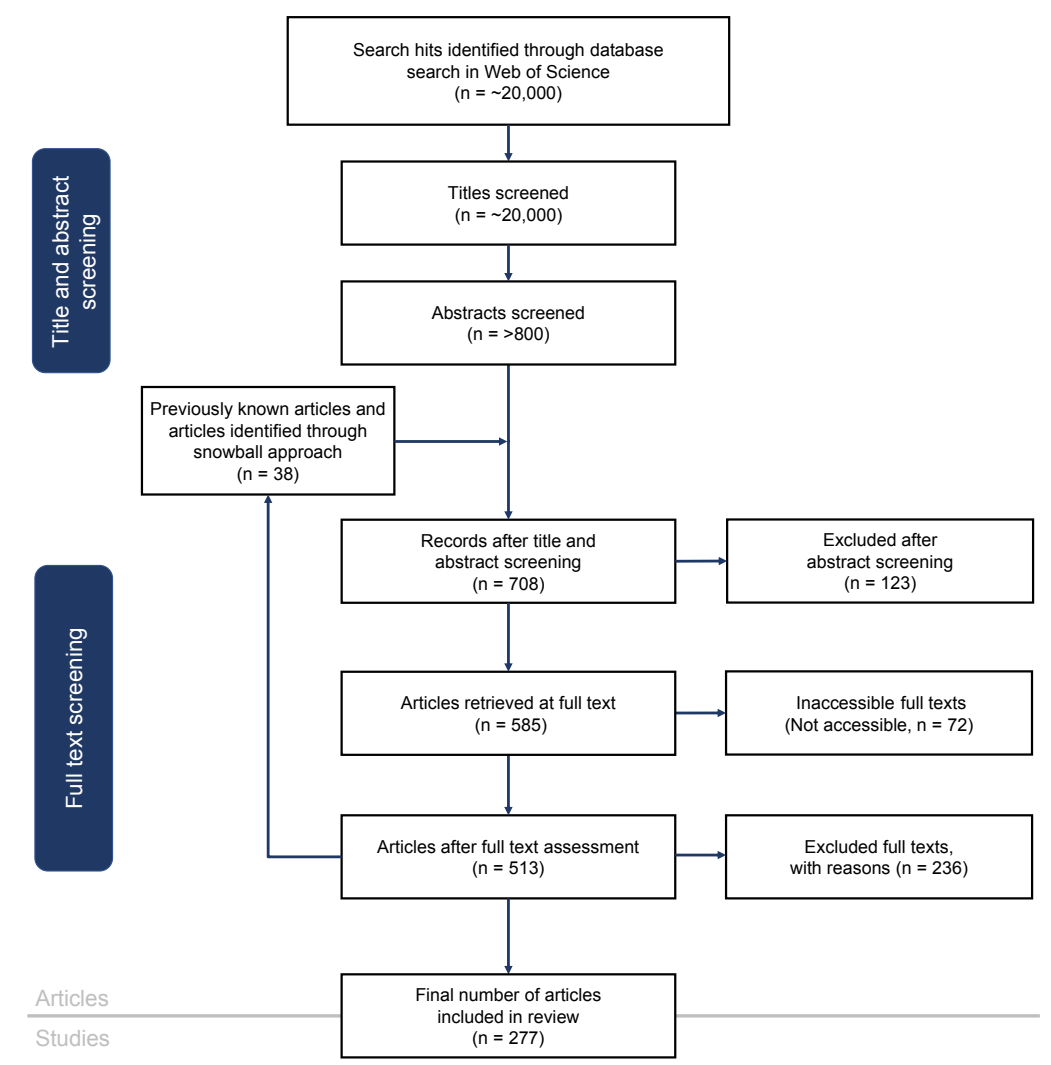

Fig. A.I-1: Flow diagram of the search and review process. Our simplified flow diagram is based on the ROSES framework (Haddaway et al 2017).

\subsubsection{Human well-being dimensions}

Table A.I-2: Identification of human well-being dimensions affected by positive and negative non-material contributions of wildlife (WCP).

\begin{tabular}{ll} 
Human well-being dimension & Identification process \\
\hline \hline Subjective well-being & - I recorded positive or negative WCP and their effects when stud- \\
& $\begin{array}{l}\text { ies showed significant relationships / correlations between wildlife } \\
\text { measures and subjective well-being measures (e.g. Luck et al. } 2011 \text { ) }\end{array}$ \\
\hline Social well-being & - I recorded positive WCP when wildlife interactions promoted, for \\
& example, relationships with friends or social bonding (Adams et al. \\
& 1997, Lee and Davey 2015). \\
\hline & - Reported negative influence of wildlife when the knowledge of po- \\
& tential wildlife encounters limited the freedom to visit family and \\
& friends (e.g. Mayberry et al. 2017). \\
\hline Physical health & - I recorded positive or negative WCP and their effects when studies \\
& found significant relationships / correlations between wildlife meas- \\
& ures and subjective health measures (e.g. Wheeler et al. 2015). \\
\hline
\end{tabular}


Human well-being dimension Identification process

\begin{tabular}{|c|c|}
\hline & $\begin{array}{l}\text { - I recorded negative WCP when studies reported injuries and deaths } \\
\text { caused by wildlife (Chowdhury et al. 2008, Baynes-Rock 2013). We } \\
\text { also included epidemiological studies on snake bites or wildlife at- } \\
\text { tacks (Acharya et al. 2016, Penteriani et al. 2016, Singh et al. 2015). }\end{array}$ \\
\hline \multirow[t]{3}{*}{ Psychological well-being } & $\begin{array}{l}\text { - I identified positive or negative WCP and their effect on psycho- } \\
\text { logical health when studies reported significant relationships / cor- } \\
\text { relations between wildlife measures and mental and psychological } \\
\text { well-being indicators (Dallimer et al. 2012, Cox et al. 2017). }\end{array}$ \\
\hline & $\begin{array}{l}\text { - I categorized reports on nightmares, increased stress or depression } \\
\text { caused by wildlife as negative effect of WCP (Jadhav and Barua } \\
\text { 2012, Barua et al. 2013, Bond and Mkutu 2018). }\end{array}$ \\
\hline & $\begin{array}{l}\text { - Phobias towards specific wildlife taxa were also defined as nega- } \\
\text { tive WCP (e.g. Agras et al. 1969). }\end{array}$ \\
\hline \multirow[t]{3}{*}{ Emotions } & $\begin{array}{l}\text { - I identified positive or negative WCP and their effect on emotions } \\
\text { when studies reported significant relationships / correlations be- } \\
\text { tween wildlife measures and measures for emotions and affective } \\
\text { responses (e.g. Marselle et al. 2015). }\end{array}$ \\
\hline & $\begin{array}{l}\text { - Positive WCP where identified when studies reported people ex- } \\
\text { pressing joy, interest (e.g. awe, pleasure) and surprise after wildlife } \\
\text { experiences (Curtin 2009, MacKerron and Mourato 2013). }\end{array}$ \\
\hline & $\begin{array}{l}\text { - Negative WCP were identified when people felt disgust, sadness, } \\
\text { fear or anger towards wildlife or after wildlife experiences (Røskaft } \\
\text { et al. 2003, Davey et al 1998, Tucker and Bond 1997). }\end{array}$ \\
\hline \multirow[t]{3}{*}{ Security } & $\begin{array}{l}\text { - Positive WCP were identified when people, for instance, expe- } \\
\text { rienced a sense of freedom after wildlife encounters (Bryce et al. } \\
\text { 2016). }\end{array}$ \\
\hline & $\begin{array}{l}\text {-Negative WCP were identified when studies reported people feelin } \\
\text { g worry or concern due to wildlife living in the vicinity (Dhakal and } \\
\text { Thapa 2019, Mayberry et al. 2017). }\end{array}$ \\
\hline & $\begin{array}{l}\text { - Negative WCP were also found when people perceived higher risk } \\
\text { to health and social safety or felt insecure and less control (Sakurai } \\
\text { et al. } 2013 \text {, Young et al. } 2015 \text {, Sponarski et al. 2015). }\end{array}$ \\
\hline \multirow[t]{2}{*}{ Connection to wildlife } & $\begin{array}{l}\text { - I identified positive or negative WCP when studies reported sig- } \\
\text { nificant relationships / correlations between wildlife measures and } \\
\text { connection to nature measures (e.g. connectedness to nature scale) } \\
\text { (Luck et al. 2011, Cox and Gaston 2016). }\end{array}$ \\
\hline & $\begin{array}{l}\text { - We identified positive or negative WCP when interviewed peo- } \\
\text { ple or questionnaire respondents expressed a connection to wildlife } \\
\text { (Clark et al. 2019, Skibins and Sharp 2017). }\end{array}$ \\
\hline \multirow[t]{2}{*}{ Identity } & $\begin{array}{l}\text { - Positive WCP were mostly found when studies describe a kinship } \\
\text { between humans and wildlife (Aiyadurai 2016) or show how expe- } \\
\text { riences with wildlife improve people`s sense of self and feelings of } \\
\text { being one with nature (Folmer et al. 2019). }\end{array}$ \\
\hline & $\begin{array}{l}\text { - I also recorded positive WCP when studies found correlations be- } \\
\text { tween identity measures (e.g. based on questionnaire answers) and } \\
\text { wildlife characteristics at a specific site/area (e.g. Bryce et al. 2016). }\end{array}$ \\
\hline Sense of place & $\begin{array}{l}\text { - I identified positive WCP when studies reported how wildlife ex- } \\
\text { periences fostered place identity or when people felt attachment to } \\
\text { places because of wildlife (Folmer et al. 2019, Haywood et al. 2016). }\end{array}$ \\
\hline Spirituality & $\begin{array}{l}\text { - I identified positive effects of wildlife on spirituality when studies } \\
\text { reported how wildlife played a positive role in people`s religious } \\
\text { faith or beliefs (e.g. Clarke 2016, Ghosal et al. 2015). }\end{array}$ \\
\hline
\end{tabular}




\begin{tabular}{|c|c|}
\hline Human well-being dimension & Identification process \\
\hline & $\begin{array}{l}\text { - Negative WCP and their effect on spiritual meaning of animals, } \\
\text { negative superstitions beliefs (signs of bad luck, bad omens etc.), } \\
\text { magic and taboos (e.g. Ohemeng et al. 2017, Pasierowska 2017, } \\
\text { Ceríaco 2012). }\end{array}$ \\
\hline Inspiration & $\begin{array}{l}\text { - Positive WCP were identified when studies describe how wildlife } \\
\text { taxa play a role (e.g. protagonist, messenger, teacher) in stories, folk- } \\
\text { lore (tales, myths, narratives), language (metaphors, proverbs etc.), } \\
\text { music and literature (e.g. Berndt 1940, Jernigan 2016, Biyela 2014). }\end{array}$ \\
\hline \multirow[t]{2}{*}{ Learning } & $\begin{array}{l}\text { - Learning experiences were identified when studies reported that } \\
\text { people learned things after experiencing wildlife. Such activities } \\
\text { were bird watching, wildlife photography, hunting or citizen science } \\
\text { (e.g. Hughes } 2013 \text {, Zamudio et al. } 2013 \text {, Hanisch et al. } 2019 \text {, Bal- } \\
\text { lantyne et al. 2011) }\end{array}$ \\
\hline & $\begin{array}{l}\text { - Learning experiences were also recorded when studies show how } \\
\text { people reflect on wildlife experiences and categorize these experi- } \\
\text { ences as opportunity for education and learning (Soga et al. 2016). }\end{array}$ \\
\hline
\end{tabular}

\subsubsection{Categories for wildlife taxonomic groups}

Table A.I-3: Categories for wildlife taxonomic groups and wildlife measures.

\section{Subject of interest}

Wildlife taxonomic group

\section{Categorization}

(1) Mammals (aquatic and terrestrial), (2) Birds, (3) Reptiles, (4) Amphibians, and (5) Wildlife: The term covers studies in which only a broad terminology for wildlife was used or articles which addressed activities with unspecified wildlife. In each case however, it was evident that the studies were mainly referring to vertebrate species.

Wildlife measure
(1) Species richness: objective numbers of species, (2) Perceived Richness: subjective estimates of species numbers by people, (3) Diversity: biodiversity indices (e.g. Shannon Index), (4) Abundance: population numbers of species, (5) Single Species: only one single species was studied, (6) Species Lists or Groups: studies examined loosely defined species groups (e.g. birds, carnivores or snakes) or a list of different study species, and (7) Wildlife or animals in general: researchers studied wildlife or animals in general and we assume that these terms mostly includes wild vertebrates 


\subsubsection{Network plots}

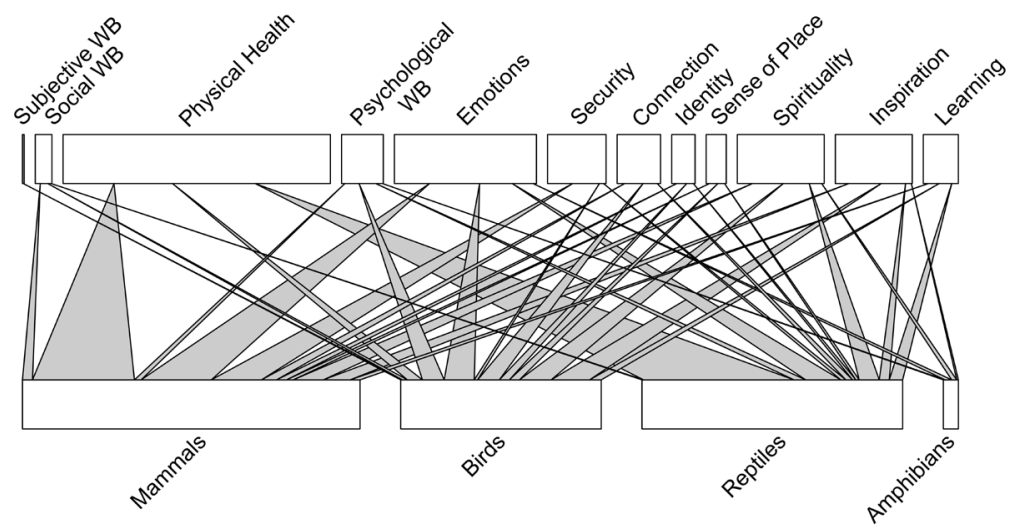

Fig. A.I-2: Number of all identified positive and negative effects of non-material contributions of wildlife affecting different human well-being dimensions (well-being =WB). Effects are sorted by wildlife species group. Proportion of effects for each human well-being dimension: Subjective WB $=0.2 \%$, Social WB = $2.0 \%$, Physical Health $=32.9 \%$, Psychological WB $=5.1 \%$, Emotions $=17.5 \%$, Security $=7.2 \%$, Connection $=5.3 \%$, Identity $=2.9 \%$, Sense of Place $=2.5 \%$, Spirituality $=10.7 \%$, Inspiration $=9.4 \%$, Learning $=$ $4.3 \%$.

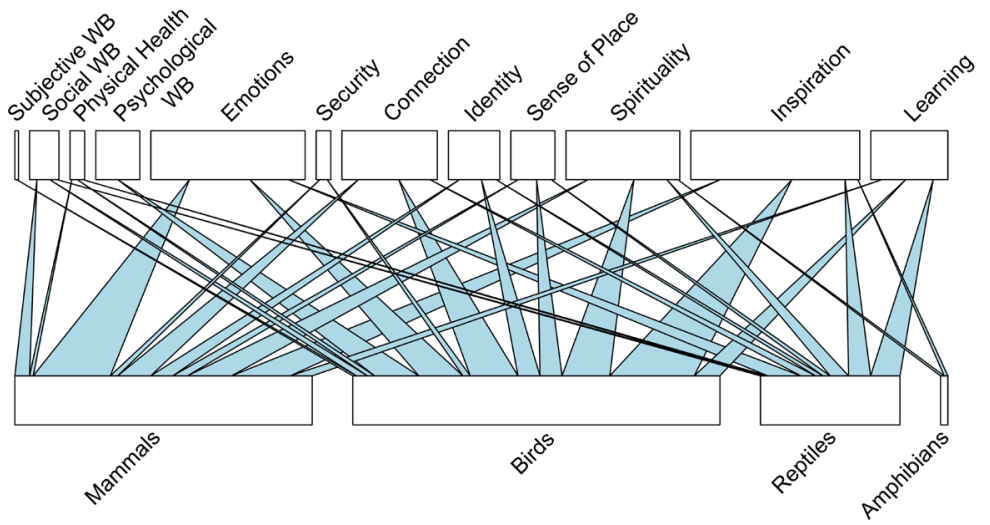

Fig. A.I-3: Number of identified positive effects of non-material contributions of wildlife sorted by wildlife species group and affecting different human well-being dimensions ( well-being $=\mathrm{WB}$ ). Proportion of effects for each human well-being dimension: Subjective WB $=0.5 \%$, Social $\mathrm{WB}=3.6 \%$, Physical Health $=1.8 \%$, Psychological WB $=5.4 \%$, Emotions $=19.0 \%$, Security $=1.8 \%$, Connection $=11.8 \%$, Identity $=$ $6.3 \%$, Sense of Place $=5.4 \%$, Spirituality $=14.1 \%$, Inspiration $=20.8 \%$, Learning $=9.5 \%$.

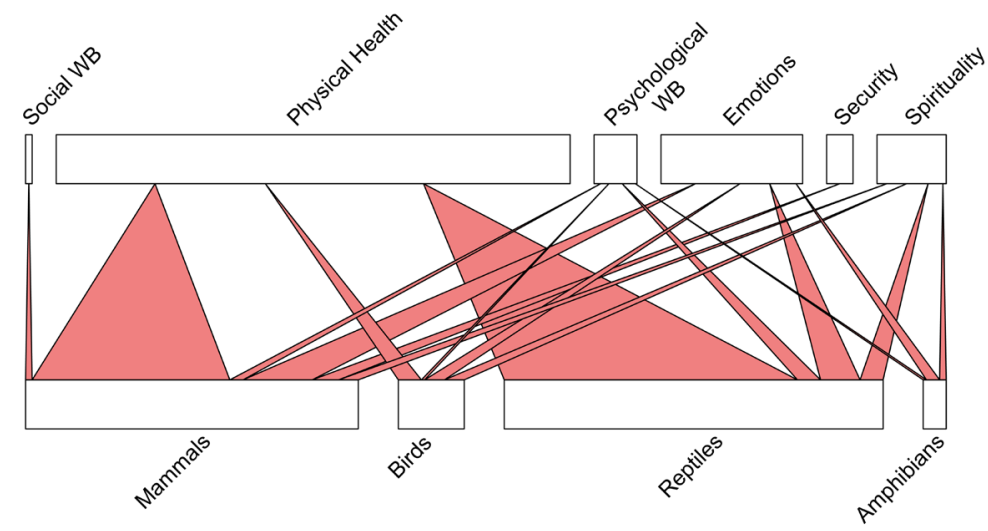

Fig. A.I-4: Number of identified negative effects of non-material contributions of wildlife sorted by wildlife species group and affecting different human well-being (well-being $=\mathrm{WB}$ ). Proportion of effects for each human well-being dimension: Subjective WB $=0$, Social WB $=0.8 \%$, Physical Health $=64.2 \%$, Psychological $\mathrm{WB}=5.4 \%$, Emotions $=17.7 \%$, Security $=3.3 \%$, Connection $=0$, Identity $=0$, Sense of Place $=0$, Spirituality $=8.6 \%$, Inspiration $=0$, Learning $=0$. 


\subsubsection{References}

Acharya, K.P., Paudel, P.K., Neupane, P.R., Köhl, M., 2016. Human-wildlife conflicts in Nepal: Patterns of human fatalities and injuries caused by large mammals. PLoS One 11, 1-18.

Adams, C.E., Leifester, J.A., Herron, J.S.C., 1997. Understanding birders and constituents: waterfowl hunters. Wildl. Soc. Bull. 25, 653-660.

Agras, S., Sylvester, D., Oliveau, D., 1969. The epidemiology of common fears and phobia. Compr. Psychiatry $10,151-156$.

Aiyadurai, A., 2016. 'Tigers are our brothers': understanding human-nature relations in the Mishmi Hills, Northeast India. Conserv. Soc. 14, 305-316.

Ballantyne, R., Packer, J., Sutherland, L.A., 2011. Visitors' memories of wildlife tourism: Implications for the design of powerful interpretive experiences. Tour. Manag. 32, 770-779.

Barua, M., Bhagwat, S.A., Jadhav, S., 2013. The hidden dimensions of human-wildlife conflict: health impacts, opportunity and transaction costs. Biol. Conserv. 157, 309-316.

Baynes-Rock, M., 2013. Local tolerance of Hyena attacks in East Hararge. Anthrozoos 26, 421-433.

Berndt, R.M., 1940. A curlew and owl legend from the Narunga Tribe, South Australia. Oceania 10, 456-462.

Biyela, N.G., 2014. Animal metaphors representing human images: a case study on king shaka, the founder of the zulu nation in South Africa. Anthropologist 18, 639-646.

Bond, J., Mkutu, K., 2018. Exploring the hidden costs of human-wildlife conflict in northern Kenya. Afr. Stud. Rev. 61, 33-54.

Bryce, R., Irvine, K.N., Church, A., Fish, R., Ranger, S., Kenter, J.O., 2016. Subjective well-being indicators for large-scale assessment of cultural ecosystem services. Ecosyst. Serv. 21, 258-269.

Ceríaco, L.M.P., 2012. Human attitudes towards herpetofauna: the influence of folklore and negative values on the conservation of amphibians and reptiles in Portugal. J. Ethnobiol. Ethnomed. 8, 8.

Chowdhury, A.N., Mondal, R., Brahma, A., Biswas, M.K., 2008. Eco-psychiatry and environmental conservation: study from Sundarban Delta, India. Environ. Health Insights 2, 61-76.

Clark, D.N., Jones, D.N., James Reynolds, S., 2019. Exploring the motivations for garden bird feeding in south-east England. Ecol. Soc. 24, 26.

Clarke, P.A., 2016. Birds and the spirit world of the Lower Murray, South Australia. J. Ethnobiol. 36, 746-764.

Cox, D.T.C., Gaston, K.J., 2016. Urban bird feeding: connecting people with nature. PLoS One 11, 1-13.

Cox, D.T.C., Shanahan, D.F., Hudson, H.L., Plummer, K.E., Siriwardena, G.M., Fuller, R.A., Anderson, K., Hancock, S., Gaston, K.J., 2017. Doses of neighborhood nature: the benefits for mental health of living with nature. Bioscience 67, 147-155.

Curtin, S., 2009. Wildlife tourism: the intangible, psychological benefits of human-wildlife encounters. Curr. Issues Tour. 12, 451-474.

Dallimer, M., Irvine, K.N., Skinner, A.M.J., Davies, Z.G., Rouquette, J.R., Maltby, L.L., Warren, P.H., Armsworth, P.R., Gaston, K.J., 2012. Biodiversity and the feel-good factor: understanding associations between self-reported human well-being and species richness. Bioscience 62, 47-55.

Davey, G.C., McDonald, A.S., Hirisave, U., Prabhu, G.G., Iwawaki, S., Jim, C.I., Merckelbach, H., de Jong, P.J., Leung, P.W., Reimann, B.C., 1998. A cross-cultural study of animal fears. Behav. Res. Ther. $36,735-50$.

Dhakal, B., Thapa, B., 2019. Residents' perceptions of human-elephant conflict: case study in Bahundangi, Nepal. Environ. Dev. Sustain. 21, 461-481.

Folmer, A., Haartsen, T., Huigen, P.P.P., 2019. How ordinary wildlife makes local green places special. Landsc. Res. 44, 393-403.

Ghosal, S., Skogen, K., Krishnan, S., 2015. Locating human-wildlife interactions: landscape constructions 
and responses to large carnivore conservation in India and Norway. Conserv. Soc. 13, 265-274.

Haddaway, N., Macura, B., Whaley, P., Pullin, A., 2017. ROSES flow diagram for systematic reviews.

Hanisch, E., Johnston, R., Longnecker, N., 2019. Cameras for conservation: wildlife photography and emotional engagement with biodiversity and nature. Hum. Dimens. Wildl. 24, 267-284.

Haywood, B.K., Parrish, J.K., Dolliver, J., 2016. Place-based and data-rich citizen science as a precursor for conservation action. Conserv. Biol. 30, 476-486.

Hughes, K., 2013. Measuring the impact of viewing wildlife: Do positive intentions equate to long-term changes in conservation behaviour? J. Sustain. Tour. 21, 42-59.

Jadhav, S., Barua, M., 2012. The elephant vanishes: impact of human - elephant conflict on people's wellbeing. Health Place 18, 1356-1365.

Jernigan, K., 2016. Beings of a feather: learning about the lives of birds with Amazonian peoples. Ethnobiol. Lett. 7, 41-47.

Lee, W.N., Davey, G., 2015. Chinese visitors' experiences of nature and wild macaques: inspiration and personal growth for living in Hong Kong. Hum. Dimens. Wildl. 20, 206-219.

Luck, G.W., Davidson, P., Boxall, D., Smallbone, L., 2011. Relations between urban bird and plant communities and human well-being and connection to nature. Conserv. Biol. 25, 816-826.

MacKerron, G., Mourato, S., 2013. Happiness is greater in natural environments. Glob. Environ. Chang. 23, 992-1000.

Marselle, M.R., Irvine, K.N., Lorenzo-Arribas, A., Warber, S.L., 2015. Moving beyond green: exploring the relationship of environment type and indicators of perceived environmental quality on emotional well-being following group walks. Int. J. Environ. Res. Public Health 12, 106-130.

Mayberry, A.L., Hovorka, A.J., Evans, K.E., 2017. Well-being impacts of human-elephant conflict in Khumaga, Botswana: exploring visible and hidden dimensions. Conserv. Soc. 15, 280-291.

Ohemeng, F., Lawson, E.T., Ayivor, J., Leach, M., Waldman, L., Ntiamoa-Baidu, Y., 2017. Socio-cultural Determinants of Human-Bat Interactions in Rural Ghana. Anthrozoos 30, 181-194.

Pasierowska, R.L., 2017. "Screech owls allus holler "round the house before death": Birds and the souls of black folk in the 1930s American South. J. Soc. Hist. 51, 27-46.

Penteriani, V., Delgado, M., Pinchera, F., Naves, J., Fernández-gil, A., Kojola, I., Härkönen, S., Norberg, H., Frank, J., Fedriani, J.M., Sahlén, V., Støen, O., Swenson, J.E., 2016. Human behaviour can trigger large carnivore attacks in developed countries. Sci. Rep. 6, 1-8.

Røskaft, E., Bjerke, T., Kaltenborn, B., 2003. Patterns of self-reported fear towards large carnivores among the Norwegian public. Evol. Hum. Behav. 24, 184-198.

Sakurai, R., Jacobson, S.K., Ueda, G., 2013. Public perceptions of risk and government performance regarding bear management in Japan. Ursus 24, 70-82.

Singh, Abhishek, Goel, Shewtank, Singh, AnuragAmbroz, Goel, A., Chhoker, V., Goel, Shelesh, Naik, S., Kaur, M., 2015. An epidemiological study of snakebites from rural Haryana. Int. J. Adv. Med. Heal. Res. 2, 39.

Skibins, J.C., Sharp, R.L., 2017. Evaluation of the brown bear viewing experience at Katmai national park and preserve: implications for management. Hum. Dimens. Wildl. 22, 476-482.

Soga, M., Gaston, K.J., Koyanagi, T.F., Kurisu, K., Hanaki, K., 2016. Urban residents’ perceptions of neighbourhood nature: does the extinction of experience matter? Biol. Conserv. 203, 143-150.

Sponarski, C.C., Vaske, J.J., Bath, A.J., 2015. An attitudinal differences among residents, park staff, and visitors toward coyotes in Cape Breton highlands national park of Canada. Soc. Nat. Resour. 28, 720-732.

Tucker, M., Bond, N.W., 1997. The roles of gender, sex role, and disgust in fear of animals. Pers. Individ. Dif. 22, 135-138.

Wheeler, B.W., Lovell, R., Higgins, S.L., White, M.P., Alcock, I., Osborne, N.J., Husk, K., Sabel, C.E., Depledge, M.H., 2015. Beyond greenspace: an ecological study of population general health and indi- 
cators of natural environment type and quality. Int. J. Health Geogr. 14, 1-17.

Young, J.K., Ma, Z., Laudati, A., Berger, J., 2015. Human-Carnivore Interactions: Lessons Learned from Communities in the American West. Hum. Dimens. Wildl. 20, 349-366.

Zamudio, F., Bello-Baltazar, E., Estrada-Lugo, E.I.J., 2013. Learning to hunt Crocodiles: social organization in the process of knowledge generation and the emergence of management practices among Mayan of Mexico. J. Ethnobiol. Ethnomed. 9, 35. 


\subsection{Author contributions}

Authors:

Joel Methorst (JM, PhD candidate), Ugo Arbieu (UA), Aletta Bonn (AB), Katrin Böhning-Gaese (KBG), Thomas Müller (TM)

(1) Development and planning

PhD candidate (JM): $80 \%$

UA, KBG and TM: in total $20 \%$

(2) Compilation of data and preparation of figures

$\mathrm{PhD}$ candidate $(\mathrm{JM}): 100 \%$

- JM conducted the entire literature search and review.

- JM organised and compiled the data tables and prepared all figures in the manuscript and supplementary material.

(3) Data analyses and interpretation of results

PhD candidate (JM): $80 \%$

- JM conducted all descriptive statistics and interpreted the results.

UA, AB, KGB and TM: 20\%

- UA, AB, KGB and TM contributed to the interpretation of results.

(4) Preparation of manuscript

PhD candidate (JM): 70\%

$\mathrm{UA}, \mathrm{AB}$ and $\mathrm{KGB}$ : in total $10 \%$

TM: $20 \%$ 


\section{Appendix II}

\subsection{Manuscript}

Title:

'Species richness is positively related to mental health - a study for Germany'

Status: in review $(10.12 .2020)$

Authors:

Joel Methorst (corresponding author): joel.methorst@senckenberg.de, German Centre for Integrative Biodiversity Research (iDiv) Halle-Jena-Leipzig, Senckenberg Biodiversity and Climate Research Centre (SBiK-F) \& Goethe University Frankfurt am Main Department of Biological Sciences, Frankfurt am Main, Germany

Aletta Bonn: aletta.bonn@idiv.de, Helmholtz-Centre for Environmental Research UFZ, Friedrich Schiller University Jena \& German Centre for Integrative Biodiversity Research (iDiv) Halle-Jena-Leipzig, Leipzig, Germany

Melissa Marselle: melissa.marselle@idiv.de, Helmholtz-Centre for Environmental Research - UFZ, Friedrich Schiller University Jena \& German Centre for Integrative Biodiversity Research (iDiv) Halle-Jena-Leipzig, Leipzig, Germany

Katrin Böhning-Gaese: katrin.boehning-gaese@senckenberg.de, Senckenberg Biodiversity and Climate Research Centre (SBiK-F), Goethe University Frankfurt am Main - Department of Biological Sciences, \& German Centre for Integrative Biodiversity Research (iDiv) Halle-Jena-Leipzig, Frankfurt am Main, Germany

Katrin Rehdanz: rehdanz@economics.uni-kiel.de, Department of Economics, Kiel University, Kiel, Germany 


\begin{abstract}
Nature benefits human health. To date, however, little is known whether biodiversity relates to hu-man health. While some local and city level studies show that species diversity, as a measure of bio-diversity, can have positive effects, there is a lack of studies about the relationship between different species diversity measures and human health, especially at larger spatial scales. Here, we conduct cross-sectional analyses of the association between species diversity and human health across Germany, while controlling for socio-economic factors and other nature characteristics.

As indicators for human health, we use the mental (MCS) and physical health (PCS) component scales of the German Socio-Economic Panel (SOEP, Short Form Health Questionnaire-SF12). For species diversity, we use species richness and abundance estimates of two species groups: plants and birds. We phrase the following hypotheses: plant and bird species are positively associated with mental and physical health (H1 \& H3); bird abundance is positively related to mental health (H2).

Our results demonstrate a significant positive relationship between plant and bird species richness and mental health across all model variations controlling for a multitude of other factors. These re-sults highlight the importance for species diversity for people's mental health and well-being. There-fore, policy makers, landscape planners and greenspace managers on the local and national level should consider supporting biodiverse environments to promote mental health and wellbeing. For this purpose, we propose to use species diversity measures as indicators for salutogenic (health promoting) characteristics of nature, landscape and urban green space.
\end{abstract}




\section{Introduction}

A large number of studies has examined the beneficial effects of nature for human health (Gascon et al., 2015; Kondo et al., 2018; Sandifer et al., 2015). Nature positively influences multiple aspects of human health, ranging from mental to physical health. For example, it has been shown that living in close proximity to urban parks or water bodies is related to better perceived physical health and mental health (e.g. Gascon et al., 2015; Triguero-Mas et al., 2015). The majority of these studies, however, focuses on the quantity (size and proximity) of greenspace without consideration of its quality (e.g. van den Berg et al., 2015). Consequently, little is known about how the different qualities of nature, such as biodiversity, contribute to physical and mental health (Aerts et al., 2018; Marselle et al., 2019).

A few studies have found positive associations between biodiversity and human health (e.g. Aerts et al., 2018; Marselle et al., 2019) and some specifically focus on species diversity as a measure for biodiversity. For instance, higher bird and plant species richness in urban parks was related to heightened psychological well-being (Fuller et al., 2007) and afternoon bird abundance was associated with better mental health in urbanized areas (Cox et al., 2017b). Two mechanisms have been proposed. Attention restoration (Attention Restoration Theory) refers to the possibility that an environment can influence a person's ability to concentrate or direct attention (Kaplan, 1995) while the stress reduction (Stress Reduction Theory) considers the physiological impact of viewing environments which then facilitates the reduction of psychological stress (Ulrich, 1991).

Beyond mental health and well-being, people visiting urban parks with high species diversity (including plants and insects) reported higher overall health, a composite measure covering both mental and physical health aspects, and perceived restoration (Carrus et al., 2015). Similarly, a higher prevalence of 'good' overall human health was observed among people living in areas with higher bird species richness (Wheeler et al., 2015). These studies used objective measures for species richness based on ecological monitoring schemes. However, efforts have also been made to explore the effect of perceived species richness, a subjective measure where people are asked to estimate species richness in a specific area (see e.g. Dallimer et al., 2012; Lindemann-Matthies et al., 2010). In particular, Dallimer et al. (2012) found, that perceived - but not objective (ecological) - bird, plant and butterfly species richness was positively related to psychological well-being in 
urban parks.

Most of the studies examining the effect of species diversity on human health were conducted at a smaller scale (e.g. urban parks, neighbourhoods, cities), apart from one national-scale study so far (i.e. Wheeler et al., 2015). To better understand how general the relationship between species diversity and human health is, epidemiological studies on a larger spatial scale are needed to identify relevant associations and provide evidence-based information for local and national policy design, landscape planning as well as urban greenspace management.

In this study, we go beyond previous efforts and study the relationship between species diversity and human health at the regional scale, using Germany as a case study. We combine and analyse macroecological data from across Germany and socio-economic data from the German Socio-Economic Panel (SOEP, Goebel et al., 2019). We use both species richness and abundance as measures for species diversity and focus on two species groups: plants (only species richness) and birds. Species richness captures the number of different species of plants and animals, while abundance accounts for the number of individuals, here for birds, as no appropriate abundance data was available for plants at this scale. Both variables represent objective measures of species diversity and are based on ecological data. Human health is separately investigated as mental and physical health. We use the mental health component scale (MCS) and physical health component scale (PCS), two important indicators for 'Health Related Quality of Life' (e.g. Busija et al., 2011; Coons et al., 2000). MCS and PCS are composite variables derived from a set of questions which each address specific aspects of human health (e.g. mental and emotional state for the MCS, physical pain for the PCS). We also make use of the large amount of socio-economic and demographic variables provided by the SOEP, including household income, education status or employment status.

In our study, we address three hypotheses. First, we expect that objective plant and bird species richness have a positive influence on mental health $(\mathrm{H} 1)$ because local scale studies have shown that both plant and bird species richness are positively related to mental health and well-being (Dallimer et al., 2012; Fuller et al., 2007). Second, we hypothesise that bird abundance is positively associated with mental health (H2) as studies have shown that bird afternoon abundance in urban parks influences mental health (Cox et al., 2017b). Third, we assume that bird and plant diversity variables are positively 
associated with physical health (H3). Some studies could show a positive influence of species richness (e.g. birds and plants) on general and composite human health measures (Carrus et al., 2015; Wheeler et al., 2015). Furthermore, various studies and reviews have highlighted the potential benefits of species richness in regard to vector-borne diseases, gut microbial communities, allergies or asthma (Aerts et al., 2018; Lovell et al., 2014; Sandifer et al., 2015).

\section{Data and methods}

\subsection{Socio-economic and demographic variables}

Socio-economic data was obtained from the German Socio-Economic Panel (SOEP), a longitudinal panel survey of private households across Germany which now includes nearly 15,000 households and about 30,000 persons (Goebel et al., 2019). The panel was started in 1984 and new surveys have been added annually since then. Data is usually collected with face-to-face interviews. The SOEP data provides socio-economic, demographic and health information on the individual and household level. It also provides the geographical location of each household at the county level (German: Landkreise, county codes from 31.12.2013, $\mathrm{n}=402$ ). Access to the SOEP data was granted by the German Institute for Economic Research (German: Deutsches Institut für Wirtschaftsforschung) after specific preconditions were met and the data protection regulations signed. In order to align the SOEP data with the species diversity and nature indicators we use macroecological data aggregated at the by county level. This spatial level has also been used for aggregated ecosystem services data to assist in decision making and spatial planning in Germany (Rabe et al., 2016).

Our analysis focuses on SOEP data from the year 2008 (SOEP-Data Version 33.1), covering a sample of more than 13,000 individuals located in 394 counties (a slight reduction in the number of counties due to missing data and data removal). These counties differ in their size, ranging from 37.2 to 5470.3 square kilometres (see Table 1). We chose the survey year 2008 as it lies within the collection period of the bird atlas data for Germany (for further details see section 2.3.1). Importantly, unlike other survey years, the 2008 SOEP survey also includes information on respondents' mental and physical health. In addition, we include data only available in the 2009 SOEP survey on walking distance to parks (green space availability) and the 'Big Five'-personality variables (openness, con- 
Tab. 1: Summary statistics for selected variables $(n=13,328)$. Shown are only the continuous variables. Summary statistics of all variable are shown in the Supplementary Material (Appendix II, Table A.II-4 \& Table A.II-5).

\begin{tabular}{|c|c|c|c|c|}
\hline & Min. & Mean & Median & Max. \\
\hline \multicolumn{5}{|l|}{ Personal characteristics } \\
\hline MCS & 5.32 & 50.83 & 52.52 & 76.54 \\
\hline PCS & 12.27 & 49.29 & 51.44 & 73.61 \\
\hline Income (EUR) & 554 & 2817 & 2500 & 9200 \\
\hline Age (years) & 18 & 50.18 & 50 & 99 \\
\hline Doctor visits (no./year) & 0 & 9.79 & 8 & 396 \\
\hline Hospital visits (no. in year 2007) & 0 & 1.37 & 0 & 240 \\
\hline Body mass index & 13.36 & 26.13 & 25.59 & 59.03 \\
\hline No. of friends (no./person) & 0 & 4.21 & 3 & 90 \\
\hline \multicolumn{5}{|l|}{$\begin{array}{l}\text { Macro-economic characteristics (at the } \\
\text { county level) }\end{array}$} \\
\hline GDP per capita (1000 EUR) & 13.2 & 29.85 & 27.2 & 91.8 \\
\hline Unemployment rate $(\%)$ & 1.6 & 8.34 & 7.8 & 19.4 \\
\hline Population density (no. people/km2) & 39.1 & 828.4 & 299.8 & 4274.5 \\
\hline \multicolumn{5}{|l|}{ Species diversity (county level) } \\
\hline Plant species richness (no. of species) & 670.17 & 1134 & 1130.8 & 1785.86 \\
\hline Bird abundance (no. breeding pairs) & 10601.36 & 38269 & 38710 & 69514.08 \\
\hline Bird species richness (no. of species) & 59.16 & 104.8 & 105.46 & 145.65 \\
\hline \multicolumn{5}{|l|}{$\begin{array}{l}\text { Nature and climate characteristics } \\
\text { (at the county level) }\end{array}$} \\
\hline Blue space $(\%)$ & 0 & 1.1 & 0.37 & 32.45 \\
\hline Green space $(\%)$ & 2.49 & 42.15 & 38.62 & 97.76 \\
\hline $\begin{array}{l}\text { Landscape heterogeneity } \\
\text { (Shannon index, H') }\end{array}$ & 0.77 & 1.36 & 1.36 & 1.91 \\
\hline Topographic heterogeneity (metre) & 9.94 & 178.3 & 158.09 & 1307.97 \\
\hline Protected areas $(\%)$ & 0 & 20.45 & 8.12 & 99.99 \\
\hline Temperature $\left({ }^{\circ} \mathrm{C}\right)$ & 5.69 & 9.24 & 9.31 & 10.95 \\
\hline Precipitation (cm/year) & 51.52 & 80.77 & 79.97 & 190.7 \\
\hline County area size (km2) & 37.22 & 973.9 & 839.9 & 5470.34 \\
\hline
\end{tabular}

scientiousness, extraversion, agreeableness, and neuroticism). We combine information from the two survey years using respondent's unique identifiers. For consistency, our final sample includes only those individuals that did not move between 2008 and 2009, ensuring that walking distance did not change.

Our selection of socio-economic and demographic variables is based on previous studies explaining differences in MCS and PCS (e.g. Nesterko et al., 2013) as well as studies examining the influence of green space and neighbourhood environment on PCS and MCS (Petersen et al., 2018; Sugiyama et al., 2008). Socio-economic and demographic variables include: age, gender, household income, family status, labor force status, edu- 
cational attainment, migratory background, and urban residency. Health-related information includes: frequency of doctor visits, body mass index, frequency of sport exercise, disability, and number of friends. The 'Big Five' personality variables (Costa and McCrae, 1985) were also included in order to account for personality differences between survey respondents. All socio-economic, demographic, health and personality variables were obtained from the SOEP.

A

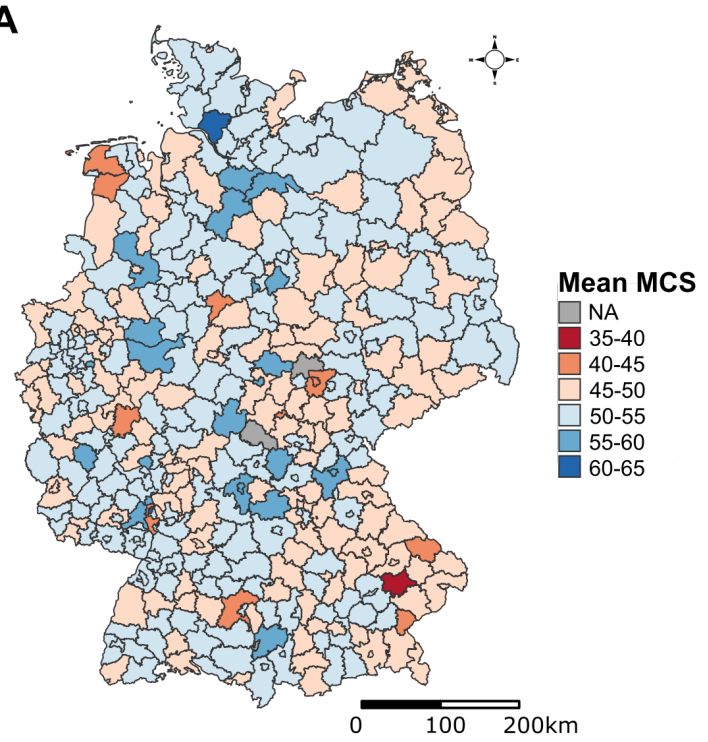

B

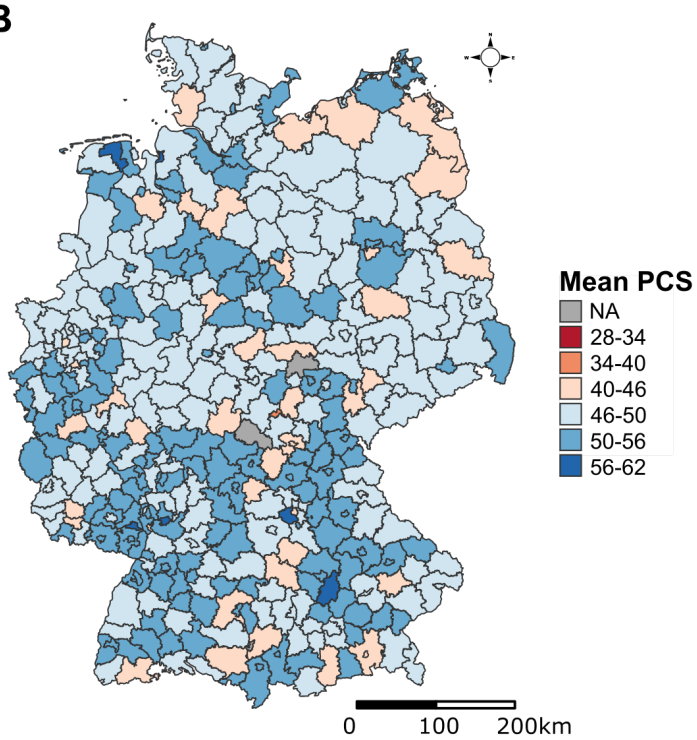

Fig. 1: Mental health (A, mean MCS) and physical health (B, mean PCS) scores on county level across Germany from 2008. Higher mean MCS and PCS scores indicate better mental or physical health. Shown are values for 394 counties based on SOEP (Socio-Economic Panel Germany) survey data ( $\mathrm{n}=13,328)$. Data for some counties was not available due to missing data. The number of observations per county ranges from 1 to 480 (median $=25)$. MCS $=$ Mental Health Component Scale. PCS = Physical Health Component Scale. For more information see Methods section.

\subsection{Physical and mental health}

Every second year the SOEP survey includes physical and mental health questions, which includes the Short Form 12 (SF-12, version 2) health survey (Ware et al., 1995). The SF-12 has been validated for use in Germany (Andersen et al., 2007). The 12 questions carry a mixture of positively and negatively worded items (on a 5 or 6 point ordinal scale) addressing eight domains of mental and physical health-related topics: general health; vitality; mental health; emotional roles; social functioning; physical functioning; role physical, and; bodily pain (see Supplementary Material, Table A.II-1 for more information on the wording). The answers to each of the 12 items are used to calculate MCS and PCS component scale scores which are provided with the SOEP data. The MCS and PCS scores range from 0-100, with higher scores indicating better health (Fig. 1, Supplementary Material, Table A.II-4). MCS and PCS are well-established indicators for human 
Health-Related Quality of Life (HRQoL) (Ware and Sherbourne, 1992). HRQoL refers to an individuals' perceptions of their physical, psychological, and social functioning (e.g. Testa and Simonson, 1996). Both the MSC and PCS have been successfully used in previous green space and health studies (Petersen et al., 2018; Sugiyama et al., 2008).

\subsection{Access to parks and gardens}

To account for people's potential access to nature, reported information on walking distance to public parks and green space (German: 'Entfernung zu Fuss zu Grünanlagen') was included. Walking distance is a subjective measure which accounts for potential physical limitations and was assessed in terms of minutes by participants (Siegel et al., 2010). In addition, information on the availability of a private garden was also provided and converted to a dummy variable $(1=$ garden, $0=$ no garden $)$. Both variables were obtained from the 2009 SOEP questionnaire.

\subsection{Macro-economic data}

The following macro-economic factors, which might influence human health, were also take into account: population density, GDP per capita, unemployment rate, and county area size $(\mathrm{km} 2)$. All macro-economic variables are measured at the county level. Information on GDP per capita and unemployment rate were provided by SOEP, data on population density and county size were available from the Federal Statistical Office of Germany (German: Statistisches Bundesamt). In addition, we created a dummy variable (East-Germany dummy) for federal states which were formerly part of the German Democratic Republic to account for potential socio-economic differences between people living in East or West-Germany (e.g. Bramesfeld et al., 2010; Easterlin and Plagnol, 2008).

\subsection{Macroecological data}

\subsubsection{Species diversity}

To study the role of species diversity for human health across Germany we collated macroecological data on species richness (number of different species) and abundance for two taxonomic groups: plant and bird species. These two species groups were the 
only taxa for whom nationwide data was available. A plant species richness map (Fig. 2) was calculated based on plant distribution data for Germany. The data was obtained from the German atlas for flowering plants and ferns 'Verbreitungsatlas der Farn- und Blütenpflanzen Deutschlands' (Deutschland Netzwerk Phytodiversität \& Bundesamt für Naturschutz, 2013), which provides occurrence data on a 10x10km grid ('Topographische Karte' - TK 25 grid). The atlas was created by merging multiple plant databases from German federal states and validating the results with expert knowledge.

Bird species richness and abundance maps (Fig. 2) were created based on data provided by the 'Atlas of German Breeding Birds' (Gedeon et al., 2014). The monitoring for the bird atlas was conducted by volunteers between the years 2005-2009 and similar to the plant atlas, the final data on bird species distribution and population size (number of breeding pairs) is provided for the same $10 \times 10 \mathrm{~km}$ grid as used for the plant atlas. The population sizes of birds were provided as grouped or discretized continuous variables (e.g. 1-100, 101-200, 201-300 breeding pairs) and we therefore calculated the mean for these groups in order to obtain continuous abundance estimates for each species within a 10x10km grid cell. If an abundance estimate for a specific species and a specific grid cell was missing, we calculated the abundance based on the mean of neighbouring grid cells (max. $=8$ grid cells). Total bird abundance was the sum of all abundance data for one grid cell.
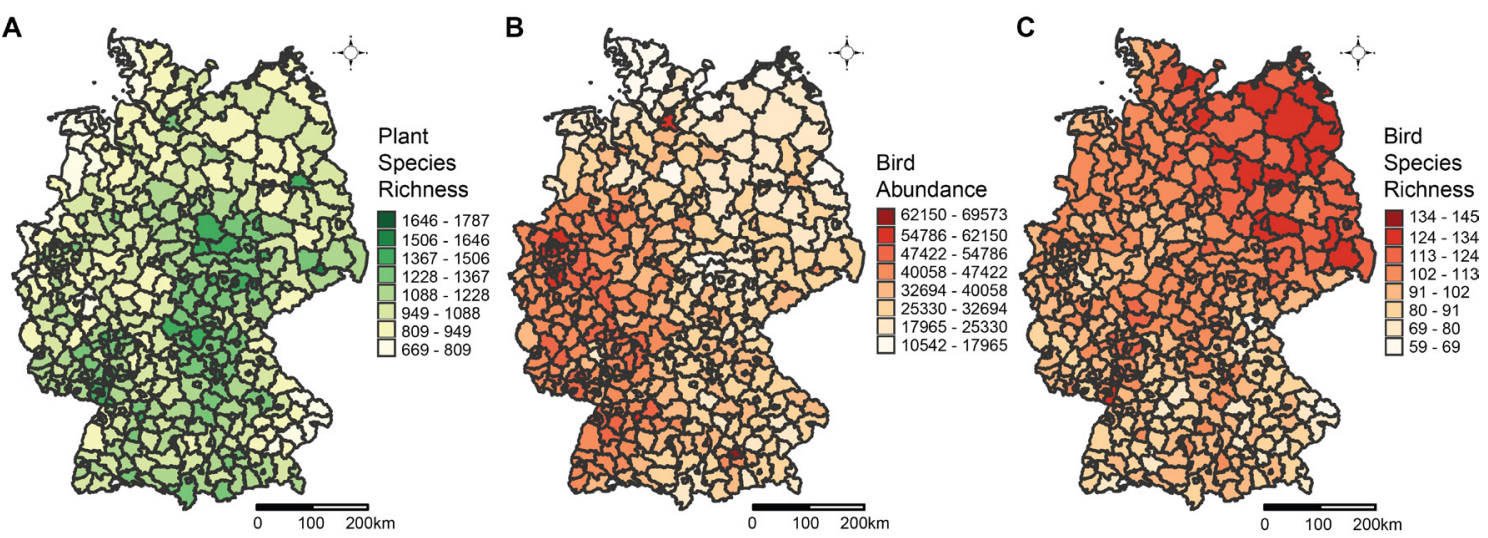

Fig. 2: Species diversity measures on county level across Germany. Shown are area weighted mean plant species richness (A), bird abundance (B) and bird species richness (C). Species richness was measured as the number of species and abundances are based on numbers of bird breeding pairs.

\subsubsection{Nature characteristics}

It has been shown that green space or protected area cover influence human health in epidemiological studies (e.g. van den Berg et al., 2015; Wheeler et al., 2015). Similarly, 
blue space is also known to positively affect human health and well-being (de Vries et al., 2016; e.g. Gascon et al., 2015). Furthermore, different nature characteristics and land cover types may also influence species richness patterns (e.g. Atauri and De Lucio, 2001; Deutschewitz et al., 2003). We therefore include different nature characteristics in our analyses to identify the independent effect of species diversity on mental and physical health (MCS and PCS). The following variables were included: blue space cover, green space cover, protected area cover, landscape heterogeneity and topographic heterogeneity.

The percentages of both blue and green space cover in each German county were calculated based on land cover data from the CORINE Land Cover database from 2006. The CORINE database publishes aggregated sets of land-cover classifications as raster data with a $100 \mathrm{~m}$ resolution where the number of land cover types are reduced from 44 to 15 or 5 land cover types. These different categories were organised into blue and green space categories. The blue space category was comprised of mainly terrestrial water bodies. The green space category was comprised of all types of vegetated areas. The percentage of area covered within each county was calculated using the raster cells categorized as either blue or green space (see Supplementary Material, Table A.II-3). Due to the spatial resolution of the CORINE data, the variables for blue and green space most likely only include larger water bodies or vegetated areas (approx. 25 hectares).

We used the 15 land cover types of the CORINE land cover data from 2006 to calculate landscape heterogeneity (the variation of different landcover types) on the county level. We determined the number of CORINE raster cells for each land cover type within each $10 \times 10 \mathrm{~km}$ grid cell. Shannon-Index $\left(\mathrm{H}^{\prime}\right)$ was calculated based on the frequency of the different land cover types within each $10 \times 10 \mathrm{~km}$ grid cell; this was done using the $\mathrm{R}$ package 'vegan' (Oksanen et al., 2017). As additional measure of landscape heterogeneity, we used topographic heterogeneity. Topographic heterogeneity and elevation have been identified as indicators for scenic views and landscapes with high recreational and aesthetic value (de Almeida Rodrigues et al., 2018; Sherrouse et al., 2011). Topographic heterogeneity was determined using the elevational range (difference between min and max. elevation) within each 10x10km grid cell. The necessary data for these calculations were quarried from a 200m Digital Terrain Model (DGM 200) from the Federal Agency for Cartography and Geodesy. 
For protected areas in Germany, we collected spatial data from a 2008 Digital Landscape Model (DLM 250) published by the Federal Agency for Cartography and Geodesy (German: Bundesamt für Kartographie und Geodäsie, https://gdz.bkg.bund.de). The DLM 250 provides data on the location and size of national parks, wildlife parks (German: 'Naturparks') and biosphere reserves (German: 'Biosphärenreservat'). In the DLM 250, national parks are classified according to the IUCN category II, wildlife parks were established under section 22, paragraph 4 of Germany's Federal Nature Conservation Act (BNatSchG) and biosphere reserves are assigned by the UNESCO Worlds Network of Biosphere Reserves (Bundesamt für Naturschutz, 2008). We summarized the total area covered by all three protected area types within a county and then calculated the percentages.

\subsubsection{Climate characteristics}

As atmospheric temperature or temperature fluctuations can pose a risk to human health and well-being (e.g. Basu, 2009; Yu et al., 2012), these climate variables were included in our analyses. We downloaded a multi-annual raster dataset for mean temperature and mean precipitation, for the years 1981-2010. From this raster data, we extracted values (Version v1.0, $1 \mathrm{~km}$ resolution) by using the same 10x10km grid as before (TK25, see section 2.3) and then calculated mean temperature and precipitation estimates for each grid cell. These data came from the German weather service's Climate Data Center website (https://opendata.dwd.de/climate_environment/CDC/).

\subsection{Merging data}

In a final step before the data analysis, we merged the SOEP data with our macroecological data (species diversity, nature characteristics and climate). To allow the merging of the data all the macroecological variables had to be aggregated to the county level. To do this, the $10 \times 10 \mathrm{~km}$ grids were superimposed over each German county $(\mathrm{n}=402$, mean area size $=973.90 \mathrm{~km} 2$ ) to estimate area weighted means for each county. Within each German county we determined the intersecting polygons from the $10 \times 10 \mathrm{~km}$ grid and then weighed the values of each grid polygon by the percent of area it covers within the county. Area weighted means for the following macroecological variables were calculated: plant species richness, bird species richness, bird abundance, landscape heterogeneity, 
topographic heterogeneity, temperature and precipitation. Excluded from this data processing step were the variables for percent area covered by blue space, green space and protected areas because they already represented information on county level. The final data set contained socio-economic and health data on the individual level and information on species diversity (Fig. 2), nature characteristics, climate and macro-economic factors on the county level. Our final data set contained information for 13,328 individuals living within 394 counties after removing all missing values (summary statistics can be found in Supplementary Material, Table A.II-4 \& Table A.II-5).

\subsection{Empirical analysis}

We used linear regression models (ordinary least squares, OLS) to study the relationship between species diversity and MCS or PCS while accounting for various socio-economic and demographic characteristics as well as macro-economic factors. To answer hypotheses 1-3, we included different measures of species diversity as predictor variables: plant species richness, bird species richness or bird abundance. To avoid multicollinearity issues (Suplementary Material, Table A.II-6) each OLS regression contained either one single species diversity variable (Table 2 , models I-VI) or a maximum of two species diversity variables (Table 3, models VII-XII). In addition, we include access to parks and gardens as well as nature and climate characteristics such as blue space cover, green space cover landscape heterogeneity, topographic heterogeneity and protected area cover. All species diversity variables were introduced into the models with their natural logarithm.

To identify and reduce multicollinearity, we calculated Generalized Variance Inflation Factors (GVIF, Fox and Monette, 1992) and correlations (Suplementary Material, Table A.II-6) and excluded control variables with GVIF scores $>10$ and correlation coefficients $>0.6$ (Dormann et al., 2013). Based on the outcomes of the multicollinearity tests, we excluded green space, topographic heterogeneity and precipitation from our final models (Suplementary Material, Table A.II-6). An exception to this rule is the correlation between the East-Germany dummy and unemployment rate. We included these two variables in the same models because both variables can explain the variation of MCS and PCS across Germany. To make sure this decision does not affect our results, we also tested models where we replaced unemployment rate by GDP per capita. These tests produced the same overall results which, however, are not shown here. 
Our specification procedure followed a stepwise process (for a definition of the variables see Supplementary Material, Table A.II-2). In the first step (aka. the basic model), we added the different combinations of species diversity variables and a set of control variables. In the basic model, the control variables include variables for local level access to nature measured as walking distance to parks and a garden dummy, socio-economic and health variables (log-transformed household income, age, gender, family status, labor force status, education, migratory background, and urban residency, number of doctor visits, number of hospital visits, number of friends, body mass index, frequency of sport exercise, disability status, and personality), macro-economic variables (unemployment rate, population density and area size of each county) as well as the East-Germany and federal state dummies. In the second step we added county-level nature and climate characteristics (blue space cover, protected area cover, landscape heterogeneity and mean temperature). Here (Tables $1 \&$ 2, Supplementary Material, Table A.II-7 \& Table A.II-8) we show OLS models with all variables, including nature and climatic factors. To account for heteroscedasticity in the OLS models and the hierarchical structure (individuals living in countries) of the data set, we used heteroscedasticity-robust clustered standard errors. This procedure relaxes the assumption that observations are independent and adjusts standard errors for intra-regional correlation (Moulton, 1990). Data preparation and all analyses were conducted with R Studio (Version 1.0.143).
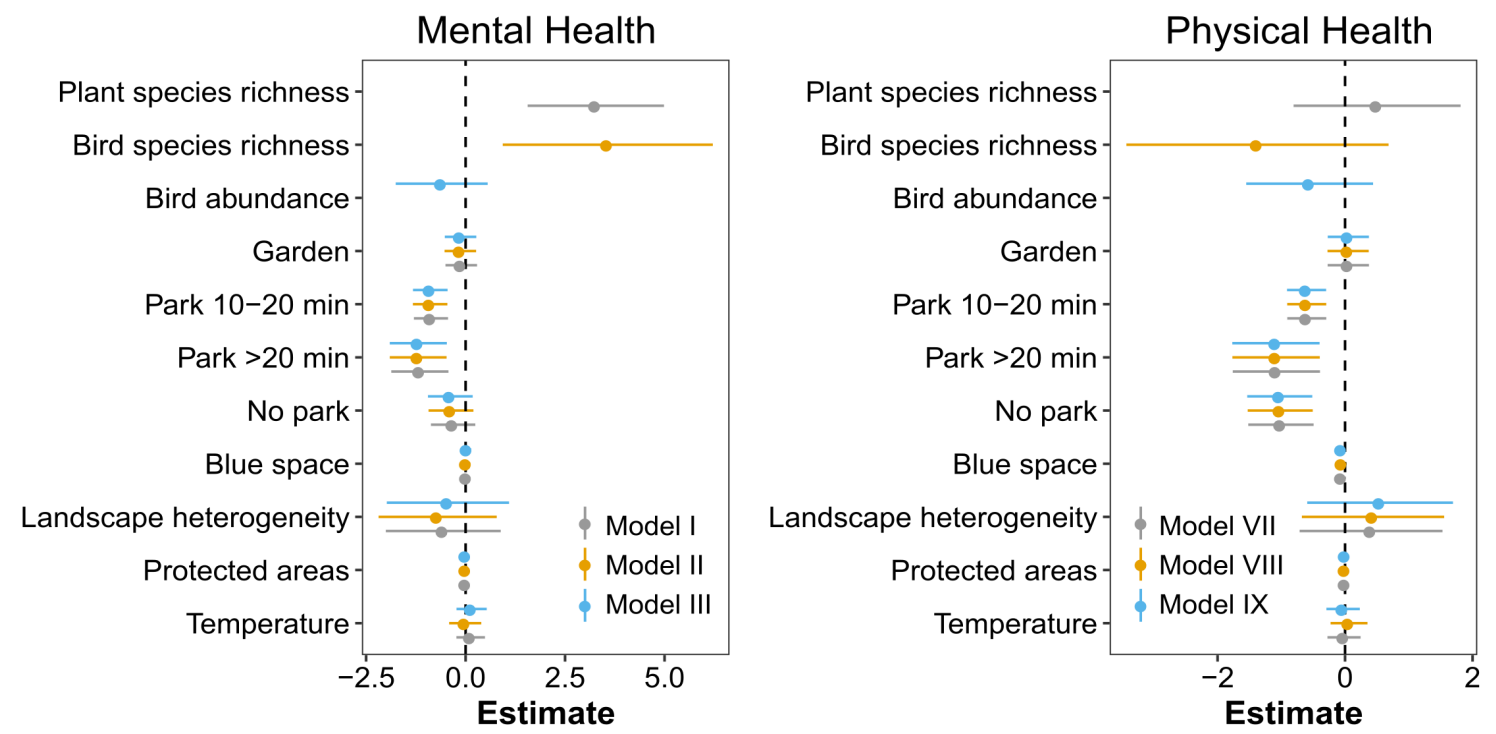

Fig. 3: Selected model coefficients with $95 \%$ confidence intervals for species diversity, access to a garden \& parks (measured in minutes walking distance), nature characteristics and climate. Shown are all models from Table 2 with mental health and physical health as dependent variables (model names in the legend correspond to the OLS models form Table 2 and 3). Detailed results for all models and independent variables are presented in the Supplementary Material, Table A.II-7 \& Table A.II-8. 


\section{Results}

Figures 1 and 2 display the variation of human health (Fig. 1) and species diversity (Fig. 2) across Germany. Mean values for MCS and PCS per county range between 37-61 and 28-59 for mental and physical health, respectively (Fig. 1). The county with the highest number of plant species reports approx. 1786 different species (Min. $=670$, based on area weighted mean values). Bird richness in a county ranges from 59 to 146 species while total bird abundance can range between 1000 and 6000 breeding pairs (Fig. 2 and Table 1). Values for the species diversity measures also show specific spatial patterns (Fig. 2). For example, high plant species richness can be observed in regions of central and south-western Germany while high values of bird species richness are found in Eastern Germany. In contrast, bird abundance estimates are highest in Western Germany (Fig. 2).

Tab. 2: OLS models with one species diversity variable. Each model contains the same set of control variables: socio-economic variables ${ }^{1}$, macro-economic variables ${ }^{2}$, Big 5 personality variables as well as an East-Germany dummy and federal state dummies. Shown are coefficients and standardized coefficients $(\beta)$, standard errors in parenthesis and t-values. P-values are indicated by asterisk symbols: $*<0.05, * *<0.01$, $* * *<0.001$. Roman numbers I-VI represent different OLS models.

\begin{tabular}{|c|c|c|c|c|c|c|}
\hline & \multicolumn{3}{|c|}{ Mental health } & \multicolumn{3}{|c|}{ Physical health } \\
\hline & I & II & III & IV & $\mathbf{V}$ & VI \\
\hline \multicolumn{7}{|l|}{ Species diversity } \\
\hline \multirow{3}{*}{$\begin{array}{l}\text { Log plant species } \\
\text { richness }\end{array}$} & $3.27 / .06$ & - & - & $0.50 / .01$ & - & - \\
\hline & $(0.87)$ & & & $(0.67)$ & & \\
\hline & $3.74 * * *$ & & & 0.75 & & \\
\hline \multirow{3}{*}{$\begin{array}{l}\text { Log bird species } \\
\text { richness }\end{array}$} & - & $3.57 / .05$ & - & - & $-1.38 /-.02$ & - \\
\hline & & $(1.35)$ & & & $(1.05)$ & \\
\hline & & $2.65 * *$ & & & -1.31 & \\
\hline \multirow[t]{3}{*}{ Log bird abundance } & - & - & $-0.6 /-.02$ & - & - & $-0.56 /-.02$ \\
\hline & & & $(0.59)$ & & & $(0.51)$ \\
\hline & & & -1.02 & & & -1.1 \\
\hline \multicolumn{7}{|l|}{$\begin{array}{l}\text { Access garden and } \\
\text { parks }\end{array}$} \\
\hline \multirow[t]{3}{*}{ Garden } & $-0.11 /-.01$ & $-0.13 /-.01$ & $-0.13 /-.01$ & $0.05 / .00$ & $0.05 / .00$ & $0.05 / .00$ \\
\hline & $(0.20)$ & $(0.20)$ & $(0.20)$ & $(0.17)$ & $(0.17)$ & $(0.17)$ \\
\hline & -0.54 & -0.66 & -0.63 & 0.31 & 0.29 & 0.31 \\
\hline \multirow{3}{*}{$\begin{array}{l}\text { Park in } 10-20 \text { walk- } \\
\text { ing minutes }{ }^{3}\end{array}$} & $-0.87 /-.04$ & $-0.89 /-.04$ & $-0.89 / .04$ & $-0.6 /-.02$ & $-0.6 /-.03$ & $-0.6 /-.03$ \\
\hline & $(0.22)$ & $(0.22)$ & $(0.22)$ & $(0.16)$ & $(0.16)$ & $(0.16)$ \\
\hline & $-3.98 * * *$ & $-4.03 * * *$ & $-4.00 * * *$ & $-3.85 * * *$ & $-3.85 * * *$ & $-3.86 * * *$ \\
\hline \multirow{3}{*}{$\begin{array}{l}\text { Park }>20 \text { walking } \\
\text { minutes }^{3}\end{array}$} & $-1.15 /-.03$ & $-1.19 /-.03$ & $-1.19 /-.03$ & $-1.08 /-.03$ & $-1.08 /-.03$ & $-1.09 /-.03$ \\
\hline & $(0.37)$ & $(0.37)$ & $(0.37)$ & $(0.35)$ & $(0.35)$ & $(0.35)$ \\
\hline & $-3.14 * *$ & $-3.28 * *$ & $-3.25 * *$ & $-3.09 * *$ & $-3.10 * *$ & $-3.10 * *$ \\
\hline \multirow[t]{3}{*}{ No park ${ }^{3}$} & $-0.32 /-.01$ & $-0.37 /-.01$ & $-0.39 /-.01$ & $-1.01 /-.03$ & $-1.02 /-.03$ & $-1.03 /-.03$ \\
\hline & $(0.29)$ & $(0.29)$ & $(0.29)$ & $(0.26)$ & $(0.26)$ & $(0.26)$ \\
\hline & -1.11 & -1.28 & -1.34 & $-3.85 * * *$ & $-3.91 * * *$ & $-3.94 * * *$ \\
\hline
\end{tabular}




\begin{tabular}{|c|c|c|c|c|c|c|}
\hline & \multicolumn{3}{|c|}{ Mental health } & \multicolumn{3}{|c|}{ Physical health } \\
\hline \multicolumn{7}{|l|}{ Nature \& Climate } \\
\hline \multirow[t]{3}{*}{ Blue space } & $0.03 / .01$ & $0.03 / .01$ & $0.04 / .01$ & $-0.05 /-.01$ & $-0.05 /-.01$ & $-0.05 /-.01$ \\
\hline & $(0.05)$ & $(0.05)$ & $(0.05)$ & $(0.04)$ & $(0.04)$ & $(0.04)$ \\
\hline & 0.6 & 0.54 & 0.85 & -1.55 & -1.29 & -1.49 \\
\hline \multirow[t]{3}{*}{ Protected area cover } & $-0.56 /-.01$ & $-0.7 /-0.02$ & $-0.45 /-.01$ & $0.41 / .01$ & $0.44 / .01$ & $0.55 / .01$ \\
\hline & $(0.74)$ & $(0.76)$ & $(0.78)$ & $(0.57)$ & $(0.57)$ & $(0.58)$ \\
\hline & -0.76 & -0.93 & -0.57 & 0.71 & 0.77 & 0.94 \\
\hline \multirow{3}{*}{$\begin{array}{l}\text { Landscape heteroge- } \\
\text { neity }\end{array}$} & $0.01 / .02$ & $0.01 / .02$ & $0.01 / .03$ & $0.01 / .01$ & $0.004 / .01$ & $-0.01 / 0.02$ \\
\hline & $(0.01)$ & $(0.01)$ & $(0.01)$ & $(0.004)$ & $(0.004)$ & $(0.003)$ \\
\hline & 1.9 & $2.16^{*}$ & 1.93 & 1.34 & 1.06 & 1.64 \\
\hline \multirow[t]{3}{*}{ Temperature } & $0.13 / .01$ & $-0.01 / .00$ & $0.15 / .01$ & $-0.02 /-.00$ & $0.06 / .01$ & $-0.03 /-.00$ \\
\hline & 0.18 & 0.21 & 0.19 & 0.13 & 0.15 & 1.33 \\
\hline & 0.7 & -0.05 & 0.78 & -0.12 & 0.42 & -0.23 \\
\hline Adj. R-squared & 0.2 & 0.2 & 0.2 & 0.46 & 0.46 & 0.46 \\
\hline AIC & 94990.49 & 95001.93 & 95012.22 & 90928.91 & 90927.25 & 90927.64 \\
\hline Observations & 13,328 & 13,328 & 13,328 & 13,328 & 13,328 & 13,328 \\
\hline Clusters & 394 & 394 & 394 & 394 & 394 & 394 \\
\hline \multicolumn{7}{|c|}{$\begin{array}{l}{ }^{1} \text { Household income, age, sex, family status, employment status, education, migrant, urban resident, } \\
\text { body mass index, doctor visits, hospital visits, strong disability, number of friends, sport exercise. } \\
{ }^{2} \text { Unemployment-rate, population density, county area size }(\mathrm{km} 2) \text {. } \\
{ }^{3} \text { Reference group = walking distance to park }<10 \text { minutes. }\end{array}$} \\
\hline
\end{tabular}

\subsection{Species diversity}

\subsubsection{Species diversity and human health}

Our models with mental health (MCS) as dependent variable show a significant positive correlation between plant and bird species richness and mental health (Fig. 3, Tables 2-3), supporting hypothesis 1 (H1). Plant species richness was positively associated with mental health in model I $(\mathrm{t}=3.74, \mathrm{p}<0.001)$, model VII $(\mathrm{t}=2.82, \mathrm{p}<0.01)$, and model VIII $(\mathrm{t}=3.83, \mathrm{p}<0.001)$. Model II $(\mathrm{t}=2.65, \mathrm{p}<0.01)$ and model IV $(\mathrm{t}=2.62, \mathrm{p}<0.01)$ show that bird species richness is positively related to mental health. For bird abundance, there is no significant relationship with mental health (Tables 2-3); hypothesis 2 is not supported (H2). Looking at the combined effect of two species diversity variables together in the same model, plant species richness is always significant - independent of bird species richness or abundance (Table 3, Models VII \& VIII). In addition, bird species richness is only significant when omitting plant species richness (compare Models II, VIII and IV).

Considering the adjusted R-square values, models with two species diversity measures (Table 3) did not differ in regard to their model fit compared to the models with one sin- 
Tab. 3: OLS models with two species diversity variables. Each model contains the same set of control variables: socio-economic variables ${ }^{1}$, macro-economic variables ${ }^{2}$, Big 5 personality variables as well as an East-Germany dummy and federal state dummies. Shown are coefficients and standardized coefficients $(\beta)$, standard errors in parenthesis and t-values. P-values are indicated by asterisk symbols: $*<0.05, * *<0.01$, $* * *<0.001$. Roman numbers VII-XII represent different OLS models.

\begin{tabular}{|c|c|c|c|c|c|c|}
\hline & \multicolumn{3}{|c|}{ Mental health } & \multicolumn{3}{|c|}{ Physical health } \\
\hline & I & II & III & IV & $\mathbf{V}$ & VI \\
\hline \multicolumn{7}{|l|}{ Species diversity } \\
\hline \multirow{3}{*}{$\begin{array}{l}\text { Log plant species } \\
\text { richness }\end{array}$} & $2.78 / .05$ & $3.30 / .06$ & - & $0.99 / .01$ & $0.53 / .01$ & - \\
\hline & $(0.99)$ & $(0.86)$ & & $(0.73)$ & $(0.67)$ & \\
\hline & $2.82 * *$ & $3.83 * * *$ & & 1.38 & 0.79 & \\
\hline \multirow{3}{*}{$\begin{array}{l}\text { Log bird species } \\
\text { richness }\end{array}$} & $1.94 / .03$ & - & $3.55 / .05$ & $-1.96 /-.02$ & - & $-1.4 /-.02$ \\
\hline & (1.49) & & $(1.36)$ & $(1.14)$ & & $(1.06)$ \\
\hline & 1.3 & & $2.62 * *$ & -1.72 & & -1.32 \\
\hline \multirow[t]{3}{*}{ Log bird abundance } & - & $-0.67 /-.02$ & $-0.57 /-.02$ & - & $-0.57 /-.02$ & $-0.57 /-.02$ \\
\hline & & $(0.58)$ & $(0.6)$ & & $(0.51)$ & $(0.50)$ \\
\hline & & -1.16 & -0.96 & & -1.11 & -1.14 \\
\hline
\end{tabular}

Access garden and parks

\begin{tabular}{|c|c|c|c|c|c|c|}
\hline \multirow[t]{2}{*}{ Garden } & $\begin{array}{c}-0.11 /-.01 \\
(0.20)\end{array}$ & $\begin{array}{c}-0.11 / .01 \\
(0.30)\end{array}$ & $\begin{array}{c}-0.13 /-.01 \\
(0.40)\end{array}$ & $\begin{array}{c}0.06 / .00 \\
(0.17)\end{array}$ & $\begin{array}{c}0.06 / .00 \\
(0.18)\end{array}$ & $\begin{array}{c}0.05 / .00 \\
(0.19)\end{array}$ \\
\hline & -0.56 & -0.516 & -0.64 & 0.33 & 0.33 & 0.31 \\
\hline \multirow[t]{2}{*}{$\begin{array}{l}\text { Park in } 10-20 \text { walk- } \\
\text { ing minutes }{ }^{3}\end{array}$} & $\begin{array}{c}-0.88 /-.04 \\
(0.22)\end{array}$ & $\begin{array}{c}-0.87 /-.04 \\
(0.23)\end{array}$ & $\begin{array}{c}-0.89 /-.04 \\
(0.24)\end{array}$ & $\begin{array}{c}-0.6 /-.02 \\
(0.16)\end{array}$ & $\begin{array}{c}-0.6 /-.02 \\
(0.17)\end{array}$ & $\begin{array}{c}-0.6 /-.03 \\
(0.16)\end{array}$ \\
\hline & $-4.00 * * *$ & $-3.98 * * *$ & $-4.03 * * *$ & $-3.83 * * *$ & $-3.85 * * *$ & $-3.85 * * *$ \\
\hline \multirow[t]{2}{*}{$\begin{array}{l}\text { Park }>20 \text { walking } \\
\text { minutes }^{3}\end{array}$} & $\begin{array}{c}-1.16 /-.03 \\
(0.37)\end{array}$ & $\begin{array}{c}-1.15 /-.03 \\
(0.38)\end{array}$ & $\begin{array}{c}-1.19 /-.03 \\
(0.39)\end{array}$ & $\begin{array}{c}-1.07 /-.03 \\
(0.35)\end{array}$ & $\begin{array}{c}-1.08 /-.03 \\
(0.36)\end{array}$ & $\begin{array}{c}-1.08 /-.03 \\
(0.37)\end{array}$ \\
\hline & $-3.16 * *$ & $-3.13 * *$ & $-3.27 * *$ & $-3.07 * *$ & $-3.09 * *$ & $-3.10 * *$ \\
\hline \multirow[t]{2}{*}{ No park ${ }^{3}$} & $\begin{array}{c}-0.32 /-.01 \\
(0.29)\end{array}$ & $\begin{array}{c}-0.33 /-.01 \\
(0.28)\end{array}$ & $\begin{array}{c}-0.38 /-.01 \\
(0.29)\end{array}$ & $\begin{array}{c}-1 /-.03 \\
(0.26)\end{array}$ & $\begin{array}{c}-1.02 /-.03 \\
(0.27)\end{array}$ & $\begin{array}{c}-1.03 /-.03 \\
(0.28)\end{array}$ \\
\hline & -1.13 & -1.15 & -1.32 & $-3.83 * * *$ & $-3.89 * * *$ & $-3.96 * * *$ \\
\hline \multicolumn{7}{|l|}{ Nature \& Climate } \\
\hline \multirow[t]{2}{*}{ Blue space } & $\begin{array}{c}0.02 / .01 \\
(0.05)\end{array}$ & $\begin{array}{c}0.03 / .01 \\
(0.05)\end{array}$ & $\begin{array}{c}0.03 / .01 \\
(0.05)\end{array}$ & $\begin{array}{c}-0.05 /-.01 \\
(0.04)\end{array}$ & $\begin{array}{c}-0.05 /-.01 \\
(0.05)\end{array}$ & $\begin{array}{c}-0.05 /-.01 \\
(0.06)\end{array}$ \\
\hline & 0.47 & 0.6 & 0.55 & -1.32 & -1.55 & -1.28 \\
\hline \multirow[t]{2}{*}{ Protected area cover } & $\begin{array}{c}0.01 / .03 \\
(0.01)\end{array}$ & $\begin{array}{c}0.01 / .03 \\
(0.02)\end{array}$ & $\begin{array}{c}0.01 / .03 \\
(0.03)\end{array}$ & $\begin{array}{l}0.004 / .01 \\
(0.004)\end{array}$ & $\begin{array}{c}0.01 / .01 \\
(0.005)\end{array}$ & $\begin{array}{l}0.01 / .01 \\
(0.006)\end{array}$ \\
\hline & $2.12 *$ & $2.15^{*}$ & $2.34 *$ & 1.01 & 1.69 & 1.39 \\
\hline \multirow[t]{2}{*}{$\begin{array}{l}\text { Landscape heteroge- } \\
\text { neity }\end{array}$} & $\begin{array}{c}-0.62 /-.01 \\
(0.74)\end{array}$ & $\begin{array}{c}-0.38 /-.01 \\
(0.75)\end{array}$ & $\begin{array}{c}-0.55 /-.01 \\
(0.77)\end{array}$ & $\begin{array}{c}0.47 / .01 \\
(0.57)\end{array}$ & $\begin{array}{c}0.56 / .01 \\
(0.58)\end{array}$ & $\begin{array}{c}0.59 / .01 \\
(0.58)\end{array}$ \\
\hline & -0.84 & -0.51 & -0.71 & 0.82 & 0.96 & 1.02 \\
\hline \multirow[t]{2}{*}{ Temperature } & $\begin{array}{c}0.04 / .00 \\
(0.20)\end{array}$ & $\begin{array}{c}0.10 / .01 \\
(0.19)\end{array}$ & $\begin{array}{c}-0.03 / .00 \\
(0.21)\end{array}$ & $\begin{array}{c}0.08 / .01 \\
(0.15)\end{array}$ & $\begin{array}{c}-0.04 / .00 \\
(0.13)\end{array}$ & $\begin{array}{c}-0.04 / .00 \\
(0.14)\end{array}$ \\
\hline & 0.17 & 0.55 & -0.15 & 0.53 & -0.29 & 0.27 \\
\hline Adj. R-squared & 0.2 & 0.2 & 0.2 & 0.46 & 0.46 & 0.46 \\
\hline AIC & 94989.47 & 94990.32 & 95002.35 & 90926.72 & 90928.81 & 90927.15 \\
\hline Observations & 13328 & 13328 & 13328 & 13328 & 13328 & 13328 \\
\hline
\end{tabular}




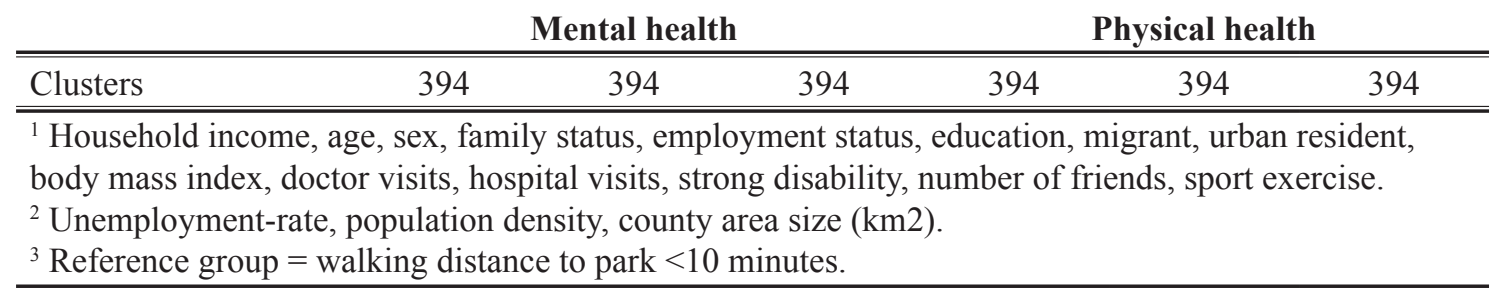

gle species diversity measure (Table 2). By using the results from these 'single variable' models (Table 2, Models I \& II) we calculated the potential improvement in mental health (increase of MCS scores) based on percentwise increases in plant or bird species richness. Based on the calculations, a 10\% increase in plant species richness is related with an increase in MCS by a score of 0.31 (coef. $=3.27$; 95\% CI: $1.56,4.99$ ). Calculations for bird species richness reveal an increase in mean MCS by score of 0.34 (coef. $=3.57 ; 95 \% \mathrm{CI}$ : $0.93,6.21)$.

In regard to physical health (PCS), we did not find any significant relationship between our species diversity measures and PCS (Fig. 3, Tables 2-3). Based on these findings we reject our third hypothesis (H3) that species diversity is positively related to human physical health.

\subsubsection{Access to parks and gardens}

Shorter walking distances to public parks improve mental and physical health, while longer walking distances negatively influence both health variables (Tables 2-3, Fig. 3). For example, using the mean of the estimated coefficients (Table 2, Models I-III \& IV$\mathrm{VI}$ ), an increase in walking distance by 10 minutes decreases mental and physical health (MCS and PCS) scores by approximately 0.86 and 0.60 , respectively (mean 95\% CI: MCS $=-1.31,-0.45 ;$ PCS $=-0.91,-0.3)$. Walking distances beyond 20 minutes decrease mental health values on average by 1.18 (mean 95\% CI: $-1.90,-0.46$ ) and physical health by about 1.08 (mean 95\% CI: $-1.77,-0.4$ ) compared to walking distances of less than $10 \mathrm{~min}$. We find a significant negative effect of not having any access to public parks on physical health, which was not found in any mental health model. When parks are not reachable on foot, physical health drops by approx. 1.02 points (mean 95\% CI: -1.53 , -0.51). In our analyses the availability of gardens has no significant effect on mental and physical health. 


\subsubsection{Nature and climate characteristics}

County level blue space cover, landscape heterogeneity and temperature are not significantly related with mental and physical health (Fig. 3, Tables 2-3). However, protected area cover is positively related to mental health (MCS), but not consistently across all models (Table 2-3).

\section{Discussion}

In accordance with our hypotheses, we find a positive association of plant and bird species richness with mental health (H1). These results report, according to our knowledge, the first national-scale relationship between species diversity and mental health. The only comparable study at the national level found a significant positive relationship between bird species richness and 'good' overall health prevalence, an indicator that covers both mental and physical health aspects (Wheeler et al., 2015). Based on previous findings we assumed that higher bird abundance would be related to better mental health (Cox et al., 2017b). Contrary to these expectations, we find no effect of bird abundance on mental health (H2) and no relationship between species diversity measures (birds and plants) and physical health (H3). In the following, we compare our results to those of earlier studies.

Our results on mental health and plant and bird species richness at a regional scale are also in line with previous research conducted in urban areas using the same objective (ecological) measures for species richness. These studies show that plant species richness in public parks can reduce stress (Lindemann-Matthies and Matthies, 2018) and plant and bird species richness can positively affect psychological well-being (Fuller et al., 2007). Furthermore, in an experimental online survey, participants who watched videos with high bird species richness reported less anxiety (Wolf et al., 2017). Studies using subjective measures of perceived species richness find similar significant positive relationships with psychological well-being for birds and plants (e.g. Dallimer et al., 2012). However, the effect of perceived species richness on different well-being measures is not always consistent (Hoyle et al., 2017; Southon et al., 2018). While it is not clear yet whether the influence of objective species richness is more prevalent compared to perceived richness, these results signify that people's identification skills for animals and plants (Dallimer et al., 2012; Shwartz et al., 2014) or their aesthetic taste and appreciation of natural diversity (Lindemann-Matthies et al., 2010) might plays an important role in how species rich- 
ness affects well-being. Also, acoustics could matter, as studies have demonstrated that listening to bird songs has a positive effect on perceived attention restoration and stress reduction (e.g. Ratcliffe et al., 2013).

We find no significant effect of bird abundance on mental health. This is contrary to results from a previous (local) study that found that afternoon - but not morning - bird abundances can be positively associated with better mental health, suggesting that bird behaviour (different activity levels during the day) and visibility may influence the likelihood of a person experiencing and benefiting from birds (Cox et al., 2017b). The German bird atlas data used in this study was likely sampled in the early morning and therefore provides bird abundance estimates which are probably not correlated to afternoon bird activities. This characteristic of the bird abundance variable may explain our study outcome. In addition, the atlas data were sampled across multiple years and thus cannot be compared to the local afternoon bird abundance estimates collected in an urban neighbourhood (Cox et al., 2017b). Another factor to be considered is that our bird abundance variable might be influenced by certain bird species with high population numbers in urbanized areas (e.g. crows, seagulls). These species are not necessarily popular among the general public (Bjerke and Østdahl, 2004) and thus might not have any positive, possibly even negative, effects on people's emotions and mental state (e.g. Ratcliffe et al., 2013). Overall, our study might indicate that on the national-scale the exposure to more birds (e.g. measured via abundance) may be less important for people, or even less perceivable, compared to bird species richness. Possibly bird species richness is a better predictor for health at larger scales than bird abundance which may vary locally, even considering cases where people struggle to perceive high species richness (Dallimer et al., 2012; Shwartz et al., 2014).

The following two mechanisms might explain this positive effect of species richness on human mental health and well-being. Both attention restoration (Kaplan, 1995) and stress reduction (Ulrich, 1991) may contribute to improved mental health in counties of high plant and bird species richness (e.g. Marselle et al., 2019). However, the mechanistic relationship between species diversity and mental health is not yet clear; no study has tested attention restoration or stress recovery as mediators (Marselle et al., 2019). Positive emotions might be another potential mediator between species diversity and mental health (Irvine et al., 2019) and may offer an alternative explanation for the observed correlation. For example, studies have shown that activities with birds (e.g. feeding and 
bird watching) may benefit human mental health by fostering positive emotions (e.g. Cox and Gaston, 2016). However, there is no consensus in regard to the mediating role of emotions and future research needs to depict the specific mechanisms that link species diversity and mental health. Triggers for positive emotions could be the attractiveness of species rich plant communities (Hoyle et al., 2017; Southon et al., 2018) or the diversity of bird songs (Hedblom et al., 2014).

For physical health, we find no significant relationship with species diversity even though some studies show the positive effects of species richness as well as microbial diversity on human health (Aerts et al., 2018; Wheeler et al., 2015). Compared to mental health, physical health might not be directly influenced by species richness or abundance. Instead, the relationship between physical health and species diversity could be more indirect, i.e. mediated through other factors (Hartig et al., 2014; Markevych et al., 2017). For instance, studies highlighted the importance of outdoor physical activity as well as the frequency and duration of green space use for the relationship between nature and human health (Cox et al., 2017a; Sugiyama et al., 2008). With regard to species diversity, we argue that a potential relationship between species diversity and physical health may only be expected, when mediators such as physical activity in green space are accounted for. However, this assumption remains speculative and needs to be tested in future research as the SOEP survey does not include detailed information on people's use of nature or outdoor activities in species-rich environments.

Similar to previous studies we show that better mental and physical health is associated with shorter walking distance between the place of residence and parks or recreational areas, i.e. the availability of green space (e.g. World Health Organization, 2016). Importantly, we find that people's mental and physical health is at lower levels (lower MCS and PCS scores) when they live further away from parks compared to people living closer to parks (see Results). This finding is in line with the concept of nearby nature and WHO guidelines for accessibility to urban greenspace (World Health Organization, 2016). Unfortunately, the measure of distance to public parks does not provide any information on whether or not a person actually uses the park or green space. Nonetheless, this indicator is a valid approximation of green space use as the proximity to green space is an important determinant of usage (e.g. Coombes et al., 2010) and, notably, because we used the reported proximity estimated by survey participants, not a geographical distance measure derived from maps. 
It is important to note, that access to green space and parks can be influenced by social and economic factors (e.g. Dai, 2011; Hoffimann et al., 2017). This is relevant, since the association between human health and neighbourhood green space can differ in regard to the socio-economic status (e.g. income, education) of people (Cole et al., 2019; Ruijsbroek et al., 2017) and because socio-economic status also often determines human health and well-being (e.g. Adler et al., 1994). Similar to green space, the availability of biodiversity may also be related to higher socio-economic status, especially in cities (e.g. Leong et al., 2018). This so-called 'luxury effect' might also influence the relationship between biodiversity and human health. Future research should address this topic and disentangle the complex relationship between socio-economic factors, biodiversity and human health.

We find a positive effect of protected area cover on mental health, albeit not robust, that corresponds to previous findings (e.g. Wheeler et al., 2015). This could hint towards the benefits of outdoor recreational activities offered by protected areas (e.g. Puhakka et al., 2017). Some epidemiological studies find positive associations between blue space or landscape heterogeneity (Gascon et al., 2015; Rantakokko et al., 2017) and human health. However, we fail to find a significant relationship between regional blue space cover or landscape heterogeneity and mental or physical health. Overall, our county-level nature variables might not reflect access to recreational areas or salutogenic (health promoting) nature characteristics well enough to show any influence on our dependent variables. Our landscape heterogeneity variable might be too coarse and, to some extent, also includes various land cover types which might not provide benefits to human health. Instead, we argue that the reported walking distance data on the individual level better describes the real access and use of green space compared to our measures on county level. This argument is supported by our results (see above).

Due to the cross-sectional nature of our analyses our study has limited power to infer causal links between species richness and mental health. One possible strategy to report a causal relationship in empirical studies is to use panel data. While the SOEP provides such data across longer time periods, we are limited by the availability of appropriate, representative data for bird and plant species richness across the same time period. Another caveat is related to the spatial scale of our study where we use German counties 
as a unit to describe people's experienced environment, as this was the finest resolution at which information was available for all variables across Germany. As a consequence, there might be a pronounced local variation in species richness and other nature characteristics within each county, which can influence estimated confidence intervals in our results.

As this study is an epidemiological study on the macro-level, we do not know whether or not people directly experience higher plant and bird species richness, for instance via visits to urban parks or green space. Therefore, an alternative explanation for our results might be that high species richness is a proxy for a salutogenic nature characteristics (de Vries and Snep, 2019) or good environmental quality (Wheeler et al., 2015). Multiple other studies support this argument by presenting evidence that plant species richness declines in areas with lower environmental quality (e.g. Duprè et al., 2010) or that bird species richness may be higher in landscapes characterized by elements with high restorative potential (e.g. Velarde et al., 2007) such as local landscape diversity or diverse forests (Gil-Tena et al., 2007; Weber et al., 2004).

Based on this assumption, we propose the use of species diversity measures (e.g. species richness) as indicators to nature's salutogenic effects on a macro level (e.g. regional and national level), as we show that simple measures of green or blue space cover or other nature characteristics might not be adequate proxies. Some studies have used bird species richness as an indicator for environmental quality (see Wheeler et al., 2015) and a report by the EU Joint Research Council presented a European map for habitat quality based on common bird species distribution data (Maes et al., 2015), albeit its original purpose was to help to monitor breeding habitats for birds. It might therefore be possible to create regional and national level indicators based on measures of species diversity whose functionality go beyond the maintenance of ecosystems and species conservation, but in addition help monitor species diversity as a health promoting nature characteristic. On the local and city level, species diversity can be used as a quality indicator for green space and should therefore be highly relevant for urban planning, but more research on this subject is necessary (Taylor and Hochuli, 2017). 


\section{Conclusion}

In this national-scale study we demonstrate that species diversity is positively related to human mental health. This relationship does is not only confirm previous findings detected at smaller spatial scales (Aerts et al., 2018; Fuller et al., 2007; Marselle et al., 2019), but is also of great potential for future research and policies as species diversity might be seen as a salutogenic, health promoting characteristic of natural areas.

Our study results may demonstrate that the protection of rural and urban habitats promoting high species richness not only serves conservation goals but also improves human well-being and good health-related quality of life (Cook et al., 2019). This is especially important since it is projected that our world will face major biodiversity loss in the future (Díaz et al., 2019; IPBES, 2019) which will also threaten the benefits provided by biodiversity to human well-being. Securing species diversity can be considered as additional means to foster public health and to avoid increasing public health services costs, especially since countries of the Global North are facing rising problems of mental health and associated high costs to society (e.g. OECD / European Union, 2018). For this purpose, species diversity might present a good macro-level indicator to not only monitor species loss and conservation success but also to assess salutogenic nature characteristics, i.e. health-related ecosystem services and Nature's Contributions to People (e.g. Geijzendorffer and Roche, 2013).

Knowledge of biodiversity-health linkages can inform landscape planners and urban greenspace managers to devise strategies to employ nature-based solutions to promote human well-being (Heiland et al., 2019). In regard to cities and urban areas, our results may be helpful for a better management of green space quality; i.e., the planning and layout of urban parks and recreation areas should foster high species richness and enable access, for example, to plants and wildlife to promote positive experiences and restoration (e.g. Bell et al., 2017; Carrus et al., 2015). In addition, landscape and urban planning should foster easy access to biodiverse areas in daily life as an important measure to promote public health. Likewise, protected areas should not only be valued for their contribution to biodiversity conservation, but also as 'health hubs' (MacKinnon et al., 2019). Conversely, health aspects of biodiverse areas and their spatial arrangements should be incorporated in environmental impact assessments and national and local environment strategies. Overall, we hope our study provides tangible evidence to employ species rich- 
ness not only as an indicator for conservation planning but also for landscape planning and for policies promoting public health. 


\section{References}

Adler, N.E., Boyce, T., Chesney, M.A., Cohen, S., Folkman, S., Kahn, R.L., Syme, S.L., 1994. Socioeconomic status and health: The challenge of the gradient. Am. Psychol. 49, 15-24.

Aerts, R., Honnay, O., Van Nieuwenhuyse, A., 2018. Biodiversity and human health: mechanisms and evidence of the positive health effects of diversity in nature and green spaces. Br. Med. Bull. 127, 5-22.

Andersen, H.H., Mühlbach, A., Nübling, M., Schupp, J., Wagner, G.G., 2007. Computation of standard values for physical and mental health scale scores using the SOEP Version of SF-12v2. Schmollers Jahrb. 127, 171-182.

Atauri, J.A., De Lucio, J. V., 2001. The role of landscape structure in species richness distribution of birds, amphibians, reptiles and lepidopterans in Mediterranean landscapes. Landsc. Ecol. 16, 147-159.

Basu, R., 2009. High ambient temperature and mortality: a review of epidemiologic studies from 2001 to 2008. Environ. Heal. A Glob. Access Sci. Source 8.

Bell, S.L., Westley, M., Lovell, R., Wheeler, B.W., Bell, S.L., Westley, M., Lovell, R., Wheeler, B.W., 2017. Everyday green space and experienced well-being: the significance of wildlife encounters. Landsc. Res. 6397, 1-12.

Bjerke, T., Østdahl, T., 2004. Animal-related attitudes and activities in an urban population. Anthrozoos 17, 109-129.

Bramesfeld, A., Grobe, T., Schwartz, F.W., 2010. Prevalence of depression diagnosis and prescription of antidepressants in East and West Germany: An analysis of health insurance data. Soc. Psychiatry Psychiatr. Epidemiol. 45, 329-335.

Bundesamt für Naturschutz, B., 2008. Forschung und Monitoring in den deutschen Biosphärenreservaten. BfN Broschüre 1-33.

Busija, L., Pausenberger, E., Haines, T.P., Haymes, S., Buchbinder, R., Osborne, R.H., 2011. Adult measures of general health and health-related quality of life. Arthritis Care Res. 63, S383-S412.

Carrus, G., Scopelliti, M., Lafortezza, R., Colangelo, G., Ferrini, F., Salbitano, F., Agrimi, M., Portoghesi, L., Semenzato, P., Sanesi, G., 2015. Go greener, feel better? The positive effects of biodiversity on the well-being of individuals visiting urban and peri-urban green areas. Landsc. Urban Plan. 134, 221-228.

Cole, H.V.S., Triguero-Mas, M., Connolly, J.J.T., Anguelovski, I., 2019. Determining the health benefits of green space: does gentrification matter? Heal. Place 57, 1-11.

Cook, P.A., Howarth, M., Wheater, C.P., 2019. Biodiversity and health in the face of climate change: implications for public health, in: Marselle, M.R., Stadler, J., Korn, H., Irvine, K.N., Bonn, A. (Eds.), Biodiversity and Health in the Face of Climate Change. Springer International Publishing, Cham, pp. 251-281.

Coombes, E., Jones, A.P., Hillsdon, M., 2010. The relationship of physical activity and overweight to objectively measured green space accessibility and use. Soc. Sci. Med. 70, 816-822.

Coons, S.J., Rao, S., Keininger, D.L., Hays, R.D., 2000. A comparative review of generic quality-of-life instruments. Pharmacoeconomics 17, 13-35.

Costa, P.T., McCrae, R.R., 1985. The NEO personality inventory, in: The NEO Personality Inventory:

Manual, Form S and Form R. Psychological Assessment Ressources Inc., pp. 223-256.

Cox, D.T.C., Gaston, K.J., 2016. Urban bird feeding: connecting people with nature. PLoS One 11, 1-13.

Cox, D.T.C., Shanahan, D.F., Hudson, H.L., Fuller, R.A., Anderson, K., Hancock, S., Gaston, K.J., 2017a.

Doses of nearby nature simultaneously associated with multiple health benefits. Int. J. Environ. Res. Public Health 14, E172.

Cox, D.T.C., Shanahan, D.F., Hudson, H.L., Plummer, K.E., Siriwardena, G.M., Fuller, R.A., Anderson, K., Hancock, S., Gaston, K.J., 2017b. Doses of neighborhood nature: the benefits for mental health of living with nature. Bioscience 67, 147-155. 
Dai, D., 2011. Racial/ethnic and socioeconomic disparities in urban green space accessibility: Where to intervene? Landsc. Urban Plan. 102, 234-244.

Dallimer, M., Irvine, K.N., Skinner, A.M.J., Davies, Z.G., Rouquette, J.R., Maltby, L.L., Warren, P.H., Armsworth, P.R., Gaston, K.J., 2012. Biodiversity and the feel-good factor: understanding associations between self-reported human well-being and species richness. Bioscience 62, 47-55.

de Almeida Rodrigues, A., da Cunha Bustamante, M.M., Sano, E.E., 2018. As far as the eye can see: scenic view of Cerrado national parks. Perspect. Ecol. Conserv. 16, 31-37.

de Vries, S., Snep, R., 2019. Biodiversity in the context of 'Biodiversity - Mental Health' research, in: Marselle, M.R., Stadler, J., Korn, H., Irvine, K.N., Bonn, A. (Eds.), Biodiversity and Health in the Face of Climate Change. Springer International Publishing, Cham, pp. 159-173.

de Vries, S., ten Have, M., van Dorsselaer, S., van Wezep, M., Hermans, T., de Graaf, R., 2016. Local availability of green and blue space and prevalence of common mental disorders in the Netherlands. Br. J. Psychiatry Open 2, 366-372.

Deutschewitz, K., Lausch, A., Kühn, I., Klotz, S., 2003. Native and alien plant species richness in relation to spatial heterogeneity on a regional scale in Germany. Glob. Ecol. Biogeogr. 12, 299-311.

Díaz, S., Settele, J., Brondizio, E.S., Ngo, H.T., Agard, J., Arneth, A., Balvanera, P., Brauman, K.A., Butchart, S.H.M., Chan, K.M.A., Garibaldi, L.A., Ichii, K., Liu, J., Subramanian, S.M., Midgley, G.F., Miloslavich, P., Molnár, Z., Obura, D.O., Pfaff, A., Polasky, S., Purvis, A., Razzaque, J., Reyers, B., Chowdhury, R.R., Shin, Y.-J., Visseren-Hamakers, I., Willis, K., Zayas, C.N., 2019. Pervasive human-driven decline of life on Earth points to the need for transformative change. Science 366, eaax3100.

Dormann, C.F., Elith, J., Bacher, S., Buchmann, C., Carl, G., Carré, G., Marquéz, J.R.G., Gruber, B., Lafourcade, B., Leitão, P.J., Münkemüller, T., Mcclean, C., Osborne, P.E., Reineking, B., Schröder, B., Skidmore, A.K., Zurell, D., Lautenbach, S., 2013. Collinearity: a review of methods to deal with it and a simulation study evaluating their performance. Ecography. 36, 027-046.

Duprè, C., Stevens, C.J., Ranke, T., Bleeker, A., Peppler-Lisbach, C., Gowing, D.J.G., Dise, N.B., Dorland, E., Bobbink, R., Diekmann, M., 2010. Changes in species richness and composition in European acidic grasslands over the past 70 years: The contribution of cumulative atmospheric nitrogen deposition. Glob. Chang. Biol. 16, 344-357.

Easterlin, R.A., Plagnol, A.C., 2008. Life satisfaction and economic conditions in East and West Germany pre- and post-unification. J. Econ. Behav. Organ. 68, 433-444.

Fox, J., Monette, G., 1992. Generalized collinearity diagnostics. J. Am. Stat. Assoc. 87, 178-183.

Fuller, R.A., Irvine, K.N., Devine-Wright, P., Warren, P.H., Gaston, K.J., 2007. Psychological benefits of greenspace increase with biodiversity. Biol. Lett. 3, 390-4.

Gascon, M., Mas, M.T., Martínez, D., Dadvand, P., Forns, J., Plasència, A., Nieuwenhuijsen, M.J., 2015. Mental health benefits of long-term exposure to residential green and blue spaces: a systematic review. Int. J. Environ. Res. Public Health 12, 4354-4379.

Gedeon, K., Grüneberg, C., Mitschke, A., Sudfeldt, C., Eickhorst, W., Fischer, S., Flade, M., Frick, S., Geiersberger, I., Koop, B., Kramer, M., Krüger, T., Roth, N., Ryslav, T., Stübin, S., Sudmann, S.R., Steffens, R., Vökler, F., Witt, K., 2014. Atlas Deutscher Brutvogelarten - Atlas of German Breeding Birds, 1st ed. Stiftung Vogelmonitoring Deutschland \& Dachverband Deutscher Avifaunisten (DDA), Münster.

Geijzendorffer, I.R., Roche, P.K., 2013. Can biodiversity monitoring schemes provide indicators for ecosystem services? Ecol. Indic. 33, 148-157.

Gil-Tena, A., Saura, S., Brotons, L., 2007. Effects of forest composition and structure on bird species richness in a Mediterranean context: implications for forest ecosystem management. For. Ecol. Manage. 242, 470-476.

Goebel, J., Grabka, M.M., Liebig, S., Kroh, M., David, R., Carsten, S., Schupp, J., 2019. The German 
Socio-Economic Panel (SOEP). J. Econ. Stat. 239, 345-360.

Hartig, T., Mitchell, R., de Vries, S., Frumkin, H., 2014. Nature and health. Annu. Rev. Public Health 35 , 207-228.

Hedblom, M., Heyman, E., Antonsson, H., Gunnarsson, B., 2014. Bird song diversity influences young people's appreciation of urban landscapes. Urban For. Urban Green. 13, 469-474.

Heiland, S., Weidenweber, J., Thompson, C.W., 2019. Linking landscape planning and health, in: Marselle, M.R., Stadler, J., Korn, H., Irvine, K.N., Bonn, A. (Eds.), Biodiversity and Health in the Face of Climate Change. Springer International Publishing, Cham, pp. 425-448.

Hoffimann, E., Barros, H., Ribeiro, A.I., 2017. Socioeconomic inequalities in green space quality and accessibility_Evidence from a Southern European city. Int. J. Environ. Res. Public Health 14, 916.

Hoyle, H., Hitchmough, J., Jorgensen, A., 2017. All about the 'wow factor'? The relationships between aesthetics, restorative effect and perceived biodiversity in designed urban planting. Landsc. Urban Plan. 164, 109-123.

IPBES, 2019. The global assessment report on biodiversity and ecosystem services - summary for policy makers. IPBES secretariat, Bonn.

Irvine, K.N., Hoesly, D., Bell-Williams, R., Warber, S.L., 2019. Biodiversity and spiritual well-being, in: Marselle, M.R., Stadler, J., Korn, H., Irvine, K.N., Bonn, A. (Eds.), Biodiversity and Health in the Face of Climate Change. Springer International Publishing, Cham, pp. 213-247.

Kaplan, S., 1995. The resporative benefits of nature: toward and integrative framework. J. Environ. Psychol. 15, 169-182.

Kondo, M.C., Fluehr, J.M., McKeon, T., Branas, C.C., 2018. Urban green space and its impact on human health. Int. J. Environ. Res. Public Health 15, 445.

Leong, M., Dunn, R.R., Trautwein, M.D., 2018. Biodiversity and socioeconomics in the city: a review of the luxury effect. Biol. Lett. 14, 20180082.

Lindemann-Matthies, P., Junge, X., Matthies, D., 2010. The influence of plant diversity on people's perception and aesthetic appreciation of grassland vegetation. Biol. Conserv. 143, 195-202.

Lindemann-Matthies, P., Matthies, D., 2018. The influence of plant species richness on stress recovery of humans. Web Ecol. 18, 121-128.

Lovell, R., Wheeler, B.W., Higgins, S.L., Irvine, K.N., Depledge, M.H., 2014. A systematic review of the health and well-being benefits of biodiverse environments. J. Toxicol. Environ. Heal. - Part B Crit. Rev. 17, 1-20.

MacKinnon, K., van Ham, C., Reilly, K., Hopkins, J., 2019. Nature-based solutions and protected areas to improve urban biodiversity and health, in: Marselle, M.R., Stadler, J., Korn, H., Irvine, K.N., Bonn, A. (Eds.), Biodiversity and Health in the Face of Climate Change. Springer International Publishing, Cham, pp. 363-380.

Maes, J., Fabrega, N., Zulian, G., Barbosa, A., Ivits, E., Polce, C., Vandecasteele, I., Marí, I., Guerra, C., Castillo, C.P., Vallecillo, S., Baranzelli, C., Barranco, R., Batista, F., Trombetti, M., Lavalle, C., 2015. Mapping and assessment of ecosystems and their services trends in ecosystems and ecosystem - JRC report number JRC94889.

Markevych, I., Schoierer, J., Hartig, T., Chudnovsky, A., Hystad, P., Dzhambov, A.M., Vries, S. De, Triguero-mas, M., Brauer, M., Nieuwenhuijsen, M.J., Lupp, G., Richardson, E.A., Astell-burt, T., Dimitrova, D., Feng, X., Sadeh, M., Standl, M., Heinrich, J., Fuertes, E., 2017. Exploring pathways linking greenspace to health: theoretical and methodological guidance. Environ. Res. 158, 301-317.

Marselle, Melissa R., Martens, D., Dallimer, M., Irvine, K.N., 2019. Review of the mental health and well-being benefits of biodiversity, in: Marselle, M.R., Stadler, J., Korn, H., Irvine, K., Bonn, A. (Eds.), Biodiversity and Health in the Face of Climate Change. Springer International Publishing, Cham, pp. 175-211.

Moulton, B.R., 1990. An illustration of a pitfall in estimating the effects of aggregate variables on micro 
units. Rev. Econ. Stat. 72, 334.

Nesterko, Y., Braehler, E., Grande, G., Glaesmer, H., 2013. Life satisfaction and health-related quality of life in immigrants and native-born Germans: The role of immigration-related factors. Qual. Life Res. 22, 1005-1013.

OECD / European Union, 2018. Health at a Glance: Europe 2018, Health at a Glance: Europe. OECD Publishing, Paris.

Oksanen, J., Blanchet, F.G., Friendly, M., Kindt, R., Legendre, P., Mcglinn, D., Minchin, P.R., O 'hara, R.B., Simpson, G.L., Solymos, P., Henry, M., Stevens, H., Szoecs, E., Wagner, H., 2017. vegan: community ecology package.

Petersen, E., Schoen, G., Liedtke, G., Zech, A., 2018. Relevance of urban green space for physical activity and health-related quality of life in older adults. Qual. Ageing Older Adults 19, 158-166.

Puhakka, R., Pitkänen, K., Siikamäki, P., 2017. The health and well-being impacts of protected areas in Finland. J. Sustain. Tour. 25, 1830-1847.

Rabe, S.E., Koellner, T., Marzelli, S., Schumacher, P., Grêt-Regamey, A., 2016. National ecosystem services mapping at multiple scales - The German exemplar. Ecol. Indic. 70, 357-372.

Rantakokko, M., Keskinen, K.E., Kokko, K., Portegijs, E., 2017. Nature diversity and well-being in old age. Aging Clin. Exp. Res. 30, 527-532.

Ratcliffe, E., Gatersleben, B., Sowden, P.T., 2013. Bird sounds and their contributions to perceived attention restoration and stress recovery. J. Environ. Psychol. 36, 221-228.

Ruijsbroek, A., Droomers, M., Kruize, H., Van Kempen, E., Gidlow, C.J., Hurst, G., Andrusaityte, S., Nieuwenhuijsen, M.J., Maas, J., Hardyns, W., Stronks, K., Groenewegen, P.P., 2017. Does the health impact of exposure to neighbourhood green space differ between population groups? An explorative study in four European cities. Int. J. Environ. Res. Public Health 14, 618.

Sandifer, P.A., Sutton-Grier, A.E., Ward, B.P., 2015. Exploring connections among nature, biodiversity, ecosystem services, and human health and well-being: opportunities to enhance health and biodiversity conservation. Ecosyst. Serv. 12, 1-15.

Sherrouse, B.C., Clement, J.M., Semmens, D.J., 2011. A GIS application for assessing, mapping, and quantifying the social values of ecosystem services. Appl. Geogr. 31, 748-760.

Shwartz, A., Turbé, A., Simon, L., Julliard, R., 2014. Enhancing urban biodiversity and its influence on city-dwellers: An experiment. Biol. Conserv. 171, 82-90.

Siegel, N.A., Huber, S., Gensicke, A., Geue, D., Stimmel, S., Stutz, F., 2010. SOEP 2009 Methodenbericht. TNS Infratest Sozialforschung, Munich.

Southon, G.E., Jorgensen, A., Dunnett, N., Hoyle, H., Evans, K.L., 2018. Perceived species-richness in urban green spaces: Cues, accuracy and well-being impacts. Landsc. Urban Plan. 172, 1-10.

Sugiyama, T., Leslie, E., Giles-Corti, B., Owen, N., 2008. Associations of neighbourhood greenness with physical and mental health: do walking, social coherence and local social interaction explain the relationships? J. Epidemiol. Community Heal. 62, e9-e9.

Taylor, L., Hochuli, D.F., 2017. Defining greenspace: multiple uses across multiple disciplines. Landsc. Urban Plan. 158, 25-38.

Testa, M.A., Simonson, D.C., 1996. Assesment of quality-of-life outcomes. N. Engl. J. Med. 34, 835-840.

Triguero-Mas, M., Dadvand, P., Cirach, M., Martínez, D., Medina, A., Mompart, A., Basagaña, X., Gražulevičienė, R., Nieuwenhuijsen, M.J., 2015. Natural outdoor environments and mental and physical health: relationships and mechanisms. Environ. Int. 77, 35-41.

Ulrich, R.S., 1991. Stress recovery during exposure to natural environments. J. Environ. Psychol. 11, 201-230.

van den Berg, M., Wendel-Vos, W., van Poppel, M., Kemper, H., van Mechelen, W., Maas, J., 2015. Health benefits of green spaces in the living environment: a systematic review of epidemiological studies. Urban For. Urban Green. 14, 806-816. 
Velarde, M.D., Fry, G., Tveit, M., 2007. Health effects of viewing landscapes - landscape types in environmental psychology. Urban For. Urban Green. 6, 199-212.

Ware, J.E., Kosinski, M., Keller, S.D., 1995. How to score the SF12 physical and mental health summary scales, Second. ed, New England Medical Center, Boston. New England Medical Center, Boston, MA.

Ware, J.E., Sherbourne, C.D., 1992. The MOS 36-item short-form health survey (SF-36): I. conceptual framework and item selection. Med. Care 30, 473-483.

Weber, D., Hintermann, U., Zangger, A., 2004. Scale and trends in species richness: considerations for monitoring biological diversity for political purposes. Glob. Ecol. Biogeogr. 13, 97-104.

Wheeler, B.W., Lovell, R., Higgins, S.L., White, M.P., Alcock, I., Osborne, N.J., Husk, K., Sabel, C.E., Depledge, M.H., 2015. Beyond greenspace: an ecological study of population general health and indicators of natural environment type and quality. Int. J. Health Geogr. 14, 1-17.

World Health Organization, 2016. Urban green spaces and health. WHO Regional Office for Europe, Copenhagen.

Yu, W., Mengersen, K., Wang, X., Ye, X., Guo, Y., Pan, X., Tong, S., 2012. Daily average temperature and mortality among the elderly: A meta-analysis and systematic review of epidemiological evidence. Int. J. Biometeorol. 56, 569-581. 


\subsection{Supplementary Material}

\section{Supplementary Material}

'Species richness is positively related to mental health - a study for Germany'

Authors:

Joel Methorst, Aletta Bonn, Melissa Marselle, Katrin Böhning-Gaese, Katrin Rehdanz 


\subsubsection{Socio-economic and health data description}

Here we present the MCS and PCS survey items and detailed descriptions of each variable used in our study.

Table A.II-1: Health questions asked in the SOEP version of the SF-12 v2 questionnaire to create the MCS and PCS indicators. Both the English and German version is presented.

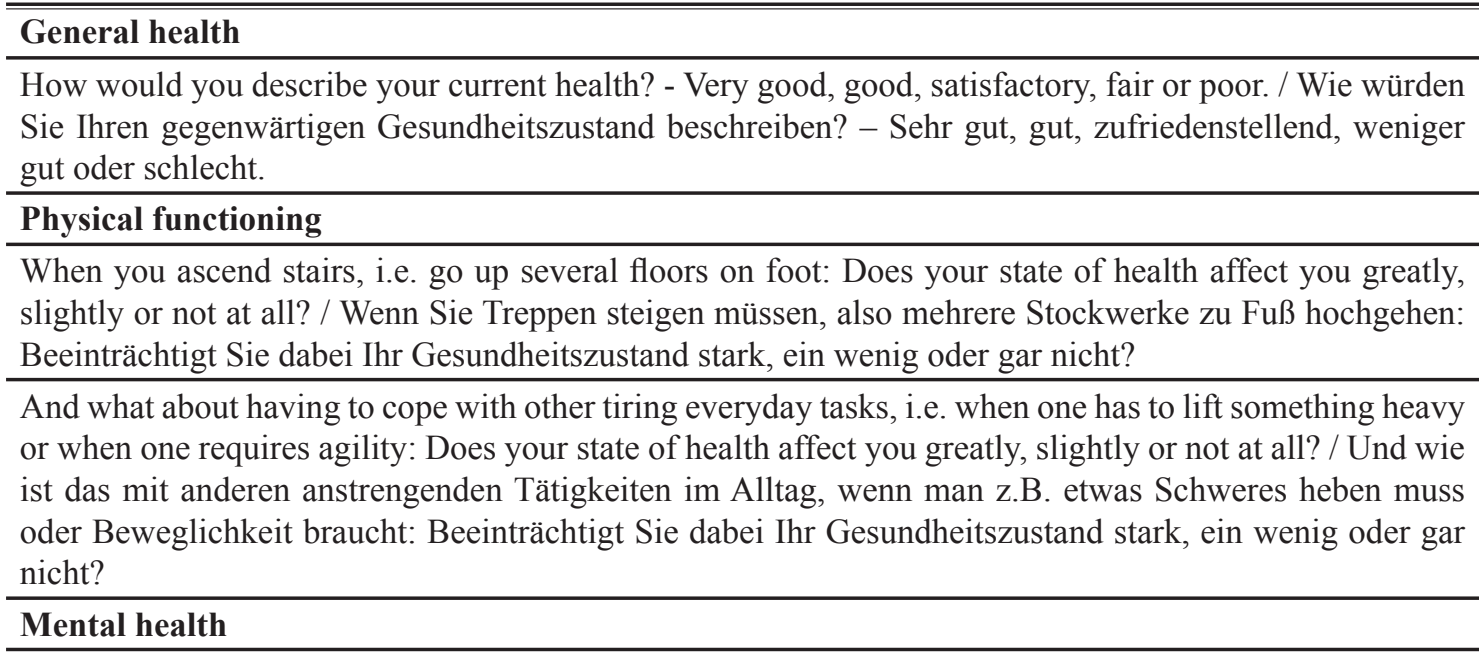

Please think about the last four weeks. How often did it occur within this period of time that you felt rundown and melancholy? - Always, often, sometimes, almost never or never. / Bitte denken Sie einmal an die letzten vier Wochen. Wie oft kam es in dieser Zeit vor, dass Sie sich niedergeschlagen und trübsinnig fühlten? - Immer, oft, manchmal, fast nie, nie.

Please think about the last four weeks. How often did it occur within this period of time that you felt relaxed and well-balanced? - Always, often, sometimes, almost never or never. / Bitte denken Sie einmal an die letzten vier Wochen. Wie oft kam es in dieser Zeit vor, dass Sie sich ruhig und ausgeglichen fühlten? - Immer, oft, manchmal, fast nie, nie.

Vitality
Please think about the last four weeks. How often did it occur within this period of time that you used
up a lot of energy? - Always, often, sometimes, almost never or never. / Bitte denken Sie einmal an die
letzten vier Wochen. Wie oft kam es in dieser Zeit vor, dass Sie jede Menge Energie verspürten? - Immer,
oft, manchmal, fast nie, nie.

\begin{tabular}{l} 
Bodily pain \\
\hline Please think about the last four weeks. How often did it occur within this period of time that you had \\
strong physical pains? - Always, often, sometimes, almost never or never. / Bitte denken Sie einmal an \\
die letzten vier Wochen. Wie oft kam es in dieser Zeit vor, dass Sie starke körperliche Schmerzen hatten? \\
- Immer, oft, manchmal, fast nie, nie. \\
\hline Role physical \\
\hline Please think about the last four weeks. How often did it occur within this period of time that due to phys- \\
ical health problems you achieved less than you wanted to at work or in everyday tasks? - Always, often, \\
sometimes, almost never, never. / Bitte denken Sie einmal an die letzten vier Wochen. Wie oft kam es in \\
dieser Zeit vor, dass Sie wegen gesundheitlicher Probleme körperlicher Art in Ihrer Arbeit oder Ihren all- \\
täglichen Beschäftigungen weniger geschafft haben als Sie eigentlich wollten? - Immer, oft, manchmal, \\
fast nie, nie. \\
Please think about the last four weeks. How often did it occur within this period of time that due to \\
physical health problems you were limited in some form at work or in everyday tasks? - Always, often, \\
sometimes, almost never, never. / Bitte denken Sie einmal an die letzten vier Wochen. Wie oft kam es \\
in dieser Zeit vor, dass Sie wegen gesundheitlicher Probleme körperlicher Art in Ihrer Arbeit oder Ihren \\
alltäglichen Beschäftigungen in der Art Ihrer Tätigkeiten eingeschränkt waren? - Immer, oft, manchmal, \\
fast nie, nie.
\end{tabular}




\section{Role emotional}

Please think about the last four weeks. How often did it occur within this period of time that due to mental health or emotional problems you achieved less than you wanted to at work or in everyday tasks? - Always, often, sometimes, almost never, never. / Bitte denken Sie einmal an die letzten vier Wochen. Wie oft kam es in dieser Zeit vor, dass Sie wegen seelischer oder emotionaler Probleme in Ihrer Arbeit oder Ihren alltäglichen Beschäftigungen weniger geschafft haben als Sie eigentlich wollten? - Immer, oft, manchmal, fast nie, nie.

Please think about the last four weeks. How often did it occur within this period of time that due to mental health problems you carried out your work or everyday tasks less thoroughly than usual? - Always, often, sometimes, almost never, never. / Bitte denken Sie einmal an die letzten vier Wochen. Wie oft kam es in dieser Zeit vor, dass Sie wegen seelischer oder emotionaler Probleme in Ihrer Arbeit oder Ihren alltäglichen Beschäftigungen Ihre Arbeit oder Tätigkeit weniger sorgfältig als sonst gemacht haben? - Immer, oft, manchmal, fast nie, nie.

\section{Social functioning}

Please think about the last four weeks. How often did it occur within this period of time that due to physical or mental health problems you were limited socially, i.e. in contact with friends, acquaintances or relatives? - Always, often, sometimes, almost never, never. / Bitte denken Sie einmal an die letzten vier Wochen. Wie oft kam es in dieser Zeit vor, dass Sie wegen gesundheitlicher oder seelischer Probleme in Ihren sozialen Kontakten, z.B. mit Freunden, Bekannten oder Verwandten, eingeschränkt waren? - Immer, oft, manchmal, fast nie, nie.

Table A.II-2: Variables and their detailed descriptions.

\begin{tabular}{|c|c|c|}
\hline Main category & Subcategory & Description \\
\hline \multirow[t]{2}{*}{ Human health } & Mental health & $\begin{array}{l}\text { Mental Health Component Scale (MCS) from the } \\
\text { SOEP short form } 12 \text { (SF-12) health questionnaire. }\end{array}$ \\
\hline & Physical health & $\begin{array}{l}\text { Physical Health Component Scale (PCS) from the } \\
\text { SOEP short form } 12 \text { (SF-12) health questionnaire. }\end{array}$ \\
\hline Personality & 'Big Five' & $\begin{array}{l}\text { Openness to experience, conscientiousness, extro- } \\
\text { version, agreeableness and neuroticism (Big Five } \\
\text { Inventory SOEP, BFI-S). }\end{array}$ \\
\hline \multirow[t]{12}{*}{ Socio-economic factors } & Household income & $\begin{array}{l}\text { Net household income in } € \text { where the upper and } \\
\text { lower } 1 \% \text { of values were removed. }\end{array}$ \\
\hline & Age & Age $(<18$ years $)$ \\
\hline & Male & $\begin{array}{l}\text { Binary variable for males }(\text { males }=1, \text { females }= \\
0 \text { ). }\end{array}$ \\
\hline & Educational & $\begin{array}{l}\text { Four categories: tertiary, secondary, primary or } \\
\text { still in school. }\end{array}$ \\
\hline & Labor force status & $\begin{array}{l}\text { Six categories: not working, employed, unem- } \\
\text { ployed, part time employment, in education and } \\
\text { parental leave. }\end{array}$ \\
\hline & Family status & $\begin{array}{l}\text { Six categories: married, separated but married, } \\
\text { single, divorced, widowed or other relationship. }\end{array}$ \\
\hline & Doctor visits & Number of doctor visits in the same year. \\
\hline & Hospital visits & Number of hospital visits in the previous year. \\
\hline & Body mass index & Body mass index. \\
\hline & No. of friends & Number of friends per person. \\
\hline & $\begin{array}{l}\text { Frequency of sport } \\
\text { exercise }\end{array}$ & $\begin{array}{l}\text { Four categories: almost never, several times a } \\
\text { year, at least once a month or at least one a week. }\end{array}$ \\
\hline & Urban & $\begin{array}{l}\text { Binary variable for urban areas (urban }=1 \text {, rural } \\
=0 \text { ). }\end{array}$ \\
\hline Macro-economic factors & GDP per capita & GDP per capita for each county (in $1000 €$ ). \\
\hline
\end{tabular}




\begin{tabular}{|c|c|c|}
\hline Main category & Subcategory & Description \\
\hline & Unemployment rate & Unemployment rate for each county (in \%). \\
\hline & Population density & Population density (people/km2) for each county. \\
\hline & East-Germany & $\begin{array}{l}\text { Binary variable for counties belonging to the } \\
\text { former German Democratic Republic (GDR) (zero } \\
\text { otherwise). }\end{array}$ \\
\hline & County area size & Area size $(\mathrm{km} 2)$ of each county in Germany. \\
\hline \multirow[t]{2}{*}{ Local access to nature } & Distance to parks & $\begin{array}{l}\text { Walking distance to parks in } 4 \text { categories: No park } \\
\text { / not reachable on foot, }<10 \mathrm{~min} \text { walking distance, } \\
\text { 10-20min walking distance and }<20 \text { min walking } \\
\text { distance. }\end{array}$ \\
\hline & Garden & $\begin{array}{l}\text { Binary variable indicating the ownership of a } \\
\text { garden }(\text { garden }=1 \text {, no garden }=0) \text {. }\end{array}$ \\
\hline \multirow[t]{3}{*}{ Species diversity } & Plant species richness & $\begin{array}{l}\text { Area weighted mean species richness (no. of spe- } \\
\text { cies) of plants per county. }\end{array}$ \\
\hline & Bird abundance & $\begin{array}{l}\text { Area weighted mean bird abundance (no. of breed- } \\
\text { ing pairs) per county. }\end{array}$ \\
\hline & Bird species richness & $\begin{array}{l}\text { Area weighted mean species richness (no. of spe- } \\
\text { cies) of birds per county. }\end{array}$ \\
\hline \multirow[t]{7}{*}{$\begin{array}{l}\text { Nature and climate char- } \\
\text { acteristics }\end{array}$} & Blue space & $\begin{array}{l}\text { Share of area covered by water bodies in each } \\
\text { county (in \%). }\end{array}$ \\
\hline & Green space & $\begin{array}{l}\text { Share of area covered by vegetated areas in each } \\
\text { county (in \%). }\end{array}$ \\
\hline & Protected areas & $\begin{array}{l}\text { Share of area covered by protected areas in each } \\
\text { county (in \%). }\end{array}$ \\
\hline & $\begin{array}{l}\text { Landscape heteroge- } \\
\text { neity }\end{array}$ & $\begin{array}{l}\text { Area weighted mean Shannon Diversity Index } \\
\text { (H') of land cover classes for each county. }\end{array}$ \\
\hline & $\begin{array}{l}\text { Topographic heteroge- } \\
\text { neity }\end{array}$ & $\begin{array}{l}\text { Area weighted mean elevation range (metre) for } \\
\text { each county. }\end{array}$ \\
\hline & Temperature & $\begin{array}{l}\text { Area weighted mean temperatures }\left({ }^{\circ} \mathrm{C}\right) \text { for each } \\
\text { county. }\end{array}$ \\
\hline & Precipitation & $\begin{array}{l}\text { Area weighted mean precipitation ( } \mathrm{cm} / \text { year) for } \\
\text { each county. }\end{array}$ \\
\hline
\end{tabular}




\subsubsection{CORINE land cover categorization}

Here we report the categorizations of land cover types from the CORINE land cover database (Table A.II-3). Based on these land cover types we calculated the variables for landscape heterogeneity, green space and blue space cover.

Table A.II-3: Land cover categories used to estimate habitat heterogeneity as well as green and blue space.

\begin{tabular}{|c|c|c|c|}
\hline 5 Categories & 15 Categories & 44 Categories & $\begin{array}{l}\text { Green and } \\
\text { blue space }\end{array}$ \\
\hline \multirow[t]{11}{*}{ Artificial surfaces } & Urban fabric & Continuous urban fabric & l \\
\hline & & Discontinuous urban fabric & \\
\hline & $\begin{array}{l}\text { Industrial, commercial } \\
\text { and transport units }\end{array}$ & Industrial or commercial units & \\
\hline & & $\begin{array}{l}\text { Road and rail networks and associ- } \\
\text { ated land }\end{array}$ & \\
\hline & & Port areas & \\
\hline & & Airports & \\
\hline & $\begin{array}{l}\text { Mine, dump and con- } \\
\text { struction sites }\end{array}$ & Mineral extraction sites & \\
\hline & & Dump sites & \\
\hline & & Construction sites & \\
\hline & $\begin{array}{l}\text { Artificial, non-agricul- } \\
\text { tural vegetated areas }\end{array}$ & Green urban areas & \\
\hline & & Sport and leisure facilities & \\
\hline \multirow[t]{11}{*}{ Agricultural areas } & Arable land & Non-irrigated arable land & Green space \\
\hline & & Permanently irrigated land & \\
\hline & & Rice fields & \\
\hline & Permanent crops & Vineyards & \\
\hline & & Fruit trees and berry plantations & \\
\hline & & Olive groves & \\
\hline & Pastures & Pastures & \\
\hline & $\begin{array}{l}\text { Heterogeneous agricul- } \\
\text { tural areas }\end{array}$ & $\begin{array}{l}\text { Annual crops associated with per- } \\
\text { manent crops }\end{array}$ & \\
\hline & & Complex cultivation patterns & \\
\hline & & $\begin{array}{l}\text { Land principally occupied by ag- } \\
\text { riculture, with significant areas of } \\
\text { natural vegetation }\end{array}$ & \\
\hline & & Agro-forestry areas & \\
\hline \multirow{7}{*}{$\begin{array}{l}\text { Forest and semi natu- } \\
\text { ral areas }\end{array}$} & Forests & Broad-leaved forest & Green space \\
\hline & & Coniferous forest & \\
\hline & & Mixed forest & \\
\hline & $\begin{array}{l}\text { Scrub and/or herba- } \\
\text { ceous vegetation asso- } \\
\text { ciations }\end{array}$ & Natural grasslands & Green space \\
\hline & & Moors and heathland & \\
\hline & & Sclerophyllous vegetation & \\
\hline & & Transitional woodland-shrub & \\
\hline
\end{tabular}




\begin{tabular}{llll} 
5 Categories & 15 Categories & 44 Categories & $\begin{array}{c}\text { Green and } \\
\text { blue space }\end{array}$ \\
\hline \hline \multirow{2}{*}{$\begin{array}{l}\text { Open spaces with little } \\
\text { or no vegetation }\end{array}$} & Beaches, dunes, sands & $/$ \\
& & Bare rocks \\
& Sparsely vegetated areas & \\
& & Burnt areas \\
Wetlands & Inland wetlands & Inland marshes & Green space \\
& & Peat bogs & Green space \\
& Maritime wetlands & Salt marshes & \\
& & Salines & Blue space \\
& Inland waters & Water courses & Blue space \\
& & Water bodies & \\
Mater bodies & Coastal lagoons & \\
& & Estuaries & \\
\hline \hline
\end{tabular}

\subsubsection{Summary statistics}

Presented here are summary statistics of the data used in our study (Table A.II-4 and Table A.II-5).

Table A.II-4: Summary statistics of continuous variables $(\mathrm{n}=13,328)$

\begin{tabular}{lcccc} 
Variables & Min. & Mean & Median & Max. \\
\hline Personal characteristics & & & & \\
MCS & 5.32 & 50.83 & 52.52 & 76.54 \\
PCS & 12.27 & 49.29 & 51.44 & 73.61 \\
Income (EUR) & 554 & 2817 & 2500 & 9200 \\
Age (years) & 18 & 50.18 & 50 & 99 \\
Doctor visits (no./year) & 0 & 9.79 & 8 & 396 \\
Hospital visits (no. in year 2007) & 0 & 1.37 & 0 & 240 \\
Body mass index & 13.36 & 26.13 & 25.59 & 59.03 \\
No. of friends (no./person) & 0 & 4.21 & 3 & 90 \\
Macro-economic characteristics (at the & & & & \\
county level) & 13.2 & 13.2 & 13.2 & 13.2 \\
GDP per capita (1000 EUR) & 1.6 & 8.34 & 7.8 & 19.4 \\
Unemployment rate (\%) & 39.1 & 828.4 & 299.8 & 4274.5 \\
Population density (no. people/km2) & & & & \\
Species diversity (county level) & 670.17 & 1134 & 1130.8 & 1785.86 \\
Plant species richness & & & & \\
(no. of species) & 10601.36 & 38269 & 38710 & 69514.08 \\
$\begin{array}{l}\text { Bird abundance } \\
\text { (no. breeding pairs) }\end{array}$ & & & & \\
\end{tabular}




\begin{tabular}{lcccc} 
Variables & Min. & Mean & Median & Max. \\
\hline \hline $\begin{array}{l}\text { Bird species richness } \\
\text { (no. of species) }\end{array}$ & 59.16 & 104.8 & 105.46 & 145.65 \\
$\begin{array}{l}\text { Nature and climate characteristics (at the } \\
\text { county level) }\end{array}$ & & & \\
Blue space (\%) & 0 & & & \\
Green space $(\%)$ & 2.49 & 42.15 & 38.62 & 97.76 \\
Landscape heterogeneity & 0.77 & 1.36 & 1.36 & 1.91 \\
(Shannon index, H') & & & & \\
Topographic heterogeneity (metre) & 9.94 & 178.3 & 158.09 & 1307.97 \\
Protected areas $(\%)$ & 0 & 20.45 & 8.12 & 99.99 \\
Temperature $\left({ }^{\circ} \mathrm{C}\right)$ & 5.69 & 9.24 & 9.31 & 10.95 \\
Precipitation $(\mathrm{cm} /$ year) & 51.52 & 80.77 & 79.97 & 190.7 \\
County area size $(\mathrm{km} 2)$ & 37.22 & 973.9 & 839.9 & 5470.34 \\
& & & & \\
\hline \hline
\end{tabular}

Table A.II-5: Summary statistics of categorical and dummy variables $(\mathrm{n}=13,328)$

\section{Variables}

Male (male $=1$; female $=0$ )

Migrant $($ migrant $=1$, non-migrant $=0)$

Disabled $($ disabled $=1$, non-disabled $=0$ )

Urban (urban $=1$, rural $=0$ )

Garden $($ garden $=1$, no garden $=0)$

Distance to parks

No park / not reachable on foot

Park $<10$ min walking distance (reference group)

Park 10-20min walking distance

Park $<20$ min walking distance

Education

In school (reference group)

Primary education

Secondary education

Tertiary education

Family status

Married (reference group)

62.42

Separated but married

Single

Divorced

Widowed

6.69

Other relationship

0.09

Labour force status 


\begin{tabular}{lc} 
Variables & Percent \\
\hline \hline None working (reference group) & 29.99 \\
Employed & 58.86 \\
Unemployed & 3.99 \\
Part time employment & 3.29 \\
In education & 2.6 \\
Parental leave & 1.26 \\
& \\
Frequency of sport exercise & \\
\hline Sport: almost never (reference group) & 32.53 \\
Sport: several times a year & 18.82 \\
Sport: at least once a month & 7.41 \\
Sport: at least one a week & 41.24 \\
\end{tabular}

\subsubsection{Correlations}

Table A.II-6: Pairwise correlation coefficients of selected variables $(\mathrm{n}=13,328)$. Asterisk symbols indicate p-values $<0.01$.

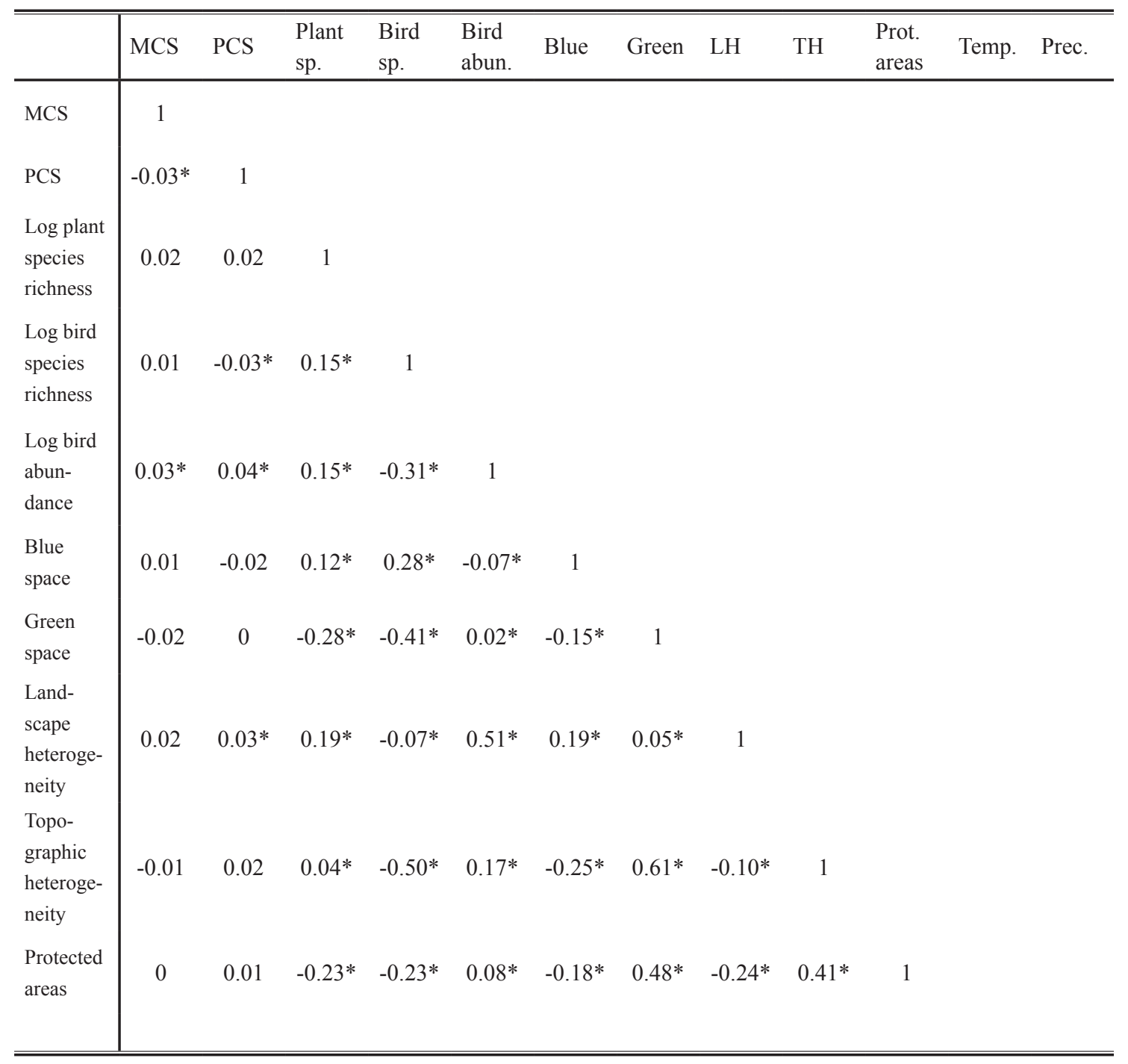




\begin{tabular}{l|ccccccccccccc}
\hline \hline & MCS & PCS & $\begin{array}{l}\text { Plant } \\
\text { sp. }\end{array}$ & $\begin{array}{l}\text { Bird } \\
\text { sp. }\end{array}$ & $\begin{array}{l}\text { Bird } \\
\text { abun. }\end{array}$ & Blue & Green & LH & TH & $\begin{array}{l}\text { Prot. } \\
\text { areas }\end{array}$ & Temp. Prec. \\
\hline $\begin{array}{l}\text { Tempera- } \\
\text { ture }\end{array}$ & $0.03^{*}$ & 0.02 & $0.08^{*}$ & $0.28^{*}$ & $0.38^{*}$ & $0.14^{*}$ & $-0.53^{*}$ & $0.33^{*}$ & $-0.51^{*}$ & $-0.24^{*}$ & 1 & \\
$\begin{array}{l}\text { Precipita- } \\
\text { tion }\end{array}$ & 0 & 0.02 & $-0.23^{*}$ & $-0.61^{*}$ & $0.35^{*}$ & $-0.17^{*}$ & $0.57^{*}$ & $0.16^{*}$ & $0.62^{*}$ & $0.20^{*}$ & $-0.35^{*}$ & 1 \\
\hline \hline
\end{tabular}

\subsubsection{Results for the species diversity models}

Here we present the results for the species diversity models calculated with ordinary least squares (OLS).

Table A.II-7: OLS models with one single species diversity variable. Each model contains the same set of socio-economic variables, macro-economic variables as well as nature and climate characteristics. Shown are coefficients, standard errors in parenthesis and t-values. P-values are indicated by asterisk symbols: * $<0.05, * *<0.01, * * *<0.001$.

\begin{tabular}{|c|c|c|c|c|c|c|}
\hline & \multicolumn{3}{|c|}{ MCS } & \multicolumn{3}{|c|}{ PCS } \\
\hline & $\mathbf{I}$ & II & III & IV & $\mathbf{V}$ & VI \\
\hline \multicolumn{7}{|l|}{ Species diversity } \\
\hline \multirow[t]{3}{*}{ Log plant species richness } & 3.27 & - & - & 0.5 & - & - \\
\hline & 0.87 & & & 0.67 & & \\
\hline & $3.74 * * *$ & & & 0.75 & & \\
\hline \multirow[t]{3}{*}{ Log bird species richness } & - & 3.57 & - & - & -1.38 & - \\
\hline & & 1.35 & & & 1.05 & \\
\hline & & $2.65 * *$ & & & -1.31 & \\
\hline \multirow[t]{3}{*}{ Log bird abundance } & - & - & -0.6 & - & - & -0.56 \\
\hline & & & 0.59 & & & 0.51 \\
\hline & & & -1.02 & & & -1.1 \\
\hline \multicolumn{7}{|l|}{ Access garden and parks } \\
\hline \multirow[t]{3}{*}{ Garden } & -0.11 & -0.13 & -0.13 & 0.05 & 0.05 & 0.05 \\
\hline & 0.2 & 0.2 & 0.2 & 0.17 & 0.17 & 0.17 \\
\hline & -0.54 & -0.66 & -0.63 & 0.307 & 0.29 & 0.31 \\
\hline Park $<10$ walking minutes & \multicolumn{6}{|c|}{ Reference group } \\
\hline \multirow{3}{*}{$\begin{array}{l}\text { Park in 10-20 walking min- } \\
\text { utes }\end{array}$} & -0.87 & -0.89 & -0.89 & -0.6 & -0.6 & -0.6 \\
\hline & 0.22 & 0.22 & 0.22 & 0.16 & 0.16 & 0.16 \\
\hline & $-3.98 * * *$ & $-4.03 * * *$ & $-4.00 * * *$ & $-3.85 * * *$ & $-3.85 * * *$ & $-3.86 * * *$ \\
\hline \multirow[t]{3}{*}{ Park $<20$ walking minutes } & -1.15 & -1.19 & -1.19 & -1.08 & -1.08 & -1.09 \\
\hline & 0.37 & 0.37 & 0.37 & 0.35 & 0.35 & 0.35 \\
\hline & $-3.14 * *$ & $-3.28 * *$ & $-3.25 * *$ & $-3.09 * *$ & $-3.10 * *$ & $-3.104 * *$ \\
\hline \multirow[t]{3}{*}{ No park } & -0.32 & -0.37 & -0.39 & -1.01 & -1.02 & -1.03 \\
\hline & 0.29 & 0.29 & 0.29 & 0.26 & 0.26 & 0.26 \\
\hline & -1.11 & -1.28 & -1.34 & $-3.85 * * *$ & $-3.91 * * *$ & $-3.94 * * *$ \\
\hline
\end{tabular}




\begin{tabular}{|c|c|c|c|c|c|c|}
\hline & \multicolumn{3}{|c|}{ MCS } & \multicolumn{3}{|c|}{ PCS } \\
\hline \multicolumn{7}{|l|}{ Nature \& Climate } \\
\hline \multirow[t]{3}{*}{ Blue space } & 0.03 & 0.03 & 0.04 & -0.05 & -0.05 & -0.05 \\
\hline & 0.05 & 0.05 & 0.05 & 0.04 & 0.04 & 0.04 \\
\hline & 0.6 & 0.54 & 0.85 & -1.55 & -1.29 & -1.49 \\
\hline \multirow[t]{3}{*}{ Landscape heterogeneity } & -0.56 & -0.7 & -0.45 & 0.41 & 0.44 & 0.55 \\
\hline & 0.74 & 0.76 & 0.78 & 0.57 & 0.57 & 0.58 \\
\hline & -0.76 & -0.93 & -0.57 & 0.71 & 0.77 & 0.94 \\
\hline \multirow[t]{3}{*}{ Protected areas } & 0.01 & 0.01 & 0.01 & 0.01 & 0.004 & -0.01 \\
\hline & 0.01 & 0.01 & 0.01 & 0.004 & 0.004 & 0.003 \\
\hline & 1.9 & $2.16^{*}$ & 1.93 & 1.34 & 1.06 & 1.64 \\
\hline \multirow[t]{3}{*}{ Temperature } & 0.13 & -0.01 & 0.15 & -0.02 & 0.06 & -0.03 \\
\hline & 0.18 & 0.21 & 0.19 & 0.13 & 0.15 & 1.33 \\
\hline & 0.7 & -0.05 & 0.78 & -0.12 & 0.42 & -0.23 \\
\hline
\end{tabular}

Socio-economic variables

\begin{tabular}{|c|c|c|c|c|c|c|}
\hline \multirow[t]{3}{*}{ Household income } & 0.86 & 0.88 & 0.88 & 0.83 & 0.84 & 0.84 \\
\hline & 0.2 & 0.21 & 0.21 & 0.18 & 0.18 & 0.18 \\
\hline & $4.22 * * *$ & $4.28 * * *$ & $4.30 * * *$ & $4.68 * * *$ & $4.69 * * *$ & $4.71 * * *$ \\
\hline \multirow[t]{3}{*}{ Age } & 0.08 & 0.08 & 0.08 & -0.18 & -0.18 & -0.18 \\
\hline & 0.01 & 0.01 & 0.01 & 0.01 & 0.01 & 0.01 \\
\hline & $9.292 * * *$ & $9.34 * * *$ & $9.339 * * *$ & $-24.46^{* * *}$ & $-24.43 * * *$ & $-24.42 * * *$ \\
\hline \multirow[t]{3}{*}{ Male } & 0.85 & 0.86 & 0.85 & 0.77 & 0.77 & 0.77 \\
\hline & 0.15 & 0.15 & 0.15 & 0.16 & 0.16 & 0.16 \\
\hline & $5.70 * * *$ & $5.71 * * *$ & $5.71 * * *$ & $4.84 * * *$ & $4.83 * * *$ & $4.84 * * *$ \\
\hline \multirow[t]{3}{*}{ Doctor visits } & -0.05 & -0.05 & -0.05 & -0.15 & -0.15 & -0.15 \\
\hline & 0.01 & 0.01 & 0.01 & 0.01 & 0.01 & 0.01 \\
\hline & $-6.18 * * *$ & $-6.15 * * *$ & $-6.19 * * *$ & $-13.46^{* * *}$ & $-13.46^{* * *}$ & $-13.47 * * *$ \\
\hline \multirow[t]{3}{*}{ Hospital visits } & -0.09 & -0.09 & -0.09 & -0.08 & -0.08 & -0.08 \\
\hline & 0.02 & 0.02 & 0.02 & 0.02 & 0.02 & 0.02 \\
\hline & $-5.85 * * *$ & $-5.90 * * *$ & $-5.85 * * *$ & $-4.79 * * *$ & $-4.77 * * *$ & $-4.76 * * *$ \\
\hline \multirow[t]{3}{*}{ Nr. of friends } & 0.137 & 0.14 & 0.14 & -0.01 & -0.01 & -0.01 \\
\hline & 0.03 & 0.03 & 0.03 & 0.02 & 0.02 & 0.02 \\
\hline & $5.64 * * *$ & $5.67 * * *$ & $5.621 * * *$ & -0.53 & -0.56 & -0.54 \\
\hline \multirow[t]{3}{*}{ Body mass index } & 0.08 & 0.08 & 0.08 & -0.33 & -0.33 & -0.33 \\
\hline & 0.02 & 0.02 & 0.02 & 0.02 & 0.02 & 0.02 \\
\hline & $4.19 * * *$ & $4.17 * * *$ & $4.19 * * *$ & $-20.93 * * *$ & $-20.89 * * *$ & $-20.90 * * *$ \\
\hline \multirow[t]{3}{*}{ Disabled } & -1.63 & -1.62 & -1.62 & -6.44 & -6.44 & -6.43 \\
\hline & 0.3 & 0.3 & 0.3 & 0.26 & 0.27 & 0.27 \\
\hline & $-5.40 * * *$ & $-5.37 * * *$ & $-5.35 * * *$ & $-24.28 * * *$ & $-24.29 * * *$ & $-24.23 * * *$ \\
\hline \multirow[t]{3}{*}{ Migrant } & 0.45 & 0.47 & 0.5 & -0.07 & -0.06 & -0.06 \\
\hline & 0.41 & 0.4 & 0.4 & 0.32 & 0.31 & 0.32 \\
\hline & 1.11 & 1.16 & 1.24 & -0.23 & -0.17 & -0.19 \\
\hline Sport: almost never & \multicolumn{6}{|c|}{ Reference group } \\
\hline \multirow[t]{2}{*}{ Sport: several times a year } & -0.55 & -0.55 & -0.56 & 0.11 & 0.1 & 0.11 \\
\hline & 0.26 & 0.26 & 0.26 & 0.22 & 0.22 & 0.22 \\
\hline
\end{tabular}




\begin{tabular}{|c|c|c|c|c|c|c|}
\hline & \multicolumn{3}{|c|}{ MCS } & \multicolumn{3}{|c|}{ PCS } \\
\hline & $-2.13 *$ & $-2.13 *$ & $-2.15^{*}$ & 0.48 & 0.46 & 0.48 \\
\hline \multirow[t]{3}{*}{ Sport: at least once a month } & -0.25 & -0.24 & -0.24 & 0.87 & 0.88 & 0.87 \\
\hline & 0.33 & 0.33 & 0.33 & 0.29 & 0.29 & 0.29 \\
\hline & -0.75 & -0.73 & -0.73 & $3.07 * *$ & $3.074 * *$ & $3.063 * *$ \\
\hline \multirow[t]{3}{*}{ Sport: at least one a week } & 0.97 & 0.98 & 0.98 & 1.5 & 1.5 & 1.51 \\
\hline & 0.21 & 0.21 & 0.21 & 0.18 & 0.18 & 0.18 \\
\hline & $4.58 * * *$ & $4.64 * * *$ & $4.59 * * *$ & $8.38 * * *$ & $8.36^{* * *}$ & $8.41 * * *$ \\
\hline Family status: married & \multicolumn{6}{|c|}{ Reference group } \\
\hline \multirow{3}{*}{$\begin{array}{l}\text { Family status: separated but } \\
\text { married }\end{array}$} & -1.39 & -1.36 & -1.38 & 1.12 & 1.11 & 1.11 \\
\hline & 0.52 & 0.52 & 0.52 & 0.49 & 0.49 & 0.49 \\
\hline & $-2.67 * *$ & $-2.62 * *$ & $-2.67 * *$ & $2.27 *$ & $2.26^{*}$ & $2.26^{*}$ \\
\hline \multirow[t]{3}{*}{ Family status: single } & 0.19 & 0.19 & 0.18 & 0.16 & 0.15 & 0.16 \\
\hline & 0.28 & 0.27 & 0.27 & 0.21 & 0.21 & 0.21 \\
\hline & 0.68 & 0.7 & 0.65 & 0.73 & 0.71 & 0.73 \\
\hline \multirow[t]{3}{*}{ Family status: divorced } & -0.9 & -0.91 & -0.91 & 0.26 & 0.26 & 0.26 \\
\hline & 0.32 & 0.32 & 0.32 & 0.27 & 0.27 & 0.27 \\
\hline & $-2.83 * *$ & $-2.84 * *$ & $-2.84 * *$ & 0.96 & 0.96 & 0.96 \\
\hline \multirow[t]{3}{*}{ Family status: widowed } & -1.76 & -1.74 & -1.76 & 0.11 & 0.1 & 0.11 \\
\hline & 0.38 & 0.38 & 0.38 & 0.35 & 0.35 & 0.35 \\
\hline & $-4.63 * * *$ & $-4.58 * * *$ & $-4.65 * * *$ & 0.31 & 0.28 & 0.31 \\
\hline \multirow{3}{*}{$\begin{array}{l}\text { Family status: other relation- } \\
\text { ship }\end{array}$} & -0.63 & -0.54 & -0.59 & -3.21 & -3.24 & -3.19 \\
\hline & 3.42 & 3.32 & 3.29 & 1.73 & 1.74 & 1.73 \\
\hline & -0.185 & -0.16 & -0.18 & -1.855 & -1.867 & -1.84 \\
\hline None working & \multicolumn{6}{|c|}{ Reference group } \\
\hline \multirow[t]{3}{*}{ In education } & -0.18 & -0.15 & -0.13 & 0.91 & 0.92 & 0.92 \\
\hline & 0.65 & 0.65 & 0.65 & 0.46 & 0.46 & 0.46 \\
\hline & -0.28 & -0.23 & -0.2 & $1.97^{*}$ & $1.99 *$ & $1.20 *$ \\
\hline \multirow[t]{3}{*}{ Full-time employed } & -1.48 & -1.47 & -1.48 & 1.37 & 1.37 & 1.37 \\
\hline & 0.24 & 0.24 & 0.24 & 0.24 & 0.24 & 0.24 \\
\hline & $-6.26 * * *$ & $-6.21 * * *$ & $-6.27 * * *$ & $5.83 * * *$ & $5.82 * * *$ & $5.82 * * *$ \\
\hline \multirow[t]{3}{*}{ Part-time employed } & -0.76 & -0.76 & -0.76 & 0.73 & 0.73 & 0.73 \\
\hline & 0.44 & 0.44 & 0.44 & 0.38 & 0.38 & 0.38 \\
\hline & -1.73 & -1.72 & -1.72 & 1.91 & 1.91 & 1.91 \\
\hline \multirow[t]{3}{*}{ Parental leave } & 0.41 & 0.44 & 0.4 & 2.44 & 2.42 & 2.44 \\
\hline & 0.74 & 0.74 & 0.74 & 0.62 & 0.62 & 0.62 \\
\hline & 0.55 & 0.6 & 0.54 & $3.95 * * *$ & $3.90 * * *$ & $3.95 * * *$ \\
\hline \multirow[t]{3}{*}{ Unemployed } & -1.11 & -1.09 & -1.1 & 0.44 & 0.43 & 0.44 \\
\hline & 0.52 & 0.52 & 0.52 & 0.45 & 0.45 & 0.45 \\
\hline & $-2.14^{*}$ & $-2.09 *$ & $-2.12 *$ & 0.96 & 0.95 & 0.97 \\
\hline In school & \multicolumn{6}{|c|}{ Reference group } \\
\hline \multirow[t]{3}{*}{ Primary education } & 0.61 & 0.64 & 0.62 & -1.19 & -1.2 & -1.18 \\
\hline & 0.83 & 0.83 & 0.83 & 0.46 & 0.46 & 0.46 \\
\hline & 0.73 & 0.77 & 0.74 & $-2.58 * *$ & $-2.61 * *$ & $-2.58 * *$ \\
\hline
\end{tabular}




\begin{tabular}{lcccccc} 
& \multicolumn{3}{c}{ MCS } & \multicolumn{3}{c}{ PCS } \\
\hline \hline Secondary education & 0.64 & 0.66 & 0.66 & 0.02 & 0.02 & 0.03 \\
& 0.82 & 0.82 & 0.82 & 0.42 & 0.42 & 0.42 \\
Tertiary education & 0.78 & 0.8 & 0.81 & 0.05 & 0.05 & 0.08 \\
& 0.17 & 0.21 & 0.22 & 1.04 & 1.05 & 1.06 \\
Urban & 0.85 & 0.85 & 0.85 & 0.43 & 0.43 & 0.42 \\
& 0.2 & 0.24 & 0.26 & $2.45^{*}$ & $2.48^{*}$ & $2.50^{*}$ \\
& 0.04 & 0.06 & 0.13 & 0.07 & 0.09 & 0.1 \\
& 0.3 & 0.31 & 0.32 & 0.23 & 0.23 & 0.23
\end{tabular}

Macro-economic variables

\begin{tabular}{|c|c|c|c|c|c|c|}
\hline \multirow[t]{3}{*}{ Unemployment rate } & 0.001 & -0.01 & -0.01 & 0.03 & 0.04 & 0.02 \\
\hline & 0.06 & 0.06 & 0.06 & 0.05 & 0.05 & 0.05 \\
\hline & 0.002 & -0.2 & -0.15 & 0.68 & 0.8 & 0.43 \\
\hline \multirow[t]{3}{*}{ Population density } & -0.001 & 0.001 & 0.001 & 0.001 & 0.001 & 0.001 \\
\hline & 0.001 & 0.001 & 0.001 & 0.001 & 0.001 & 0.001 \\
\hline & -0.76 & 0.61 & 0.69 & 0.3 & 0.37 & 1.06 \\
\hline \multirow[t]{3}{*}{ County area size } & 0.001 & 0.001 & 0.001 & -0.001 & -0.001 & -0.001 \\
\hline & 0.001 & 0.001 & 0.001 & 0.001 & 0.001 & 0.001 \\
\hline & $2.22 *$ & 1.19 & 1.2 & -0.48 & -0.58 & -0.71 \\
\hline \multirow[t]{3}{*}{ Constant } & 14.19 & 21 & 42.14 & 56.58 & 65.79 & 65.45 \\
\hline & 6.63 & 6.5 & 6.57 & 5.2 & 5.16 & 5.75 \\
\hline & $2.14^{*}$ & $3.23 * *$ & $6.41 * * *$ & $10.88 * * *$ & $12.76^{* * *}$ & $11.38 * * *$ \\
\hline Federal state dummies & yes & yes & yes & yes & yes & yes \\
\hline East-Germany dummy & yes & yes & yes & yes & yes & yes \\
\hline Big 5 & yes & yes & yes & yes & yes & yes \\
\hline Adj. R-squared & 0.2 & 0.2 & 0.2 & 0.46 & 0.46 & 0.46 \\
\hline AIC & 94990.49 & 95001.93 & 95012.22 & 90928.91 & 90927.25 & 90927.64 \\
\hline Observations & 13,328 & 13,328 & 13,328 & 13,328 & 13,328 & 13,328 \\
\hline Clusters & 394 & 394 & 394 & 394 & 394 & 394 \\
\hline
\end{tabular}


Table A.II-8: OLS models with one two species diversity variables. Each model contains the same set of socio-economic variables, macro-economic variables as well as nature and climate characteristics. Shown are coefficients, standard errors in parenthesis and t-values. P-values are indicated by asterisk symbols: * $<0.05, * *<0.01, * * *<0.001$.

\begin{tabular}{|c|c|c|c|c|c|c|}
\hline & \multicolumn{3}{|c|}{ MCS } & \multicolumn{3}{|c|}{ PCS } \\
\hline & VII & VIII & IX & $\mathbf{X}$ & XI & XII \\
\hline \multicolumn{7}{|l|}{ Species diversity } \\
\hline \multirow[t]{3}{*}{ Log plant species richness } & 2.78 & 3.3 & - & 0.99 & 0.53 & - \\
\hline & 0.99 & 0.86 & & 0.73 & -0.67 & \\
\hline & $2.82 * *$ & $3.83 * * *$ & & 1.38 & & \\
\hline \multirow[t]{3}{*}{ Log bird species richness } & 1.94 & - & 3.55 & -1.96 & - & -1.4 \\
\hline & 1.49 & & 1.36 & 1.14 & & 1.06 \\
\hline & 1.3 & & $2.62 * *$ & -1.72 & & -1.32 \\
\hline \multirow[t]{3}{*}{ Log bird abundance } & - & -0.67 & -0.57 & - & -0.57 & -0.57 \\
\hline & & 0.58 & 0.6 & & 0.51 & 0.5 \\
\hline & & -1.16 & -0.96 & & -1.11 & -1.14 \\
\hline \multicolumn{7}{|l|}{ Access garden and parks } \\
\hline \multirow[t]{3}{*}{ Garden } & -0.11 & -0.11 & -0.13 & 0.06 & 0.06 & 0.05 \\
\hline & 0.2 & 0.2 & 0.2 & 0.17 & 0.17 & 0.17 \\
\hline & -0.56 & -0.516 & -0.64 & 0.33 & 0.33 & 0.31 \\
\hline Park $<10$ walking minutes & \multicolumn{6}{|c|}{ Reference group } \\
\hline \multirow{3}{*}{$\begin{array}{l}\text { Park in 10-20 walking min- } \\
\text { utes }\end{array}$} & -0.88 & -0.87 & -0.89 & -0.6 & -0.6 & -0.6 \\
\hline & 0.22 & 0.22 & 0.22 & 0.16 & 0.17 & 0.16 \\
\hline & $-4.00 * * *$ & $-3.98 * * *$ & $-4.03 * * *$ & $-3.83 * * *$ & $-3.85 * * *$ & $-3.85 * * *$ \\
\hline \multirow[t]{3}{*}{ Park $<20$ walking minutes } & -1.16 & -1.15 & -1.19 & -1.07 & -1.08 & -1.08 \\
\hline & 0.37 & 0.37 & 0.37 & 0.35 & 0.35 & 0.35 \\
\hline & $-3.16^{* *}$ & $-3.13 * *$ & $-3.27 * *$ & $-3.07 * *$ & $-3.09 * *$ & $-3.10^{* *}$ \\
\hline \multirow[t]{3}{*}{ No park } & -0.32 & -0.33 & -0.38 & -1 & -1.02 & -1.03 \\
\hline & 0.29 & 0.28 & 0.29 & 0.26 & 0.26 & 0.26 \\
\hline & -1.13 & -1.15 & -1.32 & $-3.83 * * *$ & $-3.89 * * *$ & $-3.96 * * *$ \\
\hline
\end{tabular}

Nature \& Climate

\begin{tabular}{lcccccc}
\hline Blue space & 0.02 & 0.03 & 0.03 & -0.05 & -0.05 & -0.05 \\
& 0.05 & 0.05 & 0.05 & 0.04 & 0.04 & 0.04 \\
Landscape heterogeneity & 0.47 & 0.6 & 0.55 & -1.32 & -1.55 & -1.28 \\
& -0.62 & -0.38 & -0.55 & 0.47 & 0.56 & 0.59 \\
Protected areas & 0.74 & 0.75 & 0.77 & 0.57 & 0.58 & 0.58 \\
& -0.84 & -0.51 & -0.71 & 0.82 & 0.96 & 1.02 \\
Temperature & 0.01 & 0.01 & 0.01 & 0.004 & 0.01 & 0.01 \\
& 0.01 & 0.01 & 0.01 & 0.004 & 0.004 & 0.004 \\
& $2.12^{*}$ & $2.15 *$ & $2.34 *$ & 1.01 & 1.69 & 1.39 \\
& 0.04 & 0.1 & -0.03 & 0.08 & -0.04 & -0.04 \\
& 0.2 & 0.19 & 0.21 & 0.15 & 0.13 & 0.14 \\
\hline \hline
\end{tabular}




\begin{tabular}{|c|c|c|c|c|c|c|}
\hline \multirow{2}{*}{ Socio-economic variables } & \multicolumn{3}{|c|}{ MCS } & \multicolumn{3}{|c|}{ PCS } \\
\hline & & & & & & \\
\hline \multirow[t]{3}{*}{ Household income } & 0.86 & 0.86 & 0.88 & 0.823 & 0.83 & 0.84 \\
\hline & 0.2 & 0.2 & 0.21 & 0.18 & 0.18 & 0.18 \\
\hline & $4.23 * * *$ & $4.24 * * *$ & $4.30 * * *$ & $4.66 * * *$ & $4.70 * * *$ & $4.72 * * *$ \\
\hline \multirow[t]{3}{*}{ Age } & 0.08 & 0.08 & 0.08 & -0.181 & -0.18 & -0.18 \\
\hline & 0.01 & 0.01 & 0.01 & 0.01 & 0.01 & 0.01 \\
\hline & $9.30 * * *$ & $9.31 * * *$ & $9.35 * * *$ & $-24.44 * * *$ & $-24.43 * * *$ & $-24.40 * * *$ \\
\hline \multirow[t]{3}{*}{ Male } & 0.86 & 0.85 & 0.86 & 0.77 & 0.77 & 0.77 \\
\hline & 0.15 & 0.15 & 0.15 & 0.16 & 0.16 & 0.16 \\
\hline & $5.71 * * *$ & $5.70 * * *$ & $5.72 * * *$ & $4.83^{* * *}$ & $4.84 * * *$ & $4.83^{* * *}$ \\
\hline \multirow[t]{3}{*}{ Doctor visits } & -0.05 & -0.05 & -0.05 & -0.15 & -0.15 & -0.15 \\
\hline & 0.01 & 0.01 & 0.01 & 0.01 & 0.01 & 0.01 \\
\hline & $-6.17 * * *$ & $-6.21 * * *$ & $-6.18 * * *$ & $-13.46 * * *$ & $-13.47 * * *$ & $-13.47 * * *$ \\
\hline \multirow[t]{3}{*}{ Hospital visits } & -0.09 & -0.09 & -0.09 & -0.08 & -0.08 & -0.08 \\
\hline & 0.02 & 0.02 & 0.02 & 0.02 & 0.02 & 0.02 \\
\hline & $-5.87 * * *$ & $-5.83 * * *$ & $-5.88 * * *$ & $-4.77 * * *$ & $-4.77 * * *$ & $-4.75 * * *$ \\
\hline \multirow[t]{3}{*}{ Nr. of friends } & 0.14 & 0.14 & 0.14 & -0.01 & -0.01 & -0.01 \\
\hline & 0.03 & 0.03 & 0.03 & 0.02 & 0.02 & 0.02 \\
\hline & $5.67 * * *$ & $5.63 * * *$ & $5.66 * * *$ & -0.58 & -0.55 & -0.57 \\
\hline \multirow[t]{3}{*}{ Body mass index } & 0.08 & 0.08 & 0.08 & -0.33 & -0.33 & -0.33 \\
\hline & 0.02 & 0.02 & 0.02 & 0.02 & 0.02 & 0.02 \\
\hline & $4.18 * * *$ & $4.21 * * *$ & $4.18 * * *$ & $-20.88 * * *$ & $-20.91 * * *$ & $-20.87 * * *$ \\
\hline \multirow[t]{3}{*}{ Disabled } & -1.63 & -1.62 & -1.61 & -6.44 & -6.43 & -6.43 \\
\hline & 0.3 & 0.3 & 0.3 & 0.27 & 0.27 & 0.27 \\
\hline & $-5.39 * * *$ & $-5.37 * * *$ & $-5.35 * * *$ & $-24.28 * * *$ & $-24.23 * * *$ & $-24.23 * * *$ \\
\hline \multirow[t]{3}{*}{ Migrant } & 0.44 & 0.46 & 0.47 & -0.06 & -0.06 & -0.05 \\
\hline & 0.4 & 0.41 & 0.4 & 0.32 & 0.32 & 0.31 \\
\hline & 1.1 & 1.13 & 1.18 & -0.2 & -0.21 & -0.15 \\
\hline Sport: almost never & \multicolumn{6}{|c|}{ Reference group } \\
\hline \multirow[t]{3}{*}{ Sport: several times a year } & -0.55 & -0.55 & -0.55 & 0.1 & 0.11 & 0.1 \\
\hline & 0.26 & 0.26 & 0.26 & 0.2 & 0.22 & 0.22 \\
\hline & $-2.12^{*}$ & $-2.12^{*}$ & $-2.13 *$ & 0.47 & 0.48 & 0.47 \\
\hline \multirow[t]{3}{*}{ Sport: at least once a month } & -0.25 & -0.25 & -0.24 & 0.87 & 0.87 & 0.87 \\
\hline & 0.33 & 0.33 & 0.33 & 0.29 & 0.29 & 0.29 \\
\hline & -0.75 & -0.75 & -0.73 & $3.07 * *$ & $3.06 * *$ & $3.07 * *$ \\
\hline \multirow[t]{3}{*}{ Sport: at least one a week } & 0.98 & 0.97 & 0.99 & 1.5 & 1.51 & 1.5 \\
\hline & 0.21 & 0.21 & 0.21 & 0.18 & 0.18 & 0.18 \\
\hline & $4.61 * * *$ & $4.59 * * *$ & $4.65 * * *$ & $8.36^{* * *}$ & $8.41 * * *$ & $8.40 * * *$ \\
\hline Family status: married & \multicolumn{6}{|c|}{ Reference group } \\
\hline \multirow{3}{*}{$\begin{array}{l}\text { Family status: separated but } \\
\text { married }\end{array}$} & -1.38 & -1.39 & -1.37 & 1.11 & 1.11 & 1.11 \\
\hline & 0.52 & 0.52 & 0.52 & 0.49 & 0.49 & 0.49 \\
\hline & $-2.65 * *$ & $-2.68 * *$ & $-2.63 * *$ & $2.25^{*}$ & $2.25^{*}$ & $2.24^{*}$ \\
\hline \multirow[t]{2}{*}{ Family status: single } & 0.19 & 0.19 & 0.19 & 0.15 & 0.16 & 0.15 \\
\hline & 0.28 & 0.28 & 0.27 & 0.22 & 0.21 & 0.21 \\
\hline
\end{tabular}




\begin{tabular}{|c|c|c|c|c|c|c|}
\hline & \multicolumn{3}{|c|}{ MCS } & \multicolumn{3}{|c|}{ PCS } \\
\hline & 0.7 & 0.68 & 0.7 & 0.71 & 0.73 & 0.71 \\
\hline \multirow[t]{3}{*}{ Family status: divorced } & -0.9 & -0.89 & -0.91 & 0.26 & 0.26 & 0.26 \\
\hline & 0.32 & 0.32 & 0.32 & 0.27 & 0.27 & 0.27 \\
\hline & $-2.83 * *$ & $-2.83 * *$ & $-2.84 * *$ & 0.96 & 0.96 & 0.95 \\
\hline \multirow[t]{3}{*}{ Family status: widowed } & -1.75 & -1.76 & -1.74 & 0.1 & 0.11 & 0.1 \\
\hline & 0.38 & 0.38 & 0.38 & 0.35 & 0.35 & 0.35 \\
\hline & $-4.60 * * *$ & $-4.63 * * *$ & $-4.581 * * *$ & 0.27 & 0.31 & 0.28 \\
\hline \multirow{3}{*}{$\begin{array}{l}\text { Family status: other relation- } \\
\text { ship }\end{array}$} & -0.59 & -0.6 & -0.52 & -3.25 & -3.19 & -3.21 \\
\hline & 3.41 & 3.4 & 3.3 & 1.74 & 1.74 & 1.74 \\
\hline & -0.17 & -0.18 & -0.16 & -1.87 & -1.84 & -1.85 \\
\hline None working & \multicolumn{6}{|c|}{ Reference group } \\
\hline \multirow[t]{3}{*}{ In education } & -0.18 & -0.17 & -0.14 & 0.91 & 0.92 & 0.93 \\
\hline & 0.65 & 0.65 & 0.65 & 0.46 & 0.46 & 0.46 \\
\hline & -0.28 & -0.26 & -0.22 & $1.97 *$ & $1.99 *$ & $2.01 *$ \\
\hline \multirow[t]{3}{*}{ Full-time employed } & -1.48 & -1.48 & -1.48 & 1.37 & 1.37 & 1.36 \\
\hline & 0.24 & 0.24 & 0.24 & 0.24 & 0.24 & 0.24 \\
\hline & $-6.23 * * *$ & $-6.27 * * *$ & $-6.21 * * *$ & $5.81 * * *$ & $5.82 * * *$ & $5.81 * * *$ \\
\hline \multirow[t]{3}{*}{ Part-time employed } & -0.76 & -0.76 & -0.76 & 0.73 & 0.73 & 0.73 \\
\hline & 0.44 & 0.44 & 0.44 & 0.39 & 0.39 & 0.39 \\
\hline & -1.73 & -1.73 & -1.73 & 1.91 & 1.91 & 1.91 \\
\hline \multirow[t]{3}{*}{ Parental leave } & 0.43 & 0.41 & 0.45 & 2.41 & 2.44 & 2.42 \\
\hline & 0.74 & 0.74 & 0.74 & 0.62 & 0.62 & 0.62 \\
\hline & 0.58 & 0.56 & 0.6 & $3.90 * * *$ & $3.96 * * *$ & $3.90 * * *$ \\
\hline \multirow[t]{3}{*}{ Unemployed } & -1.11 & -1.11 & -1.09 & 0.43 & 0.44 & 0.44 \\
\hline & 0.52 & 0.52 & 0.52 & 0.46 & 0.45 & 0.44 \\
\hline & $-2.12^{*}$ & $-2.14^{*}$ & $-2.09 *$ & 0.95 & 0.96 & 0.96 \\
\hline In school & \multicolumn{6}{|c|}{ Reference group } \\
\hline \multirow[t]{3}{*}{ Primary education } & 0.63 & 0.62 & 0.65 & -1.21 & -1.18 & -1.2 \\
\hline & 0.83 & 0.83 & 0.83 & 0.46 & 0.46 & 0.46 \\
\hline & 0.75 & 0.74 & 0.78 & $-2.62 * *$ & $-2.58 * *$ & $-2.61 * *$ \\
\hline \multirow[t]{3}{*}{ Secondary education } & 0.64 & 0.65 & 0.67 & 0.02 & 0.03 & 0.03 \\
\hline & 0.8 & 0.82 & 0.82 & 0.42 & 0.42 & 0.42 \\
\hline & 0.78 & 0.79 & 0.81 & 0.04 & 0.07 & 0.07 \\
\hline \multirow[t]{3}{*}{ Tertiary education } & 0.17 & 0.18 & 0.21 & 1.04 & 1.05 & 1.06 \\
\hline & 0.85 & 0.85 & 0.85 & 0.43 & 0.42 & 0.42 \\
\hline & 0.2 & 0.21 & 0.25 & $2.44 *$ & $2.48 *$ & $2.50 *$ \\
\hline \multirow[t]{3}{*}{ Urban } & 0.03 & 0.07 & 0.09 & 0.08 & 0.09 & 0.11 \\
\hline & 0.3 & 0.3 & 0.31 & 0.22 & 0.23 & 0.23 \\
\hline & 0.1 & 0.24 & 0.29 & 0.34 & 0.4 & 0.49 \\
\hline \multicolumn{7}{|l|}{ Macro-economic variables } \\
\hline \multirow[t]{3}{*}{ Unemployment rate } & -0.01 & -0.01 & -0.02 & 0.04 & 0.02 & 0.03 \\
\hline & 0.06 & 0.06 & 0.06 & 0.05 & 0.05 & 0.05 \\
\hline & -0.13 & -0.24 & -0.39 & 0.84 & 0.41 & 0.54 \\
\hline
\end{tabular}




\begin{tabular}{|c|c|c|c|c|c|c|}
\hline \multirow[b]{2}{*}{ Population density } & \multicolumn{3}{|c|}{ MCS } & \multicolumn{3}{|c|}{ PCS } \\
\hline & -0.001 & -0.001 & 0.001 & -0.001 & 0.001 & 0.001 \\
\hline & 0.001 & 0.001 & 0.001 & 0.001 & 0.001 & 0.001 \\
\hline & -0.41 & -0.23 & 0.98 & -0.23 & 0.82 & 0.91 \\
\hline \multirow[t]{3}{*}{ County area size } & 0.001 & 0.001 & 0.001 & -0.001 & -0.001 & -0.001 \\
\hline & 0.001 & 0.001 & 0.001 & 0.001 & 0.001 & 0.001 \\
\hline & $1.99 *$ & $2.13 *$ & 1.12 & -0.26 & -0.54 & -0.65 \\
\hline \multirow[t]{3}{*}{ Constant } & 9.2 & 20.63 & 26.77 & 61.58 & 62.01 & 71.5 \\
\hline & 7.45 & 9.12 & 9.14 & 6.00 & 7.26 & 7.03 \\
\hline & 1.24 & $2.26^{*}$ & $2.93 * *$ & $10.27 * * *$ & $8.55^{* * *}$ & $10.18^{* * *}$ \\
\hline Federal state dummies & yes & yes & yes & yes & yes & yes \\
\hline East-Germany dummy & yes & yes & yes & yes & yes & yes \\
\hline Big 5 & yes & yes & yes & yes & yes & yes \\
\hline Adj. R-squared & 0.2 & 0.2 & 0.2 & 0.46 & 0.46 & 0.46 \\
\hline AIC & 94989.47 & 94990.32 & 95002.35 & 90926.72 & 90928.81 & 90927.15 \\
\hline Observations & 13,328 & 13,328 & 13,328 & 13,328 & 13,328 & 13,328 \\
\hline Clusters & 394 & 394 & 394 & 394 & 394 & 394 \\
\hline
\end{tabular}




\subsection{Author contributions}

Authors:

Joel Methorst (JM, PhD candidate), Aletta Bonn (AB), Melissa Marselle (MM), Katrin Böhning-Gaese (KBG), Katrin Rehdanz (KR)

(1) Development and planning

$\mathrm{PhD}$ candidate $(\mathrm{JM}): 80 \%$

KR and KBG: in total $20 \%$

(2) Compilation of data and preparation of figures

PhD candidate (JM): $100 \%$

- JM collected online open source datasets, organised and compiled the ecological and socio-economic datasets and calculated indicators with spatial data in R. JM prepared all figures in the manuscript and supplementary material.

(3) Data analyses and interpretation of results

PhD candidate (JM): $80 \%$

- JM conducted all statistical analyses and interpreted the results.

$\mathrm{AB}, \mathrm{MM}, \mathrm{KGB}$ and KR: $20 \%$

- KR and KGB gave some advice on statistical analyses. All co-authors added their insights to the interpretation of results.

(4) Preparation of manuscript

$\mathrm{PhD}$ candidate $(\mathrm{JM}): 80 \%$

AB, MM, KGB and KR: 20\% 


\section{Appendix III}

\subsection{Manuscript}

Title:

'The importance of species diversity for human well-being in Europe'

Status:printed online in Ecological Economics

Citation:

Joel Methorst, Katrin Rehdanz, Thomas Mueller, Bernd Hansjürgens, Aletta Bonn, Katrin Böhning-Gaese (printed online): "The importance of species diversity for human well-being in Europe", Ecological Economics. DOI: https://doi.org/10.1016/j. ecolecon.2020.106917 


\title{
ARTICLE IN PRESS
}

Ecological Economics $\mathrm{xxx}(\mathrm{xxxx}) \mathrm{xxx}$

Analysis

\section{The importance of species diversity for human well-being in Europe}

\author{
Joel Methorst $^{\mathrm{a},{ }^{*}, \text { Katrin Rehdanz }}{ }^{\mathrm{b}}$, Thomas Mueller ${ }^{\mathrm{c}}$, Bernd Hansjürgens ${ }^{\mathrm{d}}$, Aletta Bonn ${ }^{\mathrm{e}}$, \\ Katrin Böhning-Gaese ${ }^{\mathrm{f}}$
}

${ }^{a}$ German Centre for Integrative Biodiversity Research (iDiv) Halle-Jena-Leipzig, Senckenberg Biodiversity and Climate Research Centre (SBiK-F) \& Goethe University Frankfurt am Main, Frankfurt am Main, Germany

${ }^{\mathrm{b}}$ Department of Economics, Kiel University, Kiel, Germany

' Senckenberg Biodiversity and Climate Research Centre (SBiK-F) \& Goethe University Frankfurt am Main, Frankfurt am Main, Germany

${ }^{\mathrm{d}}$ Helmholtz-Centre for Environmental Research - UFZ, Martin Luther University Halle-Wittenberg \& German Centre for Integrative Biodiversity Research (iDiv) Halle-

Jena-Leipzig, Leipzig, Germany

${ }^{\mathrm{e}}$ Helmholtz-Centre for Environmental Research - UFZ, Friedrich Schiller University Jena \& German Centre for Integrative Biodiversity Research (iDiv) Halle-JenaLeipzig, Leipzig, Germany

${ }^{\mathrm{f}}$ Senckenenberg Biodiversity and Climate Research Centre (SBiK-F), Goethe University Frankfurt am Main \& German Centre for Integrative Biodiversity Research (iDiv) Halle-Jena-Leipzig, Frankfurt am Main, Germany

\section{A R T I C L E I N F O}

\section{Keywords:}

Subjective Well-Being

Life-Satisfaction

Nature Contributions to People

Ecosystem Services

Nature Valuation

Biodiversity

\begin{abstract}
A B S T R A C T
Nature affects human well-being in multiple ways. However, the association between species diversity and human well-being at larger spatial scales remains largely unexplored. Here, we examine the relationship between species diversity and human well-being at the continental scale, while controlling for other known drivers of well-being. We related socio-economic data from more than 26,000 European citizens across 26 countries with macroecological data on species diversity and nature characteristics for Europe. Human well-being was measured as self-reported life-satisfaction and species diversity as the species richness of several taxonomic groups (e.g. birds, mammals and trees). Our results show that bird species richness is positively associated with lifesatisfaction across Europe. We found a relatively strong relationship, indicating that the effect of bird species richness on life-satisfaction may be of similar magnitude to that of income. We discuss two, non-exclusive pathways for this relationship: the direct multisensory experience of birds, and beneficial landscape properties which promote both bird diversity and people's well-being. Based on these results, this study argues that management actions for the protection of birds and the landscapes that support them would benefit humans. We suggest that political and societal decision-making should consider the critical role of species diversity for human well-being.
\end{abstract}

\section{Introduction}

Over the past decades a substantial body of research has highlighted the positive effects of nature on human well-being (e.g. Hartig et al., 2014; MA, 2005; Russell et al., 2013; Sandifer et al., 2015). The Intergovernmental Science-Policy Platform for Biodiversity and Ecosystem Services (IPBES) has named these benefits and services Nature's Contributions to People (NCP) (Díaz et al., 2018). According to the IPBES framework and the NCP concept, nature affects the material (e.g. food and building material) and non-material (e.g. physical and psychological health, inspiration and spirituality) aspects of human livelihood, and is a key factor in regulating important environmental processes (e.g. air and climate regulation) (Díaz et al., 2015; IPBES, 2014). Of these three types of NCP, non-material NCP or services with no obvious material benefits may be the most difficult to study, especially as they are, by definition, intangible and subjective (Chan et al., 2012), and difficult to conceptualize (Fish et al., 2016; Satz et al., 2013). However, knowledge generated from research on non-material NCP is important because it may provide complementary information for natural resource management and policy decisions that are otherwise largely based on material NCP (e.g. Adams and Morse, 2019).

A number of indicators are available as measures of non-material NCP (e.g. Hernández-Morcillo et al., 2013; Sterling et al., 2017; Zorondo-Rodríguez et al., 2016). Several studies have investigated non-

\footnotetext{
* Corresponding author.

E-mail addresses: joel.methorst@senckenberg.de (J. Methorst), rehdanz@economics.uni-kiel.de (K. Rehdanz), thomas.mueller@senckenberg.de (T. Mueller), bernd.hansjuergens@ufz.de (B. Hansjürgens), aletta.bonn@idiv.de (A. Bonn), katrin.boehning-gaese@senckenberg.de (K. Böhning-Gaese).

https://doi.org/10.1016/j.ecolecon.2020.106917

Received 26 February 2020; Received in revised form 17 November 2020; Accepted 18 November 2020

0921-8009/C 2020 The Author(s). Published by Elsevier B.V. This is an open access article under the CC BY-NC-ND license

(http://creativecommons.org /icenses/by-nc-nd/4.0/).
} 
material NCP by using subjective measures of well-being such as lifesatisfaction or subjective health measures. City residents, for instance, living close to urban green space such as parks exhibit higher levels of life-satisfaction (Bertram and Rehdanz, 2015; Krekel et al., 2016; White et al., 2017). Within cities and beyond, studies also show that good access to vegetated areas is related to better cognitive function and development (Bratman et al., 2012; Reuben et al., 2019), fewer symptoms of depression (Cohen-Cline et al., 2015; Miles et al., 2012), lower self-reported stress (van den Berg et al., 2010) and lower risk of psychiatric disorders (de Vries et al., 2016; Engemann et al., 2019).

While these studies use a variety of indicators to examine human well-being, they have used a very limited set of indicators to describe nature. For instance, many studies mainly focus on the extent (e.g. size, total area cover) or proximity to water bodies (e.g. lakes, rivers) and vegetated areas (e.g. natural areas, urban parks), also termed blue or green space (Gascon et al., 2015; Völker and Kistemann, 2011; World Health Organization, 2017). More recently, studies have explored links between biodiversity, non-material NCP and human well-being (e.g. Lovell et al., 2014; Marselle et al., 2019; Sandifer et al., 2015), but few have made use of ecological measures of species diversity (e.g. based on field sampling and monitoring) as indicators for biodiversity.

Using such species diversity measures, a recent study demonstrated that faunal and floral species richness (number of species) is positively related to the subjective well-being of residents in the State of Victoria, Australia (Mavoa et al., 2019). Higher plant species richness is also positively associated with people's ability to recover from stress (Lindemann-Matthies and Matthies, 2018) while composite measures of multi-taxa species richness (plants, birds and bees/butterflies) are related to restorative benefits of urban parks (Wood et al., 2018). Other studies show positive relationships between bird and plant species richness and psychological well-being in urban parks (Fuller et al., 2007), although results are not always consistent (Dallimer et al., 2012). Furthermore, bird species richness and abundance are linked to personal and neighborhood well-being (Luck et al., 2011) and afternoon bird abundance is associated with better mental health in urban residents (Cox et al., 2017). These studies provide valuable insights on how humans can benefit from species diversity and argue that positive effects can be attributed to the fact that people enjoy watching and interacting with birds (Belaire et al., 2015; Cox and Gaston, 2016), or that they appreciate the aesthetic value of plant diversity (Hoyle et al., 2017; Lindemann-Matthies et al., 2010; Southon et al., 2017).

Despite recent efforts to study the non-material influence of species diversity on different measures of human well-being, several open questions remain. First, most of the studies were conducted on a small spatial scale such as urban parks or urbanized areas. In comparison, our knowledge about the effect of species diversity on human well-being on a larger spatial scale is still very limited (but see Wheeler et al., 2015, for a national study in the UK). Second, to our knowledge, researchers have not yet investigated the effect of species diversity on life-satisfaction as an indicator for human well-being. However, an assessment of the largescale relationship between species diversity and life-satisfaction may help us to understand if observed local-level patterns can be generalized beyond the specific local setting and are also evident on larger spatial scales while including a wider range of species numbers (diversity) and non-urban residents, who may have a different relationships with species diversity. Analyses of such large-scale relationships may also enable us to conduct comparisons between countries or regions, highlight research needs and provide knowledge on non-material NCP that can inform national and regional policy and management decisions.

The aim of this study is therefore to examine the relationship between species diversity and life-satisfaction on a continental level, focusing on multiple species groups and accounting for the potentially confounding effects of other nature characteristics and socio-economic factors. In our analyses, we relate life-satisfaction scores and socioeconomic data of more than 26,000 European citizens from 26 countries with macroecological data on the regional level for species diversity and other nature characteristics. Species diversity is measured as the species richness of birds, mammals (including megafauna) and trees. In addition, we compiled indicators for other nature and climate characteristics such as landscape and topographic heterogeneity, the area of green and blue space, or protected area cover.

\section{Empirical approach}

The assessment of people's self-reported life-satisfaction as a measure of subjective well-being has undergone critical evaluation (Kahneman et al., 1997; Kahneman and Krueger, 2006) and the conceptual underpinnings of using such data as a tool for preference elicitation and non-market valuation have been extensively discussed (Welsch, 2020; Welsch, 2009; Welsch and Ferreira, 2014). In recent years the approach has increasingly been used for preference elicitation and non-market valuation of environmental amenities and disamenities (for a recent review see Maddison et al., 2020). All of these studies established that subjective well-being is positively related to environmental quality and negatively related to environmental disamenities.

\subsection{The econometric model}

To assess the relationship between species richness and lifesatisfaction we extended the general econometric model approach used previously (e.g. Ferrer-i-Carbonell and Frijters, 2004) to include species richness measures ${ }^{2}$ :

$\mathrm{LS}_{\mathrm{ijr}}=\alpha+\beta \ln \left(\mathrm{Y}_{\mathrm{i}}\right)+\gamma \mathrm{X}_{\mathrm{i}}+\delta \mathrm{G}_{\mathrm{j}}+\varphi \ln \left(\mathrm{D}_{\mathrm{j}}\right)+\eta \mathrm{N}_{\mathrm{j}}+\tau_{r}+\varepsilon_{\mathrm{ij}}$

where $L S_{i j}$ represents self-reported life-satisfaction of individual $i$ in NUTS region $j$. NUTS regions represent an EU classification of spatial units for Europe (French: Nomenclature des unités territoriales statistiques). $Y_{i}$ is reported household income of individual $i, \boldsymbol{X}_{\boldsymbol{i}}$ is a vector of demographic and socio-economic variables of individual $i, \boldsymbol{G}_{j}$ is a vector of geographical variables, $\boldsymbol{D}_{\boldsymbol{j}}$ represents a vector of species richness measures, $\boldsymbol{N}_{\boldsymbol{j}}$ is a vector of other nature and climate characteristics, and $\tau_{r}$ symbolizes country dummies (several NUTS regions $j$ can be grouped within a country). The variables $G_{j}, D_{j}$, and $N_{j}$ were all measured at the NUTS regional level. The error term is represented by $\varepsilon_{i j}$, and $\beta$, as well as the vectors $\gamma, \delta, \varphi$ and $\eta$.

Various assumptions about the functional form of the econometric model are worth discussing. Following empirical findings regarding the functional form of income, household income is introduced into the model with its natural logarithm. Similar to the other nature characteristics, species richness measures were calculated on the NUTS regional level in the econometric model. Initially, we considered different specifications of species richness including linear and loglinear (natural logarithm) but the results presented focus on the loglinear specification of species richness of different taxonomic groups to account for a diminishing marginal utility at higher species richness values. Results from models with the linear specification are included in the supplementary information (Supplementary Tables S10-13).

\section{Material and methods}

\subsection{Socio-economic data}

Life-satisfaction and socio-economic data were derived from the 2012 European Quality of Life Survey (EQLS) with data for several thousand individuals $(n=43,636)$ from 34 European countries and 330

\footnotetext{
1 This included a considerable range of environmental (dis)amenities such as air pollution, airport noise, green space, natural disasters and climate parameters. For a recent overview of the literature see Maddison et al. (2020).
}

${ }^{2}$ See e.g. Ferrer-i-Carbonell and Frijters (2004). 
NUTS regions, with 1 to 38 NUTS regions per country due to their variable size (see summary statistics in Supplementary Table S3), as NUTS regions are classified according to average population size and existing administrative units. ${ }^{3}$ In the EQLS, most NUTS regions are categorized as NUTS 2 regions, but the data for Great Britain and France are on the NUTS 1 level while data for Lithuania and Latvia are on NUTS 3 level. EQLS data for Luxembourg, Cyprus, Croatia, Macedonia, Malta and Estonia were grouped on the NUTS 0 level, because either NUTS 1 or NUTS 2 levels were not clearly defined, or macro-economic data was only available at the national level (see below). The EQLS interviews were carried out by GfK Belgium between 2011 and 2012 with people aged 18 years and older. For more information see www.eurofound. europa.eu; data are offered by the UK Data Archive (University of Essex, Colchester, January 2014, 2nd Edition).

In the EQLS, information on life-satisfaction is obtained by asking individuals the following question: "All things considered, how satisfied would you say you are with your life these days?". Respondents can choose from an ordinal scale of 1 to 10 , where 1 means very dissatisfied and 10 means very satisfied. For our analysis, we included demographic and socio-economic explanatory variables from the EQLS at the individual level that have previously been found to have both positive and negative significant effects on life-satisfaction: income, age, gender, type of residential area (urban or rural), education level, health status, household structure/ marital status, employment status and volunteering behavior (Dolan et al., 2008; Meier and Stutzer, 2008). A quadratic term of age is also included, to account for the reported U-shaped relationship between age and life satisfaction (e.g. Dolan et al., 2008; Frey and Stutzer, 2002). Information on respondents' monthly net household income is measured in income categories (e.g. the first category delimits a net monthly income $<50$ EUR). Based on the categorical income variable we calculated the mean of each income category $(n=22)$ in order to create a continuous income variable (e.g. to the lowest income category we assigned an income value of 25 EUR) (see Supplementary Table S1). We also accounted for the likelihood of a person experiencing green space by using data from a 5-item question in the EQLS which describes how the survey participants assess their access to recreational areas (e.g. sport facilities) or green space. We term the variable 'Recreation Access' and its five categories are: access with (1) great difficulty, (2) with some difficulty, (3) easily, (4) very easily and (5) service not used.

Additionally, we added macro-economic indicators at the NUTS level, in particular GDP, population density and unemployment rate as explanatory variables to the models. Data were available from the year 2011 at the NUTS 2 level by Eurostat (http://ec.europa.eu/eurostat/); data for Luxembourg, Cyprus, Macedonia, Malta and Estonia were often available only on country level. When values for 2011 were missing we used values from the year before or after (data for Serbia and Kosovo was not available) and when data for a specific region was missing, we calculated the average across lower-level NUTS regions (e.g. Croatia, France and UK). We calculated the size of each NUTS region to account for the different area sizes in the data analyses. Further, we added a binary variable termed "Eastern Europe" for all former European socialist countries (i.e. Latvia, Lithuania, Estonia, Poland, Czech Republic, Slovakia, Hungary, Romania and Bulgaria), since economic development and life-satisfaction in Eastern Europe, especially in former parts of the USSR and countries of the Warsaw Pact, is on average much lower compared to Western Europe, even accounting for confounding variables (Bonini, 2008). We do not report results for population density because we excluded this variable from our statistical models due to high correlations with green space area cover. Still, our analyses accounts for population characteristics to a certain degree as we include

\footnotetext{
${ }^{3}$ NUTS level 1 regions are the largest (3-7 million people), NUTS level 2 an intermediate (0.8-3 million people), and NUTS level 3 areas the smallest spatial unit (150-800 thousand people). The three NUTS levels are spatially nested.
}

information on individual's urban residency (see also Wheeler et al., 2015) with a binary variable termed "Urban" ( $1=$ urban residents, $0=$ rural residents).

\subsection{Species richness, nature characteristics and climate}

We compiled data on species richness, other characteristics of nature and climate for Europe from spatial data (atlas data or species distribution maps) and satellite imagery. For all data, except for data on green space, blue space and protected areas, we calculated variables by first compiling values on a European Universal Transversal Mercator (UTM) $50 \times 50 \mathrm{~km}$ grid (see European Breeding Bird Atlas; EBBA). We then calculated the area weighted mean of these variables for each NUTS region (Table 1). This was done by weighting each variable value in a 50 $\times 50 \mathrm{~km}$ grid cell, which overlaps a specific NUTS-region, with the percentage of area shared by the grid cell and the NUTS region. For the data on green space, blue space and protected areas we calculated the percentage cover within the NUTS region (Table 1). The data for species richness, nature characteristics and climate were merged with the socioeconomic data by using NUTS regions as matching ID. Our final data set contains two types of data, life-satisfaction and socio-economic data at the level of interviewed individuals, and species richness, nature characteristics, climate and the macro-economic variables at the level of the NUTS region which the individual inhabits.

\subsubsection{Species richness}

We use species richness as species diversity measure and calculated this variable for four species groups: birds, mammals, megafauna and trees (Table 1). We selected species groups for which a positive effect on humans has been demonstrated in local scale studies and for which species distribution data are available at the European scale. As data on European plant species distribution is not yet available, we used data on tree species richness.

Bird data was obtained from the first European Bird Census Council's (EBCC) European Breeding Bird Atlas (EBBA) (Hagemeijer and Blair, 1997) (www.gbif.org, DOI:10.15468/adtfvf, accessed April 2017). The atlas data is available on a $50 \times 50 \mathrm{~km}$ UTM grid map and contains information about the presence ("probable" and "confirmed" breeding records) and absence of 486 European breeding bird species collected mainly from 1980 to 1990 . The temporal mismatch of the sampling periods between the EQLS and the EBBA atlas data should not be a major issue for this study because there have not been any major changes in species richness over time at the spatial scale of this study across Europe and within European countries (Koleček et al., 2010; Van Turnhout et al., 2007). Changes have mainly been observed for bird abundances (e.g. population numbers) within agricultural landscapes or in species community composition (Bowler et al., 2019; Reif et al., 2013; Le Viol et al., 2012). We provide additional analyses supporting these arguments in the supplementary information (Fig. S1, Supplementary Tables S14 \& S15).

The EBBA data contains grid values of somewhat variable data quality across Europe (Hagemeijer and Blair, 1997). We dealt with the variable data quality by compiling two different versions of the bird atlas, one original data set that contains all grid cells and one data set where low quality grid cells, as identified in the EBBA (Hagemeijer and Blair, 1997), were defined as missing ( $n=219,3.7 \%)$. Based on both versions of the EBBA two variables for area weighted mean bird species richness were calculated for each NUTS region and then used in the analyses. Here (Figs. 1-3, Supplementary Tables S6-S13), we report only the results for bird species richness based on the original EBBA data set because the statistical models for the two species richness measures yielded the same overall results.

Information on mammal and megafauna species distribution in Europe was obtained from global IUCN range maps retrieved from the IUCN Red List data portal (www.iucnredlist.org, accessed 16 December 2016). We treated the IUCN presence categories 'extant', 'probably 


\section{ARTICLEE IN PRESS}

J. Methorst et al.

Table 1

Description of independent variables for species richness, nature characteristics and climate.

\begin{tabular}{|c|c|c|c|}
\hline Main Category & Subcategory & Indicator & Literature \\
\hline \multirow[t]{7}{*}{ Species richness } & Bird species richness & Area weighted mean species richness in NUTS region. & (Huby et al., 2006) \\
\hline & $\begin{array}{l}\text { Mammal species richness } \\
\text { (all species) }\end{array}$ & $\begin{array}{l}\text { We tested two bird data sets, one original data set with bird species richness values } \\
\text { of all } 50 \times 50 \mathrm{~km} \text { grid cells, and a second data set for which grid cells with low data }\end{array}$ & \\
\hline & $\begin{array}{l}\text { Mammal species richness } \\
\text { (no bats) }\end{array}$ & quality were removed. & \\
\hline & Megafauna species richness & & \\
\hline & $(>44 \mathrm{~kg})$ & & \\
\hline & $\begin{array}{l}\text { Megafauna species richness } \\
(>0.5 \mathrm{~kg})\end{array}$ & & \\
\hline & Tree species richness & & \\
\hline \multirow[t]{6}{*}{$\begin{array}{l}\text { Other nature } \\
\text { characteristics }\end{array}$} & Landscape heterogeneity & $\begin{array}{l}\text { Area weighted mean Shannon Diversity for land cover types in NUTS region. We } \\
\text { used two classifications of land cover types, one with } 5 \text { and one with } 15 \text { land-cover } \\
\text { classes (for classification see Supplementary Table S2) }\end{array}$ & (Wheeler et al., 2015) \\
\hline & Topographic heterogeneity & $\begin{array}{l}\text { Area weighted mean elevational range and standard deviation in elevational range } \\
\text { in NUTS region }\end{array}$ & (Wilson and Gallant, 2000) \\
\hline & Green space & $\begin{array}{l}\text { Area covered by vegetated areas in NUTS region (\%): green space was defined as } \\
\text { arable land, permanent crops, pastures, heterogeneous agricultural areas, forests or } \\
\text { scrub and/or herbaceous vegetation }\end{array}$ & $\begin{array}{l}\text { (Krekel et al., 2016; Maas et al., 2008; } \\
\text { White et al., 2017, White et al., } \\
\text { 2013b) }\end{array}$ \\
\hline & Blue space & $\begin{array}{l}\text { Area covered by water bodies in NUTS region (\%): blue space was defined as inland } \\
\text { and marine waters }\end{array}$ & \\
\hline & Coastline & Coastline dummy variable describing which NUTS regions have a coastline. & (Kopmann and Rehdanz, 2013) \\
\hline & Protected area cover & Area covered by Natura 2000 sites in NUTS region (\%) & (Huby et al., 2006) \\
\hline Climate & $\begin{array}{l}\text { Heating and cooling degree } \\
\text { days (HDD and CDD) }\end{array}$ & Area weighted mean HDD and CDD in NUTS region & $\begin{array}{l}\text { (Maddison and Rehdanz, 2011; } \\
\text { Spinoni et al., 2015) }\end{array}$ \\
\hline
\end{tabular}

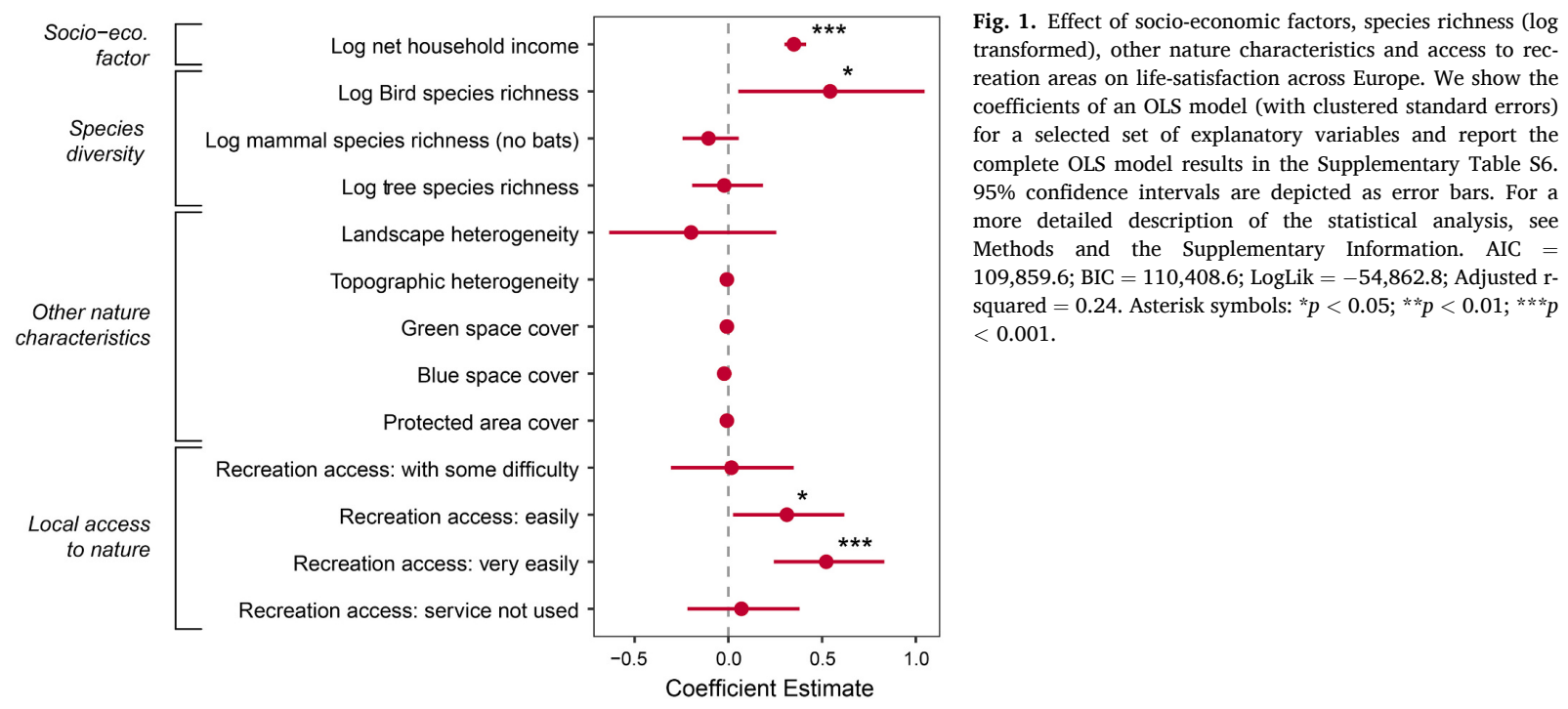

extant' and 'possibly extant' as presences and then determined the area weighted mean species richness of all mammal and megafauna species. We wanted to account for the diverse ways humans might perceive and respond to different mammal taxa; we hence calculated species richness for different mammal groups. We considered (1) all mammal species, and (2) all mammal species excluding bats, which comprise a significant proportion of mammal diversity. We assume that bats are less noticeable to people because they are mainly active at night. For megafauna, we defined two variables based on body size measures (Jones et al., 2009), (1) mammals with a body mass larger than $44 \mathrm{~kg}$, and (2) mammals with a mass larger than $0.5 \mathrm{~kg}$. Mammals with a mass $>44 \mathrm{~kg}$ have been defined as megafauna (Barnosky, 2008; Doughty et al., 2016) and are often described as charismatic, especially in wildlife or ecotourism (Lindsey et al., 2007; Skibins et al., 2013). To consider also the fact that many species with medium body size (e.g. fox, hare) are also appreciated by humans (e.g. Bell et al., 2017; Folmer et al., 2019), we additionally defined megafauna as mammals with an adult body mass larger than $0.5 \mathrm{~kg}$.

Tree species distribution data was obtained from Mauri et al. (2017). This EU-Forest dataset includes a total of 588,983 occurrence records for 242 tree species across Europe (not including Iceland, Turkey and Macedonia). For each $50 \times 50 \mathrm{~km}$ grid cell, we identified the tree species occurrences that lay within a grid cell and compiled the total number of forest tree species per grid cell.

We examined how much our species richness data varied within NUTS regions and determined for each species group whether the within-region variance of species richness was a major factor explaining the overall variation of species richness across Europe (between-region variance). For this purpose, we took species richness values from the $50 \times 50 \mathrm{~km}$ grid intersecting with the NUTS regions and performed simple 


\section{ARTICLE IN PRESS}

J. Methorst et al.

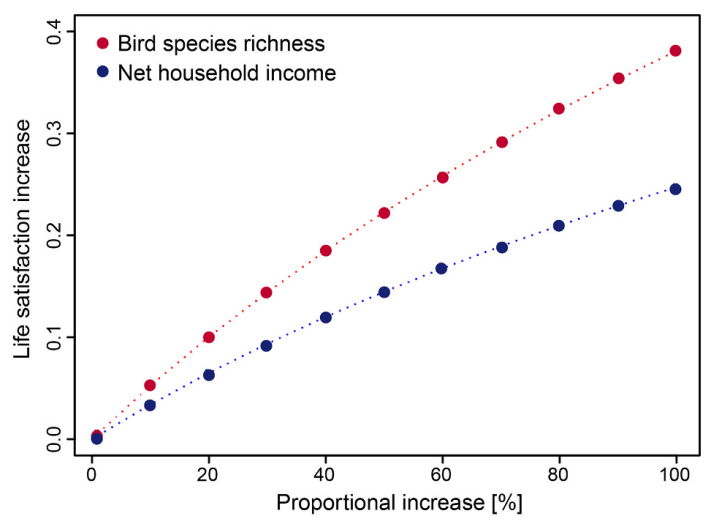

Fig. 2. Estimated life-satisfaction increase in relation to bird species richness and income. Estimates are based on the coefficients for log-transformed mean bird species richness and log-transformed net household income obtained from the OLS model (Fig. 1). In the OLS model we correct for socio- and macroeconomic factors.

ANOVAs with species richness as the response variable and the NUTS regions as predictor variable. We only used species richness values (intersecting grid polygons) that covered at least $1 \%$ of the NUTS region area (max. of 66 values within a NUTS region, median $=11$ ). Based on the ANOVA results we then calculated the percentage of overall variance across Europe explained by the within- and the between-region variation (NUTS region) by dividing the between-regions and residual sum of squares with the total sum of squares.

\subsubsection{Other nature characteristics}

Beside species richness we also used data for the following nature characteristics: landscape heterogeneity, topographic heterogeneity, green and blue space area cover, the presence or absence of coastlines and protected area cover (Table 1 ).

We selected variables reflecting landscape heterogeneity, because people prefer heterogeneous landscapes for recreation (Paracchini et al., 2014) and because heterogeneous landscapes are often viewed as providing scenic views (Schirpke et al., 2013). To estimate landscape heterogeneity for each NUTS region we used data on land cover from the Coordination of Information on the Environment (CORINE) Land Cover database that provides land cover for the year 2012 in 44 land-cover categories as raster data (250 m resolution). We calculated landscape heterogeneity based on two different CORINE land cover classifications: one with 5 and the other with 15 aggregated land cover categories (see Supplementary Table S2). First, we determined the number of raster data points per land cover type within each $50 \times 50 \mathrm{~km}$ grid cell. We then calculated for both land cover classifications the Shannon-Diversity Index for each grid cell. Both landscape heterogeneity variables were strongly correlated and performed similar during our analyses. We hence report results only for the classification based on 15 land-cover classes.

As additional measure of landscape heterogeneity, we used topographic heterogeneity. Topographic heterogeneity and elevation have been identified as indicators for landscapes with high recreational and aesthetic value (Peña et al., 2015; Sherrouse et al., 2011) or scenic views (de Almeida Rodrigues et al., 2018). We calculated the elevational range (meters) and standard deviation of the elevations within each $50 \times 50$ $\mathrm{km}$ grid based on a global digital elevation model (GTOPO30, 30 arc sec resolution) provided by the US Geological Survey (https://eart hexplorer.usgs.gov/). Again, due to strong correlation and similar performances of the two variables, we used in further analyses only one variable, i.e. topographic heterogeneity calculated as area weighted elevation range.

In addition, we calculated the percentage of area covered by vegetated areas (green space) and water bodies (blue space) within each NUTS region using CORINE data. Green space and blue space have both been reported to have a positive effect on human well-being (Krekel et al., 2016; Völker and Kistemann, 2011). We defined green space as CORINE categories representing green vegetation and blue space as inland and marine waters (Table 1). We calculated the amount of green and blue space as the proportional area cover for each NUTS region. As an additional indicator for blue space, we created a binomial variable which describes whether a NUTS region has a coastline or not.

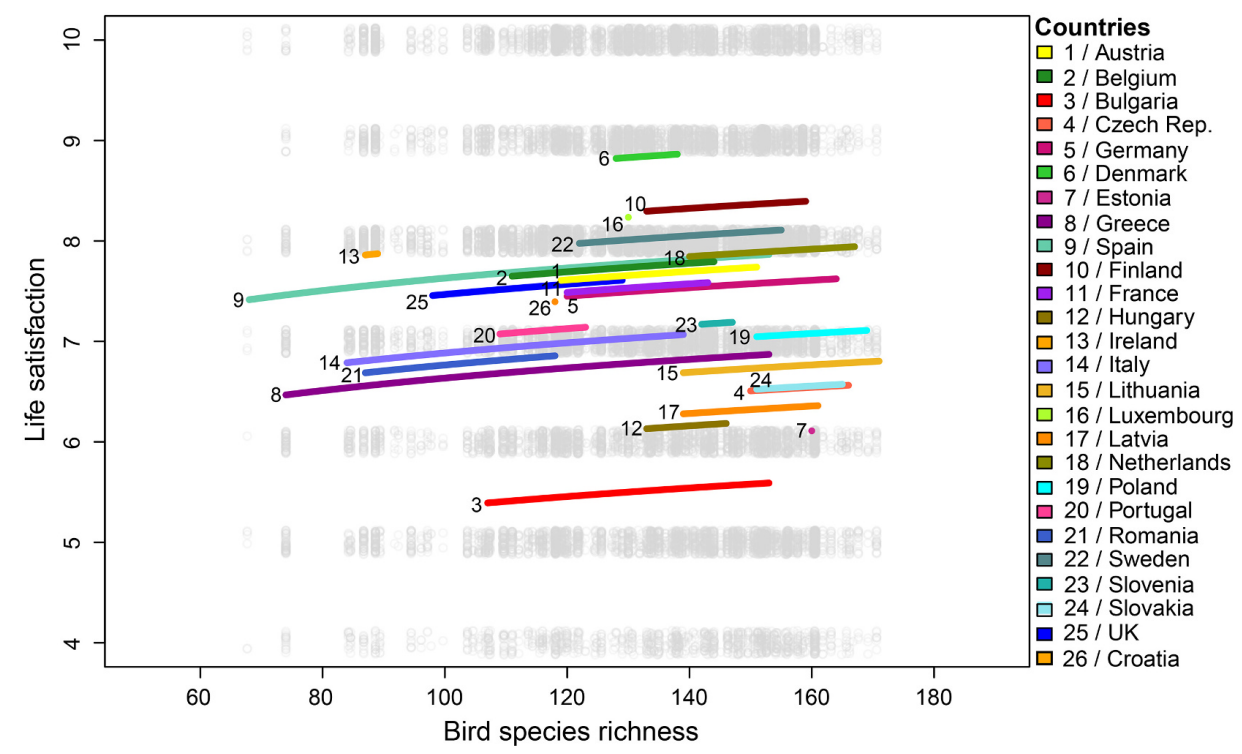

Fig. 3. Predicted range of life-satisfaction and bird species richness relationships across 26 European countries. Predicted values of life-satisfaction show a positive relationship between bird species richness across European countries (coloured lines). The length of each coloured line is equivalent to the range between minimum and maximum bird species richness in each country. Grey points in the background represent the raw data for life-satisfaction and bird species richness. 
As indicator for high nature conservation value of the landscape, we calculated the percentage area covered by protected areas within each NUTS region. We defined as protected areas the Natura 2000 sites using information from the European Environmental Agency (EEA) (Nature 2000 sites, version 2016), and calculated the proportional area covered by terrestrial Natura 2000 sites (in percent) for each NUTS region.

\subsubsection{Climate}

A number of different ways of representing the climate have been considered in the subjective well-being/life-satisfaction literature (see Maddison and Rehdanz, 2020 for a recent overview). These include maximum and minimum monthly values for temperature and precipitation, as well as annual averages and counts of hot and cold and wet and dry months. It is argued that the use of deviations (HDD or CDD) is preferred to e.g. the use of maximum and minimum values because such a specification fails to distinguish between those locations where the temperature in the coldest month is already high, and those locations where the temperature in the hottest month is still quite low (Maddison and Rehdanz, 2020). We follow this line of reasoning and use coolingdegree days (CDD) and heating degree-days (HDD).

To calculate average CDD and HDD for the past 30 years we used the E-OBS climate data set (Haylock et al., 2008) (www.ecad.eu), a European land-only gridded climate raster data set ( 0.25 degree resolution) for the period of 1st January 1950-31st August 2016 (version 14). For our calculations of CDD and HDD we used the daily mean temperature data $\left(T_{\mathrm{M}}\right)$ from 1982 to 2012 and a base temperature $\left(T_{\mathrm{b}}\right)$ of $22{ }^{\circ} \mathrm{C}$ for CDD and $15.5^{\circ} \mathrm{C}$ for HDD (Spinoni et al., 2015). In a first step, CDD and HDD were computed for each climate raster point by estimating the deviation (positive deviation $=\mathrm{CDD}$, negative deviation $=\mathrm{HDD}$ ) of $T_{M}$ from the baseline temperature $\left(T_{\mathrm{b}}\right)$ and summarizing the results across all days within the 30-year period (1 Jan. 1982-31 Dec. $2012=11,322$ days). We then divided the summarized values by 30 to obtain annual averages of CDD and HDD per climate raster grid cell. Subsequently, we calculated mean CDD and HDD for each $50 \times 50 \mathrm{~km}$ grid cell and then the area weighted mean of CDD and HDD for each NUTS region. As both variables were strongly correlated, we selected only one of them, i.e. CDD for further statistical analyses.

\subsection{The estimation procedure}

Our final data set contains information for 26,749 individuals living within 228 NUTS-regions and 26 different countries after removing missing values ${ }^{4}$ (summary statistics can be found in Supplementary Tables S3, S4). We used linear regression models (ordinary least squares, OLS) and assumed cardinality of the life-satisfaction values as it provides greater flexibility in the use of parametric approaches to analyze life satisfaction (Kubiszewski et al., 2018). We are aware of different arguments for and against the assumption that life-satisfaction values are continuous (Ferrer-i-Carbonell and Frijters, 2004; Kristoffersen, 2017; Kromrey and Rendina-Gobioff, 2003; Ng, 1997). However, it has been shown that assuming ordinality or cardinality of the response variable makes little difference when studying life-satisfaction (Ferrer-i-Carbonell and Frijters, 2004). In addition, a recent study demonstrated that it is possible to make a cardinality assumption because life-satisfaction scores are equidistant, thus supporting cardinal comparability (Kristoffersen, 2017). We include results of the ordered logit specification for comparison that show our results are robust (Supplementary Tables S7, S9, S11 \& S13).

Because our data set combines data on the individual and the NUTS level, we needed to account for possible impairments. For instance, in OLS models the hierarchical structure of the data could cause

${ }^{4}$ Due to missing species diversity and macro-economic data we could not include the following countries in our analyses: Turkey, Iceland, Malta, Cyprus, Montenegro, Macedonia, Serbia, Kosovo. correlations within groups of individuals living in the same NUTS region producing faulty standard errors. For this reason, we applied clustering at the NUTS level in the OLS regression, which relaxes the assumption that observations are independent and adjusts standard errors for intraregional correlation (Moulton, 1990). With this procedure, heteroscedasticity-robust standard errors are obtained.

The main focus of our analyses is to identify potential relationships between species richness and life-satisfaction. We therefore analyzed selected sets of species richness measures. We tested species richness effects in two types of models: a model type with multiple species richness measures (multi-taxon models) and a model type with only a single species richness measure (single-taxon models). All multi- and single-taxon models were estimated with OLS and contained logtransformed species richness variables, and the same set of additional explanatory variables. ${ }^{5}$ The final OLS model results were selected based on AIC values and adjusted r-square values. We present here results from the OLS multi-taxon model with the best model fit (all multi- and singletaxon model results are shown in the Supplementary Tables S6-S13).

To avoid multi-collinearity our multi-taxon models contained only a maximum of three species richness measures at a time: bird species richness, tree species richness and one measure for either mammal or megafauna species richness. In order to further reduce multi-collinearity we calculated the generalized variance inflation factor (GVIF) (Fox and Monette, 1992) and excluded those variables with $\operatorname{GVIF}^{\wedge}(1 /(2 * \mathrm{df}))$ scores $>10$ before conducting the final analyses (Supplementary Tables S6-S13). Additionally, we excluded explanatory variables that had a pairwise correlation coefficient higher than 0.6 (Dormann et al., 2013). Due to these decisions our final analyses encompass a reduced set of explanatory variables (we excluded population density and heating degree days).

Explanatory variables in the final models representing nature characteristics and climate were landscape and topographic heterogeneity, green and blue space cover, coastline (dummy variable), protected area cover and as a measure of climatic conditions CDD. Socio-economic explanatory variables encompassed income (log net monthly household income), health status, age, the quadratic term of age, gender, residential area (urban or rural), education level, household structure, employment status, information on the person's volunteering behavior and access to local recreation areas. As macro-economic indicators at the level of the NUTS region, we considered unemployment rate and GDP per capita (PPS). To improve model fit, we also tested models with and without the control variables "Eastern Europe" (dummy variable) and "NUTS area size".

All statistical analyses were performed in R Studio Version 1.0.143 (RStudio Team, 2016). Generalized variance inflation factors were calculated with function "vif" ("car" package) (Fox and Weisberg, 2018) and the OLS models were calculated with the "lm" function (package "stats"). For the clustering of standard errors we used the functions "cluster.vcov" from the "multiwayvcov" package (Graham et al., 2016). Ordered logit models with clustered standard errors were calculated with the functions "orm" and "robcov" ("rms" package) (Harrel Jr., 2019).

\section{Results}

\subsection{Species richness}

Bird species richness is positively related to life-satisfaction across

${ }^{5}$ Landscape heterogeneity, topographic heterogeneity, green space cover, blue space cover, coastline dummy, protected area cover, cooling degree days, recreation access, log net household income, age, age squared, male dummy, urban dummy, education, health, household structure, employment status, volunteering behavior, unemployment rate, GDP per capita (PPS), Eastern Europe dummy and NUTS region area size. 
Europe (Fig. 1). This relationship is robust across all multi-taxon and single-taxon model outcomes with $p$-values below the $5 \%$ threshold (Supplementary Tables S6-S13). Mammal-, megafauna- or tree species richness were not significantly related to life-satisfaction (Fig. 1; Supplementary Tables S6-S13).

To assess the strength of the relationship between bird species richness and life-satisfaction we compared the increase in lifesatisfaction caused by proportional changes in bird species richness and income (both log-transformed) based on the coefficients (bird coef. $=0.55,95 \% \mathrm{CI}=0.05-1.05$; income coef. $=0.36,95 \% \mathrm{CI}=0.30-0.41$ ) from the econometric model (Fig. 1). An increase in bird species richness by $10 \%$ (equivalent to approx. 14 bird species at the median of 136 bird species) is related to an increase in life-satisfaction by a value of 0.052 , while an increase in income by $10 \%$ (approx. 124 Euro at the median net household income of 1237 Euro) increase life-satisfaction by 0.034 Therefore, an increase in bird species richness by $10 \%$ is related to a raise in life-satisfaction approximately 1.53 times more than a similar proportional rise in income (Fig. 2). This effect size does not greatly vary between the models with different species richness specifications since the estimated changes in life-satisfaction based on linear and log-linear bird species richness are very similar (Supplementary Tables S10 and S12). For example, based on the linear coefficients of the multi-taxon models (Supplementary Table S10) a 10\% increase in bird species richness (14 species) would increase life-satisfaction by a value of approx. 0.07 (similar to the log-linear specification). However, please note that the confident intervals for the coefficient estimates are considerably higher for bird species richness than for income (Fig. 1) and therefore the true effect of bird species richness might be smaller, or greater.

In addition, we predicted how life-satisfaction values might increase along the range of bird species richness values within each country (Fig. 3). Based on the OLS model results presented here (Fig. 1) we first predicted life-satisfaction values for each NUTS region and afterwards calculated average values for each European country. For example, in Spain, the country with the largest range of bird species richness, lifesatisfaction is predicted to increase by 0.45 , if the bird species richness within a region would change from lowest national value to the highest value, provided a person's socio-economic status and other factors remain the same (Fig. 3). Under the same scenario, the average estimated change in life-satisfaction within all 26 European countries has a value of $0.12(\mathrm{SD}=0.11)$

To validate our OLS results, we tested whether the within-region (NUTS region) variance of our species richness variables was a major factor in explaining the overall variation of species richness across Europe (between-region variance). The results indicate that a much larger part of the total variance of bird species richness across Europe is driven by the between-region (61.4\%) variance than within-region variance (38.6\%) (Supplementary Table S5). We can therefore assume that the within-region variance of bird species richness has little influence on our overall results.

\subsection{Other nature characteristics and climate}

We also tested the influence of other nature and climate characteristics on life-satisfaction and find a positive relationship between an individual's access to recreational areas and life-satisfaction (Fig. 1, Supplementary Tables S6-S13). Across all the OLS models we find that life-satisfaction increased when people had easy or very easy access to public green spaces and recreational areas. Based on the presented OLS model (Fig. 1) the life-satisfaction scores might improve by 0.32 (95\% $\mathrm{CI}=0.02-0.62)$ when a person had easier access to recreational areas compared to access with great difficulty. When the access was very easy the life-satisfaction scores increased by 0.54 (95\% CI $=0.24-0.83$ ). For all other characteristics we find no significant effects on life-satisfaction (Fig. 1, Supplementary Tables S6-S13). Neither landscape heterogeneity, topographic heterogeneity, protected area cover nor climate have a significant association with life-satisfaction.

\section{Discussion}

This is the first continental study which explores the non-material associations between species diversity and life-satisfaction, while accounting for socio-economic factors and other nature characteristics. Our results show that bird species richness is related to life-satisfaction across Europe, and that this association may be comparable in magnitude to that of income. Due to the large confidence intervals, however, the true effect size of bird species richness might be lower, or higher than reported here. In addition, we find no significant relationships with lifesatisfaction for mammal-, megafauna- or tree species richness as well as for other nature characteristics and climate.

\subsection{Bird species richness and life-satisfaction}

With regard to bird species richness, our results correspond to previous findings from local level studies on species richness and human well-being. For instance, visitors to urban parks with higher bird species richness exhibit better psychological well-being scores than those visiting parks with lower species richness (Fuller et al., 2007). In an urban neighborhood bird species richness was found to influence personal and neighborhood well-being (Luck et al., 2011), while on the national level, subjective health was positively related to bird species richness (Wheeler et al., 2015). Furthermore, listening to bird songs can reduce psychological stress (Alvarsson et al., 2010; Medvedev et al., 2015) and has a positive influence on perceived attention restoration and stress reduction (Ratcliffe et al., 2016; Ratcliffe et al., 2013).

This relationship between bird species richness and life-satisfaction might change depending on the spatial units used in the analyses. Our main results are calculated with bird species richness data collected at the level of $50 \times 50 \mathrm{~km}$ grid cells and averaged within the NUTS regions. While it would be interesting to test our research question with finer spatial resolution data (e.g. $10 \times 10 \mathrm{~km}$ grid), no such data on species richness is consistently available across Europe. With regard to the effect size, our findings show that larger the effect of bird species richness on life-satisfaction may be of similar magnitude to that of income. Access to green space and recreational areas had a stronger overall effect on lifesatisfaction with higher life-satisfaction scores when accessibility was "easy" or "very easy" (Fig. 1), but these two variables are difficult to compare as one is a continuous and the other a categorical variable. However, these results still suggest that bird species richness, like income, access to green space or other factors, is important for lifesatisfaction at a continental level (e.g. Diener and Biswas-Diener, 2002; Dolan et al., 2008; Ma et al., 2019). An interesting future research avenue could be to test the effect of changes in income over time on life satisfaction in comparison to changes in species diversity and access to green space.

These results need to be interpreted with caution, however, as our results do not reveal causal relationships but correlations. Due to the spatial level of the analyses, it is unknown at which spatial scale people experience bird species richness and also the pathways of such experiences are hypothetical (see 5.2 Suggested mechanisms). Possible strategies to prove a causal relationship between bird species richness and life satisfaction are to carry out longitudinal studies (e.g. Alcock et al., 2014; White et al., 2013a) or to use experimental techniques that include mediators (e.g. Marselle et al., 2016). Unfortunately, we were not able to analyze time series data or conduct experiments, as currently only cross-sectional (one point or period in time) data is available for bird species richness in Europe and experiments are not feasible on such a spatial level. Nonetheless, the magnitude of the relationship between bird species richness and life-satisfaction and the quantitative comparison with income indicate potentially strong and socially relevant relationships. 


\subsection{Suggested mechanisms}

Possible mechanisms for the positive relationship between bird species richness and well-being, in this case measured as lifesatisfaction, are not well understood (Aerts et al., 2018; Hartig et al., 2011; Marselle et al., 2019). We argue that at the large spatial scale of this study two types of possible, and non-exclusive, pathways exist that may explain how bird species richness affects life-satisfaction: the effect of the direct visual and auditory experience of birds, and an effect of experiencing landscapes with features which promote both bird species richness and human well-being, making bird richness a proxy indicator of the true landscape drivers. With regard to the first pathway, seeing and observing birds and their behavior in gardens (Cox and Gaston, 2015) or in wild nature (MacKerron and Mourato, 2013) can promote positive emotions and increase well-being. A recent study could show that high bird species richness increases the positive emotional response of visitors to urban green space (Cameron et al., 2020). In an experimental online survey, participants who watched videos with high bird species richness report less anxiety (Wolf et al., 2017). One possible explanation for this positive effect might be that many birds are aesthetically appealing to humans, and relatively easy to observe compared to many other taxa. People value birds for their physical beauty, interesting behavior and pleasing songs (Belaire et al., 2015; Hedblom et al., 2014; Medvedev et al., 2015). Birds are hence one of the most "loved" biological elements by people at their favorite outdoor places (Schebella et al., 2017). In addition, songbirds and higher richness of birds are preferred over non-singing birds or higher numbers of the same bird species (Cox and Gaston, 2015). Species that are less favored tend to be pigeons, seagulls or crows (e.g. Bjerke and Østdahl, 2004), however, these unpopular species constitute only a very small proportion of overall bird species richness.

Alternatively, high bird species richness may serve as an indicator for regional and local landscape properties which themselves promote life satisfaction. At the regional scale, landscapes with high landscape diversity tend to have high bird species richness (e.g. Gil-Tena et al., 2007), and landscape elements that also have high aesthetic or recreational value are also associated with bird diversity (Oteros-rozas et al., 2018; Velarde et al., 2007). Therefore, bird species richness might be a better indicator of the recreational quality of natural landscapes than the other nature characteristics (e.g. landscape heterogeneity, protected area cover) used in this study (see section 5.4). Correspondingly, bird species richness has been used as an indicator for environmental quality in health studies (Wheeler et al., 2015) or has been included in composite measures of landscape diversity, as in the Swiss Biodiversity Monitoring program (Weber et al., 2004). Locally, high bird species richness is related to greater availability of natural space in urban areas (Loss et al., 2009), including high vegetation cover and the existence of water bodies (Beninde et al., 2015), nature characteristics which also positively influence human health and well-being (Cox et al., 2017; Luck et al., 2011; Völker and Kistemann, 2011).

Suggested mediators that link bird species richness to life satisfaction either directly or as a proxy for beneficial landscape properties are attention restoration and stress reduction. These two mediators correspond to two psychological theories, the Attention Restoration (Kaplan, 1995) and the Stress Reduction Theory (Ulrich, 1991). Both theories are well established in the nature-human health framework, for instance, as mechanisms that link positive effects of green space to human health (Hartig et al., 2014; Markevych et al., 2017). Correspondingly, experiencing birds might restore attention fatigue (Dallimer et al., 2012; Fuller et al., 2007; Marselle et al., 2016) or reduce stress (Cox et al., 2017; Wolf et al., 2017). Certain landscape properties such as habitat diversity might increase well-being via the same two mediators (Carrus et al., 2015; Fuller et al., 2007; Hipp et al., 2016). Recently, it has been suggested that positive emotions might be a third potential mediator linking species diversity and well-being (Irvine et al., 2019), offering an additional explanation for the observed correlation.
It would be interesting to gain a better understanding of the mechanisms that link species diversity and life-satisfaction. However, the lack of appropriate variables (e.g. frequency and duration of bird experiences) did not allow us to investigate the significance of the possible pathways here. Further research is therefore necessary to examine the pathways and mediators, especially across larger spatial scales (e.g. Europe). We were also not able to test whether bird abundances can be linked to life-satisfaction as regional and local bird abundance data is not consistently available across all European countries (but see British or German breeding bird atlases). Future research should also investigate the potential effect of bird traits since conspicuousness and detectability due to size, plumage, song or behavior, as well as perceived beauty may have a strong influence on life-satisfaction (e.g. Cox et al., 2017)

\subsection{No effects of mammals and trees}

We did not find any association between our mammal and megafauna richness variables and life-satisfaction (Supplementary Tables S6S13) despite the fact that mammals and especially large charismatic mammals, i.e. megafauna, can trigger positive emotional responses in humans (Curtin, 2009; Methorst et al., 2020) and foster connection to nature (Bruni et al., 2008; Cousins et al., 2009). The results for the mammal and megafauna species richness variables can be influenced by the possibility that people, especially urban residents, might not regularly encounter mammals because many mammalian species are evasive and tend to avoid places with high human population density and mainly occur in rural or less populated areas (Basille et al., 2013; Gaynor et al., 2018; Sol et al., 2013), while small mammals and bats are often difficult to detect even when present. Many birds, on the other hand, can be perceived, even subconsciously, by people due to their songs, even if they might not be visible in the vegetation, and are often very active and detectable in human vicinities (e.g. bird feeding). In addition, people tend to have negative attitudes or emotions towards many mammals as they consider several species dangerous or a nuisance (e.g. Methorst et al., 2020; Røskaft et al., 2003; Soulsbury and White, 2015), so effects could indeed be neutral or even negative for some mammal species.

With regards to tree species richness, we also did not find a significant effect on life-satisfaction, even though higher levels of tree diversity can positively influence mental well-being when watching videos in an online experiment (e.g. Wolf et al., 2017). However, when people are outdoors they might be affected rather by local vegetation cover and structure, and overall plant species richness (Dallimer et al., 2012; Hoyle et al., 2017; Lindemann-Matthies and Matthies, 2018; Luck et al., 2011) or by street tree abundance in their neighborhood (Taylor et al., 2015) than by regional patterns of tree species richness. Unfortunately, data for measures of total plant diversity were not available at the large spatial scale of our study.

\subsection{Effects of access to parks, other nature characteristics and climate variables}

We find that life-satisfaction is higher when people reported easy or very easy access to public green spaces and recreational areas, which confirms findings in other studies regarding life-satisfaction and other well-being measures (Cleary et al., 2019; Kabisch, 2019; Krekel et al., 2016; Ma et al., 2019). This result is not surprising considering that people are more likely to visit parks and natural areas, and thus obtain well-being benefits when green space is located closer to home (Coombes et al., 2010; Dallimer et al., 2014; Ekkel and de Vries, 2017; Schipperijn et al., 2010).

For the other nature characteristics, we were unable to confirm results of earlier studies that show an association of the amount of area covered by green or blue space and human well-being (de Vries et al., 2016; Gascon et al., 2015; Maas et al., 2006; White et al., 2017). We also did not find a significant relationship between protected area cover or 


\section{ARTICLE IN PRESS}

landscape heterogeneity and life-satisfaction, despite evidence that shows that such nature characteristics influence human well-being (Wheeler et al., 2015; Wyles et al., 2019).

A possible explanation for this result may be that our measures of nature characteristics might not reflect landscape quality at the large scale of this study, or how people experience nature and specific nature characteristics. For example, our measure of landscape heterogeneity includes various categories for artificial surfaces that contribute to heterogeneity but may not reflect landscape quality for humans. Instead, bird species richness may be a better indicator of local landscape characteristics important also to the well-being of humans (see above section 5.2). Furthermore, positive effects of nature characteristics such as landscape heterogeneity on human well-being are often found on finer spatial scales (e.g. Carrus et al., 2015; Rantakokko et al., 2017), e.g. within urban areas. However, such fine-grained data in combination with people's socio-economic data are not available for Europe.

Earlier studies found that climate, as represented by various temperature and precipitation variables, can influence life-satisfaction and happiness (Murray et al., 2013; Rehdanz and Maddison, 2005). Studies testing degree days in order to compare their results to ours are few. Recently, however, a global study also tested cooling and heating degree days and found a significant negative relationship between cooling degree days and high life-satisfaction scores and no relationship for heating degree days (Chapman et al., 2019). Similarly, another global study could show that cooling degree months are negatively associated with life-satisfaction (Maddison and Rehdanz, 2011). Further research is necessary in order to better understand why different measures for climate have dissimilar effects on life-satisfaction on a continental level.

\section{Conclusions}

Here we demonstrate that bird species richness is positively related to life-satisfaction across Europe, with a comparable effect to income. This result highlights the potential non-material link between species diversity and human well-being. Within the context of the IPBES framework (Díaz et al., 2018), this means that bird species richness may also provide non-material NCP to human well-being on a continental level. This information may turn out to be crucial for evidence-based policy decisions regarding environmental management (Adams and Morse, 2019) and nature-based solutions to improve human health and well-being (Cariñanos et al., 2017; Marando et al., 2016; Vujcic et al., 2017). Future research needs to further investigate and confirm the causal links of this observed relationship and explore the mechanisms involved including positive emotions, attention restoration and stress reduction (Aerts et al., 2018; Irvine et al., 2019; Marselle, 2019) or the possibility that, on a large spatial scale, bird species richness might simply be a proxy for beneficial landscape properties (e.g. landscape aesthetics, landscape diversity) or environmental quality. Even if this is the case it may prove that managing for bird diversity is a win-win strategy, with both humans and birds benefitting from management actions that promote a high diversity of natural landscape features.

The recent IPBES global and regional assessments warned that the future provision of NCP may be threatened due to increasing biodiversity loss, mainly caused by land-use change and exploitation (IPBES, 2019; 2018). In the context of our study, current declines in bird species richness and abundances in Europe and North America (e.g. Bowler et al., 2019; Rosenberg et al., 2019) could potentially also result in lower levels of human well-being. So far, the protection of birds and bird habitat has been conducted as a means of protecting bird diversity (European Union, 2010). However, this study may show that the conservation of birds and the landscapes and habitats that support them would be a very worthwhile investment in human well-being. Political and societal decision making should encourage the maintenance and creation of natural areas that support high bird diversity, thus fostering synergies between biodiversity conservation and promotion of human well-being.

\section{Author contributions}

J.M., K.R. and K.B.-G. designed the study. J.M. carried out data compilation and analysis. K.R., K.B.-G. and T.M contributed to the data analysis. J.M wrote the initial draft of the manuscript. All authors contributed substantially to the writing of the manuscript.

\section{Declaration of Competing Interest}

The authors declare that they have no known competing financial interests or personal relationships that could have appeared to influence the work reported in this paper.

\section{Acknowledgements}

The authors kindly acknowledge the support by the German Centre for Integrative Biodiversity Research (iDiv) Halle-Jena-Leipzig, funded by the German Science Foundation (DFG- FZT 118, 202548816). We also acknowledge support from the iDiv Open Science Publication Fund. We thank Peter Manning from Senckenberg Biodiversity and Climate Research Centre (SBiK-F) for his comments on the manuscript and improvements made to the writing and language.

\section{Appendix A. Supplementary information}

Supplementary information to this article can be found online at https://doi.org/10.1016/j.ecolecon.2020.106917.

\section{References}

Adams, A., Morse, J., 2019. Non-material matters: a call for integrated assessment of benefits from ecosystems in research and policy. Land Use Policy 80, 400-402. https://doi.org/10.1016/j.landusepol.2018.04.031.

Aerts, R., Honnay, O., Van Nieuwenhuyse, A., 2018. Biodiversity and human health: mechanisms and evidence of the positive health effects of diversity in nature and green spaces. Br. Med. Bull. 127, 5-22. https://doi.org/10.1093/bmb/ldy021.

Alcock, I., White, M.P., Wheeler, B.W., Fleming, L.E., Depledge, M.H., 2014. Longitudinal effects on mental health of moving to greener and less green urban areas. Environ. Sci. Technol. 48, 1247-1255. https://doi.org/10.1021/es403688w.

Alvarsson, J.J., Wiens, S., Nilsson, M.E., 2010. Stress recovery during exposure to nature sound and environmental noise. Int. J. Environ. Res. Public Health 7, 1036-1046. https://doi.org/10.3390/ijerph7031036.

Barnosky, A.D., 2008. Megafauna biomass tradeoff as a driver of quaternary and future extinctions. Proc. Natl. Acad. Sci. 105, 11543-11548. https://doi.org/10.1073/ pnas.0801918105.

Basille, M., Van Moorter, B., Herfindal, I., Martin, J., Linnell, J.D.C., Odden, J., Andersen, R., Gaillard, J.M., 2013. Selecting habitat to survive: the impact of road density on survival in a large carnivore. PLoS One 8, e65493. https://doi.org/ 10.1371/journal.pone.0065493.

Belaire, J.A., Westphal, L.M., Whelan, C.J., Minor, E.S., 2015. Urban residents' perceptions of birds in the neighborhood: biodiversity, cultural ecosystem services, and disservices. Condor 117, 192-202. https://doi.org/10.1650/CONDOR-14-128.1.

Bell, S.L., Westley, M., Lovell, R., Wheeler, B.W., Bell, S.L., Westley, M., Lovell, R., Wheeler, B.W., 2017. Everyday green space and experienced well-being: the significance of wildlife encounters. Landsc. Res. 6397, 1-12. https://doi.org/ 10.1080/01426397.2016.1267721.

Beninde, J., Veith, M., Hochkirch, A., 2015. Biodiversity in cities needs space: a metaanalysis of factors determining intra-urban biodiversity variation. Ecol. Lett. 18, 581-592. https://doi.org/10.1111/ele.12427.

Bertram, C., Rehdanz, K., 2015. The role of urban green space for human well-being. Ecol. Econ. 120, 139-152. https://doi.org/10.1016/j.ecolecon.2015.10.013.

Bjerke, T., Østdahl, T., 2004. Animal-related attitudes and activities in an urban population. Anthrozoos 17, 109-129. https://doi.org/10.2752
(1) population. Anthrozoos
089279304786991783.

Bonini, A.N., 2008. Cross-national variation in individual life satisfaction: effects of

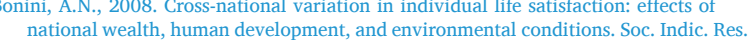
national wealth, human development, and environmental conditions. Soc. Indic. Res.
87, 223-236.

Bowler, D.E., Heldbjerg, H., Fox, A.D., de Jong, M., Böhning-Gaese, K., 2019. Long-term declines of European insectivorous bird populations and potential causes. Conserv. Biol. 33, 1120-1130. https://doi.org/10.1111/cobi.13307.

Bratman, G.N., Hamilton, J.P., Daily, G.C., 2012. The impacts of nature experience on human cognitive function and mental health. Ann. N. Y. Acad. Sci. 1249, 118-136. https://doi.org/10.1111/j.1749-6632.2011.06400.x.

Bruni, Coral M., Fraser, John, Schultz, P. Wesley, 2008. The value of zoo experiences for connecting people with nature. Visitor Studies 11, 139-150.

Cameron, R.W.F., Brindley, P., Mears, M., McEwan, K., Ferguson, F., Sheffield, D., Jorgensen, A., Riley, J., Goodrick, J., Ballard, L., Richardson, M., 2020. Where the 
wild things are! do urban green spaces with greater avian biodiversity promote more positive emotions in humans? Urban Ecosyst. https://doi.org/10.1007/s11252-02000929-z, 22 January 2020.

Cariñanos, P., Casares-Porcel, M., Díaz de la Guardia, C., Aira, M.J., Belmonte, J., Boi, M., Elvira-Rendueles, B., De Linares, C., Fernández-Rodriguez, S., MayaManzano, J.M., Pérez-Badía, R., Rodriguez-de la Cruz, D., Rodríguez-Rajo, F.J., RojoÚbeda, J., Romero-Zarco, C., Sánchez-Reyes, E., Sánchez-Sánchez, J., TormoMolina, R., Vega Maray, A.M., 2017. Assessing allergenicity in urban parks: a naturebased solution to reduce the impact on public health. Environ. Res. 155, 219-227. https://doi.org/10.1016/j.envres.2017.02.015.

Carrus, G., Scopelliti, M., Lafortezza, R., Colangelo, G., Ferrini, F., Salbitano, F., Agrimi, M., Portoghesi, L., Semenzato, P., Sanesi, G., 2015. Go greener, feel better? The positive effects of biodiversity on the well-being of individuals visiting urban and peri-urban green areas. Landsc. Urban Plan. 134, 221-228. https://doi.org/ and peri-urban green areas. Landsc.

Curtin, Susanna, 2009. Wildlife tourism: the intangible, psychological benefits of humanwildlife encounters. Current Issues in Tourism 12, 451-474.

Chan, K.M.A., Guerry, A.D., Balvanera, P., Klain, S., Satterfield, T., Basurto, X., Bostrom, A., Chuenpagdee, R., Gould, R., Halpern, B.S., Hannahs, N., Levine, J., Norton, B., Ruckelshaus, M., Russell, R., Tam, J., Woodside, U., 2012. Where are cultural and social in ecosystem services? A framework for constructive engagement. Bioscience 62, 744-756. https://doi.org/10.1525/bio.2012.62.8.7

Chapman, A., Fujii, H., Managi, S., 2019. Multinational life satisfaction, perceived inequality and energy affordability. Nat. Sustain. 2, 508-514. https://doi.org/ 10.1038/s41893-019-0303-5.

Cleary, A., Roiko, A., Burton, N.W., Fielding, K.S., Murray, Z., Turrell, G., 2019. Changes in perceptions of urban green space are related to changes in psychological wellbeing: cross-sectional and longitudinal study of mid-aged urban residents. Health Place 59, 102201. https://doi.org/10.1016/j.healthplace.2019.102201.

Cohen-Cline, H., Turkheimer, E., Duncan, G.E., 2015. Access to green space, physical activity and mental health: a twin study. J. Epidemiol. Community Health 69 , 523-529. https://doi.org/10.1136/jech-2014-204667.

Coombes, E., Jones, A.P., Hillsdon, M., 2010. The relationship of physical activity and overweight to objectively measured green space accessibility and use. Soc. Sci. Med. 70, 816-822. https://doi.org/10.1016/j.socscimed.2009.11.020.

Cousins, Jenny A., Evans, James, Sadler, Jon P., 2009. 'I've paid to observe lions, no map roads!' - An emotional journey with conservation volunteers in South Africa. Geoforum. 40, 1069-1080.

Cox, D.T.C., Gaston, K.J., 2015. Likeability of garden birds: importance of species knowledge \& richness in connecting people to nature. PLoS One 10, 1-14. https:// doi.org/10.1371/journal.pone.0141505.

Cox, D.T.C., Gaston, K.J., 2016. Urban bird feeding: connecting people with nature. PLoS One 11, 1-13. https://doi.org/10.1371/journal.pone.0158717.

Cox, D.T.C., Shanahan, D.F., Hudson, H.L., Plummer, K.E., Siriwardena, G.M., Fuller, R. A., Anderson, K., Hancock, S., Gaston, K.J., 2017. Doses of neighborhood nature: the benefits for mental health of living with nature. Bioscience 67, 147-155. https://doi, benefits for mental health of

Dallimer, M., Irvine, K.N., Skinner, A.M.J., Davies, Z.G., Rouquette, J.R., Maltby, L.L., Warren, P.H., Armsworth, P.R., Gaston, K.J., 2012. Biodiversity and the feel-good factor: understanding associations between self-reported human well-being and species richness. Bioscience 62, 47-55. https://doi.org/10.1525/bio.2012.62.1.9.

Dallimer, M., Davies, Z.G., Irvine, K.N., Maltby, L., Warren, P.H., Gaston, K.J., Armsworth, P.R., 2014. What personal and environmental factors determine frequency of urban greenspace use? Int. J. Environ. Res. Public Health 11 7977-7992. https://doi.org/10.3390/ijerph110807977.

de Almeida Rodrigues, A., da Cunha Bustamante, M.M., Sano, E.E., 2018. As far as the eye can see: scenic view of Cerrado national parks. Perspect. Ecol. Conserv. 16, 31-37. https://doi.org/10.1016/j.pecon.2017.11.004.

de Vries, S., ten Have, M., van Dorsselaer, S., van Wezep, M., Hermans, T., de Graaf, R., 2016. Local availability of green and blue space and prevalence of common mental disorders in the Netherlands. Br. J. Psychiatry Open 2, 366-372. https://doi.org/ 10.1192/bjpo.bp.115.002469.

Díaz, S., Demissew, S., Carabias, J., Joly, C., Lonsdale, M., Ash, N., Larigauderie, A., Adhikari, J.R., Arico, S., Báldi, A., Bartuska, A., Baste, I.A., Bilgin, A., Brondizio, E., Chan, K.M.A., Figueroa, V.E., Duraiappah, A., Fischer, M., Hill, R., Koetz, T., Leadley, P., Lyver, P., Mace, G.M., Martin-Lopez, B., Okumura, M., Pacheco, D., Pascual, U., Pérez, E.S., Reyers, B., Roth, E., Saito, O., Scholes, R.J., Sharma, N., Tallis, H., Thaman, R., Watson, R., Yahara, T., Hamid, Z.A., Akosim, C., AlHafedh, Y., Allahverdiyev, R., Amankwah, E., Asah, T.S., Asfaw, Z., Bartus, G., Brooks, A.L., Caillaux, J., Dalle, G., Darnaedi, D., Driver, A., Erpul, G., EscobarEyzaguirre, P., Failler, P., Fouda, A.M.M., Fu, B., Gundimeda, H., Hashimoto, S., Homer, F., Lavorel, S., Lichtenstein, G., Mala, W.A., Mandivenyi, W., Matczak, P., Mbizvo, C., Mehrdadi, M., Metzger, J.P., Mikissa, J.B., Moller, H., Mooney, H.A., Mumby, P., Nagendra, H., Nesshover, C., Oteng-Yeboah, A.A., Pataki, G., Roué, M., Rubis, J., Schultz, M., Smith, P., Sumaila, R., Takeuchi, K., Thomas, S., Verma, M., Yeo-Chang, Y, Zlatanova, D., 2015. The IPBES conceptual framework - connecting nature and people. Curr. Opin. Environ. Sustain. 14, 1-16. https://doi.org/10.1016/ j.cosust.2014.11.002.

Díaz, S., Pascual, U., Stenseke, M., Martín-lópez, B., Watson, R.T., Molnár, Z., Hill, R. Chan, K.M.A., Baste, I.A., Brauman, K.A., Polasky, S., Church, A., Lonsdale, M., Larigauderie, A., Leadley, P.W., Alexander, P.E., Oudenhoven, V., Van Der Plaat, F., Schröter, M., Lavorel, S., Aumeeruddy-thomas, Y., Bukvareva, E., Davies, K., Schroter, M., Lavorel, S., Aumeeruddy-thomas, Y., Bukvareva, E., Davies, K., Demissew, S., Erpul, G., Failler, P., Guerra, C.A., Hewitt, C.L., Keune, H., Lindley, S.,
Shirayama, Y., 2018. Assessing nature's contributions to people. Science (80-.) 359, 270-272. https://doi.org/10.1126/science.aap8826.
Diener, E., Biswas-Diener, R., 2002. Will money increase subjective well-being? Soc Indic. Res. 57, 119-169. https://doi.org/10.1023/A:1014411319119.

Dolan, P., Peasgood, T., White, M., 2008. Do we really know what makes us happy? A review of the economic literature on the factors associated with subjective wellbeing. J. Econ. Psychol. 29, 94-122. https://doi.org/10.1016/j.joep.2007.09.001.

Dormann, C.F., Elith, J., Bacher, S., Buchmann, C., Carl, G., Carré, G., Marquéz, J.R.G., Gruber, B., Lafourcade, B., Leitão, P.J., Münkemüller, T., Mcclean, C., Osborne, P.E., Reineking, B., Schröder, B., Skidmore, A.K., Zurell, D., Lautenbach, S., 2013. Collinearity: a review of methods to deal with it and a simulation study evaluating their performance. Ecography. 36, 027-046. https://doi.org/10.1111/j.16000587.2012.07348.x.

Doughty, C.E., Wolf, A., Morueta-Holme, N., Jørgensen, P.M., Sandel, B., Violle, C., Boyle, B., Kraft, N.J.B., Peet, R.K., Enquist, B.J., Svenning, J.C., Blake, S., Galetti, M., 2016. Megafauna extinction, tree species range reduction, and carbon storage in Amazonian forests. Ecography. 39, 194-203. https://doi.org/10.1111/ecog.01587.

Ekkel, E.D., de Vries, S., 2017. Nearby green space and human health: evaluating accessibility metrics. Landsc. Urban Plan. 157, 214-220. https://doi.org/10.1016/j. landurbplan.2016.06.008.

Engemann, K., Pedersen, C.B., Arge, L., Tsirogiannis, C., Mortensen, P.B., Svenning, J.C., 2019. Residential green space in childhood is associated with lower risk of psychiatric disorders from adolescence into adulthood. Proc. Natl. Acad. Sci. U. S. A. 116, 5188-5193. https://doi.org/10.1073/pnas.1807504116.

European Union, E, 2010. Directive 2009/147/EC of the European Parliament and the Council (Official Journal of the European Union).

Ferrer-i-Carbonell, A., Frijters, P., 2004. How important is methodology for the estimates of the determinants of happiness? Econ. J. 114, 641-659. https://doi.org/10.1111/ j.1468-0297.2004.00235.x.

Fish, R., Church, A., Winter, M., 2016. Conceptualising cultural ecosystem services: a novel framework for research and critical engagement. Ecosyst. Serv. 21, 208-217. https://doi.org/10.1016/j.ecoser.2016.09.002.

Folmer, A., Haartsen, T., Huigen, P.P.P., 2019. How ordinary wildlife makes local green places special. Landsc. Res. 44, 393-403. https://doi.org/10.1080/ 01426397.2018.1457142.

Fox, J., Monette, G., 1992. Generalized collinearity diagnostics. J. Am. Stat. Assoc. 87, $178-183$.

Fox, J., Weisberg, S., 2018. An R Companion to Applied Regression, Third ed. Sage Publications Inc., London.

Frey, B.S., Stutzer, A., 2002. The economics of happiness. World Econ. 3, 25-41.

Fuller, R.A., Irvine, K.N., Devine-Wright, P., Warren, P.H., Gaston, K.J., 2007. Psychological benefits of greenspace increase with biodiversity. Biol. Lett. 3 , 390-394. https://doi.org/10.1098/rsbl.2007.0149.

Gascon, M., Mas, M.T., Martínez, D., Dadvand, P., Forns, J., Plasència, A., Nieuwenhuijsen, M.J., 2015. Mental health benefits of long-term exposure to residential green and blue spaces: a systematic review. Int. J. Environ. Res. Public Health 12, 4354-4379. https://doi.org/10.3390/ijerph120404354.

Gaynor, K.M., Hojnowski, C.E., Carter, N.H., Brashares, J.S., 2018. The influence of human disturbance on wildlife nocturnality. Science. 360, 1232-1235. https://doi. rg/10.1126/science.aar7121.

Gil-Tena, A., Saura, S., Brotons, L., 2007. Effects of forest composition and structure on bird species richness in a Mediterranean context: implications for forest ecosystem management. For. Ecol. Manag. 242, 470-476. https://doi.org/10.1016/j. foreco.2007.01.080.

Graham, N., Arai, M., Hagströmer, B., 2016. Multiwayvcov: Multi-Way Standard Error Clustering.

Hagemeijer, W.J.M., Blair, M.J., 1997. The EBCC Atlas of European Breeding Birds - their Distribution and Abundance. T. \& A.D. Poyser, London.

Harrel Jr., F.E., 2019. rms: Regression Modeling Strategies. R Packag. Version 5.1-3.1.

Hartig, T., van den Berg, A.E., Hagerhall, C.M., Tomalak, M., Bauer, N., Hansmann, R., Ojala, A., Syngollitou, E., Carrus, G., van Herzele, A., Bell, S., Podesta, M.T.C., Waaseth, G., de Vries, S., 2011. Health benefits of nature experience: Psychological, social and cultural processes. In: Nilsson, K., Sangster, M., Gallis, C., Hartig, T., Seeland, K., Schipperijn, J. (Eds.), Forests, Trees and Human Health. Springer Netherlands, Dordrecht, pp. 127-168. https://doi.org/10.1007/978-90-481-9806-1 5.

Hartig, T., Mitchell, R., de Vries, S., Frumkin, H., 2014. Nature and health. Annu. Rev. Public Health 35, 207-228. https://doi.org/10.1146/annurev-publhealth-032013182443.

Haylock, M.R., Hofstra, N., Klein Tank, A.M.G., Klok, E.J., Jones, P.D., New, M., 2008 A European daily high-resolution gridded data set of surface temperature and precipitation for 1950-2006. J. Geophys. Res. Atmos. 113 https://doi.org/10.1029/ 2008JD010201.

Hedblom, M., Heyman, E., Antonsson, H., Gunnarsson, B., 2014. Bird song diversity influences young people's appreciation of urban landscapes. Urban For. Urban Green. 13, 469-474. https://doi.org/10.1016/j.ufug.2014.04.002.

Hernández-Morcillo, M., Plieninger, T., Bieling, C., 2013. An empirical review of cultural ecosystem service indicators. Ecol. Indic. 29, 434-444. https://doi.org/10.1016/j. ecolind.2013.01.013.

Hipp, J.A., Gulwadi, G.B., Alves, S., Sequeira, S., 2016. The relationship between perceived greenness and perceived restorativeness of university campuses and perceived greenness and perceived restorativeness of university campuses and
student-reported quality of life. Environ. Behav. 48, 1292-1308. https://doi.org/ student-reported quality of life.

Hoyle, H., Hitchmough, J., Jorgensen, A., 2017. All about the 'wow factor'? The relationships between aesthetics, restorative effect and perceived biodiversity in designed urban planting. Landsc. Urban Plan. 164, 109-123. https://doi.org/ 10.1016/j.landurbplan.2017.03.011. 
Huby, M., Cinderby, S., Crowe, A.M., Gillings, S., McClean, C.J., Moran, D., Owen, A., White, P.C.L., 2006. The association of natural, social and economic factors with bird species richness in rural England. J. Agric. Econ. 57, 295-312. https://doi.org/ 10.1111/j.1477-9552.2006.00053.x.

IPBES, 2014. Annex: Conceptual Framework for the Intergovernmental Science-Policy Platform on Biodiversity and Ecosystem Services (Intergovernmental Science-Policy Platform on Biodiversity and Ecosystem Services).

IPBES, 2018. The IPBES Regional Assessment Report on Biodiversity and Ecosystem Services for Europe and Central Asia. Secretariat of the Intergovernmental SciencePolicy Platform on Biodiversity and Ecosystem Services, Bonn.

IPBES, 2019. The Global Assessment Report on Biodiversity and Ecosystem Services Summary for Policy Makers. IPBES secretariat, Bonn.

Irvine, K.N., Hoesly, D., Bell-Williams, R., Warber, S.L., 2019. Biodiversity and spiritual well-being. In: Marselle, M.R., Stadler, J., Korn, H., Irvine, K.N., Bonn, A. (Eds.), Biodiversity and Health in the Face of Climate Change. Springer International Biodiversity and Health in the Face of Climate Change. Springer International
Publishing, Cham, pp. 213-247. https://doi.org/10.1007/978-3-030-02318-8 10.

Publishing, Cham, pp. 213-247. https://doi.org/10.1007/978-3-030-02318-8_-
Jones, K.E., Bielby, J., Cardillo, M., Fritz, S.A., O’Dell, J., Orme, C.D.L., Safi, K.,

Jones, K.E., Bielby, J., Cardillo, M., Fritz, S.A., O’Dell, J., Orme, C.D.L., Safi, K., Sechrest, W., Boakes, E.H., Carbone, C., Connolly, C., Cutts, M.J., Foster, J.K., Grenyer, R., Habib, M., Plaster, C.A., Price, S.A., Rigby, E.A., Rist, J., Teacher, A., a species-level database of life history, ecology, and geography of extant and recently extinct mammals. Ecology. 90 (9), 2648.

Kabisch, N., 2019. The influence of socio-economic and socio-demographic factors in the association between urban green space and health. In: M., M., J., S., H., K., K., I., A., B. (Eds.), Biodiversity and Health in the Face of Climate Change. Springer International Publishing, Cham, pp. 91-119. https://doi.org/10.1007/978-3-03002318-8_5.

Kahneman, D., Krueger, A.B., 2006. Developments in the measurement of subjective well being. J. Econ. Perspect. 20, 3-24.

Kahneman, D., Wakker, P.P., Sarin, R., 1997. Back to Bentham? Explorations of experienced utility. Q. J. Econ. 112, 375-405. https://doi.org/10.1080/ 02724980343000242

Kaplan, S., 1995. The resporative benefits of nature: toward and integrative framework. J. Environ. Psychol. 15, 169-182. https://doi.org/10.1016/0272-4944(95)90001-2.

Koleček, J., Reif, J., Štastný, K., Bejček, V., 2010. Changes in bird distribution in a Central European country between 1985-1989 and 2001-2003. J. Ornithol. 151, 923-932. https://doi.org/10.1007/s10336-010-0532-x.

Kopmann, A., Rehdanz, K., 2013. A human well-being approach for assessing the value of natural land areas. Ecol. Econ. 93, 20-33. https://doi.org/10.1016/j. ecolecon.2013.04.014.

Krekel, C., Kolbe, J., Wüstemann, H., 2016. The greener, the happier? The effect of urban land use on residential well-being. Ecol. Econ. 121, 117-127. https://doi.org/ 10.1016/j.ecolecon.2015.11.005.

Kristoffersen, I., 2017. The metrics of subjective wellbeing data: an empirical evaluation of the ordinal and cardinal comparability of life satisfaction scores. Soc. Indic. Res. 130, 845-865. https://doi.org/10.1007/s11205-015-1200-6.

Kromrey, J.D., Rendina-Gobioff, G., 2003. An empirical comparison of regression analysis strategies with discrete ordinal variables. Mult. Linear Regres. Viewpoints 29, 30-43.

Kubiszewski, I., Zakariyya, N., Costanza, R., 2018. Objective and subjective indicators of life satisfaction in Australia: how well do people perceive what supports a good life? Ecol. Econ. 154, 361-372. https://doi.org/10.1016/j.ecolecon.2018.08.017.

Le Viol, I., Jiguet, F., Brotons, L., Herrando, S., Lindström, Å., Pearce-Higgins, J.W., Reif, J., Van Turnhout, C., Devictor, V., 2012. More and more generalists: two decades of changes in the European avifauna. Biol. Lett. 8, 780-782. https://doi.org/ 10.1098/rsbl.2012.0496.

Lindemann-Matthies, P., Matthies, D., 2018. The influence of plant species richness on stress recovery of humans. Web Ecol. 18, 121-128. https://doi.org/10.5194/we-18 stress recover.

Lindemann-Matthies, P., Junge, X., Matthies, D., 2010. The influence of plant diversity on people's perception and aesthetic appreciation of grassland vegetation. Biol. on people's perception and aesthetic appreciation of grassland vegetation.
Conserv. 143, 195-202. https://doi.org/10.1016/j.biocon.2009.10.003.

Lindsey, P.A., Alexander, R., Mills, M.G.L., Romañach, S., Woodroffe, R., 2007. Wildlife viewing preferences of visitors to protected areas in South Africa: implications for the role of ecotourism in conservation. J. Ecotour. 6, 19-33. https://doi.org/ 10.2167/joe133.0.

Loss, S.R., Ruiz, M.O., Brawn, J.D., 2009. Relationships between avian diversity, neighborhood age, income, and environmental characteristics of an urban landscape Biol. Conserv. 142, 2578-2585. https://doi.org/10.1016/j.biocon.2009.06.004.

Lovell, R., Wheeler, B.W., Higgins, S.L., Irvine, K.N., Depledge, M.H., 2014. A systematic review of the health and well-being benefits of biodiverse environments. J. Toxicol. Environ. Heal. Part B Crit. Rev. 17, 1-20. https://doi.org/10.1080/ 10937404.2013.856361.

Luck, G.W., Davidson, P., Boxall, D., Smallbone, L., 2011. Relations between urban bird and plant communities and human well-being and connection to nature. Conserv. Biol. 25, 816-826. https://doi.org/10.1111/j.1523-1739.2011.01685.x.

MA, M.E.A., 2005. Ecosystems and Human Well-Being: Synthesis. Island Press, Washington, DC.

Ma, B., Zhou, T., Lei, S., Wen, Y., Htun, T.T., 2019. Effects of urban green spaces on residents' well-being. Environ. Dev. Sustain. 21, 2793-2809. https://doi.org/ 10.1007/s10668-018-0161-8.

Maas, J., Verheij, R.A., Groenewegen, P.P., De Vries, S., Spreeuwenberg, P., 2006. Green space, urbanity, and health: how strong is the relation? J. Epidemiol. Community Health 60, 587-592

Maas, J., Verheij, R.A., Spreeuwenberg, P., Groenewegen, P.P., 2008. Physical activity as a possible mechanism behind the relationship between green space and health: a multilevel analysis. BMC Public Health 8, 1-13. https://doi.org/10.1186/14712458-8-206.

MacKerron, G., Mourato, S., 2013. Happiness is greater in natural environments. Glob. Environ. Chang. 23, 992-1000. https://doi.org/10.1016/j.gloenvcha.2013.03.010. Maddison, D., Rehdanz, K., 2011. The impact of climate on life satisfaction. Ecol. Econ. 70, 2437-2445. https://doi.org/10.1016/j.ecolecon.2011.07.027.

Maddison, D., Rehdanz, K., 2020. Cross-country variations in subjective wellbeing explained by the climate. In: Maddison, D., Rehdanz, K., Welsch, H. (Eds.), Handbook on Wellbeing, Happiness and the Environment. Edward Elgar Publishing Limited, Cheltenham, UK, pp. 105-126.

Maddison, D., Rehdanz, K., Welsch, H., 2020. Handbook on Wellbeing, Happiness and the Environment. Edward Elgar Publishing Limited, Cheltenham, UK. https://doi. org/10.4337/9781788119344.

Marando, F., Salvatori, E., Fusaro, L., Manes, F., 2016. Removal of PM10 by forests as a nature-based solution for air quality improvement in the metropolitan city of Rome. Forests 7. https://doi.org/10.3390/f7070150.

Markevych, I., Schoierer, J., Hartig, T., Chudnovsky, A., Hystad, P., Dzhambov, A.M., De Vries, S., Triguero-mas, M., Brauer, M., Nieuwenhuijsen, M.J., Lupp, G., Richardson, E.A., Astell-burt, T., Dimitrova, D., Feng, X., Sadeh, M., Standl, M., Heinrich, J., Fuertes, E., 2017. Exploring pathways linking greenspace to health: theoretical and methodological guid
org $/ 10.1016 /$ j.envres.2017.06.028.

Marselle, M.R., 2019. Theoretical foundations of biodiversity and mental well-being relationships. In: Marselle, M.R., Stadler, J., Korn, H., Irvine, K.N., Bonn, A. (Eds.), Biodiversity and Health in the Face of Climate Change. Springer International Publishing, Cham, pp. 133-158. https://doi.org/10.1007/978-3-030-02318-8_7.

Marselle, M.R., Irvine, K.N., Lorenzo-Arribas, A., Warber, S.L., 2016. Does perceived restorativeness mediate the effects of perceived biodiversity and perceived naturalness on emotional well-being following group walks in nature? J. Environ. naturalness on emotional well-being following group walks in nature?
Psychol. 46, 217-232. https://doi.org/10.1016/j.jenvp.2016.04.008.

Marselle, Melissa R., Martens, D., Dallimer, M., Irvine, K.N., 2019. Review of the mental health and well-being benefits of biodiversity. In: Marselle, M.R., Stadler, J., Korn, H., Irvine, K., Bonn, A. (Eds.), Biodiversity and Health in the Face of Climate Change. Springer International Publishing, Cham, pp. 175-211. https://doi.org/ 10.1007/978-3-030-02318-8_9.

Mauri, A., Strona, G., San-Miguel-Ayanz, J., 2017. EU-Forest, a high-resolution tree occurrence dataset for Europe. Sci. Data 4, 160123. https://doi.org/10.1038/ sdata.2016.123.

Mavoa, S., Davern, M., Breed, M., Hahs, A., 2019. Higher levels of greenness and biodiversity associate with greater subjective wellbeing in adults living in Melbourne, Australia. Health Place 57, 321-329. https://doi.org/10.1016/j. healthplace.2019.05.006.

Medvedev, O., Shepherd, D., Hautus, M.J., 2015. The restorative potential of soundscapes: a physiological investigation. Appl. Acoust. 96, 20-26. https://doi.org/ 10.1016/j.apacoust.2015.03.004.

Meier, S., Stutzer, A., 2008. Is volunteering rewarding in itself? Economica 75, 39-59. https://doi.org/10.1111/j.1468-0335.2007.00597.x.

Methorst, J., Arbieu, U., Bonn, A., Böhning-Gaese, K., Müller, T., 2020. Non-material contributions of wildlife to human well-being: a systematic review. Environ. Res Lett. 15 (9), 093005.

Miles, R., Coutts, C., Mohamadi, A., 2012. Neighborhood urban form, social environment, and depression. J. Urban Health 89, 1-18. https://doi.org/10.1007/ s11524-011-9621-2.

Moulton, B.R., 1990. An illustration of a pitfall in estimating the effects of aggregate variables on micro units. Rev. Econ. Stat. 72, 334. https://doi.org/10.2307/ 2109724.

Murray, T., Maddison, D., Rehdanz, K., 2013. Do geographical variations in climate influence life-satisfaction? Clim. Chang. Econ. 4, 1350004 https://doi.org/10.1142/ S2010007813500048.

Ng, Y., 1997. A case for happiness, cardinalism, and interpersonal comparability. Econ. J. 107, 1848-1858. https://doi.org/10.1111/j.1468-0297.1997.tb00087.x.

Oteros-rozas, E., Martín-lópez, B., Fagerholm, N., Bieling, C., Plieninger, T., 2018. Using social media photos to explore the relation between cultural ecosystem services and social media photos to explore the relation between cultural ecosystem services and org/10.1016/j.ecolind.2017.02.009.

Paracchini, M.L., Zulian, G., Kopperoinen, L., Maes, J., Schägner, J.P., Termansen, M., Zandersen, M., Perez-Soba, M., Scholefield, P.A., Bidoglio, G., 2014. Mapping cultural ecosystem services: a framework to assess the potential for outdoor recreation across the EU. Ecol. Indic. 45, 371-385. https://doi.org/10.1016/j. ecolind.2014.04.018

Peña, L., Casado-Arzuaga, I., Onaindia, M., 2015. Mapping recreation supply and demand using an ecological and a social evaluation approach. Ecosyst. Serv. 13, 108-118. https://doi.org/10.1016/j.ecoser.2014.12.008.

Rantakokko, M., Keskinen, K.E., Kokko, K., Portegijs, E., 2017. Nature diversity and wellbeing in old age. Aging Clin. Exp. Res. 30, 527-532. https://doi.org/10.1007 s40520-017-0797-5.

Ratcliffe, E., Gatersleben, B., Sowden, P.T., 2013. Bird sounds and their contributions to perceived attention restoration and stress recovery. J. Environ. Psychol. 36, 221-228. https://doi.org/10.1016/j.jenvp.2013.08.004.

Ratcliffe, E., Gatersleben, B., Sowden, P.T., 2016. Associations with bird sounds: how do they relate to perceived restorative potential? J. Environ. Psychol. 47, 136-144. https://doi.org/10.1016/j.jenvp.2016.05.009.

Rehdanz, K., Maddison, D., 2005. Climate and happiness. Ecol. Econ. 52, 111-125. https://doi.org/10.1016/j.ecolecon.2004.06.015.

Reif, J., Prylová, K., Šizling, A.L., Vermouzek, Z., Štastný, K., Bejček, V., 2013. Changes in bird community composition in the Czech Republic from 1982 to 2004: increasing 
biotic homogenization, impacts of warming climate, but no trend in species richness. J. Ornithol. 154, 359-370. https://doi.org/10.1007/s10336-012-0900-9.

Reuben, A., Arseneault, L., Belsky, D.W., Caspi, A., Fisher, H.L., Houts, R.M., Moffitt, T. E., Odgers, C., 2019. Residential neighborhood greenery and children's cognitive development. Soc. Sci. Med. 230, 271-279. https://doi.org/10.1016/j. socscimed.2019.04.029.

Rosenberg, K.V., Dokter, A.M., Blancher, P.J., Sauer, J.R., Smith, A.C., Smith, P.A., Stanton, J.C., Panjabi, A., Helft, L., Parr, M., Marra, P.P., 2019. Decline of the north American avifauna. Science. 366, 120-124. https://doi.org/10.1126/science. aaw1313.

Røskaft, E., Bjerke, T., Kaltenborn, B., 2003. Patterns of self-reported fear towards large carnivores among the Norwegian public. Evol. Hum. Behav. 24, 184-198. https:// carnivores among the Norwegian public. Evol.
doi.org/10.1016/S1090-5138(03)00011-4.

RStudio Team, 2016. RStudio: Integrated Development for R.

Russell, R., Guerry, A.D., Balvanera, P., Gould, R.K., Basurto, X., Chan, K.M.A., Klain, S., Levine, J., Tam, J., 2013. Humans and nature: how knowing and experiencing nature affect well-being. Annu. Rev. Environ. Resour. 38, 473-502. https://doi.org/ affect well-being. Annu. Rev. Environ. Resour.

Sandifer, P.A., Sutton-Grier, A.E., Ward, B.P., 2015. Exploring connections among nature, biodiversity, ecosystem services, and human health and well-being: opportunities to enhance health and biodiversity conservation. Ecosyst. Serv. 12, 1-15. https://doi.org/10.1016/j. ecoser.2014.12.007.

Satz, D., Gould, R.K., Chan, K.M.A., Guerry, A., Norton, B., Satterfield, T., Halpern, B.S., Levine, J., Woodside, U., Hannahs, N., Basurto, X., Klain, S., 2013. The challenges of incorporating cultural ecosystem services into environmental assessment. Ambio 42, 675-684. https://doi.org/10.1007/s13280-013-0386-6.

Schebella, M.F., Weber, D., Lindsey, K., Daniels, C.B., 2017. For the love of nature: exploring the importance of species diversity and micro-variables associated with favorite outdoor places. Front. Psychol. 8 https://doi.org/10.3389/ fpsyg.2017.02094. Article 2094.

Schipperijn, J., Ekholm, O., Stigsdotter, U.K., Toftager, M., Bentsen, P., KamperJørgensen, F., Randrup, T.B., 2010. Factors influencing the use of green space: Jørgensen, F., Randrup, T.B., 2010. Factors influencing the use of green space:
results from a Danish national representative survey. Landsc. Urban Plan. 95, results from a Danish national representative survey. Landsc. U

Schirpke, U., Tasser, E., Tappeiner, U., 2013. Predicting scenic beauty of mountain regions. Landsc. Urban Plan. 111, 1-12. https://doi.org/10.1016/j. landurbplan.2012.11.010.

Sherrouse, B.C., Clement, J.M., Semmens, D.J., 2011. A GIS application for assessing, mapping, and quantifying the social values of ecosystem services. Appl. Geogr. 31, 748-760. https://doi.org/10.1016/j. apgeog.2010.08.002.

Skibins, J.C., Powell, R.B., Hallo, J.C., 2013. Charisma and conservation: charismatic megafauna's influence on safari and zoo tourists' pro-conservation behaviors. miogavers. Conserv. 22, 959-982. https://doi.org/10.1007/s10531-013-0462-z.

Sol, D., Lapiedra, O., González-Lagos, C., 2013. Behavioural adjustments for a life in the city. Anim. Behav. 85, 1101-1112. https://doi.org/10.1016/j.anbehav.2013.01.023.

Soulsbury, C.D., White, P.C.L., 2015. Human-wildlife interactions in urban areas: a review of conflicts, benefits and opportunities. Wildl. Res. 42, 541-553. https://do review of conflicts, benefits

Southon, G.E., Jorgensen, A., Dunnett, N., Hoyle, H., Evans, K.L., 2017. Biodiverse perennial meadows have aesthetic value and increase residents' perceptions of site quality in urban green-space. Landsc. Urban Plan. 158, 105-118. https://doi.org/ 10.1016/j.landurbplan.2016.08.003.

Spinoni, J., Vogt, J., Barbosa, P., 2015. European degree-day climatologies and trends for the period 1951-2011. Int. J. Climatol. 35, 25-36. https://doi.org/10.1002/ joc.3959.

Sterling, E.J., Filardi, C., Toomey, A., Sigouin, A., Betley, E., Gazit, N., Newell, J., Albert, S., Alvira, D., Bergamini, N., Blair, M., Boseto, D., Burrows, K., Bynum, N., Caillon, S., Caselle, J.E., Claudet, J., Cullman, G., Dacks, R., Eyzaguirre, P.B., Gray, S., Herrera, J., Kenilorea, P., Kinney, K., Kurashima, N., MacEy, S., Malone, C., Mauli, S., McCarter, J., McMillen, H., Pascua, P., Pikacha, P., Porzecanski, A.L., De Robert, P., Salpeteur, M., Sirikolo, M., Stege, M.H., Stege, K., Ticktin, T., Vave, R., Wali, A., West, P., Winter, K.B., Jupiter, S.D., 2017. Biocultural approaches to wellbeing and sustainability indicators across scales. Nat. Ecol. Evol. 1, 1798-1806. being and sustainability indicators across sca.

Taylor, M.S., Wheeler, B.W., White, M.P., Economou, T., Osborne, N.J., 2015. Research note: urban street tree density and antidepressant prescription rates-a cross-sectional study in London, UK. Landsc. Urban Plan. 136, 174-179. https://doi.org/10.1016/j. landurbplan.2014.12.005.
Ulrich, R.S., 1991. Stress recovery during exposure to natural environments. J. Environ. Psychol. 11, 201-230. https://doi.org/10.1016/S0272-4944(05)80184-7.

van den Berg, A.E., Maas, J., Verheij, R.A., Groenewegen, P.P., 2010. Green space as buffer between stressful life events and health. Soc. Sci. Med. 70, 1203-1210. https://doi.org/10.1016/j.socscimed.2010.01.002.

Van Turnhout, C.A.M., Foppen, R.P.B., Leuven, R.S.E.W., Siepel, H., Esselink, H., 2007. Scale-dependent homogenization: changes in breeding bird diversity in the Netherlands over a 25-year period. Biol. Conserv. 134, 505-516. https://doi.org/ 10.1016/j.biocon.2006.09.011.

Velarde, M.D., Fry, G., Tveit, M., 2007. Health effects of viewing landscapes - landscape types in environmental psychology. Urban For. Urban Green. 6, 199-212. https:// doi.org/10.1016/j.ufug.2007.07.001.

Völker, S., Kistemann, T., 2011. The impact of blue space on human health and wellbeing - salutogenetic health effects of inland surface waters: a review. Int. J. Hyg. being - salutogenetic health effects of inland surface waters: a review. Int. J.
Environ. Health 214, 449-460. https://doi.org/10.1016/j.ijheh.2011.05.001.

Vujcic, M., Tomicevic-Dubljevic, J., Grbic, M., Lecic-Tosevski, D., Vukovic, O.

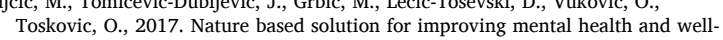
being in urban areas. Environ. Res. 158, 385-392. https://doi.org/10.1016/j. envres.2017.06.030.

Weber, D., Hintermann, U., Zangger, A., 2004. Scale and trends in species richness: considerations for monitoring biological diversity for political purposes. Glob. Ecol. Biogeogr. 13, 97-104.

Welsch, H., 2009. Implications of happiness research for environmental economics. Ecol. Econ. 68, 2735-2742. https://doi.org/10.1016/j.ecolecon.2009.06.003.

Welsch, Heinz, 2020. Happiness and environmental economics. In: Maddison, D, Rehdanz, K., Welsch, H. (Eds.), Handbook on Wellbeing, Happiness and the Environment. Edward Elgar Publishing Limited, Cheltenham, UK, pp. 71-84.

Welsch, H., Ferreira, S., 2014. Environment, well-being, and experienced preference. Int. Rev. Environ. Resour. Econ. 7, 205-239. https://doi.org/10.1561/101.00000061.

Wheeler, B.W., Lovell, R., Higgins, S.L., White, M.P., Alcock, I., Osborne, N.J., Husk, K., Sabel, C.E., Depledge, M.H., 2015. Beyond greenspace: an ecological study of Sabel, C.E., Depledge, M.H., 2015. Beyond greenspace: an ecological study of
population general health and indicators of natural environment type and quality. population general health and indicators of natural environment type and quatity
Int. J. Health Geogr. 14, 1-17. https://doi.org/10.1186/s12942-015-0009-5.

Int. J. Health Geogr. 14, 1-17. https://doi.org/10.1186/s12942-015-0009-5.
White, M.P., Alcock, I., Wheeler, B.W., Depledge, M.H., 2013a. Coastal proximity, health and well-being: results from a longitudinal panel survey. Health Place 23, 97-103.
and https://doi.org/10.1016/j.healthplace.2013.05.006.

White, M.P., Alcock, I., Wheeler, B.W., Depledge, M.H., 2013b. Would you be happier living in a greener urban area? A fixed-effects analysis of panel data. Psychol. Sci. 24, 920-928. https://doi.org/10.1177/0956797612464659.

White, M.P., Pahl, S., Wheeler, B.W., Depledge, M.H., Fleming, L.E., 2017. Natural environments and subjective wellbeing: different types of exposure are associated with different aspects of wellbeing. Health Place 45, 77-84. https://doi.org/ 10.1016/j.healthplace.2017.03.008.

Wilson, J.P., Gallant, J.C., 2000. Primary topographic attributes. In: Wilson, John P., Gallanst, J.C. (Eds.), Terrain Analysis: Principles and Applications. John Wiley \& Sons, Ltd, New York, Chichester, Weinheim, Brisbane, Singapore, Toronto, pons, Ltd, $51-85$.

Wolf, L.J., Zu Ermgassen, S., Balmford, A., White, M., Weinstein, N., 2017. Is variety the spice of life? An experimental investigation into the effects of species richness on self-reported mental well-being. PLoS One 12, 1-17. https://doi.org/10.1371/ self-reported mental well-

Wood, E., Harsant, A., Dallimer, M., de Chavez, A.C., McEachan, R.R.C., Hassall, C., 2018. Not all green space is created equal: biodiversity predicts psychological restorative benefits from urban green space. Front. Psychol. 9, 1-13. https://doi.org/ 10.3389/fpsyg.2018.02320.

World Health Organization, 2017. Urban Green Space Interventions and Health: A Review of Impacts and Effectiveness. WHO Regional Office for Europe, Copenhagen.

Wyles, K.J., White, M.P., Hattam, C., Pahl, S., King, H., Austen, M., 2019. Are some natural environments more psychologically beneficial than others? The importance of type and quality on connectedness to nature and psychological restoration.
Environ. Behav. 51, 111-143. https://doi.org/10.1177/0013916517738312.

Zorondo-Rodríguez, F., Grau-Satorras, M., Kalla, J., Demps, K., Gómez-Baggethun, E., García, C., Reyes-García, V., 2016. Contribution of natural and economic capital to subjective well-being: empirical evidence from a small-scale society in Kodagu (Karnataka), India. Soc. Indic. Res. 127, 919-937. https://doi.org/10.1007/s11205(Karnataka), 


\subsection{Supplementary Material}

Supplementary Material

'The importance of species diversity for human well-being in Europe'

Authors:

Joel Methorst, Katrin Rehdanz, Thomas Müller, Bernd Hansjürgens, Aletta Bonn, Katrin Böhning-Gaese 


\subsubsection{Socio-economic data description}

Here I present detailed descriptions of each variable used in our study (Table A.III-1).

Table A.III-1: Socio- and macro-economic variables and their detailed descriptions.

\begin{tabular}{|c|c|c|}
\hline Main category & Subcategory & Description \\
\hline \multirow[t]{9}{*}{$\begin{array}{l}\text { Socio-economic fac- } \\
\text { tors }\end{array}$} & $\begin{array}{l}\text { Categorical net house- } \\
\text { hold income }\end{array}$ & $\begin{array}{l}\text { Categorical income variable with } 22 \text { categories. The } \\
\text { lowest category marks net monthly income }<50 \text { EUR. } \\
\text { The highest category groups people with monthly in- } \\
\text { come }>5,500 \text { EUR. }\end{array}$ \\
\hline & $\begin{array}{l}\text { Mean of categorical net } \\
\text { household income }\end{array}$ & $\begin{array}{l}\text { Estimated mean monthly net household income based } \\
\text { on the categorical income variable (continuous varia- } \\
\text { ble). We took the midpoints of each income category. }\end{array}$ \\
\hline & $\begin{array}{l}\text { Age and quadratic term } \\
\text { of age }\end{array}$ & $\begin{array}{l}\text { Age }(<18 \text { years }) \text { and a quadratic term of age was in- } \\
\text { cluded to account for the U-shaped relationship found } \\
\text { in the literature. }\end{array}$ \\
\hline & Male/Gender & Binary variable for males. \\
\hline & Educational level & $\begin{array}{l}\text { Three categories: tertiary, secondary and primary or } \\
\text { less. }\end{array}$ \\
\hline & Health status & $\begin{array}{l}\text { Five categories: very good, good, fair, bad and very } \\
\text { bad. }\end{array}$ \\
\hline & Household structure & $\begin{array}{l}\text { Five categories: single, couple, single parent, couple } \\
\text { with child, other households. }\end{array}$ \\
\hline & Employment status & $\begin{array}{l}\text { Seven categories: employed, unemployed, unable, re- } \\
\text { tired, homemaker, student and other. }\end{array}$ \\
\hline & Volunteering & $\begin{array}{l}\text { A variable which describes how frequently people do } \\
\text { voluntary work in three categories: does not volunteer, } \\
\text { volunteers occasionally and volunteers regularly. }\end{array}$ \\
\hline \multirow[t]{2}{*}{$\begin{array}{l}\text { Macro-economic fac- } \\
\text { tors }\end{array}$} & GDP per capita & $\begin{array}{l}\text { GDP per capita in purchasing power standard (PPS) for } \\
\text { each NUTS region. }\end{array}$ \\
\hline & Unemployment rate & Unemployment rate for each NUTS region. \\
\hline \multirow{4}{*}{$\begin{array}{l}\text { Further control vari- } \\
\text { ables }\end{array}$} & Urban & Binary variable for urban areas. \\
\hline & Recreation access & $\begin{array}{l}\text { A variable which describes how the participants assess } \\
\text { their access to recreational areas in five categories: } \\
\text { great difficulty, with some difficulty, easily, very easily } \\
\text { and service not used. }\end{array}$ \\
\hline & Eastern Europe dummy & $\begin{array}{l}\text { Binary variable for all former East-Bloc countries (i.e. } \\
\text { Latvia, Lithuania, Estonia, Poland, Czech Republic, } \\
\text { Slovakia, Hungary, Romania and Bulgaria). }\end{array}$ \\
\hline & NUTS area size & Area size $(\mathrm{km} 2)$ of each NUTS region. \\
\hline
\end{tabular}




\subsubsection{CORINE land cover categorization}

Here I report the categorizations of land cover types from the CORINE land cover database (Table A.III-2 ). Based on these land cover types I calculated the variables for landscape heterogeneity, green space and blue space cover.

Table A.III-2: Land cover categories used to estimate habitat heterogeneity as well as green and blue space.

\begin{tabular}{|c|c|c|c|}
\hline 5 Categories & 15 Categories & 44 Categories & $\begin{array}{l}\text { Green and blue } \\
\text { space }\end{array}$ \\
\hline \multirow[t]{11}{*}{ Artificial surfaces } & Urban fabric & Continuous urban fabric & / \\
\hline & & Discontinuous urban fabric & \\
\hline & $\begin{array}{l}\text { Industrial, commercial } \\
\text { and transport units }\end{array}$ & Industrial or commercial units & \\
\hline & & $\begin{array}{l}\text { Road and rail networks and asso- } \\
\text { ciated land }\end{array}$ & \\
\hline & & Port areas & \\
\hline & & Airports & \\
\hline & $\begin{array}{l}\text { Mine, dump and con- } \\
\text { struction sites }\end{array}$ & Mineral extraction sites & \\
\hline & & Dump sites & \\
\hline & & Construction sites & \\
\hline & $\begin{array}{l}\text { Artificial, non-agricultur- } \\
\text { al vegetated areas }\end{array}$ & Green urban areas & \\
\hline & & Sport and leisure facilities & \\
\hline \multirow[t]{11}{*}{ Agricultural areas } & Arable land & Non-irrigated arable land & Green space \\
\hline & & Permanently irrigated land & \\
\hline & & Rice fields & \\
\hline & Permanent crops & Vineyards & \\
\hline & & Fruit trees and berry plantations & \\
\hline & & Olive groves & \\
\hline & Pastures & Pastures & \\
\hline & $\begin{array}{l}\text { Heterogeneous agricul- } \\
\text { tural areas }\end{array}$ & $\begin{array}{l}\text { Annual crops associated with } \\
\text { permanent crops }\end{array}$ & \\
\hline & & Complex cultivation patterns & \\
\hline & & $\begin{array}{l}\text { Land principally occupied by } \\
\text { agriculture, with significant areas } \\
\text { of natural vegetation }\end{array}$ & \\
\hline & & Agro-forestry areas & \\
\hline \multirow{7}{*}{$\begin{array}{l}\text { Forest and semi } \\
\text { natural areas }\end{array}$} & Forests & Broad-leaved forest & Green space \\
\hline & & Coniferous forest & \\
\hline & & Mixed forest & \\
\hline & $\begin{array}{l}\text { Scrub and/or herbaceous } \\
\text { vegetation associations }\end{array}$ & Natural grasslands & Green space \\
\hline & & Moors and heathland & \\
\hline & & Sclerophyllous vegetation & \\
\hline & & Transitional woodland-shrub & \\
\hline
\end{tabular}




\begin{tabular}{|c|c|c|c|}
\hline 5 Categories & 15 Categories & 44 Categories & $\begin{array}{l}\text { Green and blue } \\
\text { space }\end{array}$ \\
\hline & $\begin{array}{l}\text { Open spaces with little } \\
\text { or no vegetation }\end{array}$ & Beaches, dunes, sands & / \\
\hline & & Bare rocks & \\
\hline & & Sparsely vegetated areas & \\
\hline & & Burnt areas & \\
\hline & & Glaciers and perpetual snow & \\
\hline \multirow[t]{5}{*}{ Wetlands } & Inland wetlands & Inland marshes & Green space \\
\hline & & Peat bogs & \\
\hline & Maritime wetlands & Salt marshes & Green space \\
\hline & & Salines & \\
\hline & & Intertidal flats & \\
\hline \multirow[t]{5}{*}{ Water bodies } & Inland waters & Water courses & Blue space \\
\hline & & Water bodies & \\
\hline & Marine waters & Coastal lagoons & Blue space \\
\hline & & Estuaries & \\
\hline & & Sea and ocean & \\
\hline
\end{tabular}

\subsubsection{Summary statistics}

Presented here are summary statistics of the data used in our study (Table A.III-3 and Table A.III-4).

Table A.III-3: Summary statistics for continuous variables on NUTS region and individual level $(\mathrm{n}=$ 26,749).

\begin{tabular}{lcccc} 
Variable & Min. & Median & Mean & Max. \\
\hline \hline NUTS region level & & & & 170.6 \\
\hline Bird species richness & 67.67 & 136.08 & 133.1 & 55.71 \\
Mammals (all) species richness & 7.84 & 39.02 & 37.95 & 29.85 \\
Mammal (no bats) species & 2.96 & 21.6 & 20.56 & 4.93 \\
richness & & & & \\
Megafauna (>44kg) species & 0 & 3 & 2.93 & 20.77 \\
richness & & & 14.69 & 53.31 \\
Megafauna (>0.5kg) species & 0.95 & 15.75 & & 2.04 \\
richness & 1 & & 19.67 & 3578.66 \\
Tree species richness & 0.97 & 1.44 & 1.44 & 97.85 \\
Landscape heterogeneity & 13.63 & 432.57 & 574.6 & 14.65 \\
Topographic heterogeneity & 13.4 & 92.25 & 87.38 & 82.13 \\
Green space cover $(\%)$ & 0 & 0.99 & 2.05 & 358.2 \\
Blue space cover $(\%)$ & 0.71 & 19.68 & 25.04 & 5863.58 \\
Protected area cover (\%) & 0 & 14.08 & 42.39 & 68600 \\
Cooling degree days & 315.72 & 2555 & 2561 & 25347 \\
Heating degree days & 7400 & 23300 & & \\
GDP per capita (PPS) & & & & \\
& & & & \\
\hline \hline
\end{tabular}




\begin{tabular}{lcccc} 
Variable & Min. & Median & Mean & Max. \\
\hline \hline Unemployment rate (\%) & 2.7 & 8.93 & 9.99 & 30.1 \\
NUTS region area size (km2) & 163.17 & 15429 & 25693 & 227106.65 \\
Individual level & & & & \\
\hline Life-satisfaction & 1 & 7 & 7.03 & 10 \\
$\begin{array}{l}\text { Mean of categorical net house- } \\
\text { hold income (EUR) }\end{array}$ & 25 & 1237 & 1708 & 5500 \\
Age & 18 & 51 & 51.14 & 95 \\
\hline \hline
\end{tabular}

Table A.III-4: Summary statistics for categorical and dummy variables $(\mathrm{n}=26,749)$.

Variables

\begin{tabular}{lll} 
Variables & n & Percent (\%) \\
\hline Categorical variables & & \\
\hline Recreation access: great difficulty & 749 & 2.8 \\
Recreation access: with some difficulty & 2323 & 8.7 \\
Recreation access: easily & 11008 & 41.2 \\
Recreation access: very easily & 10586 & 39.6 \\
Recreation access: service not used & 2083 & 7.8 \\
Education: primary or less & 2987 & 11.2 \\
Education: secondary & 17409 & 65.1 \\
Education: tertiary & 6353 & 23.8 \\
Health: very good & 5283 & 19.8 \\
Health: good & 10136 & 37.9 \\
Health: fair & 8085 & 30.2 \\
Health: bad & 2505 & 9.4 \\
Health: very bad & 740 & 2.8 \\
Householdstructure: single & 6808 & 25.5 \\
Householdstructure: couple & 7834 & 29.3 \\
Householdstructure: single parent & 988 & 3.7 \\
Householdstructure: couple with child & 5525 & 20.7 \\
Householdstructure: other household & 5594 & 20.9 \\
Employmentstatus: employed & 12245 & 45.8 \\
Employmentstatus: unemployed & 1985 & 7.4 \\
Employmentstatus: unable & 652 & 2.4 \\
Employmentstatus: retired & 8858 & 33.1 \\
Employmentstatus: homemaker & 1597 & 6 \\
Employmentstatus: student & 1057 & 4 \\
Employmentstatus: other & 355 & 26.2 \\
Volunteering: does not volunteer & 18179 & 68 \\
Volunteering: volunters occasionally & 5646 & 21.1 \\
Volunteering: volunteers regularly & 2924 & 10.9 \\
Dummy variables & & \\
\hline Male & $0(\%)$ & 42.9 \\
Coastline & 57.1 & \\
Urban & 49.1 & \\
Eastern Europe & & \\
\hline
\end{tabular}




\subsubsection{Variation within and between NUTS regions}

I examined how much our species richness data varied within NUTS region and determined for each species group whether the within-region variance was a major factor explaining the overall variation of species richness across Europe (between-region variance).

I took species diversity values intersecting with NUTS regions from the 50x50km grid (see Methods) and performed simple ANOVAs with species richness as the response variable and the NUTS regions as factor variable. I used only species diversity values (intersecting grid polygons) that covered at least $1 \%$ of the NUTS region area. Data from Kosovo, Serbia, Turkey, Iceland, Cyprus, Malta, Macedonia and Montenegro were also removed. Based on the ANOVA results I then calculated the percentage of overall variance explained by the within- and the between-region variation by dividing the between-regions and residual sum of squares with the total sum of squares.

The results indicate that a major part of the total variance of species richness across Europe is driven by the between-region variance and not the within-region variance (Table A.III-5).

Table A.III-5: ANOVA results and percentage of variance explained by within- and between-region variance of species richness. Degrees of freedom (Df) are different for the taxonomic groups because the respective bird, mammal and tree species richness values (grid data) have varying numbers of missing values.

\begin{tabular}{|c|c|c|c|c|c|c|}
\hline & Df & $\begin{array}{l}\text { Sum of } \\
\text { Sq. }\end{array}$ & Mean Sq. & F-value & p-value & $\begin{array}{c}\text { Percent } \\
\text { explained }\end{array}$ \\
\hline \multicolumn{7}{|l|}{ Bird species richness } \\
\hline NUTS region (between) & 228 & 1171878.3 & 5139.82 & 18.36 & $<0.001$ & 61.42 \\
\hline Residuals (within) & 2630 & 736175.8 & 279.91 & - & - & 38.58 \\
\hline \multicolumn{7}{|l|}{$\begin{array}{l}\text { Mammal species rich- } \\
\text { ness }\end{array}$} \\
\hline NUTS region (between) & 229 & 274540.3 & 1198.87 & 85.58 & $<0.001$ & 88.08 \\
\hline Residuals (within) & 2651 & 37139.2 & 14.01 & - & - & 11.92 \\
\hline \multicolumn{7}{|l|}{$\begin{array}{l}\text { Mammal species rich- } \\
\text { ness (no bats) }\end{array}$} \\
\hline NUTS region (between) & 229 & 58597.08 & 255.88 & 49.3 & $<0.001$ & 80.98 \\
\hline Residuals (within) & 2651 & 13759.84 & 5.19 & - & - & 19.02 \\
\hline \multicolumn{7}{|l|}{$\begin{array}{l}\text { Megafauna species rich- } \\
\text { ness }(>44 \mathrm{~kg})\end{array}$} \\
\hline NUTS region (between) & 229 & 2573.08 & 11.24 & 34.67 & $<0.001$ & 74.97 \\
\hline Residuals (within) & 2651 & 859.04 & 0.32 & - & - & 25.03 \\
\hline \multicolumn{7}{|l|}{$\begin{array}{l}\text { Megafauna species rich- } \\
\text { ness }(>0.5 \mathrm{~kg})\end{array}$} \\
\hline NUTS region (between) & 229 & 32773.4 & 143.12 & 46.33 & $<0.001$ & 80.01 \\
\hline
\end{tabular}




\begin{tabular}{lcccccc} 
& Df & $\begin{array}{c}\text { Sum of } \\
\text { Sq. }\end{array}$ & Mean Sq. & F-value & p-value & $\begin{array}{c}\text { Percent } \\
\text { explained }\end{array}$ \\
\hline \hline $\begin{array}{l}\text { Residuals (within) } \\
\text { Tree species richness }\end{array}$ & 2651 & 8189.71 & 3.09 & - & - & 19.99 \\
NUTS region (between) & 228 & 242328.4 & 1062.84 & 20.55 & $<0.001$ & 65.45 \\
Residuals (within) & 2473 & 127935.1 & 51.73 & - & - & 34.55 \\
\hline \hline
\end{tabular}




\subsubsection{Results for OLS models with log-linear specification of species richness}

\section{Multi-taxon models}

Here I present the results for the multi-taxon models calculated with ordinary least squares (OLS) and the ordered logistic regression models (oLogit). All species richness variables have a log-linear specification.

Table A.III-6: Model results for the multi-taxon OLS models with clustered standard errors and different sets of log-transformed species richness predictor variables (OLS 1: all mammals, OLS 2: mammals (no bats), OLS 3; megafauna $>44 \mathrm{~kg}$, OLS 4: megafauna $>0.5 \mathrm{~kg}$ ). The OLS models contain the mean of the categorical net household income variable (Table A.III-1), socio-economic and macro-economic control variables (see Methods for more details). Shown are coefficients, standard errors, t-values and p-values as asterisk symbols. Response variable $=$ life-satisfaction. Asterisks: $*=\mathrm{p}<0.05 ; * *=\mathrm{p}<0.01 ; * * *=\mathrm{p}<0.001$.

\begin{tabular}{|c|c|c|c|c|}
\hline Predictor variables & OLS 1 & OLS 2 & OLS 3 & OLS 4 \\
\hline \multicolumn{5}{|l|}{ Species richness } \\
\hline \multirow[t]{3}{*}{ Log bird species richness } & 0.55 & 0.55 & 0.57 & 0.53 \\
\hline & 0.26 & 0.25 & 0.28 & 0.26 \\
\hline & $2.12 *$ & $2.17 *$ & $2.05^{*}$ & $2.06^{*}$ \\
\hline \multirow[t]{3}{*}{ Log mammal species richness (all) } & -0.11 & - & - & - \\
\hline & 0.11 & & & \\
\hline & -0.97 & & & \\
\hline \multirow{3}{*}{$\begin{array}{l}\text { Log mammal species richness (no } \\
\text { bats) }\end{array}$} & - & -0.1 & - & - \\
\hline & & 0.08 & & \\
\hline & & -1.25 & & \\
\hline \multirow{3}{*}{$\begin{array}{l}\text { Log megafauna species richness } \\
(>44 \mathrm{~kg})\end{array}$} & - & - & -0.07 & - \\
\hline & & & 0.1 & \\
\hline & & & -0.68 & \\
\hline \multirow{3}{*}{$\begin{array}{l}\text { Log megafauna species richness } \\
(>0.5 \mathrm{~kg})\end{array}$} & - & - & - & -0.03 \\
\hline & & & & 0.05 \\
\hline & & & & -0.57 \\
\hline \multirow[t]{3}{*}{ Log tree species richness } & -0.01 & -0.01 & -0.02 & -0.02 \\
\hline & 0.1 & 0.1 & 0.1 & 0.1 \\
\hline & -0.03 & -0.05 & -0.12 & -0.13 \\
\hline \multicolumn{5}{|l|}{ Other nature characteristics } \\
\hline \multirow[t]{3}{*}{ Landscape heterogeneity } & -0.19 & -0.19 & -0.19 & -0.19 \\
\hline & 0.23 & 0.23 & 0.23 & 0.23 \\
\hline & -0.82 & -0.84 & -0.81 & -0.8 \\
\hline \multirow[t]{3}{*}{ Topographic heterogeneity } & 0.01 & 0.01 & 0.01 & 0.01 \\
\hline & 0.01 & 0.01 & 0.01 & 0.01 \\
\hline & 0.18 & 0.17 & 0.14 & 0.11 \\
\hline \multirow[t]{3}{*}{ Green space cover } & -0.01 & -0.01 & -0.01 & -0.01 \\
\hline & 0.01 & 0.01 & 0.01 & 0.01 \\
\hline & -0.24 & -0.23 & -0.2 & -0.21 \\
\hline
\end{tabular}




\begin{tabular}{|c|c|c|c|c|}
\hline Predictor variables & OLS 1 & OLS 2 & OLS 3 & OLS 4 \\
\hline \multirow[t]{3}{*}{ Blue space cover } & -0.02 & -0.02 & -0.02 & -0.02 \\
\hline & 0.02 & 0.02 & 0.02 & 0.02 \\
\hline & -0.78 & -0.76 & -0.72 & -0.73 \\
\hline \multirow[t]{3}{*}{ Coastline } & -0.01 & -0.01 & -0.02 & -0.01 \\
\hline & 0.06 & 0.06 & 0.07 & 0.06 \\
\hline & -0.14 & -0.12 & -0.19 & -0.09 \\
\hline \multirow[t]{3}{*}{ Protected area cover } & 0.01 & 0.01 & 0.01 & -0.01 \\
\hline & 0.01 & 0.01 & 0.01 & 0.06 \\
\hline & 0.68 & 0.7 & 0.69 & -0.09 \\
\hline \multicolumn{5}{|l|}{ Climate } \\
\hline \multirow[t]{3}{*}{ Cooling degree days } & 0.01 & 0.01 & 0.01 & 0.01 \\
\hline & 0.01 & 0.01 & 0.01 & 0.01 \\
\hline & 1.73 & 1.68 & 1.66 & 1.66 \\
\hline \multicolumn{5}{|l|}{ Socio-economic variables } \\
\hline Recreation access: great difficulty & \multicolumn{4}{|c|}{ Reference group } \\
\hline \multirow{3}{*}{$\begin{array}{l}\text { Recreation access: with some diffi- } \\
\text { culty }\end{array}$} & 0.03 & 0.03 & 0.03 & 0.03 \\
\hline & 0.17 & 0.17 & 0.17 & 0.17 \\
\hline & 0.13 & 0.13 & 0.14 & 0.13 \\
\hline \multirow[t]{3}{*}{ Recreation access: easily } & 0.33 & 0.33 & 0.33 & 0.33 \\
\hline & 0.16 & 0.16 & 0.16 & 0.16 \\
\hline & $2.13 *$ & $2.13 *$ & $2.14^{*}$ & $2.13 *$ \\
\hline \multirow[t]{3}{*}{ Recreation access: very easily } & 0.54 & 0.54 & 0.54 & 0.54 \\
\hline & 0.16 & 0.16 & 0.16 & 0.16 \\
\hline & $3.58 * * *$ & $3.58 * * *$ & $3.58 * * *$ & $3.58 * * *$ \\
\hline \multirow[t]{3}{*}{ Recreation access: service not used } & 0.09 & 0.09 & 0.09 & 0.09 \\
\hline & -0.16 & -0.16 & -0.16 & -0.16 \\
\hline & 0.53 & 0.53 & 0.54 & 0.53 \\
\hline \multirow[t]{3}{*}{ Log net household income } & 0.36 & 0.36 & 0.36 & 0.36 \\
\hline & 0.03 & 0.03 & 0.03 & 0.03 \\
\hline & $12.09 * * *$ & $12.09 * * *$ & $12.09 * * *$ & $12.09 * * *$ \\
\hline \multirow[t]{3}{*}{ Age } & -0.05 & -0.05 & -0.05 & -0.05 \\
\hline & 0.01 & 0.01 & 0.01 & 0.01 \\
\hline & $-9.08 * * *$ & $-9.08 * * *$ & $-9.08 * * *$ & $-9.08 * * *$ \\
\hline \multirow[t]{3}{*}{ Age-squared } & 0.01 & 0.01 & 0.01 & 0.01 \\
\hline & 0.01 & 0.01 & 0.01 & 0.01 \\
\hline & $10.12 * * *$ & $10.12 * * *$ & $10.11 * * *$ & $10.12 * * *$ \\
\hline \multirow[t]{3}{*}{ Male } & -0.1 & -0.1 & -0.1 & -0.1 \\
\hline & 0.03 & 0.03 & 0.03 & 0.03 \\
\hline & $-3.98 * * *$ & $-3.98 * * *$ & $-3.99 * * *$ & $-3.99 * * *$ \\
\hline \multirow[t]{3}{*}{ Urban } & -0.17 & -0.17 & -0.17 & -0.17 \\
\hline & 0.04 & 0.04 & 0.04 & 0.04 \\
\hline & $-4.31 * * *$ & $-4.30 * * *$ & $-4.30 * * *$ & $-4.30 * * *$ \\
\hline
\end{tabular}




\begin{tabular}{|c|c|c|c|c|}
\hline Predictor variables & OLS 1 & OLS 2 & OLS 3 & OLS 4 \\
\hline Education: primary or less & \multicolumn{4}{|c|}{ Reference group } \\
\hline \multirow[t]{3}{*}{ Education: secondary } & 0.05 & 0.05 & 0.05 & 0.05 \\
\hline & 0.05 & 0.05 & 0.05 & 0.05 \\
\hline & 0.87 & 0.87 & 0.86 & 0.87 \\
\hline \multirow[t]{3}{*}{ Education: tertiary } & 0.19 & 0.19 & 0.19 & 0.19 \\
\hline & 0.06 & 0.06 & 0.06 & 0.06 \\
\hline & $3.52 * * *$ & $3.51 * * *$ & $3.53 * *$ & $3.53 * * *$ \\
\hline Health: very bad & \multicolumn{4}{|c|}{ Reference group } \\
\hline \multirow[t]{3}{*}{ Health: bad } & 0.8 & 0.79 & 0.8 & 0.79 \\
\hline & 0.11 & 0.11 & 0.11 & 0.11 \\
\hline & $7.81 * * *$ & $7.81 * * *$ & $7.81 * * *$ & $7.81 * * *$ \\
\hline \multirow[t]{3}{*}{ Health: fair } & 1.64 & 1.64 & 1.64 & 1.64 \\
\hline & 0.11 & 0.11 & 0.11 & 0.11 \\
\hline & $15.91 * * *$ & $15.9 * * *$ & $15.9 * * *$ & $15.9 * * *$ \\
\hline \multirow[t]{3}{*}{ Health: good } & 2.11 & 2.11 & 2.11 & 2.11 \\
\hline & 0.11 & 0.11 & 0.11 & 0.11 \\
\hline & $19.43 * * *$ & $19.42 * * *$ & $19.43 * * *$ & $19.42 * * *$ \\
\hline \multirow[t]{3}{*}{ Health: very good } & 2.53 & 2.53 & 2.53 & 2.53 \\
\hline & 0.12 & 0.12 & 0.12 & 0.12 \\
\hline & $21.79 * * *$ & $21.78 * * *$ & $21.79 * * *$ & $21.79 * * *$ \\
\hline Householdstructure: single & \multicolumn{4}{|c|}{ Reference group } \\
\hline \multirow[t]{3}{*}{ Householdstructure: couple } & 0.24 & 0.24 & 0.24 & 0.24 \\
\hline & 0.05 & 0.05 & 0.05 & 0.05 \\
\hline & $5.63 * * *$ & $5.63 * * *$ & $5.63 * * *$ & $5.64 * * *$ \\
\hline \multirow[t]{3}{*}{ Householdstructure: single parent } & -0.38 & -0.38 & -0.38 & -0.38 \\
\hline & 0.08 & 0.08 & 0.08 & 0.08 \\
\hline & $-5.03 * * *$ & $-5.03 * * *$ & $-5.03 * * *$ & $-5.03 * * *$ \\
\hline \multirow{3}{*}{$\begin{array}{l}\text { Householdstructure: couple with } \\
\text { child }\end{array}$} & 0.21 & 0.21 & 0.21 & 0.21 \\
\hline & 0.05 & 0.05 & 0.05 & 0.05 \\
\hline & $4.15^{* * *}$ & $4.15^{* * *}$ & $4.16^{* * *}$ & $4.17 * * *$ \\
\hline \multirow[t]{3}{*}{ Householdstructure: other household } & -0.06 & -0.06 & -0.06 & -0.06 \\
\hline & 0.05 & 0.05 & 0.05 & 0.05 \\
\hline & -1.05 & -1.05 & -1.05 & -1.05 \\
\hline Employmentstatus: employed & \multicolumn{4}{|c|}{ Reference group } \\
\hline \multirow[t]{3}{*}{ Employmentstatus: unemployed } & -0.83 & -0.83 & -0.83 & -0.83 \\
\hline & 0.07 & 0.07 & 0.07 & 0.07 \\
\hline & $-13.14 * * *$ & $-13.13 * * *$ & $-13.14 * * *$ & $-13.14 * * *$ \\
\hline \multirow[t]{3}{*}{ Employmentstatus: unable } & -0.24 & -0.24 & -0.24 & -0.24 \\
\hline & 0.11 & 0.11 & 0.11 & 0.11 \\
\hline & $-2.16^{*}$ & $-2.16^{*}$ & $-2.16^{*}$ & $-2.16^{*}$ \\
\hline \multirow[t]{3}{*}{ Employmentstatus: retired } & 0.16 & 0.16 & 0.16 & 0.16 \\
\hline & 0.06 & 0.06 & 0.06 & 0.06 \\
\hline & $2.85 * *$ & $2.86 * *$ & $2.86^{* *}$ & $2.85 * *$ \\
\hline
\end{tabular}




\begin{tabular}{|c|c|c|c|c|}
\hline Predictor variables & OLS 1 & OLS 2 & OLS 3 & OLS 4 \\
\hline \multirow[t]{3}{*}{ Employmentstatus: homemaker } & -0.08 & -0.08 & -0.08 & -0.08 \\
\hline & 0.07 & 0.07 & 0.07 & 0.07 \\
\hline & -1.13 & -1.14 & -1.14 & -1.13 \\
\hline \multirow[t]{3}{*}{ Employmentstatus: student } & 0.22 & 0.22 & 0.22 & 0.22 \\
\hline & 0.07 & 0.07 & 0.07 & 0.07 \\
\hline & $3.16 * *$ & $3.16 * *$ & $3.16 * *$ & $3.17 * *$ \\
\hline \multirow[t]{3}{*}{ Employmentstatus: other } & -0.15 & -0.15 & -0.15 & -0.15 \\
\hline & 0.11 & 0.11 & 0.11 & 0.11 \\
\hline & -1.33 & -1.33 & -1.34 & -1.33 \\
\hline Volunteering: does not volunteer & \multicolumn{4}{|c|}{ Reference group } \\
\hline \multirow[t]{3}{*}{ Volunteering: volunters occasionally } & 0.08 & 0.08 & 0.08 & 0.08 \\
\hline & 0.04 & 0.04 & 0.04 & 0.04 \\
\hline & $2.08 *$ & $2.08 *$ & $2.08 *$ & $2.08 *$ \\
\hline \multirow[t]{3}{*}{ Volunteering: volunteers regularly } & 0.19 & 0.19 & 0.19 & 0.19 \\
\hline & 0.04 & 0.04 & 0.04 & 0.04 \\
\hline & $5.2 * * *$ & $5.2 * * *$ & $5.19 * * *$ & $5.19 * * *$ \\
\hline \multicolumn{5}{|l|}{ Macro-economic variables } \\
\hline \multirow[t]{3}{*}{ Unemploymentrate } & -0.03 & -0.03 & -0.03 & -0.03 \\
\hline & 0.02 & 0.02 & 0.02 & 0.02 \\
\hline & $-2.03 *$ & $-2.03^{*}$ & $-1.99 *$ & $-1.98^{*}$ \\
\hline \multirow[t]{3}{*}{ GDP per capita (PPS) } & -0.01 & -0.01 & -0.01 & -0.01 \\
\hline & 0.01 & 0.01 & 0.01 & 0.01 \\
\hline & -1.24 & -1.22 & -1.15 & -1.15 \\
\hline \multirow[t]{3}{*}{ Eastern Europe } & -0.72 & -0.72 & -0.76 & -0.76 \\
\hline & 0.19 & 0.18 & 0.18 & 0.18 \\
\hline & $-3.91 * * *$ & $-4.09 * * *$ & $-4.42 * * *$ & $-4.33 * * *$ \\
\hline \multirow[t]{3}{*}{ NUTS region area size } & 0.01 & 0.01 & 0.01 & 0.01 \\
\hline & 0.01 & 0.01 & 0.01 & 0.01 \\
\hline & 0.14 & 0.3 & 0.32 & 0.28 \\
\hline \multirow[t]{3}{*}{ Constant } & 1.57 & 1.48 & 1.22 & 1.4 \\
\hline & 1.41 & 1.42 & 1.49 & 1.43 \\
\hline & 1.12 & 1.05 & 0.83 & 0.99 \\
\hline Country dummies & yes & yes & yes & yes \\
\hline Observations & 26,749 & 26,749 & 26,749 & 26,749 \\
\hline $\mathrm{AIC}$ & 109860.2 & 109859.6 & 109860.4 & 109860.9 \\
\hline $\mathrm{BIC}$ & 110409.2 & 110408.6 & 110409.4 & 110409.9 \\
\hline LogLik & -54863.12 & -54862.81 & -54863.21 & -54863.46 \\
\hline Adjusted R-squared & 0.24 & 0.24 & 0.24 & 0.24 \\
\hline
\end{tabular}

$\mathrm{AIC}=$ Akaike Information Criterion, $\mathrm{BIC}=$ Bayesian Information Criterion 
Table A.III-7: Model results for the ordered logit regressions models with clustered standard errors and different sets of log-transformed species richness predictor variables (oLogit 1: all mammals, oLogit 2: mammals (no bats), oLogit 3; megafauna $>44 \mathrm{~kg}$, oLogit 4 : megafauna $>0.5 \mathrm{~kg}$ ). The ordered logit models contain the mean of the categorical net household income variable (Table A.III-1), socio-economic and macro-economic control variables (see Methods for more details). Shown are coefficients, standard errors, Wald z-scores and p-values as asterisk symbols. Response variable $=$ life-satisfaction. Asterisks: * $=$ $\mathrm{p}<0.05 ; * *=\mathrm{p}<0.01 ; * * *=\mathrm{p}<0.001$.

\begin{tabular}{|c|c|c|c|c|}
\hline Predictor variables & oLogit 1 & oLogit 2 & oLogit 3 & oLogit 4 \\
\hline \multicolumn{5}{|l|}{ Species richness } \\
\hline \multirow[t]{3}{*}{ Log bird species richness } & 0.49 & 0.45 & 0.48 & 0.46 \\
\hline & 0.23 & 0.23 & 0.24 & 0.22 \\
\hline & $2.16^{*}$ & $1.99 *$ & $1.95 *$ & $2.07 *$ \\
\hline \multirow[t]{3}{*}{ Log mammal species richness (all) } & -0.18 & - & - & - \\
\hline & 0.11 & & & \\
\hline & -1.61 & & & \\
\hline \multirow{3}{*}{$\begin{array}{l}\text { Log mammal species richness (no } \\
\text { bats) }\end{array}$} & - & -0.19 & - & - \\
\hline & & 0.08 & & \\
\hline & & $-2.26^{*}$ & & \\
\hline \multirow{3}{*}{$\begin{array}{l}\text { Log megafauna species richness } \\
(>44 \mathrm{~kg})\end{array}$} & - & - & -0.06 & - \\
\hline & & & 0.09 & \\
\hline & & & -0.67 & \\
\hline \multirow{3}{*}{$\begin{array}{l}\text { Log megafauna species richness } \\
(>0.5 \mathrm{~kg})\end{array}$} & - & - & - & -0.06 \\
\hline & & & & 0.05 \\
\hline & & & & -1.22 \\
\hline \multirow[t]{3}{*}{ Log tree species richness } & -0.01 & 0.05 & -0.01 & -0.01 \\
\hline & 0.08 & 0.07 & 0.08 & 0.08 \\
\hline & -0.05 & 0.75 & -0.16 & -0.15 \\
\hline \multicolumn{5}{|l|}{ Other nature characteristics } \\
\hline \multirow[t]{3}{*}{ Landscape heterogeneity } & -0.11 & -0.13 & -0.11 & -0.11 \\
\hline & 0.19 & 0.2 & 0.2 & 0.19 \\
\hline & -0.58 & -0.67 & -0.54 & -0.56 \\
\hline \multirow[t]{3}{*}{ Topographic heterogeneity } & 0.01 & 0.01 & 0.01 & 0.01 \\
\hline & 0.01 & 0.01 & 0.01 & 0.001 \\
\hline & 0.38 & 0.3 & 0.24 & 0.24 \\
\hline \multirow[t]{3}{*}{ Green space cover } & -0.01 & -0.01 & 0.01 & 0.01 \\
\hline & 0.01 & 0.01 & 0.01 & 0.01 \\
\hline & -0.06 & -0.06 & 0.02 & 0.01 \\
\hline \multirow[t]{3}{*}{ Blue space cover } & -0.01 & -0.01 & -0.01 & -0.01 \\
\hline & 0.01 & 0.01 & 0.01 & 0.01 \\
\hline & -0.9 & -0.76 & -0.79 & -0.81 \\
\hline \multirow[t]{3}{*}{ Coastline } & 0.03 & 0.03 & 0.02 & 0.03 \\
\hline & 0.05 & 0.05 & 0.06 & 0.05 \\
\hline & 0.47 & 0.56 & 0.44 & 0.53 \\
\hline \multirow[t]{3}{*}{ Protected area cover } & 0.01 & 0.01 & 0.01 & 0.01 \\
\hline & 0.01 & 0.01 & 0.01 & 0.01 \\
\hline & 0.45 & 0.22 & 0.48 & 0.48 \\
\hline
\end{tabular}




\begin{tabular}{|c|c|c|c|c|}
\hline Predictor variables & oLogit 1 & oLogit 2 & oLogit 3 & oLogit 4 \\
\hline \multicolumn{5}{|l|}{ Climate } \\
\hline \multirow[t]{3}{*}{ Cooling degree days } & 0.01 & 0.01 & 0.01 & 0.01 \\
\hline & 0.01 & 0.01 & 0.01 & 0.01 \\
\hline & 1.81 & 1.6 & 1.68 & 1.69 \\
\hline \multicolumn{5}{|l|}{ Socio-economic variables } \\
\hline Recreation access: great difficulty & \multicolumn{4}{|c|}{ Reference group } \\
\hline \multirow{3}{*}{$\begin{array}{l}\text { Recreation access: with some diffi- } \\
\text { culty }\end{array}$} & -0.04 & -0.04 & -0.04 & -0.04 \\
\hline & 0.14 & 0.14 & 0.14 & 0.14 \\
\hline & -0.26 & -0.26 & -0.25 & -0.25 \\
\hline \multirow[t]{3}{*}{ Recreation access: easily } & 0.24 & 0.24 & 0.24 & 0.24 \\
\hline & 0.13 & 0.13 & 0.13 & 0.13 \\
\hline & 1.9 & 1.91 & 1.9 & 1.9 \\
\hline \multirow[t]{3}{*}{ Recreation access: very easily } & 0.45 & 0.44 & 0.45 & 0.44 \\
\hline & 0.13 & 0.12 & 0.13 & 0.13 \\
\hline & $3.57 * * *$ & $3.57 * * *$ & $3.58 * * *$ & $3.57 * * *$ \\
\hline \multirow[t]{3}{*}{ Recreation access: service not used } & 0.03 & 0.03 & 0.03 & 0.03 \\
\hline & 0.13 & 0.13 & 0.13 & 0.13 \\
\hline & 0.21 & 0.19 & 0.21 & 0.2 \\
\hline \multirow[t]{3}{*}{ Log net household income } & 0.33 & 0.33 & 0.33 & 0.33 \\
\hline & 0.03 & 0.03 & 0.03 & 0.03 \\
\hline & $11.90 * * *$ & $12.10 * * *$ & $11.90 * * *$ & $11.91 * * *$ \\
\hline \multirow[t]{3}{*}{ Age } & -0.04 & -0.05 & -0.04 & -0.04 \\
\hline & 0.01 & 0.01 & 0.01 & 0.01 \\
\hline & $-9.02 * * *$ & $-9.05 * * *$ & $-9.02 * * *$ & $-9.02 * * *$ \\
\hline \multirow[t]{3}{*}{ Age-squared } & 0.01 & 0.01 & 0.01 & 0.01 \\
\hline & 0.01 & 0.01 & 0.01 & 0.01 \\
\hline & $10.65 * * *$ & $10.67 * * *$ & $10.64 * * *$ & $10.65^{* * *}$ \\
\hline \multirow[t]{3}{*}{ Male } & -0.1 & -0.1 & -0.1 & -0.1 \\
\hline & 0.02 & 0.02 & 0.02 & 0.02 \\
\hline & $-4.45 * * *$ & $-4.43 * * *$ & $-4.47 * * *$ & $-4.46^{* * *}$ \\
\hline \multirow[t]{3}{*}{ Urban } & -0.15 & -0.15 & -0.15 & -0.15 \\
\hline & 0.04 & 0.04 & 0.04 & 0.04 \\
\hline & $-3.97 * * *$ & $-4.00 * * *$ & $-3.97 * * *$ & $-3.96 * * *$ \\
\hline Education: primary or less & \multicolumn{4}{|c|}{ Reference group } \\
\hline \multirow[t]{3}{*}{ Education: secondary } & 0.03 & 0.04 & 0.03 & 0.03 \\
\hline & 0.05 & 0.05 & 0.05 & 0.05 \\
\hline & 0.76 & 0.8 & 0.76 & 0.76 \\
\hline \multirow[t]{3}{*}{ Education: tertiary } & 0.13 & 0.132 & 0.132 & 0.13 \\
\hline & 0.05 & 0.05 & 0.05 & 0.05 \\
\hline & $2.64 * *$ & $2.66^{* *}$ & $2.67 * *$ & $2.65 * *$ \\
\hline Health: very bad & \multicolumn{4}{|c|}{ Reference group } \\
\hline \multirow[t]{3}{*}{ Health: bad } & 0.7 & 0.7 & 0.7 & 0.7 \\
\hline & 0.09 & 0.09 & 0.09 & 0.09 \\
\hline & $7.94 * * *$ & $7.93 * * *$ & $7.94 * * *$ & $7.94 * * *$ \\
\hline
\end{tabular}




\begin{tabular}{|c|c|c|c|c|}
\hline Predictor variables & oLogit 1 & oLogit 2 & oLogit 3 & oLogit 4 \\
\hline \multirow[t]{3}{*}{ Health: fair } & 1.5 & 1.5 & 1.5 & 1.5 \\
\hline & 0.09 & 0.09 & 0.09 & 0.09 \\
\hline & $16.00 * * *$ & $15.98 * * *$ & $15.99 * * *$ & $16.00 * * *$ \\
\hline \multirow[t]{3}{*}{ Health: good } & 1.97 & 1.98 & 1.97 & 1.97 \\
\hline & 0.1 & 0.1 & 0.1 & 0.1 \\
\hline & $19.68 * * *$ & $19.66 * * *$ & $19.68 * * *$ & $19.68 * * *$ \\
\hline \multirow[t]{3}{*}{ Health: very good } & 2.49 & 2.49 & 2.49 & 2.49 \\
\hline & 0.11 & 0.11 & 0.11 & 0.11 \\
\hline & $22.98 * * *$ & $22.94 * * *$ & $22.97 * * *$ & $22.97 * * *$ \\
\hline Householdstructure: single & \multicolumn{4}{|c|}{ Reference group } \\
\hline \multirow[t]{3}{*}{ Householdstructure: couple } & 0.26 & 0.26 & 0.26 & 0.26 \\
\hline & 0.04 & 0.04 & 0.04 & 0.04 \\
\hline & $6.51 * * *$ & $6.48 * * *$ & $6.52 * * *$ & $6.52 * * *$ \\
\hline \multirow[t]{3}{*}{ Householdstructure: single parent } & -0.33 & -0.33 & -0.33 & -0.33 \\
\hline & 0.07 & 0.07 & 0.07 & 0.07 \\
\hline & $-4.97 * * *$ & $-4.97 * * *$ & $-4.97 * * *$ & $-4.97 * * *$ \\
\hline \multirow{3}{*}{$\begin{array}{l}\text { Householdstructure: couple with } \\
\text { child }\end{array}$} & 0.23 & 0.23 & 0.23 & 0.23 \\
\hline & 0.05 & 0.05 & 0.05 & 0.05 \\
\hline & $5.05 * * *$ & $5.00 * * *$ & $5.09 * * *$ & $5.08 * * *$ \\
\hline \multirow[t]{3}{*}{ Householdstructure: other household } & -0.01 & -0.01 & -0.01 & -0.01 \\
\hline & 0.04 & 0.04 & 0.04 & 0.04 \\
\hline & -0.09 & -0.21 & -0.08 & -0.09 \\
\hline Employmentstatus: employed & \multicolumn{4}{|c|}{ Reference group } \\
\hline \multirow[t]{3}{*}{ Employmentstatus: unemployed } & -0.71 & -0.7 & -0.71 & -0.7 \\
\hline & 0.06 & 0.06 & 0.06 & 0.06 \\
\hline & $-11.83 * * *$ & $-11.75^{* * *}$ & $-11.83 * * *$ & $-11.83 * * *$ \\
\hline \multirow[t]{3}{*}{ Employmentstatus: unable } & -0.12 & -0.12 & -0.12 & -0.12 \\
\hline & 0.1 & 0.102 & 0.1 & 0.1 \\
\hline & -1.22 & -1.16 & -1.21 & -1.21 \\
\hline \multirow[t]{3}{*}{ Employmentstatus: retired } & 0.17 & 0.17 & 0.166 & 0.17 \\
\hline & 0.05 & 0.05 & 0.05 & 0.05 \\
\hline & $3.22 * *$ & $3.22 * *$ & $3.21 * *$ & $3.22 * *$ \\
\hline \multirow[t]{3}{*}{ Employmentstatus: homemaker } & 0.01 & 0.01 & 0.011 & 0.01 \\
\hline & 0.06 & 0.06 & 0.059 & 0.06 \\
\hline & 0.18 & 0.22 & 0.17 & 0.18 \\
\hline \multirow[t]{3}{*}{ Employmentstatus: student } & 0.2 & 0.2 & 0.2 & 0.2 \\
\hline & 0.06 & 0.06 & 0.062 & 0.06 \\
\hline & $3.26^{* *}$ & $3.27 * *$ & $3.26^{* *}$ & $3.26^{* *}$ \\
\hline \multirow[t]{3}{*}{ Employmentstatus: other } & -0.09 & -0.09 & -0.093 & -0.09 \\
\hline & 0.1 & 0.1 & 0.095 & 0.1 \\
\hline & -0.97 & -0.94 & -0.98 & -0.97 \\
\hline Volunteering: does not volunteer & \multicolumn{4}{|c|}{ Reference group } \\
\hline \multirow[t]{3}{*}{ Volunteering: volunters occasionally } & 0.06 & 0.06 & 0.06 & 0.06 \\
\hline & 0.03 & 0.03 & 0.03 & 0.03 \\
\hline & 1.76 & 1.76 & 1.77 & 1.77 \\
\hline
\end{tabular}




\begin{tabular}{|c|c|c|c|c|}
\hline Predictor variables & oLogit 1 & oLogit 2 & oLogit 3 & oLogit 4 \\
\hline \multirow[t]{3}{*}{ Volunteering: volunteers regularly } & 0.2 & 0.2 & 0.2 & 0.2 \\
\hline & 0.03 & 0.03 & 0.03 & 0.03 \\
\hline & $5.96 * * *$ & $5.99 * * *$ & $5.94 * * *$ & $5.94 * * *$ \\
\hline \multicolumn{5}{|l|}{ Macro-economic variables } \\
\hline \multirow[t]{3}{*}{ Unemploymentrate } & -0.02 & -0.02 & -0.02 & -0.02 \\
\hline & 0.01 & 0.01 & 0.01 & 0.01 \\
\hline & $-2.03 *$ & $-2.01 *$ & -1.92 & -1.93 \\
\hline \multirow[t]{3}{*}{ GDP per capita (PPS) } & 0.01 & 0.01 & 0.01 & 0.01 \\
\hline & 0.01 & 0.01 & 0.01 & 0.01 \\
\hline & -1.25 & -1.27 & -1.05 & -1.09 \\
\hline \multirow[t]{3}{*}{ Eastern Europe } & -0.67 & -0.61 & -0.75 & -0.74 \\
\hline & 0.16 & 0.14 & 0.15 & 0.15 \\
\hline & $-4.12 * * *$ & $-4.46 * * *$ & $-4.99 * * *$ & $-4.81 * * *$ \\
\hline \multirow[t]{3}{*}{ NUTS region area size } & 0.01 & 0.01 & 0.01 & 0.01 \\
\hline & 0.01 & 0.01 & 0.01 & 0.01 \\
\hline & -0.11 & 0.25 & 0.24 & 0.2 \\
\hline \multirow[t]{3}{*}{$y>=2$} & -0.66 & -0.75 & -1.1 & -0.96 \\
\hline & 1.23 & 1.27 & 1.3 & 1.24 \\
\hline & -0.54 & -0.59 & -0.84 & -0.77 \\
\hline \multirow[t]{3}{*}{$y>=3$} & -1.35 & -1.44 & -1.79 & -1.65 \\
\hline & 1.22 & 1.26 & 1.29 & 1.23 \\
\hline & -1.11 & -1.14 & -1.38 & -1.34 \\
\hline \multirow[t]{3}{*}{$y>=4$} & -2.07 & -2.15 & -2.5 & -2.37 \\
\hline & 1.22 & 1.25 & 1.29 & 1.23 \\
\hline & -1.7 & -1.72 & -1.94 & -1.92 \\
\hline \multirow[t]{3}{*}{$y>=5$} & -2.6 & -2.68 & -3.03 & -2.89 \\
\hline & 1.22 & 1.26 & 1.29 & 1.23 \\
\hline & $-2.13^{*}$ & $-2.14 *$ & $-2.35^{*}$ & $-2.35^{*}$ \\
\hline \multirow[t]{3}{*}{$y>=6$} & -3.53 & -3.62 & -3.97 & -3.83 \\
\hline & 1.22 & 1.26 & 1.29 & 1.23 \\
\hline & $-2.90 * *$ & $-2.88 * *$ & $-3.07 * *$ & $-3.11 * *$ \\
\hline \multirow[t]{3}{*}{$y>=7$} & -4.13 & -4.22 & -4.57 & -4.43 \\
\hline & 1.22 & 1.26 & 1.29 & 1.24 \\
\hline & $-3.38 * * *$ & $-3.35 * * *$ & $-3.53 * * *$ & $-3.59 * * *$ \\
\hline \multirow[t]{3}{*}{$y>=8$} & -5.02 & -5.108 & -5.46 & -5.32 \\
\hline & 1.23 & 1.26 & 1.3 & 1.24 \\
\hline & $-4.10 * * *$ & $-4.05 * * *$ & $-4.21 * * *$ & $-4.30 * * *$ \\
\hline \multirow[t]{3}{*}{$y>=9$} & -6.33 & -6.42 & -6.77 & -6.63 \\
\hline & 1.23 & 1.26 & 1.3 & 1.24 \\
\hline & $-5.16 * * *$ & $-5.08 * * *$ & $-5.22 * * *$ & $-5.35 * * *$ \\
\hline \multirow[t]{3}{*}{$y>=10$} & -7.31 & -7.4 & -7.75 & -7.61 \\
\hline & 1.23 & 1.27 & 1.3 & 1.24 \\
\hline & $-5.95 * * *$ & $-5.84 * * *$ & $-5.96 * * *$ & $-6.13 * * *$ \\
\hline
\end{tabular}




\begin{tabular}{lcccc} 
Predictor variables & oLogit $\mathbf{1}$ & oLogit $\mathbf{2}$ & oLogit 3 & oLogit 4 \\
\hline \hline Country dummies & yes & yes & yes & yes \\
Observations & 26,749 & 26,749 & 26,749 & 26,749 \\
AIC & 102700.6 & 102700.6 & 102702.8 & 102702.3 \\
BIC & 103307 & 103298.8 & 103309.2 & 103308.7 \\
LogLik & -51276.29 & -51277.32 & -51277.4 & -51277.15 \\
Nagelkerke R-squared & 0.25 & 0.25 & 0.25 & 0.25 \\
\hline
\end{tabular}

$\mathrm{AIC}=$ Akaike Information Criterion, $\mathrm{BIC}=$ Bayesian Information Criterion 


\section{Single-taxon models}

Here I present the results for the single-taxon models calculated with ordinary least squares (OLS) and ordered logistic regression models (oLogit). All species richness variables are log-transformed. I only show detailed results for selected predictor variables: species richness, other nature characteristics, climate and access to local recreational areas. Socio-economic variables and other explanatory variables are the same as in the multi-taxon models.

Table A.III-8: Model results for the single-taxon OLS regressions with clustered standard errors and a single log-transformed species richness predictor (OLS 1: birds, OLS 2: all mammals, OLS 3: mammals (no bats), OLS 4; megafauna $>44 \mathrm{~kg}$, OLS 5: megafauna $>0.5 \mathrm{~kg}$, OLS 6: trees). The OLS models contain the mean of the categorical net household income variable (Table A.III-1), socio-economic and macro-economic control variables (see Methods for more details). Shown are coefficients, standard errors, t-values and $\mathrm{p}$-values as asterisk symbols. Response variable $=$ life-satisfaction. Asterisks: $*=\mathrm{p}<0.05 ; * *=\mathrm{p}<0.01$; $* * *=\mathrm{p}<0.001$.

\begin{tabular}{|c|c|c|c|c|c|c|}
\hline Predictor variables & OLS 1 & OLS 2 & OLS 3 & OLS 4 & OLS 5 & OLS 6 \\
\hline \multicolumn{7}{|l|}{ Species richness } \\
\hline \multirow[t]{3}{*}{ Log bird species richness } & 0.5 & - & - & - & - & - \\
\hline & 0.24 & & & & & \\
\hline & $2.07 *$ & & & & & \\
\hline \multirow{3}{*}{$\begin{array}{l}\text { Log mammal species rich- } \\
\text { ness (all) }\end{array}$} & - & 0.03 & - & - & - & - \\
\hline & & 0.11 & & & & \\
\hline & & 0.27 & & & & \\
\hline \multirow{3}{*}{$\begin{array}{l}\text { Log mammal species rich- } \\
\text { ness (no bats) }\end{array}$} & - & - & -0.03 & - & - & - \\
\hline & & & 0.07 & & & \\
\hline & & & -0.35 & & & \\
\hline \multirow{3}{*}{$\begin{array}{l}\text { Log megafauna species } \\
\text { richness }(>44 \mathrm{~kg})\end{array}$} & - & - & - & 0.06 & - & - \\
\hline & & & & 0.08 & & \\
\hline & & & & 0.66 & & \\
\hline \multirow{3}{*}{$\begin{array}{l}\text { Log megafauna species } \\
\text { richness }(>0.5 \mathrm{~kg})\end{array}$} & - & - & - & - & 0.03 & - \\
\hline & & & & & 0.04 & \\
\hline & & & & & 0.7 & \\
\hline \multirow[t]{3}{*}{ Log tree species richness } & - & - & - & - & - & 0.07 \\
\hline & & & & & & 0.1 \\
\hline & & & & & & 0.69 \\
\hline \multicolumn{7}{|l|}{ Other nature characteristics } \\
\hline \multirow[t]{3}{*}{ Landscape heterogeneity } & -0.19 & -0.23 & -0.23 & -0.22 & -0.22 & -0.23 \\
\hline & 0.23 & 0.22 & 0.22 & 0.23 & 0.22 & 0.22 \\
\hline & -0.8 & -1.01 & -1.03 & -0.98 & -0.99 & -1.05 \\
\hline \multirow[t]{3}{*}{ Topographic heterogeneity } & 0.01 & 0.01 & 0.01 & 0.01 & 0.01 & 0.01 \\
\hline & 0.01 & 0.01 & 0.01 & 0.01 & 0.01 & 0.01 \\
\hline & 0.09 & 0.12 & 0.17 & 0.11 & 0.13 & 0.12 \\
\hline \multirow[t]{3}{*}{ Green space cover } & -0.01 & -0.01 & -0.01 & -0.01 & -0.01 & -0.01 \\
\hline & 0.01 & 0.01 & 0.01 & 0.01 & 0.01 & 0.01 \\
\hline & -0.21 & -0.35 & -0.36 & -0.36 & -0.35 & -0.34 \\
\hline
\end{tabular}




\begin{tabular}{|c|c|c|c|c|c|c|}
\hline Predictor variables & OLS 1 & OLS 2 & OLS 3 & OLS 4 & OLS 5 & OLS 6 \\
\hline \multirow[t]{3}{*}{ Blue space cover } & -0.01 & -0.01 & -0.01 & -0.01 & -0.01 & -0.01 \\
\hline & 0.02 & 0.02 & 0.02 & 0.02 & 0.02 & 0.02 \\
\hline & -0.68 & -0.43 & -0.45 & -0.46 & -0.43 & -0.3 \\
\hline \multirow[t]{3}{*}{ Coastline } & -0.01 & -0.01 & -0.01 & 0.01 & -0.01 & -0.01 \\
\hline & 0.06 & 0.06 & 0.06 & 0.06 & 0.06 & 0.06 \\
\hline & -0.06 & -0.04 & -0.07 & 0.06 & -0.03 & -0.04 \\
\hline \multirow[t]{3}{*}{ Protected area cover } & 0.01 & 0.01 & 0.01 & 0.01 & 0.01 & 0.01 \\
\hline & 0.01 & 0.01 & 0.01 & 0.01 & 0.01 & 0.01 \\
\hline & 0.74 & 1.22 & 1.23 & 1.19 & 1.21 & 1.22 \\
\hline \multicolumn{7}{|l|}{ Climate } \\
\hline \multirow[t]{3}{*}{ Cooling degree days } & 0.01 & 0.01 & 0.01 & 0.01 & 0.01 & 0.01 \\
\hline & 0.01 & 0.01 & 0.01 & 0.01 & 0.01 & 0.01 \\
\hline & 1.7 & 1.1 & 1.09 & 1.15 & 1.12 & 1.25 \\
\hline \multicolumn{7}{|l|}{ Socio-economic variables } \\
\hline Recreation access: & \multirow{2}{*}{\multicolumn{6}{|c|}{ Reference group }} \\
\hline great difficulty & & & & & & \\
\hline Recreation access: & 0.03 & 0.03 & 0.03 & 0.03 & 0.03 & 0.03 \\
\hline \multirow[t]{2}{*}{ with some difficulty } & 0.17 & 0.17 & 0.17 & 0.17 & 0.17 & 0.17 \\
\hline & 0.13 & 0.17 & 0.18 & 0.17 & 0.17 & 0.17 \\
\hline \multirow{3}{*}{$\begin{array}{l}\text { Recreation access: } \\
\text { easily }\end{array}$} & 0.33 & 0.34 & 0.34 & 0.33 & 0.34 & 0.33 \\
\hline & 0.16 & 0.16 & 0.16 & 0.16 & 0.16 & 0.16 \\
\hline & $2.13 *$ & $2.17 *$ & $2.17 *$ & $2.16^{*}$ & $2.17 *$ & $2.17 *$ \\
\hline \multirow{3}{*}{$\begin{array}{l}\text { Recreation access: } \\
\text { very easily }\end{array}$} & 0.54 & 0.55 & 0.55 & 0.55 & 0.55 & 0.55 \\
\hline & 0.16 & 0.16 & 0.16 & 0.16 & 0.16 & 0.16 \\
\hline & $3.58 * * *$ & $3.61 * * *$ & $3.61 * * *$ & $3.6 * * *$ & $3.61 * * *$ & $3.61 * * *$ \\
\hline \multirow{3}{*}{$\begin{array}{l}\text { Recreation access: } \\
\text { service not used }\end{array}$} & 0.09 & 0.09 & 0.09 & 0.09 & 0.09 & 0.09 \\
\hline & 0.16 & 0.16 & 0.16 & 0.16 & 0.16 & 0.16 \\
\hline & 0.53 & 0.55 & 0.55 & 0.55 & 0.55 & 0.55 \\
\hline \multirow[t]{3}{*}{ Constant } & 1.45 & 3.8 & 3.97 & 3.83 & 3.83 & 3.71 \\
\hline & 1.41 & 0.75 & 0.71 & 0.71 & 0.69 & 0.70 \\
\hline & 1.04 & $5.11 * * *$ & $5.61 * * *$ & $5.44 * * *$ & $5.58 * * *$ & $5.37 * * *$ \\
\hline Macro-economic factors & yes & yes & yes & yes & yes & yes \\
\hline Country dummies & yes & yes & yes & yes & yes & yes \\
\hline Observations & 26,749 & 26,749 & 26,749 & 26,749 & 26,749 & 26,749 \\
\hline AIC & 109857.2 & 109867.6 & 109868 & 109867.6 & 109867.8 & 109866.7 \\
\hline $\mathrm{BIC}$ & 110389.8 & 110400.2 & 110400.6 & 110400.2 & 110400.5 & 110399.4 \\
\hline LogLik & -54863.58 & -54868.78 & -54868.99 & -54868.78 & -54868.92 & -54868.37 \\
\hline Adjusted R-squared & 0.24 & 0.24 & 0.24 & 0.24 & 0.24 & 0.24 \\
\hline
\end{tabular}

$\mathrm{AIC}=$ Akaike Information Criterion, $\mathrm{BIC}=$ Bayesian Information Criterion 
Table A.III-9: Model results for the ordered logit regressions (with clustered standard errors) with only a single log-transformed species richness predictor (oLogit 1: birds, oLogit 2: all mammals, oLogit 3: mammals (no bats), oLogit 4; megafauna $>44 \mathrm{~kg}$, oLogit 5: megafauna $>0.5 \mathrm{~kg}$, oLogit 6 : trees). The ordered logit models contain the mean of the categorical net household income variable (Table A.III-1), socio-economic and macro-economic control variables (see Methods for more details). Shown are coefficients, standard errors, Wald z-scores and p-values as asterisk symbols. Response variable $=$ life-satisfaction. Asterisks: $*=$ $\mathrm{p}<0.05 ; * *=\mathrm{p}<0.01 ; * * *=\mathrm{p}<0.001$.

\begin{tabular}{|c|c|c|c|c|c|c|}
\hline Predictor variables & oLogit 1 & oLogit 2 & oLogit 3 & oLogit 4 & oLogit 5 & oLogit 6 \\
\hline \multicolumn{7}{|l|}{ Species richness } \\
\hline \multirow[t]{3}{*}{ Log bird species richness } & 0.41 & - & - & - & - & - \\
\hline & 0.20 & & & & & \\
\hline & $2.01 *$ & & & & & \\
\hline \multirow{3}{*}{$\begin{array}{l}\text { Log mammal species rich- } \\
\text { ness (all) }\end{array}$} & - & -0.06 & - & - & - & - \\
\hline & & 0.1 & & & & \\
\hline & & -0.56 & & & & \\
\hline $\begin{array}{l}\text { Log mammal species rich- } \\
\text { ness }\end{array}$ & - & - & -0.08 & - & - & - \\
\hline \multirow[t]{2}{*}{ (no bats) } & & & 0.06 & & & \\
\hline & & & -1.19 & & & \\
\hline \multirow{3}{*}{$\begin{array}{l}\text { Log megafauna species } \\
\text { richness }(>44 \mathrm{~kg})\end{array}$} & - & - & - & 0.04 & - & - \\
\hline & & & & 0.08 & & \\
\hline & & & & 0.50 & & \\
\hline \multirow{3}{*}{$\begin{array}{l}\text { Log megafauna species } \\
\text { richness }(>0.5 \mathrm{~kg})\end{array}$} & - & - & - & - & -0.01 & - \\
\hline & & & & & 0.04 & \\
\hline & & & & & -0.32 & \\
\hline \multirow[t]{3}{*}{ Log tree species richness } & - & - & - & - & - & 0.05 \\
\hline & & & & & & 0.07 \\
\hline & & & & & & 0.65 \\
\hline \multicolumn{7}{|l|}{ Other nature characteristics } \\
\hline \multirow[t]{3}{*}{ Landscape heterogeneity } & -0.1 & -0.14 & -0.15 & -0.13 & -0.14 & -0.14 \\
\hline & 0.19 & 0.19 & 0.19 & 0.19 & 0.19 & 0.19 \\
\hline & -0.54 & -0.77 & -0.8 & -0.7 & -0.75 & -0.77 \\
\hline \multirow[t]{3}{*}{ Topographic heterogeneity } & 0.01 & 0.01 & 0.01 & 0.01 & 0.01 & 0.01 \\
\hline & 0.01 & 0.01 & 0.01 & 0.01 & 0.01 & 0.01 \\
\hline & 0.18 & 0.32 & 0.34 & 0.21 & 0.27 & 0.22 \\
\hline \multirow[t]{3}{*}{ Green space cover } & 0.01 & -0.01 & -0.01 & -0.01 & -0.01 & -0.01 \\
\hline & 0.01 & 0.01 & 0.01 & 0.01 & 0.01 & 0.01 \\
\hline & 0.01 & -0.17 & -0.18 & -0.15 & -0.15 & -0.13 \\
\hline \multirow[t]{3}{*}{ Blue space cover } & -0.01 & -0.01 & -0.01 & -0.01 & -0.01 & -0.01 \\
\hline & 0.01 & 0.01 & 0.01 & 0.01 & 0.01 & 0.01 \\
\hline & -0.74 & -0.52 & -0.52 & -0.5 & -0.49 & -0.35 \\
\hline \multirow[t]{3}{*}{ Coastline } & 0.03 & 0.03 & 0.03 & 0.04 & 0.03 & 0.03 \\
\hline & 0.05 & 0.05 & 0.05 & 0.05 & 0.05 & 0.05 \\
\hline & 0.59 & 0.56 & 0.54 & 0.66 & 0.58 & 0.6 \\
\hline
\end{tabular}




\begin{tabular}{|c|c|c|c|c|c|c|}
\hline Predictor variables & oLogit 1 & oLogit 2 & oLogit 3 & oLogit 4 & oLogit 5 & oLogit 6 \\
\hline \multirow[t]{3}{*}{ Protected area cover } & 0.01 & 0.01 & 0.01 & 0.01 & 0.01 & 0.01 \\
\hline & 0.01 & 0.01 & 0.01 & 0.01 & 0.01 & 0.01 \\
\hline & 0.53 & 1.02 & 1.04 & 0.98 & 1.01 & 1 \\
\hline \multicolumn{7}{|l|}{ Climate } \\
\hline \multirow[t]{3}{*}{ Cooling degree days } & 0.01 & 0.01 & 0.01 & 0.01 & 0.01 & 0.01 \\
\hline & 0.01 & 0.01 & 0.01 & 0.01 & 0.01 & 0.01 \\
\hline & 1.71 & 1.16 & 1.13 & 1.21 & 1.16 & 1.31 \\
\hline \multicolumn{7}{|l|}{ Socio-economic variables } \\
\hline $\begin{array}{l}\text { Recreation access: great } \\
\text { difficulty }\end{array}$ & \multicolumn{6}{|c|}{ Reference group } \\
\hline \multirow{3}{*}{$\begin{array}{l}\text { Recreation access: with } \\
\text { some difficulty }\end{array}$} & -0.04 & -0.03 & -0.03 & -0.03 & -0.03 & -0.03 \\
\hline & 0.14 & 0.14 & 0.14 & 0.14 & 0.14 & 0.14 \\
\hline & -0.26 & -0.22 & -0.22 & -0.23 & -0.22 & -0.23 \\
\hline \multirow[t]{3}{*}{ Recreation access: easily } & 0.24 & 0.24 & 0.24 & 0.24 & 0.24 & 0.24 \\
\hline & 0.13 & 0.13 & 0.13 & 0.13 & 0.13 & 0.13 \\
\hline & 1.89 & 1.93 & 1.93 & 1.92 & 1.93 & 1.93 \\
\hline \multirow{3}{*}{$\begin{array}{l}\text { Recreation access: very } \\
\text { easily }\end{array}$} & 0.44 & 0.45 & 0.45 & 0.45 & 0.45 & 0.45 \\
\hline & 0.13 & 0.13 & 0.13 & 0.13 & 0.13 & 0.13 \\
\hline & $3.57 * * *$ & $3.6 * * *$ & $3.59 * * *$ & $3.59 * * *$ & $3.59 * * *$ & $3.6^{* * *}$ \\
\hline \multirow{3}{*}{$\begin{array}{l}\text { Recreation access: service } \\
\text { not used }\end{array}$} & 0.03 & 0.03 & 0.03 & 0.03 & 0.03 & 0.03 \\
\hline & 0.12 & 0.13 & 0.13 & 0.13 & 0.13 & 0.13 \\
\hline & 0.2 & 0.21 & 0.21 & 0.21 & 0.21 & 0.21 \\
\hline \multirow[t]{3}{*}{$y>=2$} & -0.88 & 1.35 & 1.37 & 1.08 & 1.17 & 0.99 \\
\hline & 1.22 & 0.68 & 0.62 & 0.61 & 0.6 & 0.6 \\
\hline & -0.72 & 1.97 & 2.2 & 1.77 & 1.95 & 1.65 \\
\hline \multirow[t]{3}{*}{$y>=3$} & -1.57 & 0.66 & 0.69 & 0.39 & 0.49 & 0.3 \\
\hline & 1.21 & 0.68 & 0.61 & 0.6 & 0.59 & 0.59 \\
\hline & -1.3 & 0.98 & 1.12 & 0.66 & 0.82 & 0.51 \\
\hline \multirow[t]{3}{*}{$y>=4$} & -2.29 & -0.06 & -0.03 & -0.33 & -0.23 & -0.42 \\
\hline & 1.21 & 0.67 & 0.61 & 0.6 & 0.59 & 0.58 \\
\hline & -1.9 & -0.09 & -0.05 & -0.54 & -0.39 & -0.72 \\
\hline \multirow[t]{3}{*}{$y>=5$} & -2.81 & -0.59 & -0.56 & -0.85 & -0.76 & -0.95 \\
\hline & 1.21 & 0.67 & 0.61 & $(0.60$ & 0.59 & 0.59 \\
\hline & $-2.33^{*}$ & -0.87 & -0.92 & -1.42 & -1.29 & -1.62 \\
\hline \multirow[t]{3}{*}{$y>=6$} & -3.75 & -1.52 & -1.5 & -1.79 & -1.7 & -1.88 \\
\hline & 1.21 & 0.68 & 0.61 & 0.6 & 0.6 & 0.59 \\
\hline & $-3.11 * *$ & $-2.26^{*}$ & $-2.44^{*}$ & $-2.96^{*}$ & $-2.85^{*}$ & $-3.20 *$ \\
\hline \multirow[t]{3}{*}{$y>=7$} & -4.35 & -2.12 & -2.1 & -2.39 & -2.3 & -2.48 \\
\hline & 1.21 & 0.68 & 0.62 & 0.69 & 0.6 & 0.59 \\
\hline & $-3.6^{* * *}$ & $-3.13 * * *$ & $-3.4 * * *$ & $-3.93 * * *$ & $-3.84 * * *$ & $-4.2 * * *$ \\
\hline \multirow[t]{3}{*}{$y>=8$} & -5.24 & -3.01 & -2.99 & -3.28 & -3.19 & -3.37 \\
\hline & 1.21 & 0.68 & 0.62 & 0.61 & 0.6 & 0.6 \\
\hline & $-4.32 * * *$ & $-4.43 * * *$ & $-4.81 * * *$ & $-5.37 * * *$ & $-5.3 * * *$ & $-5.67 * * *$ \\
\hline
\end{tabular}




\begin{tabular}{|c|c|c|c|c|c|c|}
\hline Predictor variables & oLogit 1 & oLogit 2 & oLogit 3 & oLogit 4 & oLogit 5 & oLogit 6 \\
\hline \multirow[t]{3}{*}{$y>=9$} & -6.55 & -4.32 & -4.3 & -4.59 & -4.5 & -4.68 \\
\hline & 1.22 & 0.68 & 0.63 & 0.62 & 0.61 & 0.6 \\
\hline & $-5.4 * * *$ & $-6.33 * * *$ & $-6.88 * * *$ & $-7.47 * * *$ & $-7.44 * * *$ & $-7.84 * * *$ \\
\hline \multirow[t]{3}{*}{$y>=10$} & -7.53 & -5.3 & -5.28 & -5.57 & -5.48 & -5.66 \\
\hline & 1.22 & 0.69 & 0.63 & 0.62 & 0.61 & 0.6 \\
\hline & $-6.19 * * *$ & $-7.72 * * *$ & $-8.38 * * *$ & $-8.98 * * *$ & $-8.98 * * *$ & $-9.39 * * *$ \\
\hline Socio-economic factors & yes & yes & yes & yes & yes & yes \\
\hline Macro-economic factors & yes & yes & yes & yes & yes & yes \\
\hline Country dummies & yes & yes & yes & yes & yes & yes \\
\hline Observations & 26,749 & 26,749 & 26,749 & 26,749 & 26,749 & 26,749 \\
\hline AIC & 102699.5 & 102707.7 & 102706.8 & 102707.7 & 102708 & 102707.2 \\
\hline $\mathrm{BIC}$ & 103289.5 & 103297.7 & 103296.8 & 103297.7 & 103298 & 103297.2 \\
\hline LogLik & -51277.77 & -51281.85 & -51281.42 & -51281.87 & -51281.99 & -51281.6 \\
\hline Nagelkerke R-squared & 0.25 & 0.25 & 0.25 & 0.25 & 0.25 & 0.25 \\
\hline
\end{tabular}

$\mathrm{AIC}=$ Akaike Information Criterion, $\mathrm{BIC}=$ Bayesian Information Criterion 


\subsubsection{Results for OLS models with linear specification of species richness}

\section{Multi-taxon models}

Here I present the results for the multi-taxon models calculated with ordinary least squares (OLS) and the ordered logistic regression models (oLogit). All species richness variables have a linear specification.

Table A.III-10: Model results for the multi-taxon OLS models with clustered standard errors and different species richness predictor sets (OLS 1: all mammals, OLS 2: mammals (no bats), OLS 3; megafauna $>44 \mathrm{~kg}$, OLS 4: megafauna $>0.5 \mathrm{~kg}$ ). The OLS models contain the mean of the categorical net household income variable (Table A.III-1), socio-economic and macro-economic control variables (see Methods for more details). Shown are coefficients, standard errors, t-values and p-values as asterisk symbols. Response variable $=$ life-satisfaction. Asterisks: $*=\mathrm{p}<0.05 ; * *=\mathrm{p}<0.01 ; * * *=\mathrm{p}<0.001$.

\begin{tabular}{|c|c|c|c|c|}
\hline Predictor variables & OLS 1 & OLS 2 & OLS 3 & OLS 4 \\
\hline \multicolumn{5}{|l|}{ Species richness } \\
\hline \multirow[t]{3}{*}{ Bird species richness } & 0.005 & 0.005 & 0.004 & 0.004 \\
\hline & 0.002 & 0.002 & 0.002 & 0.002 \\
\hline & $2.21^{*}$ & $2.39^{*}$ & 1.82 & $2.08^{*}$ \\
\hline \multirow[t]{3}{*}{ Mammal species richness (all) } & -0.01 & - & - & - \\
\hline & 0.01 & & & \\
\hline & -1.2 & & & \\
\hline \multirow[t]{3}{*}{ Mammal species richness (no bats) } & - & -0.02 & - & - \\
\hline & & 0.01 & & \\
\hline & & -1.89 & & \\
\hline \multirow[t]{3}{*}{ Megafauna species richness $(>44 \mathrm{~kg})$} & - & - & -0.01 & - \\
\hline & & & 0.04 & \\
\hline & & & -0.21 & \\
\hline \multirow{3}{*}{$\begin{array}{l}\text { Megafauna species richness } \\
(>0.5 \mathrm{~kg})\end{array}$} & - & - & - & -0.01 \\
\hline & & & & 0.01 \\
\hline & & & & -0.77 \\
\hline \multirow[t]{3}{*}{ Tree species richness } & 0.003 & 0.003 & 0.001 & 0.002 \\
\hline & 0.01 & 0.01 & 0.01 & 0.01 \\
\hline & 0.48 & 0.49 & 0.24 & 0.32 \\
\hline \multicolumn{5}{|l|}{ Other nature characteristics } \\
\hline \multirow[t]{3}{*}{ Landscape heterogeneity } & -0.22 & -0.22 & -0.2 & -0.21 \\
\hline & 0.22 & 0.23 & 0.23 & 0.23 \\
\hline & -0.97 & -0.99 & -0.88 & -0.91 \\
\hline \multirow[t]{3}{*}{ Topographic heterogeneity } & 0.01 & 0.01 & 0.01 & 0.01 \\
\hline & 0.01 & 0.01 & 0.01 & 0.01 \\
\hline & 0.37 & 0.41 & 0.14 & 0.2 \\
\hline \multirow[t]{3}{*}{ Green space cover } & -0.01 & -0.01 & -0.01 & -0.01 \\
\hline & 0.01 & 0.01 & 0.01 & 0.01 \\
\hline & -0.24 & -0.23 & -0.16 & -0.16 \\
\hline
\end{tabular}




\begin{tabular}{|c|c|c|c|c|}
\hline Predictor variables & OLS 1 & OLS 2 & OLS 3 & OLS 4 \\
\hline \multirow[t]{3}{*}{ Blue space cover } & -0.01 & -0.01 & -0.01 & -0.01 \\
\hline & 0.01 & 0.01 & 0.01 & 0.01 \\
\hline & -0.7 & -0.65 & -0.6 & -0.6 \\
\hline \multirow[t]{3}{*}{ Coastline } & -0.02 & -0.01 & -0.01 & -0.01 \\
\hline & 0.06 & 0.06 & 0.06 & 0.06 \\
\hline & -0.28 & -0.25 & -0.12 & -0.18 \\
\hline \multirow[t]{3}{*}{ Protected area cover } & 0.01 & 0.01 & 0.01 & -0.01 \\
\hline & 0.01 & 0.01 & 0.01 & 0.06 \\
\hline & 0.74 & 0.78 & 0.74 & -0.74 \\
\hline \multicolumn{5}{|l|}{ Climate } \\
\hline \multirow[t]{3}{*}{ Cooling degree days } & 0.01 & 0.01 & 0.01 & 0.01 \\
\hline & 0.01 & 0.01 & 0.01 & 0.01 \\
\hline & 1.71 & 1.58 & 1.6 & 1.6 \\
\hline \multicolumn{5}{|l|}{ Recreation access } \\
\hline Recreation access: great difficulty & \multicolumn{4}{|c|}{ Reference group } \\
\hline \multirow{3}{*}{$\begin{array}{l}\text { Recreation access: with some diffi- } \\
\text { culty }\end{array}$} & 0.02 & 0.02 & 0.02 & 0.02 \\
\hline & 0.17 & 0.17 & 0.17 & 0.17 \\
\hline & 0.13 & 0.13 & 0.13 & 0.13 \\
\hline \multirow[t]{3}{*}{ Recreation access: easily } & 0.32 & 0.32 & 0.32 & 0.32 \\
\hline & 0.15 & 0.15 & 0.15 & 0.15 \\
\hline & $2.13 *$ & $2.13 *$ & $2.13 *$ & $2.13 *$ \\
\hline \multirow[t]{3}{*}{ Recreation access: very easily } & 0.54 & 0.54 & 0.54 & 0.54 \\
\hline & 0.15 & 0.15 & 0.15 & 0.15 \\
\hline & $3.58 * * *$ & $3.58 * * *$ & $3.58 * * *$ & $3.58 * * *$ \\
\hline \multirow[t]{3}{*}{ Recreation access: service not used } & 0.08 & 0.08 & 0.08 & 0.08 \\
\hline & 0.15 & 0.15 & 0.15 & 0.15 \\
\hline & 0.53 & 0.53 & 0.53 & 0.53 \\
\hline \multirow[t]{3}{*}{ Constant } & 3.42 & 3.46 & 3.29 & 3.33 \\
\hline & 0.74 & 0.75 & 0.74 & 0.74 \\
\hline & $4.64 * * *$ & $4.63 * * *$ & $4.43 * * *$ & $4.48 * * *$ \\
\hline Socio-economic factors & yes & yes & yes & yes \\
\hline Macro-economic factors & yes & yes & yes & yes \\
\hline Country dummies & yes & yes & yes & yes \\
\hline Observations & 26,749 & 26,749 & 26,749 & 26,749 \\
\hline AIC & 109859.2 & 109855.8 & 109861.4 & 109860.7 \\
\hline $\mathrm{BIC}$ & 110408.2 & 110408.8 & 110409.4 & 110409.7 \\
\hline LogLik & -54862.58 & -54860.91 & -54863.68 & -54863.35 \\
\hline Adjusted R-squared & 0.2369 & 0.2371 & 0.2369 & 0.2369 \\
\hline
\end{tabular}


Table A.III-11: Model results for the ordered logit regressions models with clustered standard errors and different species richness predictor sets (oLogit 1: all mammals, oLogit 2: mammals (no bats), oLogit 3; megafauna $>44 \mathrm{~kg}$, oLogit 4 : megafauna $>0.5 \mathrm{~kg}$ ). The ordered logit models contain the mean of the categorical net household income variable (Table A.III-1), socio-economic and macro-economic control variables (see Methods for more details). Shown are coefficients, standard errors, Wald z-scores and p-values as asterisk symbols. Response variable $=$ life-satisfaction. Asterisks: $*=p<0.05 ; * *=p<0.01 ; * * *=p<0.001$.

\begin{tabular}{|c|c|c|c|c|}
\hline Predictor variables & oLogit 1 & oLogit 2 & oLogit 3 & oLogit 4 \\
\hline \multicolumn{5}{|l|}{ Species richness } \\
\hline \multirow[t]{3}{*}{ Bird species richness } & 0.004 & 0.004 & 0.003 & 0.004 \\
\hline & 0.002 & 0.002 & 0.002 & 0.002 \\
\hline & $2.29 *$ & $2.54 *$ & 1.67 & $2.09 *$ \\
\hline \multirow[t]{3}{*}{ Mammal species richness (all) } & -0.01 & - & - & - \\
\hline & 0.01 & & & \\
\hline & -1.68 & & & \\
\hline \multirow[t]{3}{*}{ Mammal species richness (no bats) } & - & -0.02 & - & - \\
\hline & & 0.01 & & \\
\hline & & $-3.47 * *$ & & \\
\hline \multirow[t]{3}{*}{ Megafauna species richness $(>44 \mathrm{~kg})$} & - & - & -0.002 & - \\
\hline & & & 0.04 & \\
\hline & & & -0.05 & \\
\hline \multirow{3}{*}{$\begin{array}{l}\text { Megafauna species richness } \\
(>0.5 \mathrm{~kg})\end{array}$} & - & - & - & -0.06 \\
\hline & & & & 0.05 \\
\hline & & & & -1.12 \\
\hline \multirow[t]{3}{*}{ Tree species richness } & -0.002 & 0.003 & -0.004 & -0.001 \\
\hline & 0.005 & 0.004 & 0.01 & 0.01 \\
\hline & -0.47 & 0.68 & -0.08 & -0.22 \\
\hline \multicolumn{5}{|l|}{ Other nature characteristics } \\
\hline \multirow[t]{3}{*}{ Landscape heterogeneity } & -0.14 & -0.15 & -0.11 & -0.13 \\
\hline & 0.19 & 0.19 & 0.19 & 0.19 \\
\hline & -0.74 & -0.79 & -0.6 & -0.65 \\
\hline \multirow[t]{3}{*}{ Topographic heterogeneity } & 0.01 & 0.01 & 0.01 & 0.01 \\
\hline & 0.01 & 0.01 & 0.01 & 0.01 \\
\hline & 0.67 & 0.69 & 0.21 & 0.37 \\
\hline \multirow[t]{3}{*}{ Green space cover } & -0.01 & -0.01 & 0.01 & 0.01 \\
\hline & 0.01 & 0.01 & 0.01 & 0.01 \\
\hline & -0.08 & -0.07 & 0.03 & 0.04 \\
\hline \multirow[t]{3}{*}{ Blue space cover } & -0.01 & -0.01 & -0.01 & -0.01 \\
\hline & 0.01 & 0.01 & 0.01 & 0.01 \\
\hline & -0.83 & -0.76 & -0.69 & -0.69 \\
\hline \multirow[t]{3}{*}{ Coastline } & 0.03 & 0.02 & 0.03 & 0.02 \\
\hline & 0.05 & 0.05 & 0.06 & 0.05 \\
\hline & 0.3 & 0.39 & 0.52 & 0.42 \\
\hline \multirow[t]{3}{*}{ Protected area cover } & 0.01 & 0.01 & 0.01 & 0.01 \\
\hline & 0.01 & 0.01 & 0.01 & 0.01 \\
\hline & 0.53 & 0.49 & 0.54 & 0.54 \\
\hline
\end{tabular}




\begin{tabular}{|c|c|c|c|c|}
\hline Predictor variables & oLogit 1 & oLogit 2 & oLogit 3 & oLogit 4 \\
\hline \multicolumn{5}{|l|}{ Climate } \\
\hline \multirow[t]{3}{*}{ Cooling degree days } & 0.01 & 0.01 & 0.01 & 0.01 \\
\hline & 0.01 & 0.01 & 0.01 & 0.01 \\
\hline & 1.77 & 1.51 & 1.6 & 1.6 \\
\hline \multicolumn{5}{|l|}{ Recreation access } \\
\hline Recreation access: great difficulty & \multicolumn{4}{|c|}{ Reference group } \\
\hline \multirow{3}{*}{$\begin{array}{l}\text { Recreation access: with some diffi- } \\
\text { culty }\end{array}$} & -0.04 & -0.04 & -0.03 & -0.03 \\
\hline & 0.14 & 0.14 & 0.14 & 0.14 \\
\hline & -0.26 & -0.26 & -0.25 & -0.25 \\
\hline \multirow[t]{3}{*}{ Recreation access: easily } & 0.24 & 0.24 & 0.24 & 0.24 \\
\hline & 0.13 & 0.12 & 0.13 & 0.13 \\
\hline & 1.9 & 1.91 & 1.9 & 1.9 \\
\hline \multirow[t]{3}{*}{ Recreation access: very easily } & 0.45 & 0.44 & 0.45 & 0.45 \\
\hline & 0.12 & 0.12 & 0.12 & 0.12 \\
\hline & $3.58 * * *$ & $3.58 * * *$ & $3.57 * * *$ & $3.58 * * *$ \\
\hline \multirow[t]{3}{*}{ Recreation access: service not used } & 0.03 & 0.03 & 0.03 & 0.03 \\
\hline & 0.13 & 0.13 & 0.13 & 0.13 \\
\hline & 0.21 & 0.21 & 0.21 & 0.21 \\
\hline \multirow[t]{3}{*}{$y>=2$} & -0.84 & -0.86 & -0.66 & -0.71 \\
\hline & 0.65 & 0.66 & 0.65 & 0.65 \\
\hline & -1.29 & -1.3 & -1.01 & -1.09 \\
\hline \multirow[t]{3}{*}{$y>=3$} & -0.14 & -0.17 & -0.03 & -0.03 \\
\hline & 0.64 & 0.65 & 0.64 & 0.64 \\
\hline & -0.23 & -0.26 & -0.05 & -0.04 \\
\hline \multirow[t]{3}{*}{$y>=4$} & -0.57 & -0.55 & -0.75 & -0.69 \\
\hline & 0.64 & 0.64 & 0.64 & 0.64 \\
\hline & -0.9 & -0.85 & -1.18 & -1.09 \\
\hline \multirow[t]{3}{*}{$y>=5$} & -1.1 & -1.07 & -1.27 & -1.21 \\
\hline & 0.64 & 0.64 & 0.64 & 0.64 \\
\hline & -1.72 & -1.67 & -2 & -1.91 \\
\hline \multirow[t]{3}{*}{$y>=6$} & -2.03 & -2.01 & -2.21 & -2.16 \\
\hline & 0.64 & 0.64 & 0.64 & 0.64 \\
\hline & $-3.18 * *$ & $-3.10 * *$ & $-3.45 * *$ & $-3.36^{* *}$ \\
\hline \multirow[t]{3}{*}{$y>=7$} & -2.63 & -2.61 & -2.81 & -2.75 \\
\hline & 0.64 & 0.65 & 0.64 & 0.64 \\
\hline & $-4.10 * *$ & $-4.01 * *$ & $-4.36 * *$ & $-4.27 * *$ \\
\hline \multirow[t]{3}{*}{$y>=8$} & -3.52 & -3.5 & -3.7 & -3.64 \\
\hline & 0.64 & 0.65 & 0.64 & 0.64 \\
\hline & $-5.45 * * *$ & $-5.35 * * *$ & $-7.69 * * *$ & $-5.63 * * *$ \\
\hline \multirow[t]{3}{*}{$y>=9$} & -4.83 & -4.81 & -5.99 & -4.96 \\
\hline & 0.64 & 0.66 & 0.65 & 0.64 \\
\hline & $-7.44 * * *$ & $-7.31 * * *$ & $-7.69 * * *$ & $-7.61 * * *$ \\
\hline
\end{tabular}




\begin{tabular}{lcccc} 
Predictor variables & oLogit $\mathbf{1}$ & oLogit $\mathbf{2}$ & oLogit 3 & oLogit 4 \\
\hline \hline $\mathrm{y}>=10$ & -5.81 & -5.79 & -5.99 & -5.93 \\
& 0.66 & 0.66 & 0.65 & 0.66 \\
& $-8.88 * * *$ & $-8.72 * * *$ & $-9.12 * * *$ & $-9.03 * * *$ \\
\hline Socio-economic factors & yes & yes & yes & yes \\
Macro-economic factors & yes & yes & yes & yes \\
Country dummies & yes & yes & yes & yes \\
Observations & 26,749 & 26,749 & 26,749 & 26,749 \\
AIC & 102699.8 & 102694.2 & 102704.3 & 102702.8 \\
BIC & 103306.1 & 103292.4 & 103310.7 & 103309.1 \\
LogLik & -51275.89 & -51274.09 & -51278.17 & -51277.38 \\
Nagelkerke R-squared & 0.24 & 0.24 & 0.24 & 0.24 \\
\hline
\end{tabular}

$\mathrm{AIC}=$ Akaike Information Criterion, $\mathrm{BIC}=$ Bayesian Information Criterion 


\section{Single-taxon models}

Here I present the results for the single-taxon models calculated with ordinary least squares (OLS) and ordered logistic regression models (oLogit). All species richness variables are linear. I only show detailed results for selected predictor variables: species richness, other nature characteristics, climate and access to local recreational areas. Socio-economic variables and other explanatory variables are the same as in the multi-taxon models.

Table A.III-12: Model results for the single-taxon OLS regressions with clustered standard errors and a single species richness predictor (OLS 1: birds, OLS 2: all mammals, OLS 3: mammals (no bats), OLS 4; megafauna $>44 \mathrm{~kg}$, OLS 5: megafauna $>0.5 \mathrm{~kg}$, OLS 6: trees). The OLS models contain the mean of the categorical net household income variable (Table A.III-1), socio-economic and macro-economic control variables (see Methods for more details). Shown are coefficients, standard errors, $t$-values and $p$-values as asterisk symbols. Response variable $=$ life-satisfaction. Asterisks: $*=\mathrm{p}<0.05 ; * *=\mathrm{p}<0.01 ; * * *=\mathrm{p}<0.001$.

\begin{tabular}{|c|c|c|c|c|c|c|}
\hline Predictor variables & OLS 1 & OLS 2 & OLS 3 & OLS 4 & OLS 5 & OLS 6 \\
\hline \multicolumn{7}{|l|}{ Species richness } \\
\hline \multirow[t]{3}{*}{ Bird species richness } & 0.004 & - & - & - & - & - \\
\hline & 0.002 & & & & & \\
\hline & $1.99 *$ & & & & & \\
\hline \multirow{3}{*}{$\begin{array}{l}\text { Mammal species richness } \\
\text { (all) }\end{array}$} & - & 0.001 & - & - & - & - \\
\hline & & 0.01 & & & & \\
\hline & & 0.19 & & & & \\
\hline \multirow{3}{*}{$\begin{array}{l}\text { Mammal species richness } \\
\text { (no bats) }\end{array}$} & - & - & -0.006 & - & - & - \\
\hline & & & 0.01 & & & \\
\hline & & & -0.84 & & & \\
\hline \multirow{3}{*}{$\begin{array}{l}\text { Megafauna species richness } \\
(>44 \mathrm{~kg})\end{array}$} & - & - & - & 0.03 & - & - \\
\hline & & & & 0.04 & & \\
\hline & & & & 0.77 & & \\
\hline \multirow{3}{*}{$\begin{array}{l}\text { Megafauna species richness } \\
(>0.5 \mathrm{~kg})\end{array}$} & - & - & - & - & 0.005 & - \\
\hline & & & & & 0.01 & \\
\hline & & & & & 0.49 & \\
\hline \multirow[t]{3}{*}{ Tree species richness } & - & - & - & - & - & 0.004 \\
\hline & & & & & & 0.01 \\
\hline & & & & & & 0.60 \\
\hline \multicolumn{7}{|l|}{ Other nature characteristics } \\
\hline \multirow[t]{3}{*}{ Landscape heterogeneity } & -0.19 & -0.22 & -0.24 & -0.21 & -0.22 & -0.23 \\
\hline & 0.22 & 0.22 & 0.22 & 0.22 & 0.22 & 0.22 \\
\hline & -0.85 & -1.11 & -1.07 & -0.98 & -0.99 & -1.06 \\
\hline \multirow[t]{3}{*}{ Topographic heterogeneity } & 0.01 & 0.01 & 0.01 & 0.01 & 0.01 & 0.01 \\
\hline & 0.01 & 0.01 & 0.01 & 0.01 & 0.01 & 0.01 \\
\hline & 0.11 & 0.09 & 0.26 & 0.06 & 0.09 & 0.12 \\
\hline \multirow[t]{3}{*}{ Green space cover } & -0.01 & -0.01 & -0.01 & -0.01 & -0.01 & -0.01 \\
\hline & 0.01 & 0.01 & 0.01 & 0.01 & 0.01 & 0.01 \\
\hline & -0.17 & -0.33 & -0.39 & -0.35 & -0.34 & -0.33 \\
\hline
\end{tabular}




\begin{tabular}{|c|c|c|c|c|c|c|}
\hline Predictor variables & OLS 1 & OLS 2 & OLS 3 & OLS 4 & OLS 5 & OLS 6 \\
\hline \multirow[t]{3}{*}{ Blue space cover } & -0.01 & -0.01 & -0.01 & -0.01 & -0.01 & -0.01 \\
\hline & 0.01 & 0.01 & 0.01 & 0.01 & 0.01 & 0.01 \\
\hline & -0.64 & -0.43 & -0.46 & -0.48 & -0.43 & -0.32 \\
\hline \multirow[t]{3}{*}{ Coastline } & -0.01 & -0.01 & -0.01 & 0.01 & -0.01 & -0.01 \\
\hline & 0.06 & 0.06 & 0.06 & 0.06 & 0.06 & 0.06 \\
\hline & -0.09 & -0.02 & -0.12 & 0.11 & -0.01 & -0.03 \\
\hline \multirow[t]{3}{*}{ Protected area cover } & 0.01 & 0.01 & 0.01 & 0.01 & 0.01 & 0.01 \\
\hline & 0.01 & 0.01 & 0.01 & 0.01 & 0.01 & 0.01 \\
\hline & 0.75 & 1.22 & 1.28 & 1.16 & 1.2 & 1.22 \\
\hline \multicolumn{7}{|l|}{ Climate } \\
\hline \multirow[t]{3}{*}{ Cooling degree days } & 0.01 & 0.01 & 0.01 & 0.01 & 0.01 & 0.01 \\
\hline & 0.01 & 0.01 & 0.01 & 0.01 & 0.01 & 0.01 \\
\hline & 1.63 & 1.11 & 1.02 & 1.17 & 1.14 & 1.21 \\
\hline Recreation access & & & & & & \\
\hline
\end{tabular}

\begin{tabular}{|c|c|c|c|c|c|c|}
\hline $\begin{array}{l}\text { Recreation access: great } \\
\text { difficulty }\end{array}$ & & & Referen & group & & \\
\hline \multirow{3}{*}{$\begin{array}{l}\text { Recreation access: with } \\
\text { some difficulty }\end{array}$} & 0.02 & 0.03 & 0.03 & 0.03 & 0.03 & 0.03 \\
\hline & 0.17 & 0.17 & 0.17 & 0.16 & 0.17 & 0.17 \\
\hline & 0.13 & 0.17 & 0.17 & 0.16 & 0.17 & 0.17 \\
\hline \multirow[t]{3}{*}{ Recreation access: easily } & 0.32 & 0.33 & 0.33 & 0.33 & 0.33 & 0.33 \\
\hline & 0.15 & 0.15 & 0.15 & 0.15 & 0.15 & 0.15 \\
\hline & $2.13 *$ & $2.16^{*}$ & $2.17 *$ & $2.15^{*}$ & $2.16^{*}$ & $2.16^{*}$ \\
\hline \multirow{3}{*}{$\begin{array}{l}\text { Recreation access: very } \\
\text { easily }\end{array}$} & 0.54 & 0.55 & 0.55 & 0.55 & 0.55 & 0.55 \\
\hline & 0.15 & 0.15 & 0.15 & 0.15 & 0.15 & 0.15 \\
\hline & $3.58 * * *$ & $3.61 * * *$ & $3.60 * * *$ & $3.59 * * *$ & $3.60 * * *$ & $3.60 * * *$ \\
\hline \multirow{3}{*}{$\begin{array}{l}\text { Recreation access: service } \\
\text { not used }\end{array}$} & 0.08 & 0.08 & 0.08 & 0.08 & 0.08 & 0.08 \\
\hline & 0.15 & 0.15 & 0.15 & 0.15 & 0.15 & 0.15 \\
\hline & 0.53 & 0.55 & 0.55 & 0.54 & 0.54 & 0.54 \\
\hline \multirow[t]{3}{*}{ Constant } & 3.3 & 3.85 & 4.04 & 3.82 & 3.83 & 3.81 \\
\hline & 0.75 & 0.68 & 0.69 & 0.69 & 0.68 & 0.65 \\
\hline & $4.4 * * *$ & $5.65 * * *$ & $5.86^{* * *}$ & $5.50 * * *$ & $5.62 * * *$ & $5.85^{* * *}$ \\
\hline Socio-economic factors & yes & yes & yes & yes & yes & yes \\
\hline Macro-economic factors & yes & yes & yes & yes & yes & yes \\
\hline Country dummies & yes & yes & yes & yes & yes & yes \\
\hline Observations & 26,749 & 26,749 & 26,749 & 26,749 & 26,749 & 26,749 \\
\hline AIC & 109857.6 & 109868 & 109867.1 & 109867.2 & 109867.8 & 109866.6 \\
\hline $\mathrm{BIC}$ & 110390.3 & 110400.6 & 110399.7 & 110399.8 & 110400.4 & 110399.3 \\
\hline LogLik & -54863.82 & -54868.99 & -54868.53 & -54868.58 & -54868.88 & -54868.31 \\
\hline Adjusted R-squared & 0.237 & 0.2367 & 0.2367 & 0.2367 & 0.2367 & 0.2367 \\
\hline
\end{tabular}


Table A.III-13: Model results for the ordered logit regressions (with clustered standard errors) with only a single species richness predictor (oLogit 1: birds, oLogit 2: all mammals, oLogit 3: mammals (no bats), oLogit 4; megafauna $>44 \mathrm{~kg}$, oLogit 5: megafauna $>0.5 \mathrm{~kg}$, oLogit 6 : trees). The ordered logit models contain the mean of the categorical net household income variable (Table A.III-1), socio-economic and macro-economic control variables (see Methods for more details). Shown are coefficients, standard errors, Wald $\mathrm{z}$-scores and $\mathrm{p}$-values as asterisk symbols. Response variable $=$ life-satisfaction. Asterisks: $*=\mathrm{p}<0.05 ; * *$ $=\mathrm{p}<0.01 ; * * *=\mathrm{p}<0.001$.

\begin{tabular}{|c|c|c|c|c|c|c|}
\hline Predictor variables & oLogit 1 & oLogit 2 & oLogit 3 & oLogit 4 & oLogit 5 & oLogit 6 \\
\hline \multicolumn{7}{|l|}{ Species richness } \\
\hline \multirow[t]{3}{*}{ Bird species richness } & 0.003 & - & - & - & - & - \\
\hline & 0.002 & & & & & \\
\hline & 1.88 & & & & & \\
\hline \multirow{3}{*}{$\begin{array}{l}\text { Mammal species richness } \\
\text { (all) }\end{array}$} & - & -0.002 & - & - & - & - \\
\hline & & 0.01 & & & & \\
\hline & & -0.42 & & & & \\
\hline \multirow{3}{*}{$\begin{array}{l}\text { Mammal species richness } \\
\text { (no bats) }\end{array}$} & - & - & -0.01 & - & - & - \\
\hline & & & 0.01 & & & \\
\hline & & & -1.52 & & & \\
\hline \multirow{3}{*}{$\begin{array}{l}\text { Megafauna species richness } \\
(>44 \mathrm{~kg})\end{array}$} & - & - & - & 0.03 & - & - \\
\hline & & & & 0.03 & & \\
\hline & & & & 0.79 & & \\
\hline \multirow{3}{*}{$\begin{array}{l}\text { Megafauna species richness } \\
(>0.5 \mathrm{~kg})\end{array}$} & - & - & - & - & -0.001 & - \\
\hline & & & & & 0.001 & \\
\hline & & & & & -0.06 & \\
\hline \multirow[t]{3}{*}{ Tree species richness } & - & - & - & - & - & 0.002 \\
\hline & & & & & & 0.01 \\
\hline & & & & & & 0.44 \\
\hline \multicolumn{7}{|l|}{ Other nature characteristics } \\
\hline \multirow[t]{3}{*}{ Landscape heterogeneity } & -0.11 & -0.14 & -0.16 & -0.13 & -0.14 & -0.15 \\
\hline & 0.19 & 0.19 & 0.19 & 0.19 & 0.19 & 0.19 \\
\hline & -0.59 & -0.78 & -0.84 & -0.69 & -0.74 & -0.78 \\
\hline \multirow[t]{3}{*}{ Topographic heterogeneity } & 0.01 & 0.01 & 0.01 & 0.01 & 0.01 & 0.01 \\
\hline & 0.01 & 0.01 & 0.01 & 0.01 & 0.01 & 0.01 \\
\hline & 0.21 & 0.34 & 0.51 & 0.14 & 0.25 & 0.23 \\
\hline \multirow[t]{3}{*}{ Green space cover } & 0.01 & -0.01 & -0.01 & -0.01 & -0.01 & -0.01 \\
\hline & 0.01 & 0.01 & 0.01 & 0.01 & 0.01 & 0.01 \\
\hline & 0.03 & -0.19 & -0.23 & -0.14 & -0.15 & -0.13 \\
\hline \multirow[t]{3}{*}{ Blue space cover } & -0.01 & -0.01 & -0.01 & -0.01 & -0.01 & -0.01 \\
\hline & 0.01 & 0.01 & 0.01 & 0.01 & 0.01 & 0.01 \\
\hline & -0.7 & -0.52 & -0.53 & -0.53 & -0.48 & -0.4 \\
\hline \multirow[t]{3}{*}{ Coastline } & 0.03 & 0.03 & 0.03 & 0.04 & 0.03 & 0.03 \\
\hline & 0.05 & 0.05 & 0.05 & 0.05 & 0.05 & 0.05 \\
\hline & 0.56 & 0.54 & 0.49 & 0.73 & 0.58 & 0.6 \\
\hline \multirow[t]{3}{*}{ Protected area cover } & 0.01 & 0.01 & 0.01 & 0.01 & 0.01 & 0.01 \\
\hline & 0.01 & 0.01 & 0.01 & 0.01 & 0.01 & 0.01 \\
\hline & 0.55 & 1.06 & 1.12 & 0.95 & 1.02 & 1.01 \\
\hline
\end{tabular}




\begin{tabular}{|c|c|c|c|c|c|c|}
\hline Predictor variables & oLogit 1 & oLogit 2 & oLogit 3 & oLogit 4 & oLogit 5 & oLogit 6 \\
\hline \multicolumn{7}{|l|}{ Climate } \\
\hline \multirow[t]{3}{*}{ Cooling degree days } & 0.01 & 0.01 & 0.01 & 0.01 & 0.01 & 0.01 \\
\hline & 0.01 & 0.01 & 0.01 & 0.01 & 0.01 & 0.01 \\
\hline & 1.64 & 1.15 & 1.03 & 1.25 & 1.17 & 1.24 \\
\hline \multicolumn{7}{|l|}{ Recreation access } \\
\hline $\begin{array}{l}\text { Recreation access: great } \\
\text { difficulty }\end{array}$ & \multicolumn{6}{|c|}{ Reference group } \\
\hline \multirow{3}{*}{$\begin{array}{l}\text { Recreation access: with } \\
\text { some difficulty }\end{array}$} & -0.03 & -0.03 & -0.03 & -0.03 & -0.03 & -0.03 \\
\hline & 0.14 & 0.14 & 0.14 & 0.14 & 0.14 & 0.14 \\
\hline & -0.25 & -0.22 & -0.22 & -0.23 & -0.22 & -0.23 \\
\hline \multirow[t]{3}{*}{ Recreation access: easily } & 0.24 & 0.24 & 0.24 & 0.24 & 0.24 & 0.24 \\
\hline & 0.13 & 0.13 & 0.13 & 0.13 & 0.13 & 0.13 \\
\hline & 1.9 & 1.93 & 1.94 & 1.91 & 1.93 & 1.92 \\
\hline \multirow{3}{*}{$\begin{array}{l}\text { Recreation access: very } \\
\text { easily }\end{array}$} & 0.44 & 0.45 & 0.45 & 0.45 & 0.45 & 0.45 \\
\hline & 0.12 & 0.13 & 0.13 & 0.13 & 0.13 & 0.13 \\
\hline & $3.57 * * *$ & $3.60 * * *$ & $3.60 * * *$ & $3.58 * * *$ & $3.59 * * *$ & $3.59 * * *$ \\
\hline \multirow{3}{*}{$\begin{array}{l}\text { Recreation access: service } \\
\text { not used }\end{array}$} & 0.03 & 0.03 & 0.03 & 0.03 & 0.03 & 0.03 \\
\hline & 0.13 & 0.13 & 0.13 & 0.13 & 0.13 & 0.13 \\
\hline & 0.21 & 0.21 & 0.22 & 0.2 & 0.21 & 0.21 \\
\hline \multirow[t]{3}{*}{$y>=2$} & 0.66 & 1.23 & 1.36 & 1.06 & 1.14 & 1.09 \\
\hline & 0.66 & 0.6 & 0.59 & 0.6 & 0.6 & 0.57 \\
\hline & 1.00 & 2.04 & 2.28 & 1.77 & 1.92 & 1.92 \\
\hline \multirow[t]{3}{*}{$y>=3$} & -0.03 & 0.54 & 0.67 & 0.37 & 0.45 & 0.4 \\
\hline & 0.64 & 0.59 & 0.58 & 0.59 & 0.58 & 0.55 \\
\hline & -0.04 & 0.91 & 1.12 & 0.63 & 0.78 & 0.72 \\
\hline \multirow[t]{3}{*}{$y>=4$} & -0.75 & -0.18 & -0.05 & -0.34 & -0.26 & -0.31 \\
\hline & 0.64 & 0.59 & 0.58 & 0.59 & 0.58 & 0.55 \\
\hline & -1.17 & -0.31 & -0.08 & -0.59 & -0.45 & -0.57 \\
\hline \multirow[t]{3}{*}{$y>=5$} & -1.27 & -0.71 & -0.57 & -0.87 & -0.79 & -0.84 \\
\hline & 0.64 & 0.59 & 0.58 & 0.59 & 0.58 & 0.55 \\
\hline & -1.98 & 1.2 & -0.98 & -1.48 & -1.35 & -1.52 \\
\hline \multirow[t]{3}{*}{$y>=6$} & -2.21 & -1.64 & -1.51 & -1.81 & -1.72 & -1.78 \\
\hline & 0.64 & 0.59 & 0.59 & 0.59 & 0.58 & 0.55 \\
\hline & $-3.42 * * *$ & $-2.77 * *$ & $-2.57 * *$ & $-3.05 * *$ & $-2.94 * *$ & $-3.19 * *$ \\
\hline \multirow[t]{3}{*}{$y>=7$} & -2.81 & -2.24 & -2.11 & -2.4 & -2.32 & -2.37 \\
\hline & 0.65 & 0.6 & 0.59 & 0.6 & 0.59 & 0.56 \\
\hline & $-4.33 * * *$ & $-3.76^{* * *}$ & $-3.57 * * *$ & $-4.04 * * *$ & $-3.94 * * *$ & $-4.24 * * *$ \\
\hline \multirow[t]{3}{*}{$y>=8$} & -3.7 & -3.13 & -3 & -3.3 & -3.21 & -3.27 \\
\hline & 0.65 & 0.6 & 0.6 & 0.6 & 0.59 & 0.56 \\
\hline & $-5.67 * * *$ & $-5.23 * * *$ & $-5.05 * * *$ & $-5.50 * * *$ & $-5.42 * * *$ & $-5.79 * * *$ \\
\hline \multirow[t]{3}{*}{$y>=9$} & -5.01 & -4.44 & -4.31 & -4.61 & -4.52 & -4.58 \\
\hline & 0.65 & 0.61 & 0.6 & 0.6 & 0.59 & 0.56 \\
\hline & $-7.64 * * *$ & $-7.37 * * *$ & $-7.21 * * *$ & $-7.63 * * *$ & $-7.58 * * *$ & $-8.06 * * *$ \\
\hline
\end{tabular}




\begin{tabular}{lcccccc} 
Predictor variables & oLogit 1 & oLogit 2 & oLogit 3 & oLogit 4 & oLogit 5 & oLogit 6 \\
\hline \hline y $>=10$ & -5.99 & -5.42 & -5.29 & -5.59 & -5.5 & -5.56 \\
& 0.66 & 0.61 & 0.6 & 0.61 & 0.6 & 0.57 \\
& $-9.06 * * *$ & $-8.92 * * *$ & $-8.77 * * *$ & $-9.17 * * *$ & $-9.14 * * *$ & $-9.68 * * *$ \\
\hline Socio-economic factors & yes & yes & yes & yes & yes & yes \\
Macro-economic factors & yes & yes & yes & yes & yes & yes \\
Country dummies & yes & yes & yes & yes & yes & yes \\
Observations & 26,749 & 26,749 & 26,749 & 26,749 & 26,749 & 26,749 \\
AIC & 102700.4 & 102707.7 & 102704.9 & 102707.1 & 102708 & 102707.5 \\
BIC & 103289.4 & 103297.7 & 103294.9 & 103297.1 & 103298 & 103297.5 \\
LogLik & -51278.18 & -51281.86 & -51280.46 & -51281.54 & -51282.02 & -51281.5 \\
Nagelkerke R-squared & 0.249 & 0.248 & 0.249 & 0.248 & 0.248 & 0.248 \\
\hline
\end{tabular}

$\mathrm{AIC}=$ Akaike Information Criterion, $\mathrm{BIC}=$ Bayesian Information Criterion

\subsubsection{Comparing EBBA data with recent bird species richness data from Germa-} ny and Britain

In this study I use bird distribution data obtained from the European Breeding Bird Atlas (EBBA) (Hagemeijer and Blair, 1997). Since the EBBA data was collected between 1980 and 1990 there exist a larger time gap between the bird species richness estimates and the data obtained from the European Quality of Life Survey (data collected in 2011, see Manuscript Methods). I argue that this temporal mismatch of the sampling periods should not be a major issue for this study because there have not been any major changes in species richness over time at the spatial scale of this study across Europe and within European countries (e.g. Koleček et al., 2010; Van Turnhout et al., 2007).

To make sure that there were no significant changes in bird species richness over time, which could influence our study results, I conducted additional analyses to test the robustness of our results. For this purpose, we collected data from two more recently published national bird surveys: the British and German breeding bird atlases conducted in the years 2008-2011 and 2005-2009, respectively (Gedeon et al., 2014; Gillings et al., 2019). I took the data from both atlases, which is provided on a $10 \times 10 \mathrm{~km}$ grid, and calculated bird species richness for all German and British NUTS regions. I did this in two steps - corresponding to the steps we took in our manuscript (see Methods, section 3.2 ). In the first step, we overlayed the $10 \times 10 \mathrm{~km}$ grid with the European $50 \times 50 \mathrm{~km}$ grid and calculated species richness per 50x50 grid cell. In the second step, I used the newly calculated species richness values from the 50x50 grid to estimated area weighted mean 
species richness (for details see Manuscript Methods, section 3.2.1).

I took the new bird species richness values and compared them with the old values (from the EBBA) by performing correlation analyses. The results show that old and new bird species richness values are highly correlated (Fig. A.III-3 A, B). For Germany, I find a correlation of $\mathrm{r}=0.81(\mathrm{t}=8.19, \mathrm{df}=36, \mathrm{p}=<0.001)$, for Britain the coefficient is $\mathrm{r}=0.84$ $(t=4.90, d f=10, p=<0.001)$.

A

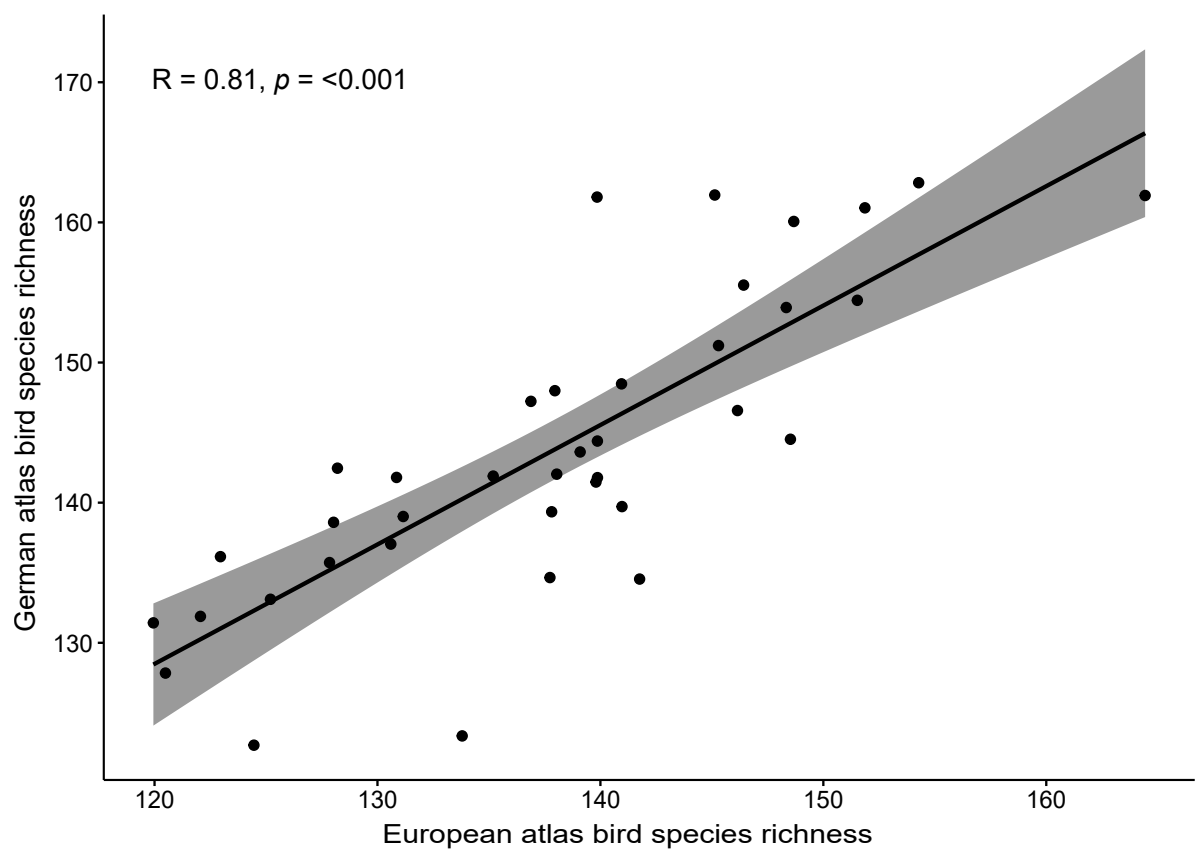

B

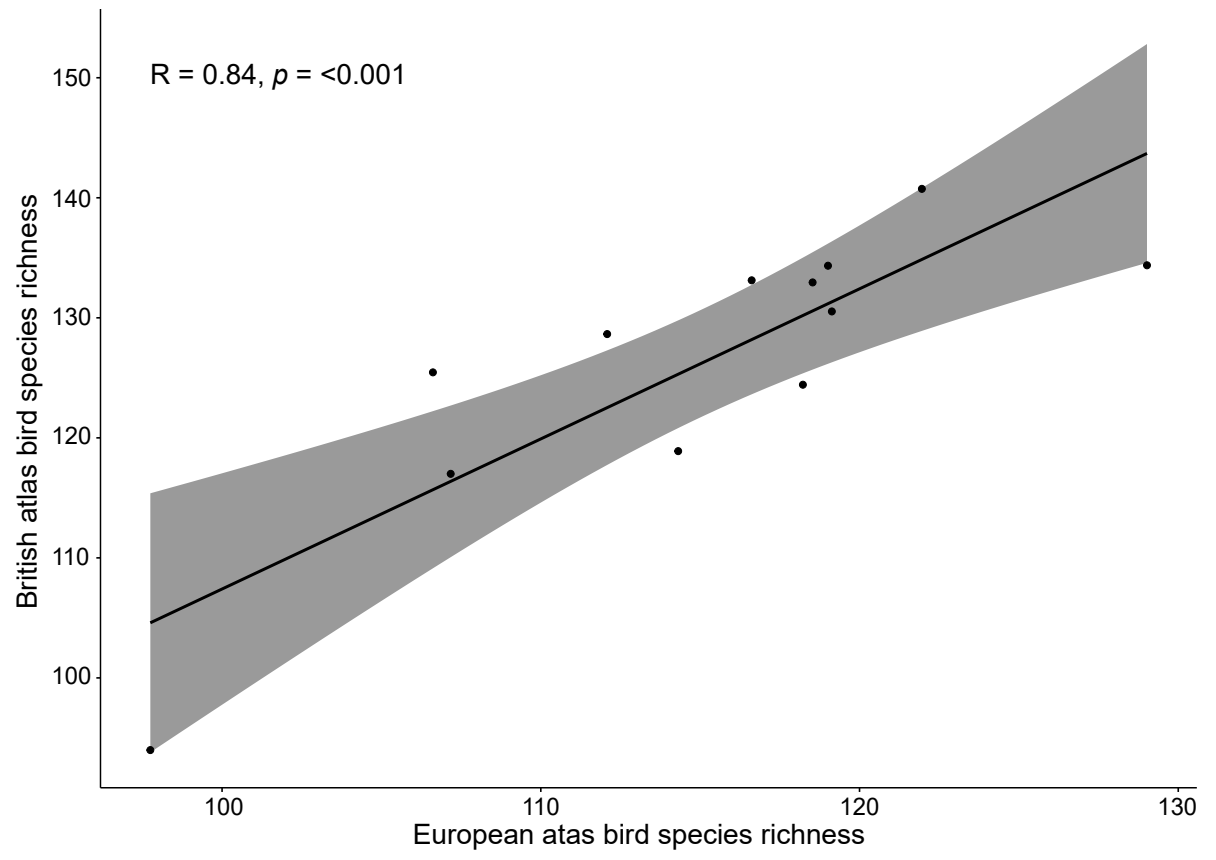

Fig. A.III-1: Correlation plots for bird species richness on NUTS regional level. A: Bird species richness in Germany based on the EBBA (collected in years 1980-1990) is compared to values based on the German Breeding Bird Atlas (collected in years 2005-2009). B: Bird species richness in Great Britain based on the EBBA is compared to values based on the British Breeding Bird Atlas (collected in years 2008-2011). 
To test the robustness of our econometric results, I replaced the old bird species richness values for Germany and Britain in our data set with the newer values (using unique NUTS regions IDs) and repeated our OLS analyses with this new 'hybrid' data set. The results show that bird species richness remains significantly positively related to life-satisfaction across Europe (Table A.III-14 \& Table A.III-15) and that our main study results are robust in regard to the time window, in which the bird data have been collected. These results also support our assumption that bird species richness at the large spatial scale of our analysis has not changed to the degree that it impacts our results.

Table A.III-14: This table shows OLS model results based on the original data-set (old) and the hybrid data-set (new). In the hybrid data-set bird species richness values were replaced by new values for Germany and Britain. Here I show results from models including all species richness variables (multi-taxon models). OLS models based on the old data-set correspond to the results in Table A.III-6. Shown are coefficients, standard errors, $\mathrm{t}$-values and $\mathrm{p}$-values as asterisk symbols. Response variable $=$ life-satisfaction. Asterisks: $*=\mathrm{p}<0.05 ; * *=\mathrm{p}<0.01 ; * * *=\mathrm{p}<0.001 . \mathrm{n}=26,749$

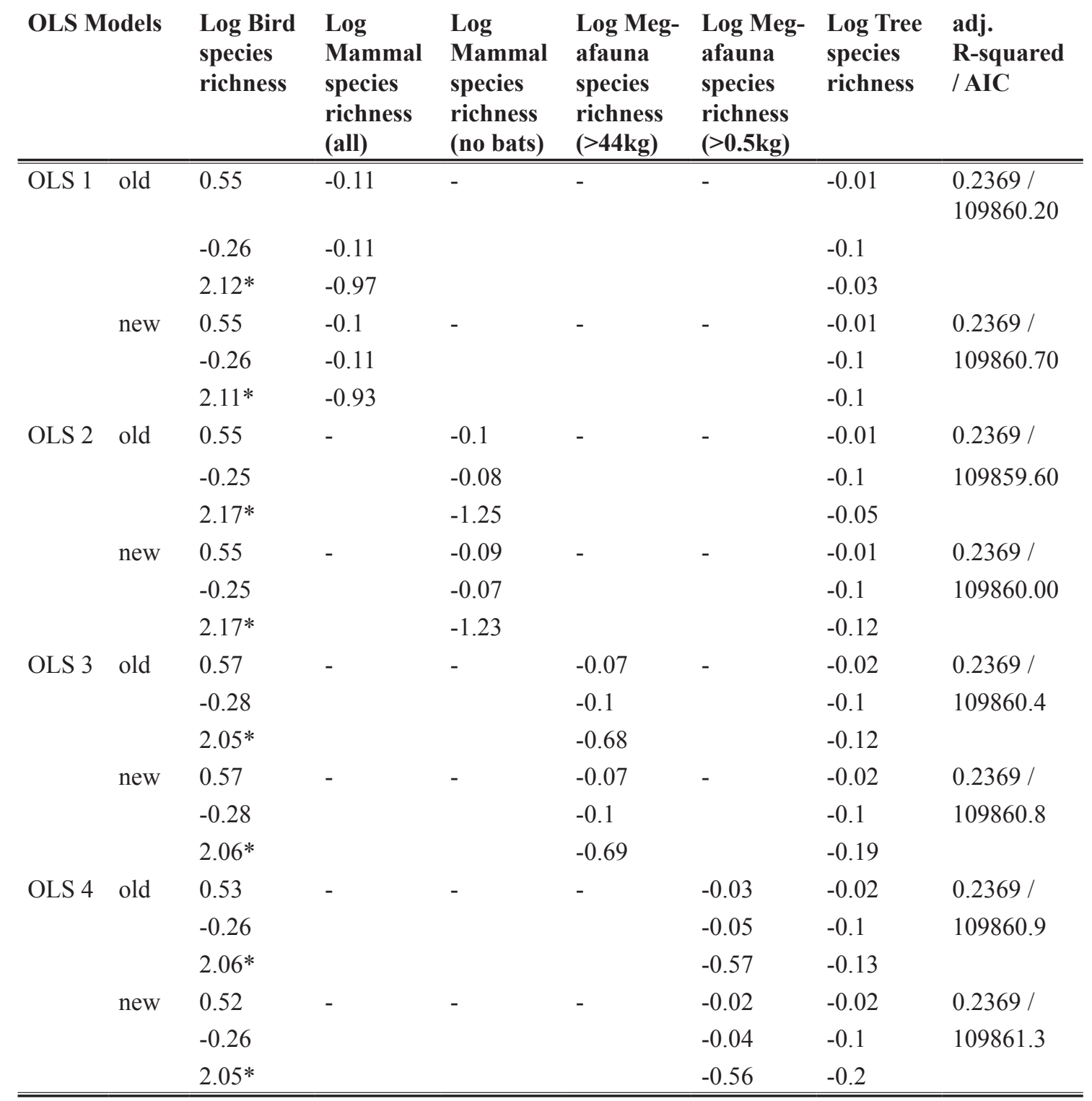


Table A.III-15: This table shows OLS model results based on the original data-set (old) and the hybrid data-set (new). In the hybrid data-set bird species richness values were replaced by new values for Germany and Britain. Here I compare selected results from models including only one species richness variable (single-taxon models) and only one species richness variable (single-taxon models). OLS models based on the old data-set correspond to the results in Table A.III-8. Shown are coefficients, standard errors, t-values and $\mathrm{p}$-values as asterisk symbols. Response variable $=$ life-satisfaction. Asterisks: $*=\mathrm{p}<0.05 ; * *=\mathrm{p}<0.01$; $* * *=\mathrm{p}<0.001 . \mathrm{n}=26,749$

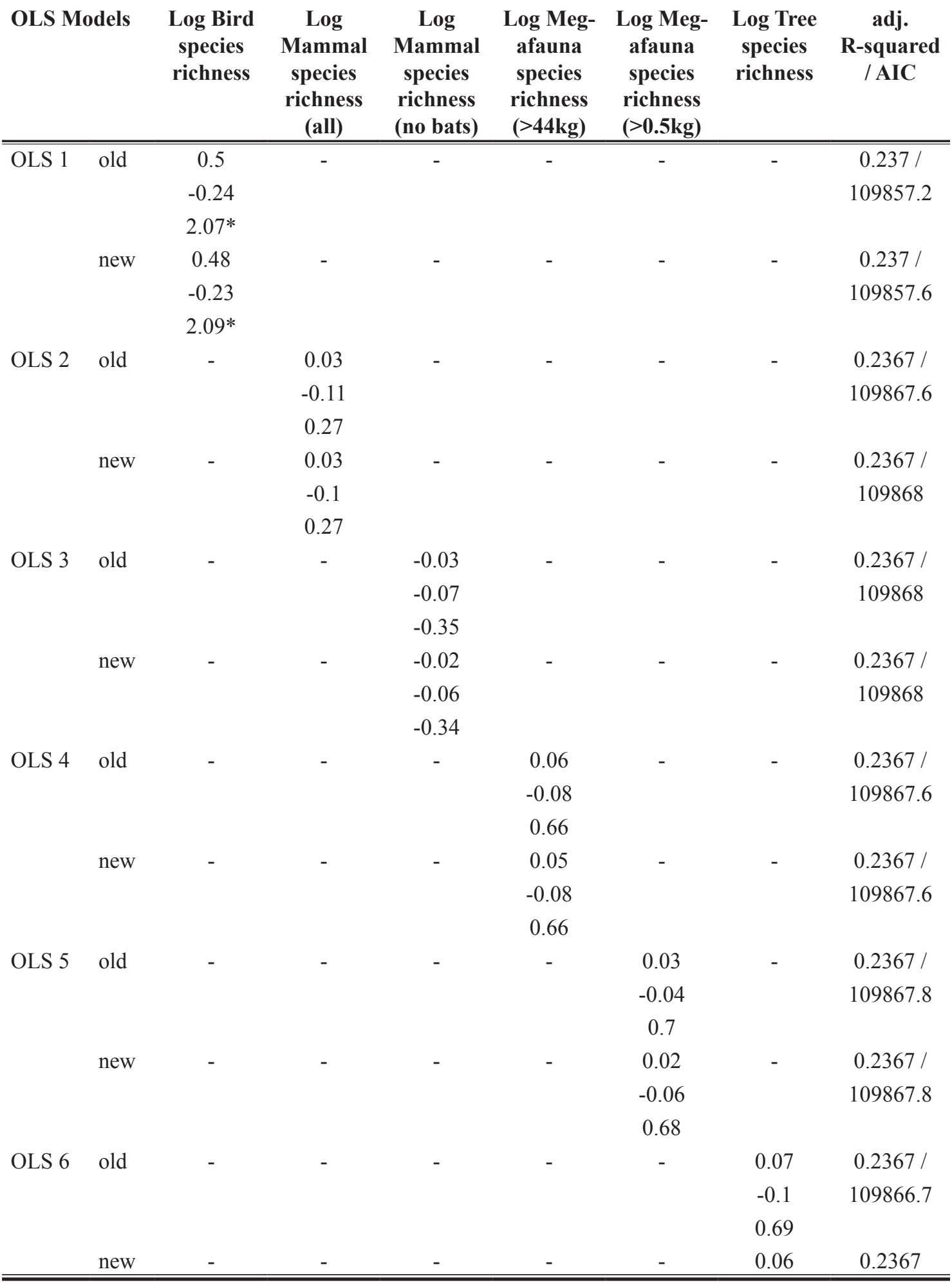




\subsection{Author contributions}

Authors:

Joel Methorst (JM, PhD candidate), Katrin Rehdanz (KR), Aletta Bonn (AB)

Bernd Hansjürgens (BH), Thomas Müller (TM), Katrin Böhning-Gaese (KBG)

(1) Development and planning

$\mathrm{PhD}$ candidate $(\mathrm{JM}): 30 \%$

KR and KBG: in total $70 \%$

(2) Compilation of data and preparation of figures

PhD candidate (JM): 100\%

- JM collected online open source datasets, organised and compiled the ecological and socio-economic datasets and calculated indicators with spatial data in R. JM prepared all figures in the manuscript and supplementary material.

(3) Data analyses and interpretation of results

$\mathrm{PhD}$ candidate (JM): $80 \%$

- JM conducted all statistical analyses and interpreted the results.

$\mathrm{KR}, \mathrm{AB}, \mathrm{TM}$ and $\mathrm{KGB}$ : in total $20 \%$

- KR, KGB and TM gave some advice on statistical analyses.

- All contributed to the interpretation of results.

(4) Preparation of manuscript

$\mathrm{PhD}$ candidate $(\mathrm{JM}): 70 \%$

TM and KGB: in total $20 \%$

$\mathrm{KR}, \mathrm{AB}$ and $\mathrm{BM}$ : in total $10 \%$ 
